\title{
Wasseraufnahme und artspezifische hydraulische Eigenschaften der Feinwurzeln von Buche, Eiche und Fichte: In situ-Messungen an Altbäumen
}

\author{
Dissertation \\ zur Erlangung des Doktorgrades \\ der Mathematisch-Naturwissenschaftlichen Fakultäten \\ der Georg-August-Universität zu Göttingen
}

vorgelegt von

Heinz Coners

aus Westerstede

Göttingen, 17.9.2001 
D 7

Referent: Prof. Dr. C. Leuschner

Korreferent: Prof. Dr. H. Dierschke

Tag der mündlichen Prüfung: 30.10.2001 


\section{Danksagung}

Zuerst möchte ich Prof. Christoph Leuschner danken, der mich in allen Höhen und Tiefen der Arbeit vorbildlich betreut hat.

Ich danke der Deutschen Forschungsgemeinschaft für die finanzielle Unterstützung im Rahmen des Projekts Le 762/2 „Wurzelwasseraufnahme“.

Ohne die tatkräftige und mitdenkende Hilfe von Mechthild Stange hätte ich die aufwendige Freiland- und Laborarbeit niemals geschafft - vielen Dank Mechthild.

Weiterhin möchte ich Sandra Korn und Regina Icke danken, die mit ihren Diplomarbeiten einen großen Beitrag zum Erkenntnisgewinn im „Wurzelwasserprojekt“ geleistet haben.

Dietrich Hertel hat sich jahrelang das Zimmer mit mir geteilt, wozu sicher oft ein hohes Maß an Toleranz notwendig war. Im letzten Jahr meiner Arbeit wurde Florian Schipka diese „Ehre“ zuteil. Euch beiden vielen Dank für die Geduld.

Ich hatte das große Glück, sowohl in Kassel als auch in Göttingen mit sehr netten Kollegen zusammen zu arbeiten. So eine tolle und menschliche Arbeitsatmosphäre gibt's so schnell nicht wieder. Ich werde hier keine Namen hervorheben - Ihr wißt schon wer gemeint ist.

Zuletzt möchte ich mich bei meiner Frau Esther und meinem Sohn Ole für meine langen „Fehlzeiten“ während der letzten Wochen entschuldigen. Das soll jetzt besser werden! Vielen Dank für Eure Geduld und die Aufmunterung, die mir jede mit Euch verbrachte Minute gebracht hat. 


\section{Inhaltsverzeichnis}

1 Einleitung 3

2 Untersuchungsflächen 5

2.1 Topographische Lage und Flächenbeschreibung . . . . . . . . . . 5

2.2 Geologie und Böden $\ldots \ldots \ldots \ldots \ldots \ldots \ldots \ldots$

2.3 Vegetation und Bestandesstruktur. . . . . . . . . . . . . . 7

2.4 Klima und Wasserhaushalt $\ldots \ldots \ldots \ldots \ldots$

3 Material und Methoden 10

3.1 Saftflußmessungen mit der heat balance Methode . . . . . . . . . . 10

3.1 Kalibrierung der Miniatur-Saftflußmeßanlangen . . . . . . . . . . . 13

3.2 Modifizierte Berechnungsmethode für kleine Saftflußraten . . . . . . 14

3.3 Saftflußmessung an Baumwurzeln unter in situ-Bedingungen . . . . . 15

3.4 Ernte und Weiterverarbeitung der untersuchten Wurzelstränge . . . . 16

$3.5 \quad$ Bestimmung der Saftflußrate im Stamm der Meßbäume . . . . . . . . . 17

$3.6 \quad$ Bestimmung des Wasserpotentials in Feinwurzeln . . . . . . . . . . . 18

$3.7 \quad$ Messung mikroklimatischer Parameter $\ldots \ldots \ldots \ldots \ldots$

3.8 Messung der Bodenfeuchte und der Bodentemperatur . . . . . . . . 19

$3.9 \quad$ Morphologisch-anatomische Untersuchungen an Baumwurzeln . . . . 20

3.10 Extraktion und Analyse des Suberins $\ldots \ldots \ldots \ldots . \ldots 20$

3.11 Bestimmung des leitenden Querschnitts am Meßpunkt . . . . . . . 21

3.12 Untersuchung der axialen hydraulischen Leitfähigkeit im Wurzelxylem 22

3.13 Wurzel-Saftflußmessungen nach experimenteller Ausschaltung des radialen Wurzelwiderstandes $\ldots \ldots \ldots \ldots . \ldots \ldots$

\begin{tabular}{|lll}
4 & Ergebnisse & 24
\end{tabular}

$4.1 \quad$ Kalibrierung der Miniatur-Saftflußmeßsysteme . . . . . . . . . . 24

4.1.1 Meßgenauigkeit der Sensoren bei mittleren und hohen Flußraten 24

\begin{tabular}{llll}
\hline 4.1 .2 & Meßgenauigkeit der Sensoren bei niedrigen Flußraten $\ldots$. & 25
\end{tabular}

$4.1 .3 \quad$ Modifizierte Methode der Saftflußberechnung . . . . . . . . 27

4.2 Vergleich der Wasseraufnahme von Buchenwurzeln auf drei unterschied-

lich wasserversorgten Standorten . . . . . . . . . . . . . . . . 30

$4.2 .1 \quad$ Morphologie der Buchenwurzeln . . . . . . . . . . . 30

4.2 .2 Klimatische und edaphische Faktoren . . . . . . . . . . . . 33

4.2 .3 Stammsaftflußrate $\ldots \ldots \ldots \ldots \ldots$

$4.2 .4 \quad$ Wasserpotential in Feinwurzeln $\ldots \ldots \ldots \ldots$ 
4.2 .5 Wasseraufnahme durch die Wurzeln . . . . . . . . . . . 41

4.3 Vergleichende Untersuchung der Wasseraufnahme durch die Wurzeln

verschiedener Baumarten . . . . . . . . . . . . . . . 46

4.3.1 Morphologische Merkmale der untersuchten Wurzeln. . . . . 46

4.3.2 Artspezifische anatomische Eigenschaften der Baumwurzeln . 50

$4.3 .3 \quad$ Klimatische und edaphische Faktoren . . . . . . . . . . . 55

4.3 .4 Stammsaftflußrate $\ldots \ldots \ldots \ldots . \ldots \ldots$

4.3 .5 Wasseraufnahme durch die Wurzeln . . . . . . . . . . . 61

$4.3 .6 \quad$ Wurzelwasserpotentiale . . . . . . . . . . . . 80

$4.3 .7 \quad$ Axiale hydraulische Leitfähigkeit . . . . . . . . . . . . . 82

4.3 .8 Radiale Leitfähigkeit $\left(L p_{r}\right)$ unter in situ-Bedingungen . . . . 83

$4.3 .9 \quad$ Flußrate in Wurzeln bei optimaler Wasserversorgung . . . . . 84

4.3 .10 Bewässerungsversuche . . . . . . . . . . . . 85

5 Diskussion 88

$5.1 \quad$ Die Eignung von Miniatur-Saftflußmeßsystemen zur Messung der Was-

seraufnahme von Baumwurzeln . . . . . . . . . . . . . . 88

5.2 Standörtliche Variabilität der Wasseraufnahme von Buchenwurzeln in

Abhängigkeit von der Wasserversorgung . . . . . . . . . . . . . . . 89

5.2.1 Die Wasserversorgung der Buchen an den drei Standorten . . 89

5.2.2 $\quad$ Das Wurzelsystem der Buche an den drei Standorten . . . . . 92

5.2 .3 Die Wasseraufnahme durch die Buchenwurzeln . . . . . . . . 92

5.3 Baumarten-Unterschiede in der Wurzelwasseraufnahme . . . . . . . . 95

5.3.1 Ökologische Ansprüche der Buche, Eiche und Fichte bezüglich der Wasserversorgung . . . . . . . . . . . . . 95

5.3.2 Artspezifische Unterschiede in der Wasseraufnahme durch die

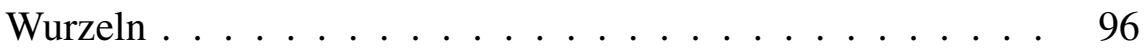

5.3.3 Anatomie und Chemie der Wurzel-Abschlußgewebe . . . . . 99

5.3.4 Die Bedeutung verschiedener wurzelspezifischer Widerstände

$\begin{array}{lll}6 & \text { Zusammenfassung } & 106\end{array}$ 


\section{Einleitung}

Pflanzen nehmen Wasser durch die Wurzeln auf und geben es über die Blätter an die Atmosphäre ab. Wurzeln und Blätter stellen also die wichtigsten Grenzflächen im soilplant-atmosphere continuum (SPAC) des Wasserflusses in Ökosystemen dar. In den vergangenen 30 Jahren wurde eine Reihe von Methoden, z.B. Steady-State Porometer, Gaswechselküvetten und Eddy-Kovarianzsysteme, zur Untersuchung der Transpiration einzelner Blätter und ganzer Bestände unter Labor- und Feldbedingungen entwickelt. Basierend auf diesen Meßmethoden wurde ein umfangreicher Satz empirischer Daten zur Transpiration erhoben, der tiefe Einblicke in die Mechanismen der Transpirationsregelung erlaubt (Lösch, 2001).

Das detaillierte Wissen über die Seite der Wasserabgabe im SPAC steht in deutlichem Gegensatz zum mangelhaften Verständnis der Aufnahmeseite. In bisherigen Studien wurde die Wasseraufnahme vorwiegend unter Laborbedingungen untersucht. Die Bestimmung der radialen Leitfähigkeit $\mathrm{Lp}_{\mathrm{r}}$ an dekapitierten Wurzelsystemen mit Hilfe der Wurzeldrucksonde lieferte wichtige Erkenntnisse zum Mechanismus der Wasseraufnahme und stellt die Basis für das composite model of water uptake dar (Steudle, 2000b).

Zur Untersuchung der Wassseraufnahme intakter transpirierender Pflanzen stehen bislang nur wenige geeignete Methoden zur Verfügung. Mit der NMR-Technik konnte die Wasseraufnahme einzelner Wurzeln visualiert werden (MacFall et al., 1991). Diese Methode ist jedoch für den Feldeinsatz zur Messung in ungestörtem Boden nicht geeignet. Ergebnisse von Laborexperimenten an isolierten Sämlingen oder Jungbäumen sind nur bedingt auf Altbestände übertragbar, weil deutliche Unterschiede bezüglich des Mykorrhizierungsgrades, der Wurzelkonkurrenz und des Bodengefüges bestehen.

Die Wasseraufnahme durch die Wurzeln ist als einzige Nachlieferungsquelle für das durch die Transpiration abgegebene Wasser von entscheidender Bedeutung. Gleichwohl konnte dieser wichtige Term in der Wasserbilanz von Waldbeständen bislang nur mit indirekten Methoden quantifiziert werden, wobei die Wasseraufnahme aus Parametern wie dem Bodenwassergehalt, der Wurzelverteilung im Boden und der Transpirationrate modelliert wurde (Molz, 1981, Barataud et al., 1995). Direkte Flußmessungen im Wurzelsystem wurden in jüngerer Zeit mit Hilfe thermoelektrischer Methoden durchgeführt (Green \& Clothier, 1988, 1995, Lott et al., 1996, Burgess et al., 1998). Durch Anwendung dieser Technik an Grobwurzeln von Grevillea robusta konnten Smith et al. (1999) einen abwärts gerichteten Wasserfluß in Senkerwurzeln eines tropischen Baumes nachweisen. Allerdings waren diese Studien auf eine geringe Anzahl von Wurzeln mit Durchmessern von etwa $2 \mathrm{~cm}$ beschränkt, die vornehmlich dem Ferntransport des Wassers dienen, hingegen für die Aufnahme von Wasser nur von 
untergeordneter Bedeutung sind.

In der vorliegenden Arbeit wird eine neue Technik vorgestellt, die es erlaubt, die Wasseraufnahme durch die Feinwurzeln der Bäume in situ zu messen. Durch den Einsatz von Miniatur-Saftflußmeßanlagen nach Senock \& Ham (1993) an 3-4 mm dünnen Wurzeln kann der Wasserfluß in terminalen Feinwurzelsträngen über Zeiträume von mehreren Wochen kontinuierlich aufgezeichnet werden. Die quantitative Ernte der untersuchten Feinwurzelstränge nach Abschluß der Messung erlaubt den Bezug der ermittelten Xylemsaftflußraten auf die zugehörige Wurzeloberfläche. Zusätzlich ermittelte Wasserpotentiale in Wurzeln und Boden ermöglichen darüber hinaus erstmals die Berechnung von in situ-Lp $\mathrm{p}_{\mathrm{r}}$-Werten und den Vergleich mit Ergebnissen aus Labormessungen an Jungpflanzen der selben Baumarten (Rüdinger et al., 1994, Steudle \& Meshcheryatov, 1996, Steudle \& Heydt, 1997).

Die Xylemsaftflußraten in Wurzeln mitteleuropäischer Baumarten können bedeutend kleiner sein als diejenigen schnellwachsender tropischer Bäume (Senock \& Leuschner, 1999). Daher wurde in mehreren Freiland- und Laborexperimenten die Meßgenauigkeit der Miniatursaftflußanlagen überprüft. Basierend auf diesen Ergebnissen wird eine modifizierte Methode der Flußberechnung für niedrige Flußraten vorgestellt.

In der vorliegenden Arbeit wurde diese Methode eingesetzt, um die Wasseraufnahme von Buchenwurzeln an 3 unterschiedlich wasserversorgten Standorten vergleichend zu untersuchen. Die dafür ausgewählten Buchenwälder im Solling, in der Lüneburger Heide und im Ziegelrodaer Forst unterscheiden sich deutlich, sowohl in ihrem Niederschlagsregime als auch bezüglich der bodenhydrologischen Eigenschaften. In einem weiteren Untersuchungsjahr wurden am Standort Lüneburger Heide artspezifische Unterschiede zwischen Buchen-, Eichen- und Fichtenwurzeln unter vergleichbaren klimatischen und edaphischen Bedingungen am gemeinsamen Standort untersucht.

Die meist dicht durchwurzelte organische Auflage in Wäldern ist nicht nur für die Nährstoffversorgung von Bedeutung, sondern spielt auch eine wichtige Rolle in der Wasserbilanz (Leuschner, 1998). Beiden vergleichenden Ansätzen zur Wasseraufnahme von Baumwurzeln war daher die Fragestellung gemein, ob sich die Wurzeln der organischen Auflage von denen im Mineralboden am jeweiligen Standort oder bei der jeweiligen Art unterscheiden. Ferner wurde die Abhängigkeit der Wasseraufnahmerate von verschiedenen Einflußgrößen wie dem Bodenwassergehalt und der Transpirationrate bzw. der atmosphärischen Transpirationsbeanspruchung durch Strahlung und Wassersättigungsdefizit der Luft untersucht.

Zur genaueren Charakterisierung artspezifischer Unterschiede wurden weiterhin anatomische Merkmale im radialen und axialen Bau der Wurzeln, sowie der Suberinisierungsgrad untersucht. Die mit diesen Merkmalen verbundene radiale und axiale Leitfähigkeit wurde durch verschiedene Labor- und Freilandexperimente an Wurzeln der drei untersuchten Baumarten verglichen. 


\section{Untersuchungsflächen}

\subsection{Topographische Lage und Flächenbeschreibung}

Lüneburger Heide Der untersuchte Buchen-Eichen-Mischwald liegt $2 \mathrm{~km}$ westlich von Unterlüß $\left(52^{\circ} 45^{\prime} \mathrm{N}, 10^{\circ} 30^{\prime} \mathrm{E}\right)$ in der Lüneburger Heide zwischen Uelzen und Celle in 115 m.ü.M. Hier wurde 1989 im Rahmen eines Projekts zur Erforschung der Walddynamik in der Lüneburger Heide eine 0.77 ha große Kernfläche eingezäunt und mit einem 36 m hohen Gerüstturm versehen, der Messungen an Blättern und Zweigen sowie oberhalb des Kronenraums der Buchen und Eichen ermöglicht. Der BuchenEichen-Mischwald ist von Fichtenbeständen umgeben, so daß im Rahmen des Artvergleichs 1999 alle 3 Arten in der Übergangszone unter ähnlichen klimatischen und edaphischen Bedingungen untersucht werden konnten (s. Kap. 4.2).

Dieser Bestand ist intensiv auf verschiedenen Ebenen mit Methoden der Waldökosystemforschung untersucht worden. Eine Synthese mehrjähriger Forschungsarbeit in diesem Projekt wurde von Leuschner (1994) erstellt; darin finden sich auch Hinweise auf weitere Arbeiten, die Anfang der 90er Jahre vor allem in Form von Diplomund Doktorarbeiten am Systematisch-Geobotanischen Institut der Universität Göttingen durchgeführt wurden. Weitere Publikationen behandeln z.B. den Gaswechsel (Terborg, 1998), den Wasserhaushalt (Backes, 1996, Leuschner et al., 1997, Backes \& Leuschner, 2000) und das Wurzelsystem (Büttner \& Leuschner, 1994, Coners et al., 1998, Hertel \& Leuschner, 1998, Hertel, 1999, Leuschner et al., 2001b) der Buchen und Eichen in diesem Mischwald.

Solling Die Buchenfläche im Solling wird im Rahmen des „Solling-Projekts“ seit Mitte der 60er Jahre intensiv untersucht. Die Kernfläche B1 liegt 510 m.ü.M. südöstlich von Silberborn $\left(51^{\circ} 46^{\prime} \mathrm{N}, 9^{\circ} 35^{\prime} \mathrm{E}\right)$. Auch hier befindet sich auf der umzäunten Kernfläche ein Meßturm, auf dem Klimaparameter innerhalb und oberhalb des Kronenraums aufgezeichnet werden.

Forschungsergebnisse aus dem Solling-Projekt sind in eine Vielzahl von Publikationen eingeflossen. Hier sei auf die Zusammenfassung von Ellenberg et al. (1986) hingewiesen, in der die Ergebnisse von 30 Jahren Ökosystemforschung im Solling ausführlich dargestellt und diskutiert werden.

Ziegelrodaer Forst Die Fläche im Ziegelrodaer Forst nahe Allstedt ist bezüglich der Infrastruktur und der verfügbaren langjährigen Meßdaten weniger umfangreich ausgestattet als diejenigen im Solling und in der Lüneburger Heide. Sie wurde 1996 
im Rahmen des Projekts „Physiologische und morphologische Plastzität der Rotbuche unter verschiedenartigen edaphischen und klimatischen Randbedingungen“ des Forschungszentrums Waldökosysteme der Universität Göttingen eingerichtet und biometrisch inventarisiert. Die eingezäunte Kernfläche (0.3 ha) liegt auf 280 m.ü.M. in der Nähe von Allstedt im Landkreis Sangerhausen (51 $\left.{ }^{\circ} 23^{\prime} N, 11^{\circ} 26^{\prime} \mathrm{E}\right)$. Hier steht für klimatische und physiologische Untersuchungen im Kronenraum der Altbäume kein Meßturm zur Verfügung.

Aufgrund der verhältnismäßig kurzen bisherigen Meßdauer auf dieser Untersuchungsfläche liegen für diesen Bestand bislang nur wenige Daten aus anderen Bereichen der Ökosystemforschung vor. Diese beschäftigen sich z.B. mit der unterirdischen Biomasseverteilung (Muhs, 1997, Hertel, 1999) und dem Wasserhaushalt (Strobel, 1997)

\subsection{Geologie und Böden}

Lüneburger Heide Die Untersuchungsfläche OB5 liegt im südwestlichen Teil des nordwestdeutschen Tieflandes im Übergangsbereich von der Endmoränenlandschaft der Lüßberge zum Sprakensehler Sander. Die Ablagerungen aus Schmelzwassersanden und -kiesen entstammen der Saaleeiszeit (Drenthe-(2)-Stadial). In der WeichselKaltzeit wurden Geschiebedecksande aufgelagert, die im Spätglazial und Holozän durch wenige $\mathrm{cm}$ bis dm starke Flugsanddecken ergänzt wurden. Als Bodenart liegt auf der Untersuchungsfläche Mittelsand vor.

Auf diesem nährstoffarmen Ausgangsmaterial hat sich eine podsolige saure Braunerde gebildet. Die Humusform ist ein rohhumusartiger Moder mit der Horizontabfolge $\mathrm{O}_{l}, \mathrm{O}_{f}, \mathrm{O}_{h}$ in der bis zu $10 \mathrm{~cm}$ mächtigen organischen Auflage.

Solling Der Buchenwald im Solling stockt auf mittlerem Buntsandstein, der periglazial mit Löß überweht wurde (Ellenberg et al., 1986). Auf diesem Untergrund bildete sich eine mäßig podsolige, pseudovergleyte, saure Braunerde. Die Bodenart in den Verwitterungshorizonten ist als lehmiger Schluff bis schluffiger Lehm einzustufen. Die organische Auflage ist mit bis zu $12 \mathrm{~cm}$ sogar noch mächtiger als in der Lüneburger Heide, wobei als Humusform auch hier ein rohhumusartiger Moder, stellenweise auch ein typischer Moder vorliegt.

Ziegelrodaer Forst Auch im Ziegelrodaer Forst wurde der mittlere Buntsandstein durch Löß (mehrere $\mathrm{cm}$ bis $\mathrm{dm}$ ) überlagert. Hier kam es allerdings nicht zur Podsolierung, so daß der Bodentyp eine schwach saure Braunerde ist. Als Bodenart liegt ein lehmiger Sand vor.

Die organische Auflage ist an diesem Standort mit etwa $3 \mathrm{~cm}\left(\mathrm{O}_{l}\right.$ und $\left.\mathrm{O}_{f}\right)$ deutlich geringmächtiger als in der Lüneburger Heide und im Solling. Die Humusform ist hier als typischer F-Mull anzusprechen. 


\subsection{Vegetation und Bestandesstruktur}

Lüneburger Heide Der Buchen-Eichen-Mischbestand in der Lüneburger Heide wird von Heinken (1993) pflanzensoziologisch als trennartenlose Tieflandvariante des Luzulo-Fagetums eingestuft. Bis auf einzelne Exemplare von Avenella flexuosa und Carex pilulifera und einigen Moosen und Flechten findet sich hier keine Krautschicht.

Tabelle 2.1: Bestandesstruktur der drei Untersuchungsflächen. Angaben zur Bestandesstruktur am Standort Lüneburger Heide nach Leuschner (1994), Solling: Ellenberg et al. (1986) und Heimann (unveröff.) (LAI), Ziegelrodaer Forst: Strobel (1997). RAI, LAI und Wurzelbiomasse nach Hertel (1999).

\begin{tabular}{l|ccc} 
& Lüneburger Heide & Solling & Ziegelrodaer Forst \\
\hline dominierende Baumart & Buche (Eiche) & Buche & Buche \\
Baumalter [a] & $100(190)$ & 150 & 120 \\
Anzahl Stämme [n ha ${ }^{-1}$ ] & 220 & 220 & 370 \\
mittl. Höhe [m] & 28 & 29 & 28 \\
LAI & 7.2 & 6.5 & 8.3 \\
RAI (<2 mm) & 9.1 & 6.1 & 3.1 \\
\hline Wurzel-Biomasse [g TM m ${ }^{-2}$ ] & & & \\
$<1 \mathrm{~mm}\left(0-40 \mathrm{~cm} \mathrm{/}>40 \mathrm{~cm}^{\text {Tiefe })}\right.$ & $312.9 / 56.5$ & $176.9 / 25.7$ & $71.2 / 35.7$ \\
$1-2 \mathrm{~mm}\left(0-40 \mathrm{~cm} />40 \mathrm{~cm}^{\text {Tiefe}}\right)$ & $134.8 / 22.7$ & $131.6 / 14.4$ & $99.9 / 51.2$
\end{tabular}

Die Baumschicht setzt sich aus etwa 100-jährigen Rotbuchen (Fagus sylvatica) und 190-jährigen Traubeneichen (Quercus petraea) im Verhältnis 5:1 zusammen (Tab. 2.1). Bezieht man die zweite Baumschicht mit etwa 10-20 m hohen Buchen mit ein, so erhöht sich dieses Verhältnis auf 9:1. Die beiden Arten stellen zusammen 220 Stämme pro ha. Die mittlere Baumhöhe beträgt $28 \mathrm{~m}$; das Kronendach ist geschlossen, was sich auch in dem hohen Bestandesblattflächenindex (LAI) von 7.2 (Hertel, 1999) widerspiegelt.

Der für die vorliegende Arbeit wichtige Bestandeswurzelflächenindex (RAI, Feinwurzeln) hat mit 9.1 auf dieser Untersuchungsfläche einen erheblich höheren Wert als im Solling oder im Ziegelrodaer Forst (Hertel, 1999). Diese Überlegenheit findet sich auch in den flächenbezogenen Wurzel-Biomassen wieder. Besonders die Feinstwurzelfraktion ist mit über $300 \mathrm{~g} \mathrm{TM} \mathrm{m}^{-2}$ im Oberboden deutlich höher als in den anderen beiden Beständen. Die vertikale Verteilung der Wurzeln im Boden hingegen ist in den drei untersuchten Wäldern ähnlich: Im Oberboden $(0-40 \mathrm{~cm})$ werden jeweils deutlich mehr Wurzeln als in den tieferen Horizonten gefunden. In der Lüneburger Heide und im Solling ist das Verhältnis allerdings mit etwa 6:1 bei den Feinstwurzeln deutlich größer als im Ziegelrodaer Forst, wo oberhalb von $40 \mathrm{~cm}$ Tiefe doppelt so viel Feinstwurzelbiomasse gefunden wurde wie in den darunterliegenden Horizonten. 
Solling Der Deckungsgrad der Krautschicht auf der Untersuchungsfläche B1 im Solling ist nur wenig größer als in der Lüneburger Heide. Sie wird im Wesentlichen von Luzula luzuloides, Avenella flexuosa und Oxalis acetosella gebildet. Der Wald ist pflanzensoziologisch als Luzulo-Fagetum typicum anzusehen (Ellenberg et al., 1986).

Die Buchen an diesem Standort sind mit etwa 150 Jahren deutlich älter als in der Lüneburger Heide und im Solling, erreichen jedoch mit $220 \mathrm{Stämmen} \mathrm{ha}^{-1}$ eine der Lüneburger Heide vergleichbare Stammdichte. Auch die Baumhöhe und der Blattflächenindex sind mit dem Mischwald in der Lüneburger Heide vergleichbar. Bezüglich der Wurzelbiomassen und des Wurzeloberflächenindex nimmt der Bestand im Solling eine Mittelstellung ein.

Ziegelrodaer Forst Meusel (1937) beschreibt den Ziegelrodaer Forst pflanzensoziologisch als Luzulo-Fagetum. Die Krautschicht der Untersuchungsfläche, die hier mit 30-40\% den höchsten Deckungsgrad der 3 Standorte aufweist, enthält mehrere Kennarten dieser Pflanzengesellschaft wie Luzula luzuloides und Vaccinium myrtillus. Allerdings sind daneben auch Arten mit höheren Ansprüchen an die Basenversorgung (Anemose nemorosa oder Poa nemoralis) und sogar calcicole Arten wie Anemone ranunculoides oder Viola reichenbachiana zu finden. Nach dem heutigen pflanzensoziologischen System wird dieser Bestand dem Galio-Fagetum zugeordnet.

Die Baumschicht des Bestandes wird von Buchen und Eichen im Verhältnis 28:1 gebildet, die Eiche ist also nur in vereinzelten Exemplaren eingestreut. Das Alter der Buchen (120 Jahre) liegt zwischen denen in der Lüneburger Heide und im Solling,

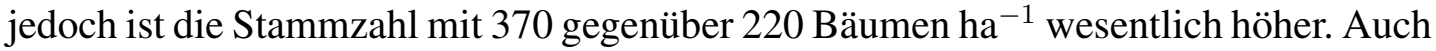
der Blattflächenindex ist hier größer. Unterirdisch werden hier dagegen die kleinsten Werte sowohl bei der Feinwurzelbiomasse (71.2 $\mathrm{g} \mathrm{TG} \mathrm{m}^{-2}$ ) als auch beim BestandesWurzeloberflächenindex (3.1) erreicht.

\subsection{Klima und Wasserhaushalt}

Lüneburger Heide Das Klima in der südlichen Lüneburger Heide ist subozeanisch kühl-gemäßigt. Die Lufttemperatur beträgt im langjährigen Mittel $8.1^{\circ} \mathrm{C}$ (Station Unterlüß des Deutschen Wetterdienstes). Der Jahresniederschlag von $801 \mathrm{~mm}$ nimmt bei den hier untersuchten 3 Waldbeständen eine Mittelstellung ein.

Solling Auch im Solling herrscht ein subozeanisch kühl-gemäßigtes Klima. Bedingt durch die Höhenlage (550 m.ü.M.) der Untersuchungsfläche liegt hier jedoch die Jahresdurchschnittstemperatur mit $6.9^{\circ} \mathrm{C}$ deutlich niedriger. Aufgrund der westexponierten Lage des Sollings fällt hier im langjährigen Mittel (1031 mm) wesentlich mehr Niederschlag als am Standort Lüneburger Heide. Diese Fläche ist also in der vorliegenden Untersuchung am besten mit Wasser versorgt. Angesichts der geringen Temperaturen ist hier eine geringere Transpirationsbeanspruchung an die Bäume zu erwarten. 
Ziegelrodaer Forst Das Klima am Standort Ziegelrodaer Forst ist gegenüber den anderen beiden Untersuchungsflächen mit hohen Sommer- und geringen Wintertemperaturen deutlich subkontinental geprägt (Klimastation Artern des Deutschen Wetterdienstes), wobei die Durchschnittstemperatur von $8.6^{\circ} \mathrm{C}$ im langjährigen Mittel etwa mit derjenigen der Lüneburger Heide vergleichbar ist. Aufgrund der Lage im Regenschatten des Harzes sind hier nur $462 \mathrm{~mm}$ Jahresniederschlag zu verzeichnen. Das exponierte Plateau des Ziegelrodaer Forstes dürfte jedoch Regenmengen um $500 \mathrm{~mm}$ erhalten.

Tabelle 2.2: Niederschlagsummen an den Standorten Solling, Lüneburger Heide und Ziegelrodaer Forst im langjährigen Mittel und in den Untersuchungsjahren 1998 und 1999. Nach Angaben des Deutschen Wetterdienstes (DWD) von den Klimastationen Holzminden-Silberborn (440 m.ü.M) für den Solling, Unterlüß (115 m.ü.M.) für die Lüneburger Heide und Artern (164 m.ü.M.) für den Ziegelrodaer Forst.

\begin{tabular}{lc|cc|cc} 
& & \multicolumn{2}{|c|}{ Langjähriges Mittel } & \multicolumn{2}{c}{ Untersuchungsjahr } \\
& & Jahr & Mai-Sep & Jahr & Mai-Sep \\
\hline Silberborn & 1998 & 1031 & 453 & 1493 & 575 \\
Artern & 1998 & 462 & 246 & 551 & 289 \\
Unterlüß & 1998 & 801 & 352 & 1176 & 468 \\
& 1999 & 801 & 352 & 756 & 289
\end{tabular}

Niederschläge in den Untersuchungsjahren Im Untersuchungsjahr 1998 erhielten alle 3 untersuchten Standorte deutlich mehr Niederschlag als im langjährigen Mittel (Tab.2.2). Die im gesamten Jahr gemessene Regenmenge übertraf an den Stationen Silberborn und Unterlüß das langjährige Mittel um etwa $45 \%$, in Artern hingegen nur um $20 \%$. In der Vegetationsperiode von Mai bis September war dieser Überschuß etwas geringer, hier wurde das langjährige Mittel in Silberborn und in Unterlüß jeweils um etwa $120 \mathrm{~mm}$, also um etwa $30 \%$ übertroffen, während in Arten während dieses Zeitraums $42 \mathrm{~mm}$ (17\%) mehr Regen als im Mittel fiel.

Das Untersuchungsjahr 1999, in dem am Standort Lüneburger Heide die Wasseraufnahme dreier Baumarten verglichen wurde, war dort hingegen mit $756 \mathrm{~mm} \mathrm{Nie-}$ derschlag ein ausgesprochen trockenes Jahr. Besonders in der Vegetationsperiode von Mai bis September lag die Regensumme $63 \mathrm{~mm}$ unter dem langjährigen Mittel, was einer Abweichung von $18 \%$ entspricht. 


\section{Material und Methoden}

\subsection{Saftflußmessungen mit der heat balance Methode}

Eine Methode zur direkten Bestimmung des Massenflusses in pflanzlichen Leitgeweben wurde erstmals von Cermak et al. (1973) vorgestellt. Dabei wird ein Stammsegment mit einer bekannten Energiemenge konstant erwärmt und aus den einzelnen Wärmeströmen die Energiebilanz (heat balance) berechnet:

$$
Q=Q_{f}+Q_{r}+Q_{v}+Q_{s}
$$

wobei $Q$ die zugeführte und $Q_{f}$ die mit dem Xylemsaftstrom abgeführte Energiemenge bezeichnet (alle Angaben in Watt). $Q_{r}, Q_{v}$ und $Q_{s}$ bilanzieren die in radialer und axialer Richtung transportierte bzw. die im Gewebe gespeicherte Wärmemenge. Diese nicht vom Saftfluß abhängigen Wärmeverluste werden in den frühen Morgenstunden kurz vor Sonnenaufgang als gemeinsame Konstante (,fiktiver Fluß“) erfaßt und von den im Tagesverlauf ermittelten Werten subtrahiert. Diesem Verfahren liegt die Annahme zugrunde, daß der Baum sich über Nacht mit Wasser aufsättigt und der Xylemsaftstrom in der späten Nacht zum Erliegen kommt.

Aus der Energiebilanz ergibt sich die Xylemsaftflußrate nach

$$
J=\frac{Q_{f}}{c\left(T_{s o}-T_{s i}\right)}
$$

wobei $J$ die Flußrate $\left(\mathrm{kg} \mathrm{s}^{-1}\right), c$ die Wärmekapazität des Wassers $\left(4187 \mathrm{~J} \mathrm{~kg}^{-1}\right.$ $\left.\mathrm{K}^{-1}\right)$ und $\left(T_{s o}-T_{s i}\right)$ die Temperaturdifferenz zwischen dem ungeheizten und geheizten Xylem bezeichnet.

Ähnliche Verfahren mit konstanter Heizung wurden von Vieweg \& Ziegler (1960) und Ittner (1968) vorgestellt. Eine mathematische Analyse der Energiebilanz erfolgte von Daum (1967) auf der Basis natürlicher Temperaturgradienten im Stamm.

Die bis dahin nur an größeren Stämmen einsetzbare heat balance Methode wurde von Sakuratani (1981) für die Messung an kleineren Durchmessern (4-15 mm) miniaturisiert. Bei diesem System erfolgt die Wärmezufuhr und die Erfassung des Temperaturgradienten an der Stammoberfläche. Die radialen und axialen Wärmeverluste $\left(Q_{v}\right.$ und $Q_{r}$ in Gleichung (3.1) ) werden hier nicht als Konstanten betrachtet, sondern gehen in ihrer tageszeitlichen Dynamik in die Berechnung der Saftflußrate ein:

Eine Thermosäule (Abb. 3.1) erfaßt die Temperaturdifferenz (E, $\mu$ Volt) zwischen der Innen- und Außenseite des Isolationsmaterials. Daraus wird nach

$$
Q_{r}=K_{g} \cdot E
$$


die radiale Wärmeleitung $Q_{r}$ berechnet. Die Wärmeleitfähigkeitskonstante des Sensors $K_{g}\left(\mathrm{~W} \mu \mathrm{V}^{-1}\right)$ wird ermittelt, wenn der Saftfluß Null ist (s.o.), indem Gleichung (3.1) und (3.3) kombiniert werden und $Q_{f}$ gleich Null gesetzt wird:

$$
K_{g}=\frac{Q-Q_{v}}{E}
$$

Obwohl $K_{g}$ eigentlich eine Materialkonstante ist, kann sich der Wert bei Installation an verschiedenen Objekten und auch im Verlauf einer langfristigen Messung an einem Objekt ändern (Sakuratani, 1984). Baker \& van Bavel (1987) empfehlen, diesen Wert durch Abschneiden des Segments nach der Messung zu bestimmen, um sicher zu gehen, daß der Fluß tatsächlich Null ist. In der vorliegenden Arbeit wurde jedoch meist über mehrere Wochen der Saftfluß in einzelnen Wurzeln gemessen, wodurch die einmalige Bestimmung von $K_{g}$ am Ende der Meßperiode einen zu großen Fehler bedeuten würde. Daher wurde hier der $K_{g}$-Wert täglich bestimmt. Um in trockenen, windigen Nächten mit einer gewissen Transpirationsbeanspruchung Fehler in der Berechnung von $K_{g}$ zu vermeiden, wurde ein graphisch-interaktives Computerprogramm (Coners, unveröff.) bei der Saftflußberechnung verwendet, das es erlaubt, solche Werte zu korrigieren.

Die im Sinne von Gleichung (3.2) ursprünglich asymmetrisch angeordneten Thermoelemente (am Ende der beheizten Zone und weit unterhalb im ungeheizten Xylem) werden bei der Miniatur-Saftflußmeßmethode nach Sakuratani paarweise symmetrisch um die Heizzone herum angebracht (s. Abb. 3.1), um damit die axiale Wärmeleitung $Q_{v}$ ermitteln zu können:

$$
Q_{v}=A \cdot K_{r} \cdot \frac{\Delta T}{\Delta x}
$$

Dabei ist $A$ die Querschnittsfläche des Segments $\left(\mathrm{m}^{2}\right), K_{r}$ die Wärmeleitfähigkeit des Gewebes ( $\mathrm{W} \mathrm{m}^{-1} \mathrm{~K}^{-1}$ ) und $\Delta T$ die Temperaturdifferenz zwischen den beiden ober- und unterhalb der Heizung angebrachten Thermoelementen im Abstand $\Delta x(\mathrm{~m})$. $K_{g}$ wurde von Sakuratani (1984) aus den Wärmeleitfähigkeiten der Gewebekomponenten berechnet und mit $0.42 \mathrm{~W} \mathrm{~m}{ }^{-1} \mathrm{~K}^{-1}$ für holziges Gewebe angegeben.

Die Wärmespeicherung im Gewebe $\left(Q_{s}\right.$ in Gleichung (3.1) $)$ ist bei größeren Durchmessern $\left(\mathrm{ab} 2 \mathrm{~cm}\right.$ ) für die korrekte Berechnung von $Q_{f}$ von Bedeutung (Grime et al. 1995a), kann aber bei geringen Durchmessern vernachlässigt werden (Senock \& Ham, 1993).

Die technische Ausführung der Sensoren nach Sakuratani wurde weiter modifiziert und steht seit einigen Jahren kommerziell zur Verfügung. Senock \& Ham $(1993,1995)$ nahmen weitere Änderungen vor, um an Gräsern mit geringem Durchmesser und unregelmäßiger Form den Saftfluß bestimmen zu können.

Dieses System nach Senock \& Ham (1993) wurde in der vorliegenden Arbeit für die Messung an Baumwurzeln eingesetzt, weil es sich an die oft unregelmäßige Form der Wurzel flexibel anpasst und die Messung selbst an sehr dünnen Wurzeln (3-4 mm) 
erlaubt, was die Arbeitszeit für die anschließende Freilegung der Wurzelstränge verkürzt oder diese häufig erst ermöglicht.

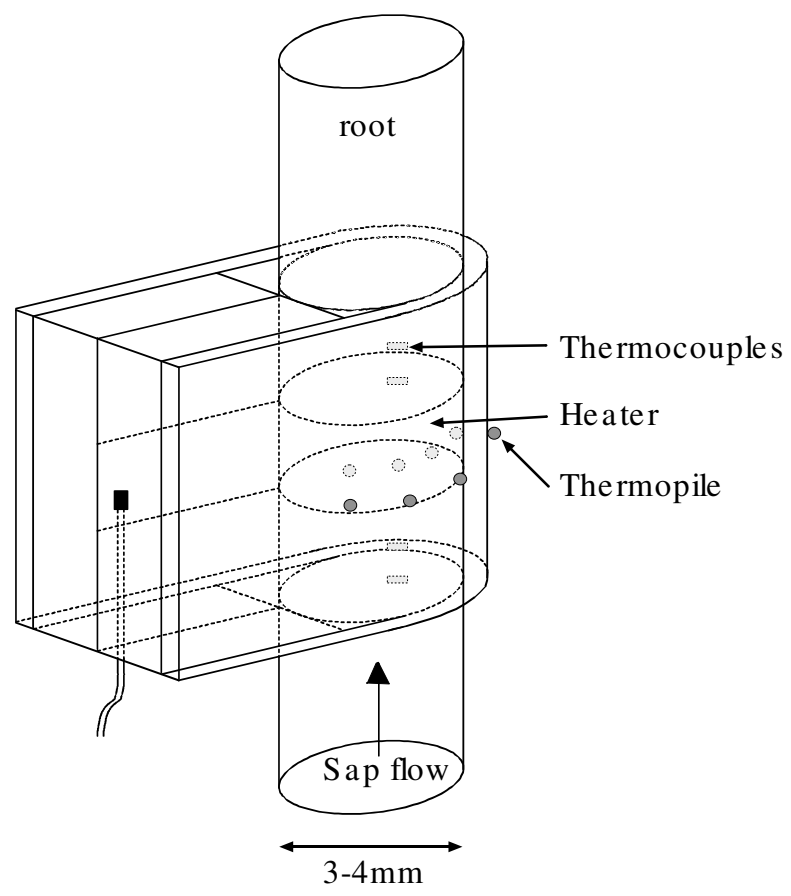

Abb. 3.1: Schematische Darstellung eines Miniatur-Saftflußsensors nach Senock \& Ham (1993).

Die Sensoren werden aus $2 \mathrm{~mm}$ starkem Kork-Neopren-Mischgewebe gefertigt, auf das ein Kapton-Heizfilm (Fa. Heater Designs Inc., Bloomington, CA, USA) aufgeklebt wird (Abb. 3.1). Mittels einer Gleichstromquelle wird der Sensor mit einer konstanten Heizleistung von ca. $0.07 \mathrm{~W}$ betrieben. 3 bzw. $6 \mathrm{~mm}$ ober- und unterhalb des Heizfilms sind Thermoelemente angebracht, die die axiale Wärmeausbreitung $\left(T_{s o}-T_{s i}\right)$ erfassen. Die Meßpunkte der Thermosäule sind alternierend an der Innenund Außenseite des Kork-Neopren-Gewebes auf Höhe des Heizfilms angebracht. Der Sensor wird um ein freigelegtes Wurzelsegment gelegt, mit einer zusätzlichen $5 \mathrm{~mm}$ starken Isolation aus Polyurethan-Schaum umgeben und mit einer Klammer befestigt.

Die gemessenen Daten wurden mit einem Campbell CR10-Datenlogger (Fa. Campbell Scientific Inc., Leicestershire, UK) in $15 \mathrm{sec}$ Intervallen aufgezeichnet und als 15 min Mittelwerte gespeichert. Die Geräte wurden im Solling mittels 220 V Netzspannung mit Strom versorgt, während in der Lüneburger Heide und im Ziegelroader Forst nur eine Solaranlage zur Verfügung stand, was häufig zu einer Mangelversorgung und damit zu Datenausfällen führte. 


\subsection{Kalibrierung der Miniatur-Saftflußmeßanlangen}

Zur Untersuchung der Meßgenauigkeit und der Einsetzbarkeit der Miniatur-Saftflußmethode an den Wurzeln heimischer Baumarten wurden umfangreiche Kalibrationsverfahren durchgeführt. Dafür wurde eine Methode für Freilandexperimente sowie ein hochauflösendes Verfahren unter kontrollierten Bedingungen im Labor entwickelt.

\subsubsection{Freilandmethode}

Im Sommer 1997 wurden auf der Untersuchungsfläche Lüneburger Heide drei Buchenschwachwurzeln mit Saftflußsensoren versehen (s. Kap. 3.3). Nach der Ermittlung des nächtlichen Nullpunktes für die Bestimmung des $K_{g}$-Wertes wurden zwei dieser Wurzeln direkt vor dem Sensor unter Wasser abgeschnitten und in ein $50 \mathrm{ml}$ großes Wasserreservoir überführt (Abb. 3.2). Dieses Reservoir wurde in den nachfolgenden fünf Stunden in $15 \mathrm{~min}$ Intervallen nachgefüllt $( \pm 0.1 \mathrm{ml})$ und so die Wassseraufnahme durch die Wurzel als Vergleichswert für die vom Sensor gemessenen Saftflußraten volumetrisch bestimmt. Die dritte Wurzel diente als Referenz für den Tagesgang der Saftflußrate in einer ungestörten Wurzel.

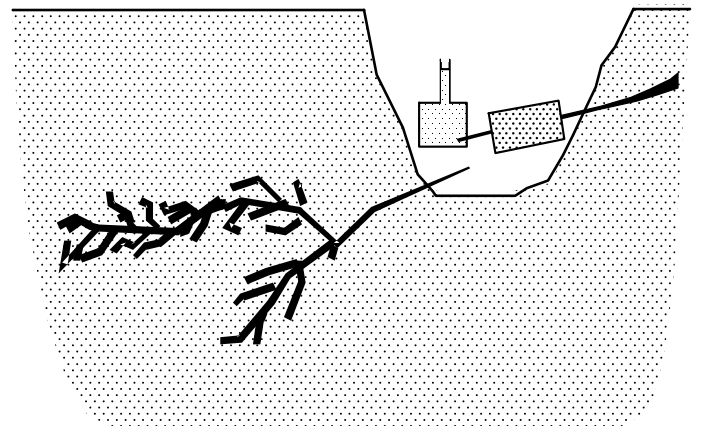

Abb. 3.2: Schematische Darstellung der Freiland-Kalibrierungsmethode.

\subsubsection{Labormethode}

Für den Laboransatz wurden frisch von der Untersuchungsfläche entnommene Wurzelsegmente $(\mathrm{d}=3-4 \mathrm{~mm}, 1=1 \mathrm{~cm})$ mit einem Saftflußsensor versehen und über einen Schlauch an eine Unterdruckpumpe angeschlossen (Abb. 3.3). Die mittels Unterdruck durch das Segment gesogene Wassermenge wird direkt aus einem $50 \mathrm{ml}$ Reservoir aufgenommen, wobei mit variierenden Unterdruckwerten von 0-900 hPa relativ zum Atmosphärendruck Flußraten von 0-20 $\mathrm{g} \mathrm{h}^{-1}$ erzeugt werden können. Evaporative Wasserverluste aus dem Reservoir wurden für jeweils 15 min vor und nach jeder Messung aufgezeichnet und von den Flußraten subtrahiert.

Die Gewichtsänderungen im Reservoir wurden von einer elektronischen Analysewaage $( \pm 0.01 \mathrm{mg}$ ) registriert und mit einem Campbell CR10 Datenlogger (Fa.Campbell Scientific Inc., Leicestershire, UK) zusammen mit den Sensorwerten in $1 \mathrm{~min}$ 


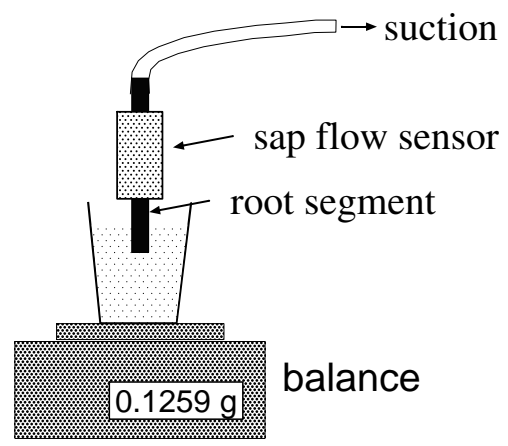

Abb. 3.3: Schematische Darstellung der Labor-Kalibrierungsmethode

Intervallen aufgezeichnet. Um Störungen durch Temperaturgradienten und Luftbewegungen zu minimieren, wurde der gesamte Aufbau mit einem lichtundurchlässigen Gehäuse umgeben.

\subsection{Modifizierte Berechnungsmethode für kleine Saftflußraten}

Aus den Kalibrierungsexperimenten in Labor und Freiland ergab sich für Flußraten $>2 \mathrm{~g} \mathrm{~h}^{-1}$ eine gute Übereinstimmung zwischen den mit den Saftflußsensoren bestimmten Flußraten und der gravimetrischen Kontrolle (s. Kap. 4.1).

Bei Werten $<2 \mathrm{~g} \mathrm{~h}^{-1}$ hingegen wird die Flußrate durch die heat-balance Methode meist deutlich überschätzt, weil in diesem Bereich die Werte für $\mathrm{T}_{\mathrm{so}}-\mathrm{T}_{\mathrm{si}}$ positiv mit der Flußrate korreliert sind und erst oberhalb dieser Grenze dem der Gleichung (3.2) zugrundeliegenden umgekehrt proportionalen Zusammenhang folgen.

Um trotz der an den Baumwurzeln gemessenen geringen Flußraten mit den Miniatursaftflußanlagen die Wasseraufnahme untersuchen zu können, wurde eine modifizierte Berechnungsmethode entwickelt, bei der die deutliche Überschätzung der Nachtwerte vermieden wird. Kleine Flußraten $\left(<2 \mathrm{~g} \mathrm{~h}^{-1}\right)$ werden dabei nach

$$
J^{*}=\beta \cdot\left(T_{s o}-T_{s i}\right)
$$

berechnet, wobei $J^{*}$ die alternativ berechnete Flußrate und $\beta$ ein empirischer Faktor $\left(0.897 \mathrm{~g} \mathrm{~h}^{-1} \mathrm{~K}^{-1}\right)$ ist. Dieser Faktor resultiert aus den Ergebnissen der Laborexperimente, die bei der Messung mit drei verschiedenen Sensoren an je zwei Wurzelsegmenten der Arten Buche, Eiche und Fichte einen konstanten linearen Zusammenhang $(r=0.92)$ zwischen $T_{\text {so }}-T_{\text {si }}$ und der gravimetrisch bestimmten Flußrate ergaben (s. Kap.4.1.2).

Die Flußrate setzt sich im Tagesgang aus den Werten für $J$ (hohe Flüsse, berechnet nach Gleichung (3.2)) und $J^{*}$ (niedrige Flüsse in der Morgen- und Abenddämmerung sowie nachts) zusammen. $J$ wird durch $J^{*}$ ersetzt, wenn folgende Kriterien erfüllt sind: $J<2 \mathrm{~g} \mathrm{~h}^{-1}$ und $E<0.995 \cdot E_{\text {nacht }}$, wobei $E$ den Wert der Thermosäule $(\mu \mathrm{V})$ angibt, 
der nachts am höchsten ist $\left(E_{\text {nacht }}\right)$, wenn der Saftfluss nahe Null ist und der größte Teil der zugeführten Wärme in radialer Richtung abgeführt wird. In der Regel ist dieser Punkt, an dem $J$ durch $J^{*}$ ersetzt wird, im Tagesverlauf kaum zu erkennen, weil beide Größen über eine weite Spanne (etwa 1-3 $\mathrm{g} \mathrm{h}^{-1}$ ) sehr ähnliche Werte annehmen.

Die Berechnung der einzelnen Flüsse sowie die Kombination der Flußrate aus $J$ und $J^{*}$ wurde mit einem graphisch-interaktiven Computerprogramm (Coners, unveröff.) durchgeführt. Hierbei ist die Möglichkeit gegeben, die nächtlichen Nullwerte von Hand zu setzen, was von Zeit zu Zeit in windigen trockenen Nächten notwendig ist, wenn die nächtliche Saftflußrate in den Wurzeln aufgrund der Transpirationsbeanspruchung im Kronenraum nicht auf Null zurückgeht. Auch in Trockenzeiten können Nacht-Saftflüsse auftreten, wenn der Baum nach Sonnenuntergang die Wasserreserven im Stamm und in den Wurzeln wieder auffüllt. In den meisten Fällen waren die nächtlichen Nullwerte durch Extrapolation von vorangegangen und nachfolgenden Tagen mit geringerer Transpiration und einer deutlichen nächtlichen Nullinie der Saftflußrate eindeutig bestimmbar.

Die Vor- und Nachteile dieser modifizierten Methode gegenüber der konventionellen Berechnungsmethode werden in Kap. 5.1 diskutiert.

\subsection{Saftflußmessung an Baumwurzeln unter in situ-Bedingungen}

Die Miniatur-Saftflußmeßsysteme wurden mit dem Ziel eingesetzt, die Wasseraufnahme durch die Baumwurzeln unter in situ-Bedingungen, also mit möglichst geringer Störung zu untersuchen. Um dies zu verwirklichen, wurden in 1-2 m Abstand zum jeweiligen Meßbaum vorsichtig je nach Bedarf 3-6 Bodengruben ausgehoben, die mit einem Durchmesser von 20-30 cm gerade ausreichend groß waren, um an den so freigelegten Wurzelsegmenten die Saftflußsensoren zu installieren (Abb. 3.4). Da in der Grube weder die zu untersuchenden noch benachbarte Wurzeln verletzt werden durften, um nicht das hydraulische System im Wurzelwerk zu stören, wurde der Boden beim Ausheben der Gruben vorsichtig mittels Druckluft (0.3 MPa) aufgelockert und mit der Hand entfernt. Je nach Bedarf wurden die Gruben bis zu $80 \mathrm{~cm}$ tief ausgehoben.

Nach Installation der Saftflußsensoren an den freigelegten Wurzelsegmenten wurde die Grube mit einer Holzplatte zum Schutz gegen Witterungseinflüsse verschlossen. Die Holzplatte wurde zusätzlich mit Aluminiumfolie versehen, um Temperaturschwankungen durch direkte Sonneneinstrahlung zu minimieren.

Mit dieser störungsarmen Methode konnte der Saftfluß in den Wurzeln über Zeiträume von mehreren Tagen bis Wochen dauerhaft aufgezeichnet werden. Dabei waren, bedingt durch die Anzahl der Meßkanäle am Logger, pro Meßbaum jeweils 10 Parallelen möglich. Nach Abschluß der Messung wurden die Wurzeln quantitativ geerntet (s. Kap. 3.4), was mit einer massiven Störung im Wurzelsystem des Meßbaumes verbunden war. Aus diesem Grund wurden die Sensoren jeweils nach einer Meßperiode 


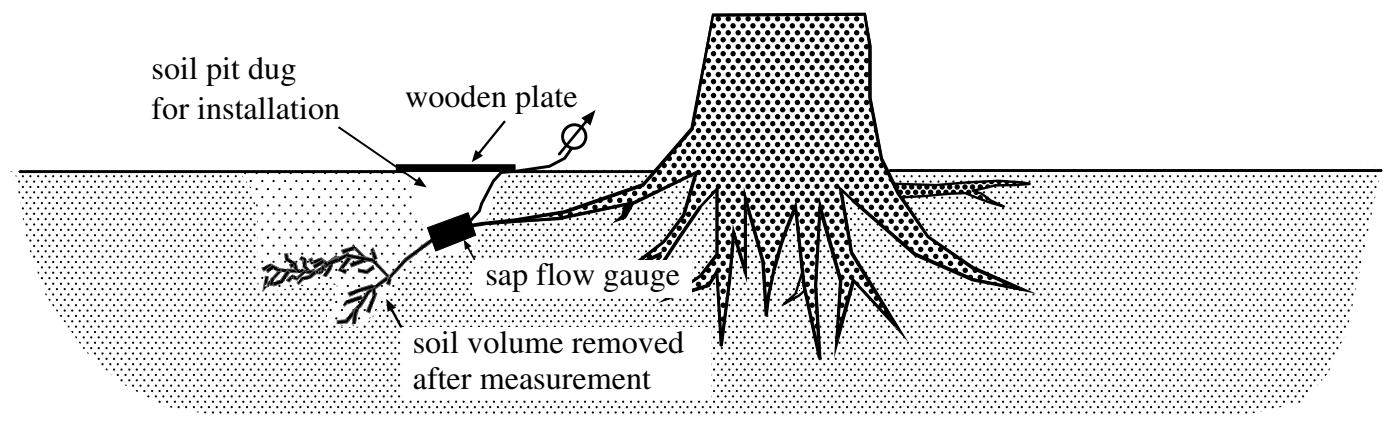

Abb. 3.4: Schematische Darstellung der in situ-Installation der Miniatur-Saftflußmeßanlagen an Baumwurzeln.

an den Wurzeln eines anderen Meßbaumes neu installiert.

In der Vegetationsperiode 1998 wurden auf diese Weise auf den Untersuchungsflächen Lüneburger Heide (OB5), Solling (B1) und Ziegelrodaer Forst (s. Kap. 2) in zwei Meßperioden (etwa Mai bis Juli bzw. Juli bis September) an jeweils 10 Buchenwurzeln der Saftfluß gemessen. Dabei wurden jeweils fünf oberflächennahe und fünf tiefstreichende Wurzeln ausgewählt, um die Wasseraufnahme aus verschiedenen Bodenhorizonten vergleichen zu können. Insgesamt wurden 1998 also 60 Wurzelstränge untersucht.

Nach diesem Schema wurde 1999 die Wasseraufnahme von Rotbuchen, Traubeneichen und Fichten in der Lüneburger Heide (OB5) vergleichend untersucht. Auch hier wurden jeweils fünf oberflächennahe und fünf tiefstreichende Wurzeln parallel untersucht. Für die oberflächennahen Wurzeln von Buche und Eiche wurde eine weitere Meßperiode von Mitte Juli bis Mitte August eingefügt, während die Fichtenwurzeln und die tiefen Mineralbodenwurzeln von Buche und Eiche in 2 Perioden untersucht wurden.

\subsection{Ernte und Weiterverarbeitung der untersuchten Wurzelstränge}

Nach Beendigung der Saftflußmessung wurden die untersuchten Wurzelstränge quantitativ geerntet, um die gemessenen Flußraten auf die Wurzeloberfläche oder Biomasse beziehen zu können. Damit bei der Ernte auch die feinen Wurzelenden erfaßt werden konnten, wurde auch hierbei mit Druckluft gearbeitet (s. Kap. 3.3). Bei der Freilegung wurden die geernteten Wurzeln nach ihrer Lage in der organischen Auflage bzw. im Mineralboden (10 cm-Tiefenstufen) getrennt in Plastiktüten verpackt. Je nach Größe und räumlicher Ausdehnung der Wurzelstränge dauerte die Freilung 1-10 Stunden, in Extremfällen wurden mehrere Tage benötigt.

Der Wurzelabschnitt, an dem der Saftflußsensor installiert gewesen war, wurde für 
die spätere mikroskopische Bestimmung des leitenden Querschnitts in Ethanol (70\%) konserviert.

Im Labor wurden die geernteten Wurzelstränge zunächst mit Wasser gereinigt und in lebende und tote Bestandteile aufgetrennt. Bei der Vitalitätsansprache wurden die Elastizität und Farbe der Wurzel als Kriterien herangezogen (Hertel, 1999, Leuschner et al., 2001b). Dieser Arbeitsschritt erwies sich trotz des hohen Zeitaufwands (mehrere Stunden pro Wurzelstrang) als sehr sinnvoll, denn der Anteil toter Wurzelteile schwankte beträchtlich. Das Auslassen der Trennung hätte also die Werte der aufnehmenden Oberfläche z.T. stark verfälscht.

Für die Bestimmung der Oberfläche wurde ein computergestütztes Bildverarbeitungssystem verwendet (WinRhizo, Fa. Régent, Quebec, Canada). Dabei wurde neben der Gesamtoberfläche auch die Verteilung der Oberfläche in den Durchmesserklassen 0-1 (Feinstwurzeln), 1-2 (Feinwurzeln) und 2-5 mm (Schwachwurzeln) berechnet (Böhm, 1979).

Um neben der Wurzeloberfläche auch das Trockengewicht als Bezugsgröße für die Wasseraufnahme verwenden zu können, wurden die Wurzeln anschließend manuell in die o.g. Durchmesserklassen aufgeteilt, für $48 \mathrm{~h}$ bei $105^{\circ} \mathrm{C}$ getrocknet und gewogen.

\subsection{Bestimmung der Saftflußrate im Stamm der Meßbäume}

Da mit der Saftflußmessung an den Wurzeln nur jeweils ein Teil der Wasseraufnahme durch das gesamte Wurzelsystem erfaßt werden konnte, wurde die Saftflußrate im Stamm als Maß für die Gesamttranspirationsleistung der untersuchten Meßbäume aufgezeichnet. Das dafür eingesetzte System P690.3 (Fa. EMS, Brno, Tschechische Republik) beruht auf dem bereits in Kap. 3.1 beschriebenen heat-balance Prinzip mit xyleminterner Heizung nach Cermak et al. (1973, 1976).

Für die Installation wird zunächst die Dicke der Borke bestimmt, indem ein Schlageisen vorsichtig eingetrieben wird, bis der Widerstand deutlich ansteigt, weil das Eisen auf das wesentlich härtere Holz stößt. Außerdem muß die Stärke des hydroaktiven Xylems, also der Splintholzanteil, ermittelt werden, was sich wesentlich schwieriger gestaltet als bei der Borke. Beim System P690.3 werden dafür Tabellen mitgeliefert, aus denen für ring- bzw. zerstreutporige Baumarten die Splintholztiefe in Abhängigkeit vom Baumalter und Durchmesser des Stammes abgeschätzt werden kann. Eine genauere Bestimmung ist mittels Färbeversuchen an Stammsegmenten möglich, was als destruktive Methode bei den untersuchten Bäumen auf den Daueruntersuchungsflächen nicht realisierbar war. Die Methode der störungsarmen Bestimmung des radialen Flußprofils in Baumstämmen (Cermak \& Nadezhdina, 1998) stand zum Zeitpunkt der Untersuchung noch nicht zur Verfügung.

Eine Kenntnis der Tiefe des hydroaktiven Xylems ist wichtig bei der Installation, damit die Heizelektroden und Temperatursensoren richtig plaziert werden können. Auch als Bezugsgröße für die Saftflußraten (Saftflußdichte) spielt dieser Wert ein große Rolle. 
Bei der Installation werden in etwa 2 m Höhe 5 Edelstahlelektroden im Abstand von $2 \mathrm{~cm}$ parallel in den Stamm eingeschlagen. Durch den angelegten Wechselstrom $(1 \mathrm{kHz}$, bis zu $200 \mathrm{~V})$ wird das Xylem zwischen den Elektroden aufgeheizt (Heizleistung konstant $1 \mathrm{~W}$ ). Die Erfassung der Wärmegradienten erfolgt durch ein System von 4 bzw. 8 Thermoelementen, die in 2 verschiedenen Tiefen unterhalb und am Ende der beheizten Zone im Holz angebracht werden. Die Länge und Tiefe der Elektroden und Thermoelemente richtet sich nach den vorher ermittelten Werten der Borken- und Splintholzstärke.

Die Regelung und Datenerfassung wird beim System P690.3 von einer zentralen Steuerungseinheit übernommen. Die gemessenen Daten werden jede Minute erfaßt und als 15 min-Mittelwerte gespeichert.

Mit dieser Methode wurde 1998 an jeweils 3 Buchen an den Standorten Solling, Lüneburger Heide und Ziegelrodaer Forst und im Sommer 1999 an jeweils 3 Buchen bzw. 2 Fichten am Standort Lüneburger Heide der Stammsaftfluß gemessen. An jedem Stamm wurden je 2 Anlagen (nord- und südexponiert) installiert.

Zur genaueren Charakterisierung der Meßbäume wurde im Herbst des jeweiligen Meßjahres von den untersuchten Bäumen eine Kronenprojektion in 8 Himmelsrichtungen angefertigt sowie die Gesamthöhe und die Lage des Kronenansatzpunktes bestimmt.

\subsection{Bestimmung des Wasserpotentials in Feinwurzeln}

Zur Bestimmung des Wasserpotentials in den Wurzeln der untersuchten Bäume wurde die Druckkammermethode nach Scholander et al. (1965) verwendet. Davon ausgehend, daß der osmotische Wert und das Matrixpotential des Apoplasten in der Regel vernachlässigbar klein sind (Tyree \& Jarvis, 1982), kann der mit der Druckkammer ermittelte Wert dem Wasserpotential gleichgesetzt werden.

Für die Messung wurden 5-10 cm lange Wurzelenden aus der organischen Auflage vorsichtig freigelegt. Um die Wurzel nicht zu verletzen, wurde der Boden mit Druckluft (0.3 MPa) aufgelockert, ohne den Luftstrahl direkt auf die Wurzel zu richten. Die freigelegte Wurzel wurde abgeschnitten und so in die Meßapparatur (Fa. PMS-Instruments, Corvallis, Oregon, USA) eingesetzt, daß sie höchstens $1 \mathrm{~cm}$ aus der Druckkammer herausragte. Anschließend wurde der Druck in der Kammer langsam erhöht (max. 0.3 MPa pro min), bis der Xylemsaft, der sich beim Schneiden im Xylem aufgrund des negativen Drucks zurückgezogen hatte, aus der Schnittfläche austrat.

Das Tagesmaximum des Wasserpotentials wurde kurz vor Sonnenaufgang ermittelt, nachdem der Baum sich über Nacht mit Wasser aufsättigen konnte. Wenn dieser Wert stark abgesenkt ist, kann davon ausgegangen werden, daß die nächtliche Transpirationspause nicht ausreicht, um die tagsüber entleerten Reserven im Stamm und den größeren Zweigen und Wurzeln wieder aufzufüllen; der Baum leidet also unter Trockenstreß. Als zweiter Meßpunkt wurde mittags, also zum Zeitpunkt maximaler Transpirationsbeanspruchung, das Minimim des Wasserpotentials erfaßt. Für jeden 
Meßpunkt wurde der Mittelwert aus 5 Einzelmessungen gebildet.

In der Vegetationsperiode 1998 wurde so an 7 Terminen in der Lüneburger Heide, sowie an 3 bzw. 5 Terminen im Solling und im Ziegelrodaer Forst das Wasserpotential in Buchenwurzeln untersucht. 1999 wurde auf diese Weise an 7 Terminen das Wurzelwasserpotential von Buchen, Eichen und Fichten verglichen. Zusätzlich wurde in diesem Jahr von einem Meßturm (s. Kap. 3.7) aus an 5 Terminen zeitgleich zu den Wurzeln das Blattwasserpotential (Sonnenblätter in $25 \mathrm{~m}$ Höhe) an Buchen und Eichen bestimmt. Werte für Fichtenadeln stehen für diesen Zeitraum nicht zur Verfügung, weil der Kronenraum der Bäume auf der Untersuchungsfläche nicht zugänglich ist.

\subsection{Messung mikroklimatischer Parameter}

Für die Messung klimatischer Parameter standen in der Lüneburger Heide (OB5) und im Solling (B1) Gerüsttürme zur Verfügung. Auf diesen wurde jeweils oberhalb des Bestands die einfallende Globalstrahlung $\left(S, \mathrm{~W} \mathrm{~m}^{-2}\right)$ mit Solarimetern nach MollGorczynski (Fa. Kipp \& Zonen, Delft, Niederlande) und das Wasserdampfsättigungsdefizit der Luft (VPD, hPa) mit Psychrometern dauerhaft erfaßt. Diese Daten wurden 1998 für die beiden genannten Flächen von der Arbeitsgruppe Prof. Dr. Gravenhorst (Institut für Bioklimatologie, Fakultät für Forstwissenschaften und Waldökologie, Universität Göttingen) zur Verfügung gestellt.

Für den Vergleich der Klimaparameter mit den Wasserhaushaltswerten auf der Basis von Tageswerten wurde von der Globalstrahlung $\left[\mathrm{W} \mathrm{m}^{-2}\right]$ die Tagessumme gebildet $\left[\mathrm{MJ} \mathrm{m}^{-2} \mathrm{~d}^{-1}\right]$. Beim Sättigungsdefizit der Luft wurden die Stundenmittel der Hellphase für jeden Tag kumuliert und so der Anteil der jahreszeitlich unterschiedlichen täglichen Sonnenscheindauer aus dem Tageswert eliminiert. Der so ermittelte Wert VPD $\mathrm{Vum}_{\text {cum }}\left[\mathrm{hPad}^{-1}\right]$ stellt somit ein geeignetes Maß für die Transpirationsbeanspruchung während eines Tages dar.

Auf der Untersuchungsfläche Ziegelrodaer Forst stand 1998 kein instrumentierter Meßturm im Bestand zur Verfügung. Daher wird hier auf Klimadaten des Deutschen Wetterdienstes von der $14 \mathrm{~km}$ entfernt liegenden Klimastation Artern zurückgegriffen. Diese Werte sind aufgrund der Entfernung nicht auf Stundenbasis auf die klimatischen Verhältnisse im untersuchten Bestand zu übertragen. Sie stellen aber in Form von Tagessummen eine vertretbare Bezugsgröße für Vergleiche des Regionalklimas mit den anderen Standorten im Solling und in der Lüneburger Heide dar.

\subsection{Messung der Bodenfeuchte und der Bodentemperatur}

Als wichtige bodenhydrologische Parameter wurde parallel zu den Saftflußmessungen die Bodensaugspannung $\left(\Psi_{\text {Boden }}\right)$ und der volumetrische Bodenwassergehalt $(\theta)$ ermittelt.

Dazu wurde auf den Untersuchungsflächen Lüneburger Heide und Ziegelrodaer Forst in der Nähe der Meßbäume eine Bodenstation installiert, die über die gesam- 
te Vegetationsperiode in den Tiefen 5, 30 und $60 \mathrm{~cm}$ kontinuierlich die Bodenfeuchte aufzeichnete. Zur Erfassung des volumetrischen Bodenwassergehalts dienten pro Meßtiefe 2 TDR-Sonden mit $10 \mathrm{~cm}$ langen Meßstäben (Modell P2Z, betrieben über einen Trime-MUX6 Multiplexer, Fa. Imko, Ettlingen), die alle $2 \mathrm{~h}$ abgefragt wurden. Die Bodensaugspannung wurde je Tiefe mit 3 selbstgefertigten DruckaufnehmerTensiometern (Keramikmeßkopf: $l=5 \mathrm{~cm}, d=2 \mathrm{~cm}$ ) in $15 \mathrm{~m}$-Intervallen aufgezeichnet. Die Drucksensoren wurden zu Beginn der Vegetationsperiode mit einer hängenden Wassersäule kalibriert.

Für die Untersuchungsfläche B1 im Solling wurden Bodenfeuchtedaten vom Institut für Bodenkunde und Waldernährung (Forstliche Fakultät, Universität Göttingen) für das Jahr 1998 zur Verfügung gestellt.

\subsection{Morphologisch-anatomische Untersuchungen an Baumwurzeln}

Zur anatomischen Charakterisierung der untersuchten Arten wurden Querschnitte von Buchen-, Eichen- und Fichtenwurzeln mikroskopisch untersucht. Dazu wurden von je 3 frisch im Freiland geernteten Wurzelsträngen an Stellen mit 0.5, 1 und $2 \mathrm{~mm}$ Durchmesser sowie direkt hinter der mykorrhizierten Spitze (ca. $0.25 \mathrm{~mm}$ ) jeweils 3 Proben entnommen. Diese Proben wurden in einer aufsteigenden Alkoholreihe entwässert, mit Kunststoff (Technovit 7100, Fa. Kulzer) infiltriert und mit dem Mikrotom geschnitten. Zur Ansprache der einzelnen Gewebe wurden die Schnitte mit SudanIII und Toluidinblau angefärbt. Für die Anfertigung der Mikrotomschnitte wurden Geräte und Material von der Abteilung Botanik im Fachbereich Biologie/Chemie der Universität Kassel zur Verfügung gestellt.

Die Querschnitte wurden auf das Vorhandensein einer Endodermis bzw. eines Periderms und deren Stärke (ausgedrückt in mm oder als Zahl der Zellschichten) hin untersucht. Die Längenmessungen wurden entweder direkt mit einem Meßokular oder nach Übertragung auf Papier mit einer Abbéeschen Zeichenhilfe durchgeführt, wobei jeweils eine Objektmeßplatte als Maßstab diente.

Um diese durchmesserbezogenen Größen auch auf die Entfernung von der terminalen Wurzelspitze beziehen zu können, wurde an je 5 frisch geernteten Wurzelsträngen pro Art (s. Kap 3.4) mit einer Schieblehre in Abständen von $2 \mathrm{~cm}$ bis zur Wurzelspitze der Durchmesser bestimmt und die Durchmesser-/Entfernungsbeziehung analysiert.

\subsection{Extraktion und Analyse des Suberins}

Ergänzend zu den mikroskopischen Untersuchungen zur Wurzelanatomie wurden in Kooperation mit der Arbeitsgruppe von PD Dr. Schreiber (Institut für Ökophysiologie und Vegetationsökologie, Lehrstuhl für Botanik II, Universität Würzburg) die Gehalte an Suberin, Lignin und Wachsen im Periderm in qualitativer wie auch in quantitaiver Hinsicht untersucht. 
Dazu wurden auf der Untersuchungsfläche Lüneburger Heide Frischproben von Buchen-, Eichen- und Fichtenwurzeln entnommen, im Labor mit deionisiertem Wasser gereinigt und in die Durchmesserklassen $<0.5,0.5-1$ und 1-2 mm fraktioniert. Nachdem mit dem Scanner-System (s. Kap. 3.4) die Oberfläche der Wurzelsegmente in den Durchmesserklassen bestimmt worden war, wurden die Proben in das Labor in Würzburg überführt.

Die Analyse erfolgte gemäß (Schreiber et al., 1999): Zunächst wurden die frisch geernteten Wurzeln in einer enzymatischen Pufferlösung $\left(10^{-2}\right.$ mol $1^{-1} \mathrm{NaAc}, \mathrm{pH}$ 4.50, $25^{\circ} \mathrm{C}$ ) mit $0.25 \%$ (w/v) Cellulase (Onozuka R-10, Serva, Heidelberg) und $0.25 \%$ (w/v) Pectinase (Macerozyme R-10, Serva) 3 Wochen lang mazeriert. Verbliebene Periderm-Zellwände wurden unter dem Stereomikroskop mittels Pinzetten manuell von der Stele getrennt. Das so gewonnene peridermale Abschlußgewebe wurde mit Chloroform/Methanol (1:1 v/v) für 12 Stunden bei $60^{\circ} \mathrm{C}$ extrahiert und getrocknet. Das Trockenmaterial wurde chemisch aufgelöst und das Suberin mit $\mathrm{MeOH} / \mathrm{BF}_{3}$ (Fluka) analysiert (s. Zeier \& Schreiber (1997, 1998)). Die Laborarbeiten in Würzburg wurden von Dipl. Chem. Klaus Hartmann durchgeführt.

\subsection{Bestimmung des leitenden Querschnitts am Meßpunkt}

Bei der Ernte der Wurzelstränge wurde jeweils das etwa $5 \mathrm{~cm}$ lange Segment, an dem sich der Sensor befand, in Ethanol konserviert (Kap. 3.4). Im Labor wurde von diesen Segmenten mit der Hand Querschnitte angefertigt und unter dem Mikroskop untersucht. Dabei wurden je 5 Buchen-, Eichen- und Fichtenwurzeln der organischen Auflage aus der Vegetationsperiode 1999 bearbeitet.

Die Handschnitte wurden mit SudanIII gefärbt und mit Hilfe einer Abbéeschen Zeichenapparatur anhand einer Objektmeßplatte maßstabsgetreu auf Papier übertragen. Die Zeichnungen wurden ausgewertet, indem die Tracheen und Tracheiden in Durchmesserklassen eingeteilt und vollständig gezählt wurden. Um den Zeitaufwand zu minimieren, wurde nicht der komplette Querschnitt analysiert, sondern jeweils ein großes und ein kleines Kreissegment zwischen den Markstrahlen (zusammen etwa $\frac{1}{4}$ der Gesamtfläche). Nach Bestimmung der Flächenanteile des Xylems, Phloems, der Markstrahlen und der Wurzelrinde wurde der leitende Anteil in den Kreissegmenten auf die gesamte Xylemfläche hochgerechnet. 


\subsection{Untersuchung der axialen hydraulischen Leitfähigkeit im Wurzelxylem}

Der Wasserfluß im Xylem einer Pflanze kann analog zum elektrischen Strom gemäß dem Ohmschen Gesetz formuliert werden (van den Honert, 1948, Richter, 1973):

$$
J=\frac{\Delta \Psi}{R}
$$

Dabei ist $J$ der Wasserfluß im Xylem $\left(\mathrm{kg} \mathrm{s}^{-1}\right), \Delta \Psi$ der Potentialgradient $\left(\mathrm{MPa} \mathrm{m}^{-1}\right)$ und $R$ der hydraulische Widerstand (MPa $\mathrm{kg}^{-1} \mathrm{~m}^{-1}$ ). $R$ ist der Kehrwert der axialen hydraulischen Leitfähigkeit $K\left(\mathrm{~kg} \mathrm{~m} \mathrm{MPa}{ }^{-1} \mathrm{~s}^{-1}\right)$.

Zur Bestimmung der maximalen hydraulichen Leitfähigkeit in Wurzeln wurde die Durchflußmethode nach Sperry et al. (1988) eingesetzt. Dafür wurden auf der Untersuchungsfläche Lüneburger Heide $(\mathrm{OB} 5)$ je 5 Wurzelsegmente $(1 \approx 10 \mathrm{~cm})$ von Buche, Eiche und Fichte entnommen und sofort mit Stearin an den Schnittflächen versiegelt, um die Austrocknung des Xylems zu vermeiden.

Die Leitfähigkeitsmessung erfolgte im Labor. Die Meßapparatur für diese Methode besteht aus einem blasenfrei mit Wasser gefüllten Schlauchsystem, durch das die Segmente mit einem $60 \mathrm{~cm}$ höher stehenden Vorratsgefäß verbunden sind, was einem hydrostatischen Druck von 0.006 MPa entspricht. Um emboliebedingte Gasblasen aus dem Xylem zu entfernen, kann alternativ eine Verbindung zu einem Druckgefäß (0.12$0.14 \mathrm{MPa}$ ) hergestellt werden. Die Durchflußrate wird gravimetrisch mit einem Auffanggefäß unter dem Segment ermittelt.

Vor der Messung wurden die auf der Untersuchungsfläche geernteten Segmente unter Wasser auf $5 \mathrm{~cm}$ Länge zurückgeschnitten und mit dem wassergefüllten Schlauchende der Meßapparatur verbunden, wobei darauf geachtet wurde, daß die Schnittflächen ständig mit Wasser benetzt blieben. In einem ersten Schritt wurde die aktuelle Leitfähigkeit bestimmt, indem bei einem hydrostatischen Druck von 0.006 MPa für 5 min der Durchfluß durch das Segment gemessen wurde. Anschließend wurde 5 min lang ein Druck von 0.12 bis $0.14 \mathrm{MPa}$ angelegt (,flush“). Eine weitere Durchflußmessung bei $0.006 \mathrm{MPa}$ ergab dann die maximale hydraulische Leitfähigkeit. Um sicherzugehen, daß sämtliche Gefäße vollständig mit Wasser gefüllt waren, wurden die letzten beiden Schritte nochmals wiederholt.

\subsection{Wurzel-Saftflußmessungen nach experimenteller Ausschaltung des radialen Wurzelwiderstandes}

Um die relative Bedeutung des radialen Wurzelwiderstandes und des hydraulischen Widerstandes in der Rhizosphäre gegenüber dem axialen abzuschätzen, wurden an verschiedenen Terminen 1999 Schneideexperimente an 3-4 mm starken Baumwurzeln durchgeführt. Hierbei wird durch das Schneiden unter Wasser der radiale Widerstand eliminiert und die sich neu einstellende Flußrate ist ausschließlich durch den axialen 
Widerstand im Wurzelxylem bestimmt. Die Schneideexperimente wurden analog zu Kap. 3.1.1.1 durchgeführt, indem vorsichtig freigelegte Wurzelabschnitte unter Wasser geschnitten wurden, so daß Flußrate über einen Zeitraum von mehreren Minuten bis Stunden anhand der Wasseraufnahme aus dem Reservoir verfolgt werden konnte.

Mit diesem Verfahren wurden im Sommer 1999 an verschiedenen Terminen Messungen an je 3 Buchen-, Eichen- und Fichtenwurzeln auf der Untersuchungsfläche OB5 in der Lüneburger Heide durchgeführt. Für die Messung wurden von den mit Saftflußsensoren bestückten Wurzeln der organischen Auflage solche ausgewählt, deren Meßpunkt sich in einer ausreichend großen Meßgrube befand, damit ohne große Störung das Schneideexperiment durchgeführt werden konnte.

Die Flußrate in der Wurzel unter ungestörten Bedingungen $\left(J_{i n-s i t u}\right)$ läßt sich analog zum Ohmschen Gesetz (Gleichung 3.7) aus der Wasserpotentialdifferenz zwischen der Wurzel $\left(\Psi_{\text {root }}\right)$ und dem Boden $\left(\Psi_{\text {soil }}\right)$ und dem aus dem axialen $\left(R_{a x}\right)$ und radialen $\left(R_{\text {rad }}\right)$ hydraulischen Widerstand zusammengesetzten Gesamtwiderstand des aufnehmenden Wurzelstrangs $\left(R_{t o t}\right)$ berechnen:

$$
J_{\text {in-situ }}=\frac{\Delta \Psi}{R_{\text {tot }}}=\frac{\Psi_{\text {root }}-\Psi_{\text {soil }}}{R_{\text {rad }}+R_{\text {ax }}}
$$

Nach dem Dekapitieren des Wurzelstrangs ist die exponierte Schnittfläche dem Druck der Atmosphäre ausgesetzt, das zu Null angenommen werden kann; es gilt also $\Delta \Psi=\Psi_{\text {root }}$. Weiterhin ist durch das Entfernen des Wurzelendes der radiale Widerstand ausgeschaltet. Die Flußrate $J_{\text {decap. }}$ ergibt sich also aus

$$
J_{\text {decap. }}=\frac{\Psi_{\text {root }}}{R_{a x}}
$$

Durch Einsetzen von $\Psi_{\text {root }}$ in Gleichung (3.8) und Umformen ergibt sich der axiale Widerstand nach

$$
R_{a x}=\frac{J_{i n-s i t u} \cdot R_{t o t}+\Psi_{\text {soil }}}{J_{\text {decap. }}}
$$




\section{Ergebnisse}

\subsection{Kalibrierung der Miniatur-Saftflußmeßsysteme}

Ein Vergleich aller erhobenen Saftflußdaten ergab, daß bei der herkömmlichen Berechnungsmethode nach Gleichung (3.2) Flußraten $<2 \mathrm{~g} \mathrm{~h}^{-1}$ mit einem großen Fehler, meist einer deutlichen Überschätzung, behaftet sein können. Diese Fehler stehen größtenteils mit einer ungenauen Bestimmung der Temperaturdifferenz $\mathrm{T}_{\mathrm{so}}-\mathrm{T}_{\mathrm{si}}$ bzw. deren Einsatz in Gleichung (3.2) in Zusammenhang und wirken sich nur bei geringen Flußraten aus. Da also offensichtlich Meßungenauigkeiten bei hohen und niedrigen Flußraten verschiedene Ursachen haben können, werden die Kalibrierungsexperimente für Werte $<2 \mathrm{~g} \mathrm{~h}^{-1}$ und $>2 \mathrm{~g} \mathrm{~h}^{-1}$ getrennt analysiert.

\subsubsection{Meßgenauigkeit der Sensoren bei mittleren und hohen Flußraten}

Am 7. August 1997 wurde auf der Untersuchungsfläche OB5 in der Lüneburger Heide ein Freiland-Kalibrierungsexperiment durchgeführt, um die Meßgenauigkeit der Miniatur-Saftflußsensoren an Buchenwurzeln unter in situ-Bedingungen zu untersuchen. Die 3 Sensoren wurden bereits am Vortag installiert, um mit dem in der Nacht bestimmten Nullpunkt die Saftflußrate korrekt berechnen zu können (Kap. 3.1.1.1). Um 8.30 Uhr wurden die Wurzeln Nr. 1 und 2 unter Wasser geschnitten. Von 10.30 bis 15.30 wurde dann für 5 Stunden die Wasseraufnahme dieser beiden Wurzeln aus einem Reservoir bestimmt. Wurzel Nr. 3 blieb unverletzt und diente als Kontrolle für die Saftflußrate unter ungestörten Verhältnissen (Abb. 4.1).

Der Saftfluß in der Kontrollwurzel (Nr. 3) wird im Tagesgang von den klimatischen Randbedingungen kontrolliert. Nach Sonnenaufgang setzt in der Krone die Transpiration ein und läßt in den Wurzeln die Saftflußrate ansteigen. Zur Mittagszeit erreicht die Flußrate in Wurzel Nr. 3 mit $4.2 \mathrm{~g} \mathrm{~h}^{-1}$ ein Maximum und wird dann kontinuierlich geringer, bis um etwa 20.00 Uhr kein nennenswerter Fluß mehr zu verzeichnen ist.

Die Flußrate in den beiden geschnittenen Wurzeln verhält sich im zeitlichen Verlauf grundlegend anders: In beiden Wurzeln steigt die Flußrate direkt nach dem Abschneiden sprunghaft um etwa das 7- bzw. 10-fache an (Nr. 2 von 2 auf $15 \mathrm{~g} \mathrm{~h}^{-1}$, Nr. 1 von 7.4 auf $76 \mathrm{~g} \mathrm{~h}^{-1}$ ). In den folgenden Stunden nimmt die Flußrate koninuierlich ab, ohne ein mittägliches Maximum erkennen zu lassen. Wurzel Nr. 2 weist ähnlich wie die Kontrolle ab 20.00 Uhr keinen Saftfluß mehr auf, während sich in Wurzel Nr. $1 \mathrm{ab}$ diesem Zeitpunkt ein Plateau bei etwa $4 \mathrm{~g} \mathrm{~h}^{-1}$ einstellt. Diese Wurzel nimmt also bei der optimalen Versorgung aus dem Reservoir auch in der Nacht noch deutlich meßbare Wassermengen auf, was in der vorangegangenen Nacht unter natürlichen Bedingungen 


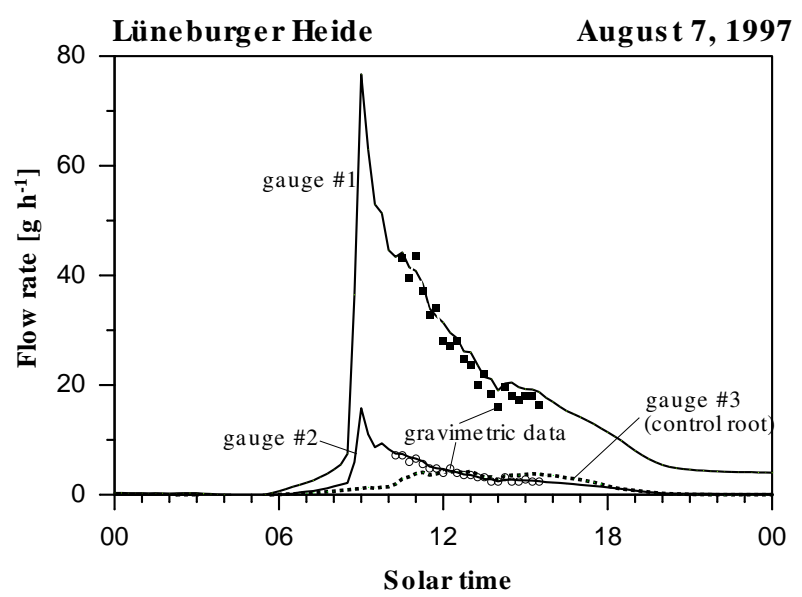

Abb. 4.1: Tagesgang der gravimetrisch bzw. thermoelektrisch bestimmten Saftflußrate in $3 \mathrm{Bu}-$ chenwurzeln, gemessen in der Lüneburger Heide am 7. August 1997. Wurzeln Nr. 1 und Nr. 2 wurden um 8.30 Uhr unter Wasser geschnitten und die Wasseraufnahme aus dem Reservoir anschließend in 15-min Intervallen gravimetrisch bestimmt (Nr. 3 = Kontrolle).

nicht der Fall war.

Die gravimetrisch bestimmten Aufnahmeraten in der Zeit von 10.30 bis $15.30 \mathrm{Uhr}$ stimmen im zeitlichen Verlauf bei beiden untersuchten Wurzeln gut mit den Werten der Saftflußsensoren überein. In der Spanne von 3 bis $42 \mathrm{~g} \mathrm{~h}^{-1}$ ergibt sich dabei zwischen den gravimetrisch bzw. thermoelektrisch ermittelten Saftflußraten in den beiden Wurzeln eine enge Korrelation $(r=0.99)$.

Der Tagesgang der Kontrollwurzel stellt ein typisches Beispiel für die Größenordnung der Flußraten in 3-4 mm starken Wurzeln heimischer Baumarten dar. Auch bei den anderen untersuchten Arten Eiche und Fichte wurden Tagesmaxima von etwa 3$10 \mathrm{~g} \mathrm{~h}^{-1}$ gemessen. Dieser Bereich konnte mit den Freiland-Kalibrierungsexperimenten nur ungenügend abgedeckt werden, weil hier die Flußrate in den Wurzeln bei optimaler Wasserversorgung unter Wegfall des radialen Widerstandes deutlich höher ist.

Der physiologisch relevante Bereich mit Saftflußraten von $0-15 \mathrm{gh}^{-1}$ wurde mit der Labormethode untersucht. Hierbei wurde in insgesamt 6 Laborexperimenten de $r$ Wasserfluß durch 2 Buchenwurzelsegmente gravimetrisch gemessen und mit 3 verschiedenen Miniatur-Saftflußsensoren thermoelektrisch verfolgt (Abb. 4.2). Daraus ergibt sich für Flußraten zwischen 1 und $15 \mathrm{~g} \mathrm{~h}^{-1}$ eine enge Beziehung mit einem Korrelationsfaktor von 0.88. Die Steigung der Regressionsgeraden (0.92) weist dabei auf eine leichte Unterschätzung höherer Flußraten hin.

\subsubsection{Meßgenauigkeit der Sensoren bei niedrigen Flußraten}

Bei den Kalibrierungsexperimenten mit der Labormethode (Abb.4.2) wurde besonders der Meßbereich unterhalb $2 \mathrm{~g} \mathrm{~h}^{-1}$ untersucht, der unter natürlichen Bedingungen eine wichige Rolle spielt. Während oberhalb dieser Grenze eine sehr gute Korrelation zwi- 


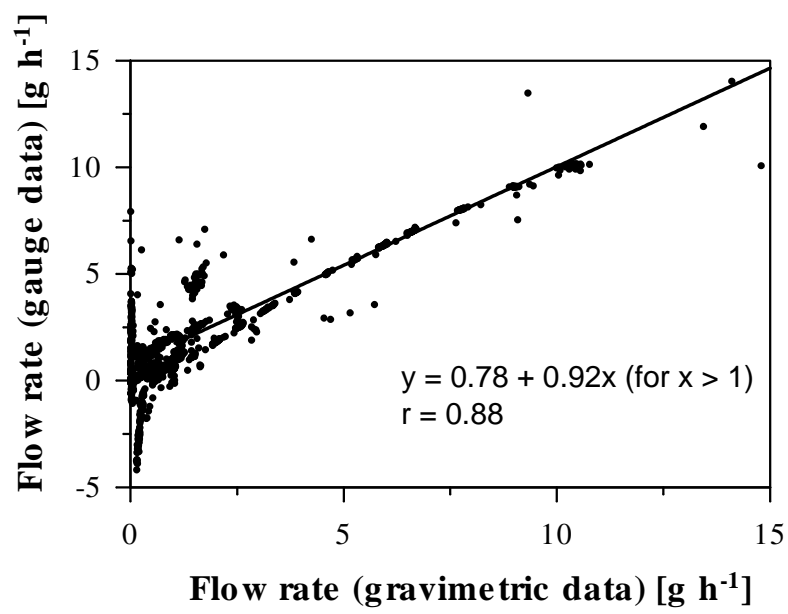

Abb. 4.2: Korrelation der gemessenen (gravimetrische Bestimmung) und der berechneten (Miniatur-Saftflußsensoren) Flußrate in 3-4 mm dicken Buchenwurzeln. Die Ergebnisse basieren auf 6 Laborexperimenten an abgeschnittenen Wurzelsegmenten.

schen den berechneten und den gravimetrisch bestimmten Flußrate besteht, weichen bei den geringen Flußraten die Werte weit $(>200 \%)$ voneinander ab, wobei in den meisten Fällen eine Überschätzung der Flußrate durch die Sensorwerte zu beobachten ist. Unter natürlichen Bedingungen im Freiland äußert sich dies in oftmals deutlich überhöhten Nachtwerten.

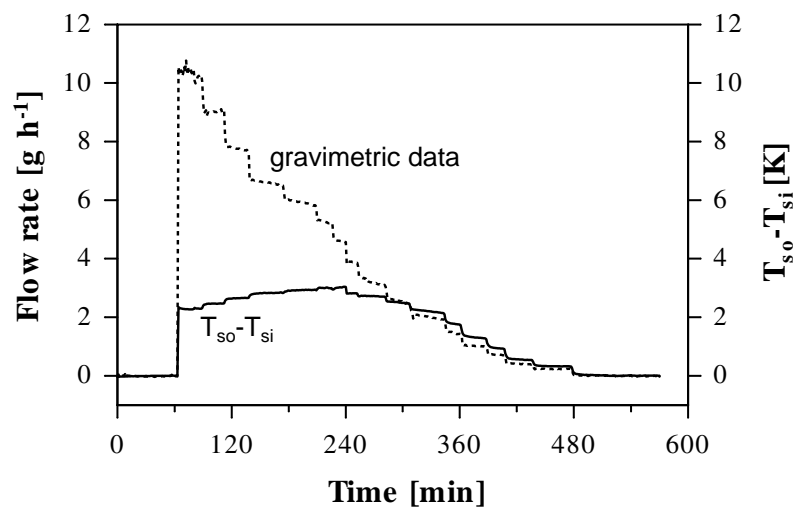

Abb. 4.3: Gravimetrisch bestimmter Fluß durch ein Buchenwurzelsegment und die Temperaturdifferenz über den beheizten Bereich $\left(\mathrm{T}_{\mathrm{so}}-\mathrm{T}_{\mathrm{si}}\right)$ eines an dem Segment installierten Sensors. Während des Laborexperiments wurde die Flußrate durch Absenken des angelegten Unterdrucks schrittweise von 11 auf $0 \mathrm{~g} \mathrm{~h}^{-1}$ erniedrigt.

Abb. 4.3 demonstriert den zeitlichen Verlauf eines Laborexperiments an einer $\mathrm{Bu}-$ chenwurzel. 60 min nach Versuchsbeginn wurde der angelegte Unterdruck stark abgesenkt, was einen Anstieg der Flußrate durch das Wurzelsegment auf $10 \mathrm{~g} \mathrm{~h}^{-1}$ zur Folge hatte. Die stufenweise Entspannung des Unterdrucks in Abständen von etwa 
30 min bis auf Atmosphärendruck bewirkte eine ebenfalls stufenweise Absenkung der Flußrate, bis nach 480 min der Fluß durch das Wurzelsegment wieder zum Erliegen kam.

Die zeitgleich mit einem Miniatur-Saftflußsensor aufgezeichnete Temperaturdifferenz $\mathrm{T}_{\mathrm{so}}-\mathrm{T}_{\mathrm{si}}$ verläuft unterhalb $2 \mathrm{~g} \mathrm{~h}^{-1}$ (ab $300 \mathrm{~min}$ ) gleichsinnig zur Flußrate. Auch die schrittweisen Änderungen durch Variation des angelegten Unterdrucks sind deutlich zu erkennen.

Bei Flußraten $>2 \mathrm{~g} \mathrm{~h}^{-1}$ ändert sich dieses Verhalten: Bei $4 \mathrm{~g} \mathrm{~h}^{-1}$ erreicht $\mathrm{T}_{\mathrm{so}}-\mathrm{T}_{\mathrm{si}}$ ein Maximum von $3 \mathrm{~K}$ und sinkt wieder auf $2.5 \mathrm{~K}$ ab, wenn die maximale Flußrate von $10 \mathrm{~g} \mathrm{~h}^{-1}$ erreicht wird. Diese gegenläufige Tendenz ist in Abb. 4.3 in der Zeit von 60240 min zu beobachten, wobei die Flußrate sinkt und der Wert von $T_{s o}-T_{s i}$ steigt. Die Grafik ist zum Verständnis dieses Zusammenhanges also von rechts nach links zu lesen.

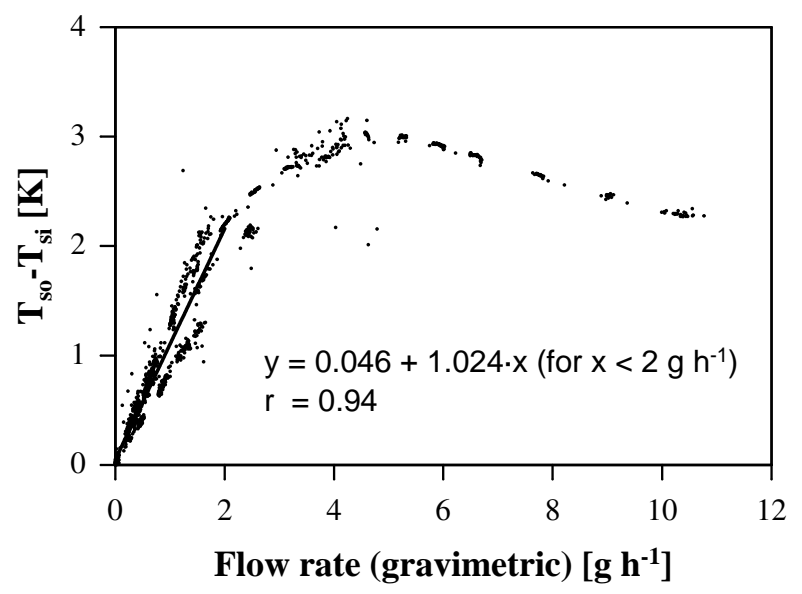

Abb. 4.4: Beziehung zwischen der Temperaturdifferenz über den beheizten Bereich eines installierten Miniatur-Saftflußsensors und der Flußrate in einem Buchenwurzelsegment.

Der direkte Zusammenhang zwischen $\mathrm{T}_{\mathrm{so}}-\mathrm{T}_{\mathrm{si}}$ und der Flußrate ist in Abb. 4.4 dargestellt. Dieser Abbildung liegen dieselben Werte wie in Abb. 4.3 zugrunde. Für Flußraten $<2 \mathrm{~g} \mathrm{~h}^{-1}$ ist eine lineare Beziehung zu beobachten, die mit der Beziehung $y=0.046+1.024 \cdot x$ für diesen Wertebereich abgebildet werden kann. Der Korrelationskoeffizient beträgt 0.94. Bei höheren Flußraten zwischen 2 und $4 \mathrm{~g} \mathrm{~h}^{-1}$ ist ein Abflachen der $\mathrm{T}_{\mathrm{so}}-\mathrm{T}_{\mathrm{si}}$-Kurve zu erkennnen. Nach dem Maximum bei $4 \mathrm{~g} \mathrm{~h}^{-1}$ sinkt die Temperaturdifferenz bis auf $2.5 \mathrm{~K}$ bei $10 \mathrm{~g} \mathrm{~h}^{-1} \mathrm{ab}$.

\subsubsection{Modifizierte Methode der Saftflußberechnung}

Analog zu Abb. 4.4 wurde in weiteren Laborexperimenten die Beziehung zwischen $\mathrm{T}_{\mathrm{so}}-\mathrm{T}_{\mathrm{si}}$ und dem Saftfluß bei Flußraten $<2 \mathrm{~g} \mathrm{~h}^{-1}$ untersucht. Wie in Abb. $4.5 \mathrm{zu}$ erkennen ist, besteht auch für Wurzelsegmente der Fichte und Eiche die gleiche Beziehung zwischen den beiden Werten. 


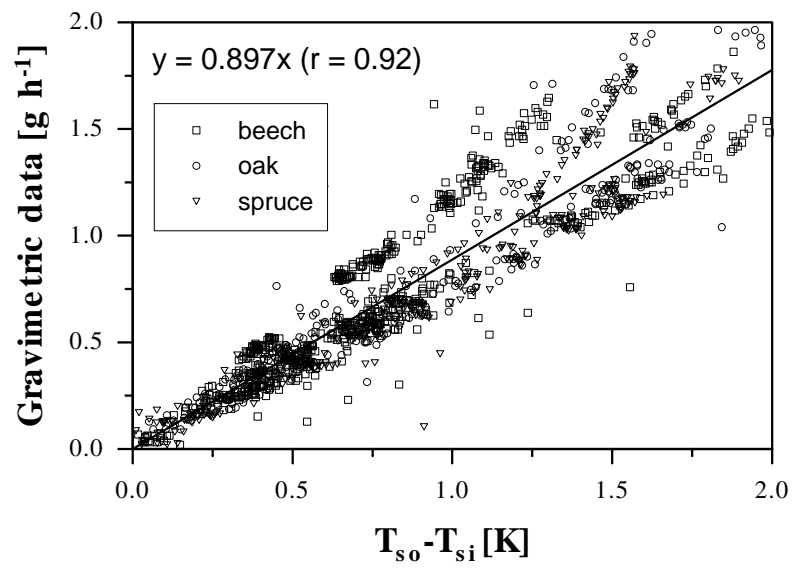

Abb. 4.5: Beziehung zwischen der Flußrate durch ein Wurzelsegment und der Temperaturdifferenz über den beheiztenBereich. Die Angaben beruhen auf Laborexperimenten mit je 3 verschiedenen Miniatur-Saftflußsensoren an je 2 Wurzelsegmenten von Buche, Eiche und Fichte.

Der hier dargestellte Zusammenhang ist die Basis für die in Kap. 3.2 vorgestellte modifizierte Methode der Saftflußberechnung aus den aufgezeichneten Temperaturwerten. Aus diesem Grund wurde in Abb. 4.5 die Zuordnung der Achsen vertauscht, um die für diese Berechnung notwendige Abhängigkeit der Flußrate von den $\mathrm{T}_{\mathrm{so}}-\mathrm{T}_{\mathrm{si}}$-Werten berechnen zu können. Da keine Unterschiede zwischen den Wurzeln der drei Baumarten zu erkennen ist, wird für die Bestimmung von $J^{*}$ in Gleichung 3.6 die Steigung $0.897 \mathrm{~g} \mathrm{~h}^{-1} \mathrm{~K}^{-1}$ der Regressionsgeraden für alle drei Arten eingesetzt.

Der Korrelationskoeffizient für diese Beziehung ist mit $0.92 \mathrm{sehr}$ hoch. Weiterhin fällt auf, daß die Streuung mit dem Ansteigen der Werte zunimmt, so daß unterhalb von $1 \mathrm{~g} \mathrm{~h}^{-1}$ die Beziehung zwischen dem Fluß und $\mathrm{T}_{\mathrm{so}}-\mathrm{T}_{\mathrm{si}}$ enger ist als bei 1-2 $\mathrm{g} \mathrm{h}^{-1}$.

Abb. 4.6 zeigt beispielhaft für eine $3 \mathrm{~mm}$ starke Buchenwurzel in der Lüneburger Heide die Tagesgänge der Saftflußrate von 10 Tagen im Juli 1998. Die Werte von $J$ (herkömmliche Berechnung nach Gleichung (3.2)) und $J^{*}$ (kleine Flußraten, berechnet mit dem empirischen Faktor $\beta$ nach Gleichung (3.6) überlappen in den Morgen- und Abendstunden über einen weiten Bereich (A). Besonders an den ersten 5 Tagen ist zu erkennen, daß $J$ deutlich höhere Nachtwerte ergibt als $J^{*}$. In dieser ersten Hälfte des dargestellten Zeitraums sind auch tagsüber nur geringe Saftflußraten zu verzeichnen, besonders am 16. Juli wird wenig Wasser durch diese Wurzel aufgenommen. Vom 20. bis 24 Juli 1998 ist im Kronenraum die Transpirationsbeanspruchung durch Strahlung und Wassersättigungsdefizit deutlich höher, was auch in den Wurzeln höhere Saftflußraten nach sich zieht. An diesen Tagen mit höheren Tagesmaxima gibt es in der Nacht nur geringe Abweichungen des herkömmlich berechneten Flusses von den in dieser Größenordnung wesentlich genaueren $J^{*}$-Werten.

Die aus diesen beiden Ausgangswerten kombinierte Saftflußrate $J$ (Abb. 4.6B) ergibt sich oberhalb von etwa $2 \mathrm{~g} \mathrm{~h}^{-1}$ aus $J$ und darunter aus $J^{*}$. Der jeweilige Übergang in den Morgen- und Abendstunden wurde nach den in Kap. 3.2 genannten Kriterien 
anhand der Flußrate $J$ und der Thermosäulenspannung $E$ rechnerisch festgelegt. Hier ist auch das Problem der unterschiedlich hohen nächtlichen Saftflußraten deutlich zu erkennen: An Tagen mit geringer und kurzer Transpirationsleistung stellt sich in der Nacht eine deutliche Nullinie der Saftflußrate in den Wurzeln ein. Dies ist besonders ausgeprägt in den Nächten vom 15./16., 16./17. und 24./25. Juli zu beobachten. Dagegen sind in den Nächten nach ausgesprochenen Strahlungstagen wie dem 19. und 21. Juli deutliche Saftflußraten zu verzeichnen, die zum Ende der jeweiligen Nacht nach Auffüllen des Stammspeichers auf Null zurückgehen.

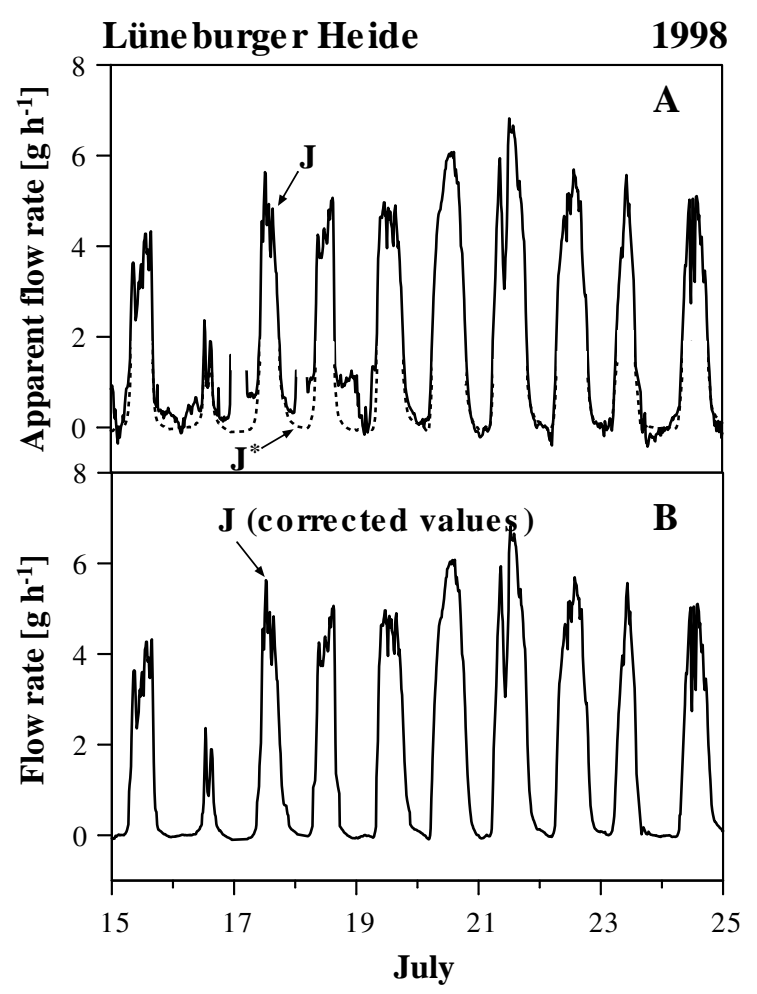

\begin{abstract}
Abb. 4.6: Tagesgänge der Saftflußrate in einer $3 \mathrm{~mm}$ starken Buchenwurzel an 10 Tagen im Juli 1998 auf der Untersuchungsfläche Lüneburger Heide OB5. (A) Nach Gleichung (3.2) (J, durchgezogene Linie) bzw. anhand der empirischen Beziehung zwischen der Flußrate und $\mathrm{T}_{\mathrm{so}}-\mathrm{T}_{\mathrm{si}}$ ( $\mathrm{J}^{*}$, Gleichung (3.6), gepunktete Linie) berechnete Saftflußrate. (B) Mit der kombinierten Methode berechnete Flußrate, wobei $\mathrm{J}$ für Flußraten $>2 \mathrm{~g} \mathrm{~h}^{-1}$ und $\mathrm{J}^{*}$ für Raten $<2 \mathrm{~g} \mathrm{~h}^{-1}$ eingesetzt wurde.
\end{abstract}

Die Genauigkeit der modifizierten Berechnungsmethode wurde anhand der Daten aus den Laborexperimenten geprüft. Abb. 4.7 zeigt den mit dieser Methode für den gesamten Bereich von 0-11 $\mathrm{g} \mathrm{h}^{-1}$ berechneten Fluß durch ein Wurzelsegment im direkten Vergleich mit den gravimetrisch ermittelten Flußraten. Die Daten beruhen auf dem in Abb. 4.3 dargestellten 10-stündigen Laborexperiment.

Die durch schrittweises Verringern des angelegten Unterdrucks induzierten Änderungen in der Flußrate werden sofort vom Saftflußsensor erfaßt und schlagen sich ohne 
Verzögerung in der berechneten Flußrate nieder. Dabei verlaufen die beiden Flußraten über die gesamte Spanne gemessener Werte gleichsinnig. Im Bereich 4-8 $\mathrm{g} \mathrm{h}^{-1}$ wird der Fluß von den Sensordaten um maximal 10\% überschätzt, während es bei $2 \mathrm{~g} \mathrm{~h}^{-1}$ zu einer Unterschätzung in der gleichen Größenordnung kommt. Selbst bei Flußraten $<0.5 \mathrm{~g} \mathrm{~h}^{-1}$, wo kleine Meßungenauigkeiten einen großen relativen Fehler verursachen können, bleiben die Abweichungen unterhalb 20\%.

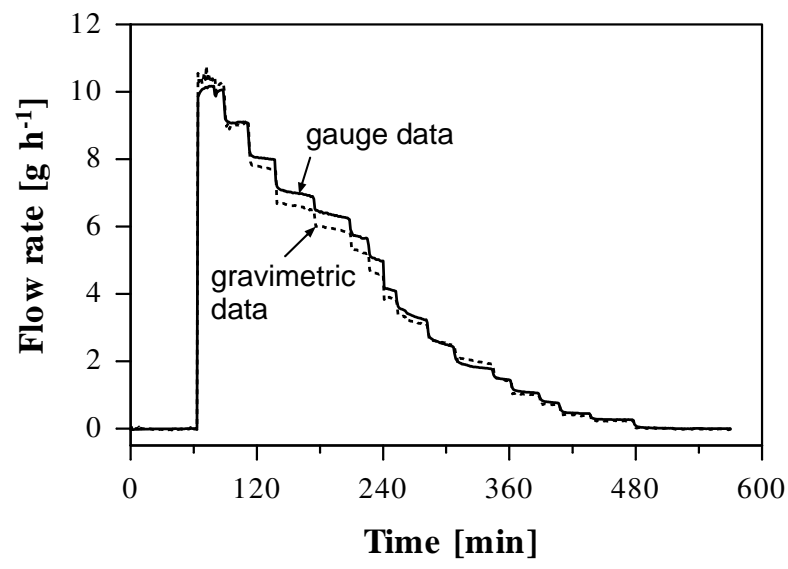

Abb. 4.7: Gravimetrisch bestimmte und aus den Meßdaten eines Saftflußsensors berechnete Flußrate in einem Buchenwurzelsegment. Änderungen in der Flußrate resultieren aus variierenden Unterdruckwerten (s. Abb. 4.3). Flußraten $>2 \mathrm{~g} \mathrm{~h}^{-1}$ wurden nach Gleichung 3.2 berechnet, Werte $<2 \mathrm{~g} \mathrm{~h}^{-1}$ ergeben sich nach Gleichung (3.6) aus $\mathrm{T}_{\mathrm{so}}-\mathrm{T}_{\mathrm{si}}$.

\subsection{Vergleich der Wasseraufnahme von Buchenwurzeln auf drei unterschiedlich wasserversorgten Standorten}

\subsubsection{Morphologie der Buchenwurzeln}

Vertikalverteilung der Wurzeloberfläche Die während der Vegetationsperiode 1998 im Solling untersuchten Auflagewurzeln besaßen mit im Mittel $1500 \mathrm{~cm}^{2}$ die größte Oberfläche (Abb. 4.8). In der Lüneburger Heide und im Ziegelrodaer Forst wurden dagegen nur etwa 800 bzw. $300 \mathrm{~cm}^{2}$ in diesem Horizont festgestellt, wobei sich nur die Werte der Untersuchungsfläche Ziegelrodaer Forst signifikant von den anderen beiden unterschieden. In jedem Fall wurde die Oberfläche aller Wurzelenden distal von der Position des Saftflußsensors (Wurzeldurchmesser 3-4 mm) ermittelt. Die genannte Abfolge der Wurzeloberfläche an den untersuchten Standorten war auch bei der Betrachtung der einzelnen Durchmesserklassen zu beobachten. Die größte Oberfläche hatten dabei jeweils die Wurzeln in der Klasse der Feinstwurzeln $<1 \mathrm{~mm}$. Die Verteilung der Oberfläche auf die Durchmesserklassen ist in Abb. 4.9 detailliert dargestellt.

Im Mineralboden dagegen besaßen die untersuchten 3-4 mm starken Buchenwurzeln der Lüneburger Heide mit im Mittel $550 \mathrm{~cm}^{2}$ eine etwa doppelt so große Ober- 


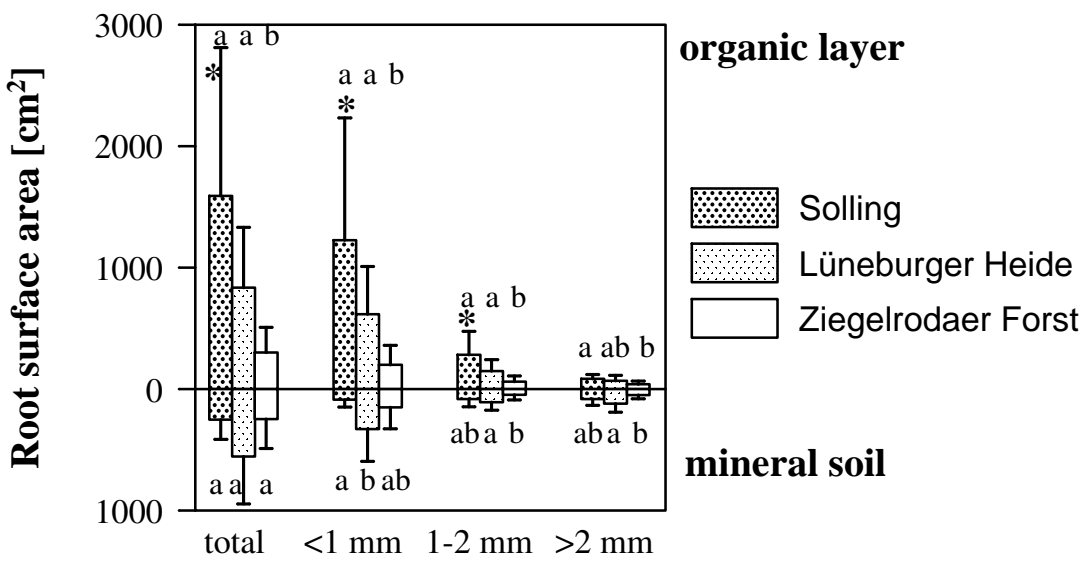

\begin{abstract}
Abb. 4.8: Oberfläche der untersuchten Wurzelstränge in der organischen Auflage und im Mineralboden, bezogen auf Wurzeln $<1 \mathrm{~mm}, 1-2 \mathrm{~mm},>2 \mathrm{~mm}$ und den gesamten Wurzelstrang distal von der Position des Saftflußsensors. Dargestellt sind Mittelwerte der Buchenwurzeln aus allen Meßperioden 1998 im Solling, der Lüneburger Heide und im Ziegelrodaer Forst. Unterschiedliche Buchstaben markieren in jeder Durchmesserklasse signifikante Unterschiede zwischen den Standorten, Sterne solche zwischen den Wurzeln der organischen Auflage und des Mineralbodens; U-Test nach Mann \& Whitney $(\mathrm{p}<0.05)$.
\end{abstract}

fläche wie diejenigen an den anderen Standorten. Dieser Unterschied war allerdings nicht signifikant. Bei den Mineralbodenwurzeln waren auch bei der Betrachtung der einzelnen Durchmesserklassen weitere Unterschiede zu erkennnen: Die Fraktion der Feinstwurzeln $(\mathrm{d}<1 \mathrm{~mm})$ hatte im Solling eine signifikant geringere Oberfläche als in der Lüneburger Heide; die Wurzeln der Buche im Ziegelrodaer Forst verhielten sich intermediär.

Während in der Lüneburger Heide und im Ziegelrodaer Forst die Oberfläche der Wurzeln in der organischen Auflage ähnlich groß war wie im Mineralboden, besaßen die untersuchten Auflagewurzeln im Solling eine signifikant größere Gesamtoberfläche, was auch in den Fraktionen der Feinst- und Feinwurzeln zu beobachten war.

Verteilung der Wurzeloberfläche auf die Durchmesserklassen Die untersuchten Auflagewurzeln im Solling und in der Lüneburger Heide waren in ihrer Zusammensetzung aus verschiedenen Durchmesserfraktionen sehr ähnlich: Jeweils etwa $70 \%$ der Gesamtoberfläche wurden von den Feinstwurzeln gestellt, während nur 20 bzw. 10\% auf die Fein- bzw. Grobwurzeln zurückzuführen war (Abb. 4.9). Bei den Wurzeln der Untersuchungsfläche im Ziegelrodaer Forst verschob sich dieses Verhältnis ein wenig zu den gößeren Durchmessern (Feinst-, Fein- bzw. Schwachwurzeln: 60, 20 bzw. 20\%). Dieser Unterschied zwischen den Untersuchungsflächen war jedoch in keiner Klasse signifikant.

Im Mineralboden machten auf allen drei Flächen die Schwachwurzeln (d > $2 \mathrm{~mm})$ mit etwa 30\% einen etwas größeren Anteil der Gesamtoberfläche aus als in der or- 


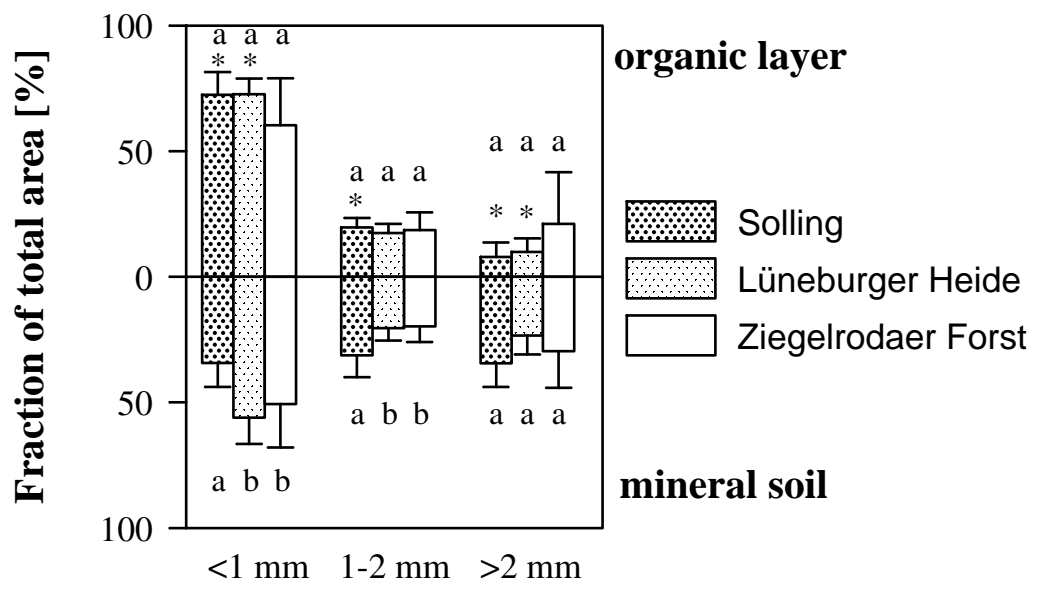

\begin{abstract}
Abb. 4.9: Verteilung der Wurzeloberfläche der untersuchten 3-4 mm starken Wurzeln auf die Durchmesserklassen. Dargestellt ist jeweils der Anteil der Durchmesserklasse 0-1 mm, 1-2 mm bzw. $>2 \mathrm{~mm}$ an der Gesamtoberfläche des jeweiligen Wurzelstrangs. Die Balken repräsentieren Mittelwerte der Buchenwurzeln aus allen Meßperioden 1998 im Solling, der Lüneburger Heide und im Ziegelrodaer Forst. Unterschiedliche Buchstaben markieren in jeder Durchmesserklasse signifikante Unterschiede zwischen den Arten, Sterne solche zwischen den Wurzeln der organischen Auflage und des Mineralbodens; Signifikanztest nach Scheffé $(\mathrm{p}<0.05)$.
\end{abstract}

ganischen Auflage. Während in der Lüneburger Heide und im Ziegelrodaer Forst der Anteil der Feinst- und Feinwurzeln von 50 bzw. 20\% an der Gesamtoberfläche eine ähnliche Dominanz der dünnen Wurzelbestandteile wie im Oberboden dokumentiert, war im Solling eine gleichmäßige Verteilung mit jeweils 30\% auf alle drei Durchmesserklassen zu verzeichnen. Dadurch ergab sich ein signifikant höherer Feinstwurzelbzw. kleinerer Feinwurzelanteil bei den Mineralbodenwurzeln des Sollings gegenüber den anderen beiden Untersuchungsflächen.

Im Vergleich zwischen den Horizonten war der Feinstwurzelanteil an den Standorten Solling und Lüneburger Heide in der organischen Auflage signifikant höher als im Mineralboden, während der Schwachwurzelanteil umgekehrt im Mineralboden signifikant größer war. Im Ziegelrodaer Forst dagegen war die Zusammensetzung der untersuchen Wurzeln im Oberboden und im tieferen Mineralboden sehr ähnlich.

Spezifische Wurzeloberfläche Die spezifische Oberfläche der zur Saftflußmessung dienenden 3-4 mm starken Wurzeln in der organischen Auflage unterschied sich nur geringfügig zwischen den 3 untersuchten Beständen (Abb. 4.10). Einzig der Solling wies mit $126 \mathrm{~cm}^{2} \mathrm{~g} \mathrm{DW}^{-1}$ in der Gesamtoberfläche eine signifikant größere spezifische Oberfläche auf als die anderen Flächen. In den Durchmesserklassen wurden erwartungsgemäß die höchsten spezifischen Oberflächen bei den Feinstwurzeln festgestellt (etwa $170 \mathrm{~cm}^{2} \mathrm{~g} \mathrm{DW}{ }^{-1}$ auf allen Flächen). Die Schwachwurzelfraktion erreichte nur noch etwa $30 \mathrm{~cm}^{2} \mathrm{~g} \mathrm{DW}^{-1}$.

Im Mineralboden besaßen die Wurzeln in der Lüneburger Heide und im Solling 


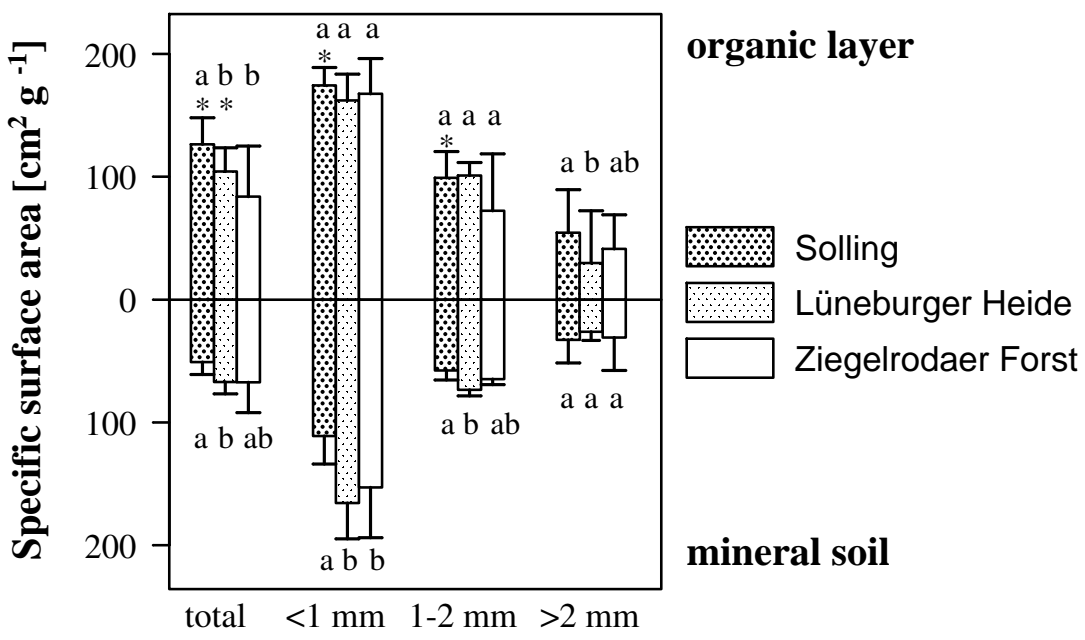

\begin{abstract}
Abb. 4.10: Spezifische Oberfläche der zur Saftflußmessung verwendeten Buchenwurzelstränge aus der organischen Auflage und dem Mineralboden. Die Balken repräsentieren Mittelwerte der Buchenwurzeln aus allen Meßperioden 1998 im Solling, der Lüneburger Heide und im Ziegelrodaer Forst. Unterschiedliche Buchstaben markieren in jeder Durchmesserklasse signifikante Unterschiede zwischen den Standorten, Sterne solche zwischen den Wurzeln der organischen Auflage und des Mineralbodens; U-Test nach Mann \& Whitney $(\mathrm{p}<0.05)$.
\end{abstract}

mit 50-60 $\mathrm{cm}^{2} \mathrm{~g} \mathrm{DW}^{-1}$ signifikant niedrigere spezifische Oberflächen als in der organischen Auflage. Bei der differenzierten Betrachtung der Durchmesserklassen war dieser Horizontunterschied nur noch für die Feinst- und Feinwurzeln im Solling signifikant. Die Mineralboden- und Auflagewurzeln im Ziegelrodaer Forst hingegen besaBen in allen Durchmesserklassen ähnlich hohe spezifische Oberflächen.

Die höchsten spezifischen Oberflächen werden erwartungsgemäß auch im Mineralboden mit 100-160 $\mathrm{cm}^{2} \mathrm{~g} \mathrm{DW}^{-1}$ in der Fraktion der Feinstwurzeln erreicht. Hier liegen die Werte für den Solling signifikant niedriger als an den anderen beiden Standorten. Das Verhältnis zwischen den Standorten kehrt sich also im Mineralboden gegenüber der organischen Auflage um, wo für den Solling die höchsten spezifischen Oberflächen $\mathrm{zu}$ verzeichnen sind.

\title{
4.2.2 Klimatische und edaphische Faktoren
}

Globalstrahlung und VPD Für die Untersuchungsflächen Lüneburger Heide und Solling liegen für den Untersuchungszeitraum 1998 Werte der Globalstrahlung und der Tageshellphasensumme für das Wassersättigungsdefizit der Luft vor (Abb. 4.11). Am Standort Ziegelrodaer Forst konnten über dem Bestand keine Klimaparameter aufgezeichnet werden. Die dargestellten $\mathrm{VPD}_{\text {cum }}$-Werte wurden an der $14 \mathrm{~km}$ entfernten Klimastation des Deutschen Wetterdienstes in Artern gemessen. Die beiden in der Lüneburger Heide und im Solling zeitgleich gemessenen Größen Sättigungsdefizit und Globalstrahlung wiesen eine große witterungsbedingte Variabilität zwischen einzel- 
nen Meßtagen auf, verhielten sich jedoch innerhalb dieser Fluktuationen gleichsinnig, d.h. an Tagen mit hohen Strahlungsflüssen war in der Regel auch ein hoher Wert für $\mathrm{VPD}_{\text {cum }}$ zu verzeichnen.

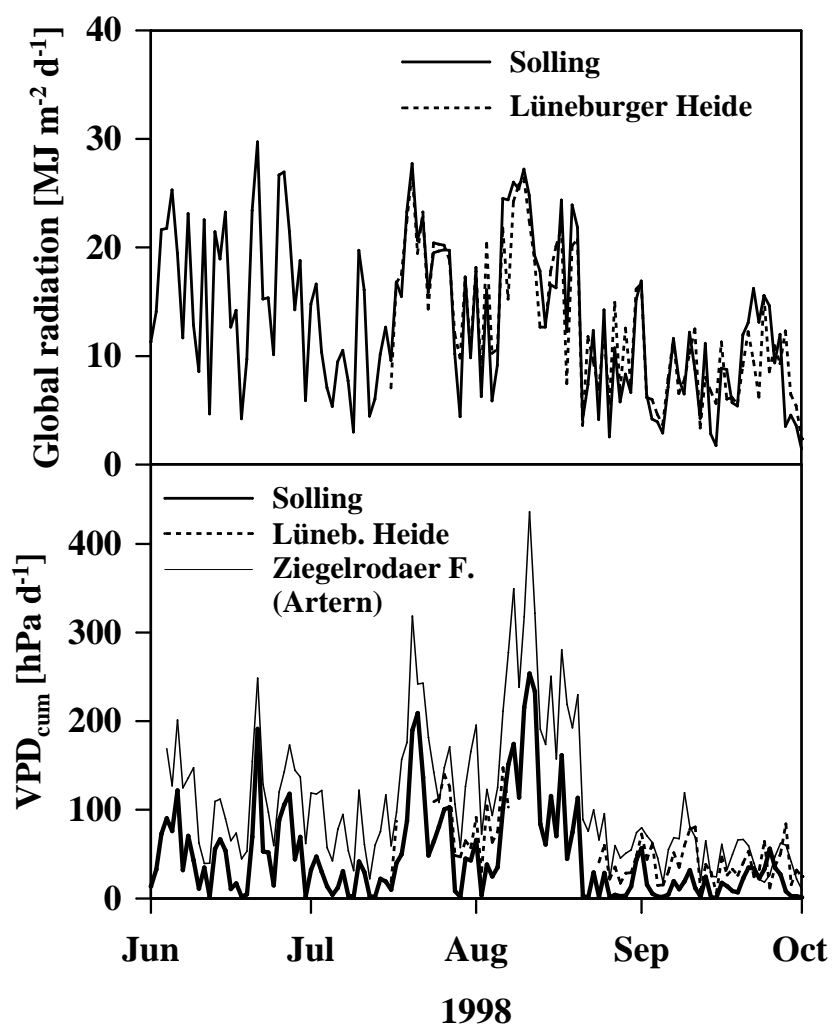

Abb. 4.11: Globalstrahlung und kumulatives Wassersättigungsdefizit der Luft (VPD $\left.{ }_{\text {cum }}\right)$ oberhalb des Bestandes, gemessen in der Vegetationsperiode 1998 von Klimatürmen an den Standorten Solling und Lüneburger Heide; Ziegelrodaer Forst: Nur Sättigungsdefizit, gemessen an der Klimastation Artern des Deutschen Wetterdienstes. Bei der Globalstrahlung wurden die gemessenen Strahlungsströme $\left[\mathrm{W} \mathrm{m}^{-2}\right.$ ] zu Tagessummen $\left[\mathrm{MJ} \mathrm{m}^{-2} \mathrm{~d}^{-1}\right]$ aufsummiert. Der Wert

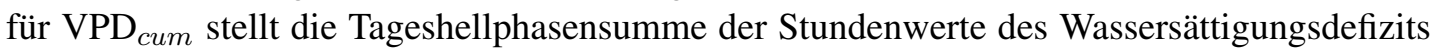
dar.

Bemerkenswert ist vor allem die enge Übereinstimmung im zeitlichen Verlauf der Witterung an diesen 3 Standorten. Trotz der großen räumlichen Distanz von etwa $200 \mathrm{~km}$ änderten sich die Tageswerte sowohl der Strahlung als auch des Sättigungsdefizits an allen 3 Standorten gleichsinnig. Nur an wenigen Tagen waren kleine Abweichungen zu beobachten.

An den Standorten Lüneburger Heide und Solling waren Spitzenwerte der Globalstrahlung von etwa $25 \mathrm{MJ} \mathrm{m}^{-2} \mathrm{~d}^{-1} \mathrm{zu}$ beobachten. Auch zeichneten sich jeweils Mitte Juli und August auf beiden Untersuchungsflächen Schönwetterperioden mit höheren Strahlungsflüssen ab. Für den Standort Lüneburger Heide liegen erst ab dem 16. Juni Klimadaten vor. 
Auch das kumulative Wassersättigungsdefizit der Atmosphäre wies diese beiden saisonalen Maxima auf. In diesen Perioden stieg das VPD cum $_{\text {an }}$ der Klimastation Artern auf über $400 \mathrm{hPad}^{-1}$. Im Solling wurden nur maximal $250 \mathrm{hPa} \mathrm{d}^{-1}$ gemessen. Für die Lüneburger Heide liegen aufgrund periodischer Meßausfälle der Psychrometer für diese beiden Schönwetterphasen Mitte Juli und Mitte August keine VPD cum $_{\text {vor, }}$ doch sind Werte zwischen denjenigen des Ziegelrodaer Forstes und und des Sollings zu erwarten, wenn man die übrigen Zeiträume mit parallel an allen 3 Standorten aufgezeichneten Daten betrachtet. So wurden Anfang Juli und ab Mitte August für die 3 Standorte Tageshellphasensummen des Sättigungsdefizites gemessen, die im Solling nahe Null, in der Lüneburger Heide bei etwa $50 \mathrm{hPa} \mathrm{d}^{-1}$ und im Ziegelrodaer Forst bei $100-150 \mathrm{hPa} \mathrm{d}^{-1}$ lagen.

Bodenwassergehalt Der Bodenwassergehalt bei Sättigung zu Beginn der Vegetationsperiode war im Oberboden (Lüneburger Heide und Ziegelodaer Forst: $5 \mathrm{~cm}$, Solling: $20 \mathrm{~cm}$ Tiefe) an allen drei Standorten mit etwa 30 vol\% gleich groß (Abb.4.12). In größeren Tiefen des Mineralbodens hingegen waren deutliche Unterschiede zwischen den Untersuchungsflächen zu erkennen: In $60 \mathrm{~cm}$ Bodentiefe enthielt der Boden im Solling mit 40 vol\% deutlich mehr Wasser als der Oberboden, während im Ziegelrodaer Forst mit 25 vol\% deutlich weniger Wasser in dieser Tiefe vorhanden war. In der Lüneburger Heide wurden sogar nur etwa 15 vol\% gemessen. Für die Flächen Lüneburger Heide und Ziegelrodaer Forst stehen zusätzlich Meßdaten für eine mittlere Bodentiefe von $30 \mathrm{~cm}$ zur Verfügung. In der Lüneburger Heide lag dieser Wert nur geringfügig oberhalb desjenigen aus $60 \mathrm{~cm}$, während im Ziegelrodaer Forst nur 20 vol\% in der Tiefe $30 \mathrm{~cm}$ zu verzeichnen waren. An diesem Standort kam es also zur Umkehr des Bodenwassergehalts im Tiefenprofil mit einem Minimum bei $30 \mathrm{~cm}$. Bemerkenswert ist, daß sowohl in der Lüneburger Heide als auch im Ziegelrodaer Forst der Oberboden $(5 \mathrm{~cm})$ den ganzen Sommer über feuchter war als der Unterboden. Im Solling nahm dagegen der Bodenwassergehalt mit der Tiefe zu.

Im zeitlichen Verlauf während der Vegetationsperiode 1998 waren am Standort Ziegelrodaer Forst die größten Änderungen im Bodenwassergehalt zu verzeichnen: In der Zeit vom 15 Juli bis zum 23 August war in allen untersuchten Tiefen eine Abnahme des Wassergehalts auf die Hälfte der Ausgangswerte zu beobachten, die nur im Oberboden durch einen kurzfristigen Anstieg Ende Juli unterbrochen wurde. AnschlieBend stieg der Bodenwassergehalt wieder über einen Zeitraum von mehreren Wochen langsam an, bis der Boden am Ende der Meßperiode nahezu wieder aufgesättigt war.

Ähnliche Schwankungen waren auf den anderen beiden Untersuchungsflächen zu beobachten, doch mit deutlich geringerer Amplitude. Nahm in der Lüneburger Heide der Wassergehalt im Oberboden noch um etwa $30 \%$ ab, so betrug die Reduktion im Solling nur etwa $20 \%$, wobei hier allerdings die tdr-Sensoren in $20 \mathrm{~cm}$ Tiefe installiert waren und so nicht die größeren Schwankungen der oberen Bodenschichten erfaßt werden konnten. Die Wiederauffüllung der Wasservorräte verlief allerdings an diesen beiden Standorten wesentlich schneller als im Ziegelrodaer Forst. Sowohl Ende Juli 

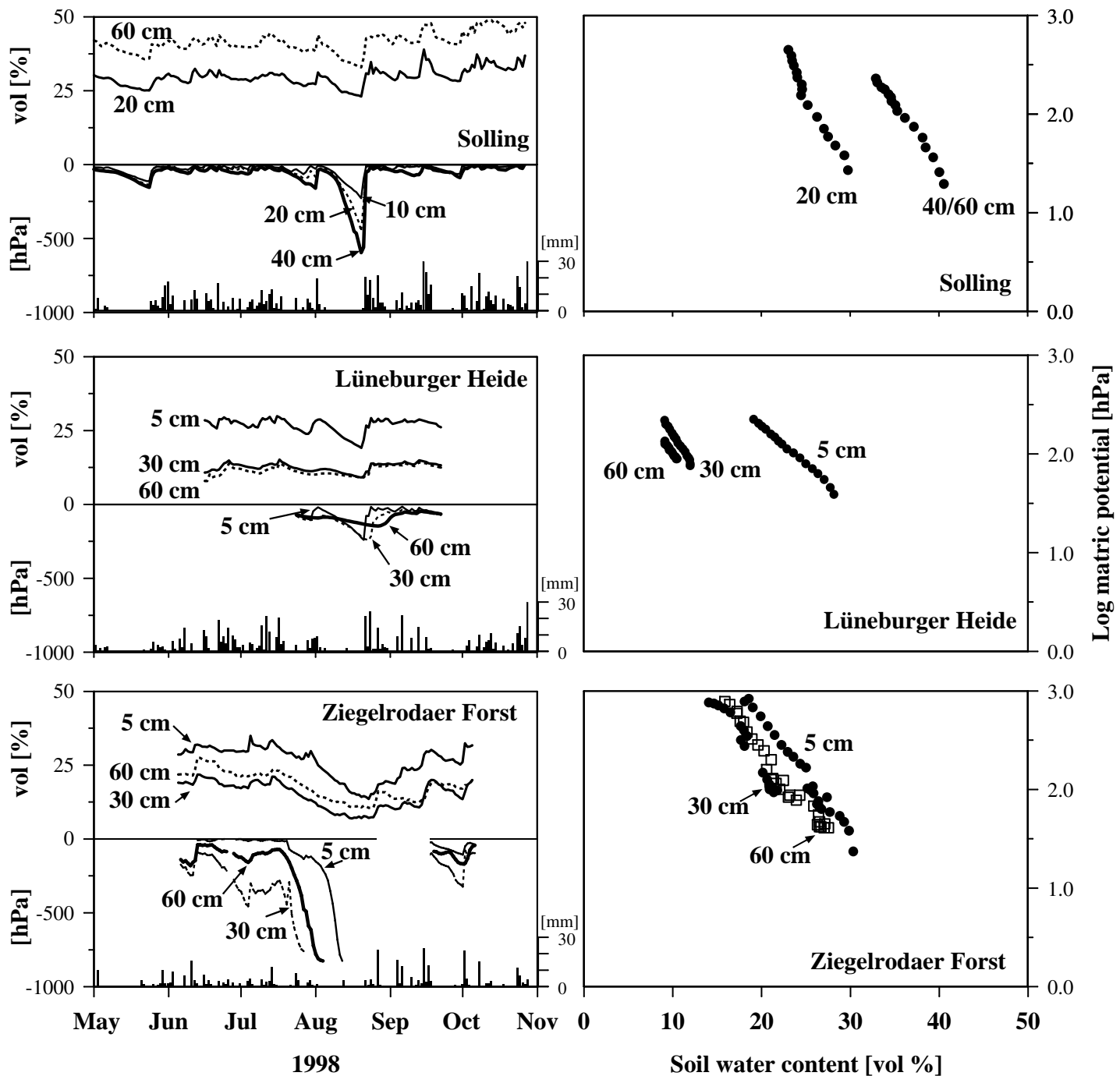

Abb. 4.12: Bodenfeuchteparameter in verschiedenen Tiefen des Mineralbodens an den Standorten Solling, Lüneburger Heide und Ziegelrodaer Forst in der Vegetationsperiode 1998. Links: Volumetrischer Bodenwassergehalt ( 2 tdr-Sonden je Tiefe), Bodenmatrixpotential (3-4 Druckaufnehmertensiometern je Tiefe) und tägliche Niederschlagssummen (DWDKlimastationen Silberborn, Unterlüß und Arten). Rechts: Feld-pF-Kurven, basierend auf den Bodenwassergehalten und -matrixpotentialen. Zum Ausschluß von Hystereseffekten bei der Tensiometermessung wurden je Kurve nur Daten aus 1-3 Desorptionsphasen verwendet. 
als auch Ende August lag der Bodenwassergehalt wenige Tage nach Erreichen des Minimums wieder auf Höhe des Ausgangswertes.

Bodenmatrixpotentiale Bei der Betrachtung der Bodenmatrixpotentiale ergibt sich ein anderes Bild: Während der Wassergehalt im Solling im Sommer 1998 kaum nennenswerte Schwankungen aufwies, ließen die Matrixpotentiale Mitte August eine kurze Trockenperiode erkennen (Abb. 4.12). Die negativsten Werte wurden mit $-596 \mathrm{hPa}$ am 20. August in $40 \mathrm{~cm}$ Tiefe erreicht. In $20 \mathrm{~cm}$ Tiefe sanken die Werte an diesem Tag auf -451 und in $10 \mathrm{~cm}$ auf nur noch $-228 \mathrm{hPa}$ ab. Nach einem Wetterumschwung mit Niederschlagsereignissen von 20-30 $\mathrm{mm} \mathrm{d}^{-1}$ entspannten sich in allen drei Meßtiefen die Matrixpotentiale innerhalb von 3 Tagen wieder auf Werte nahe Null.

In der Lüneburger Heide wurde das Minimum des Matrixpotentials nahezu zeitgleich am 21. August erreicht. Dieser mit $-240 \mathrm{hPa}$ gegenüber dem Solling deutlich geringere Wert stellte sich ebenfalls in $30 \mathrm{~cm}$ Tiefe ein, allerdings erst mit 2 Tagen Verzögerung gegenüber dem Oberboden. In $60 \mathrm{~cm}$ wurden dagegen, verzögert um weitere 4 Tage, nur $-146 \mathrm{hPa}$ gemessen.

Der Unterschied in der zeitlichen Dynamik gegenüber dem Solling wird nicht nur im verzögerten Erreichen des Minimums in verschiedenen Tiefen deutlich. Auch die Wiederbefeuchtung des Bodens nach der Trockenperiode erstreckte sich, trotz ähnlich hoher Niederschlagssummen, in den beiden tiefergelegenen Horizonten über einen Zeitraum von einer Woche, während das Matrixpotential in $5 \mathrm{~cm}$ bereits einen Tag nach dem Minimum, also am 22. August nur noch $-77 \mathrm{hPa}$ betrug.

Die negativste Bodensaugspannung war im Sommer 1998 jedoch in Ziegelrodaer Forst zu verzeichnen. Bereits am 4. Juli betrug an diesem Standort das Matrixpotential in $30 \mathrm{~cm}$ Tiefe $-457 \mathrm{hPa}$ und verblieb auch in den folgenden Wochen unterhalb von $-300 \mathrm{hPa}$. In dieser Tiefe kam es auch bereits am 28. Juli zum Ausfall der Tensiometer durch Überschreiten des Meßbereiches (0-800 hPa).

Ein ähnlicher Verlauf war auch in den anderen beiden Meßtiefen zu beobachten, wobei das erste Minimum Anfang Juni in $60 \mathrm{~cm}$ Tiefe mit $-160 \mathrm{hPa}$ wesentlich moderater ausfiel und in $5 \mathrm{~cm}$ zu diesem Zeitpunkt kaum eine Veränderung zu erkennen war. Analog erreichten die Tensiometer in $60 \mathrm{~cm}$ Tiefe am 2. August und diejenigen in $5 \mathrm{~cm}$ erst am 11. August die Grenze ihres Meßbereiches. Für alle drei untersuchten Bodentiefen stehen erst Mitte September, also nach der anhaltenden Trockenperiode, wieder verläßliche Meßwerte zur Verfügung.

Feld-pF-Kurven Die Feld-pF-Kurven geben den Zusammenhang zwischen dem Bodenwassergehalt und dem negativen Logarithmus des Bodenmatrixpotentials $(\mathrm{pF})$ wider (Abb. 4.12 rechte Seite). In allen Fällen wurde für die untersuchten Desorptionsphasen ein enger linearer Zusammenhang $(r>0.97)$ gefunden. Für die meisten Kurven ergab sich eine Steigung von etwa -0.13. Einzig im Solling war mit -0.17 für $20 \mathrm{~cm}$ Bodentiefe und -0.15 für $40 / 60 \mathrm{~cm}$ ein steilerer Verlauf zu beobachten. Deutlich fla- 
cher verlief die Feld-pF-Kurve dagegen in $5 \mathrm{~cm}$ Tiefe am Standort Lüneburger Heide (Steigung: -0.08).

Da sich solche Zusammenhänge sinnvollerweise nur in Desorptionsphasen beobachten lassen, beginnen die hier dargestellten Kurven bei $\mathrm{pF}$ 1.5, was einem Matrixpotential von etwa $-30 \mathrm{hPa}$ entspricht und enden bei $\mathrm{pF} 2.9$, also der Obergrenze des Tensiometer-Meßbereichs (-800 hPa).

Die Lage der Feld-pF-Kurven bezüglich des Bodenwassergehalts wies jedoch z.T. sehr große Unterschiede zwischen den untersuchten Standorten, aber auch zwischen den verschiedenen Bodenhorizonten auf. Die Unterschiede zwischen den Horizonten waren am Standort Ziegelrodaer Forst am geringsten. Hier stieg in 30 und $60 \mathrm{~cm}$ Tiefe das Bodenmatrixpotential von $\mathrm{pF} 1.5$ auf 2.9, wenn der Bodenwassergehalt von etwa 25 auf 15 vol\% fiel. Die Kurve für $5 \mathrm{~cm}$ Tiefe ist ein wenig in Richtung höhere Bodenwassergehalte verschoben (30-18 vol\%).

Die den pF-Kurven zugrundeliegenden Bodenwassergehalte im Oberboden lagen an den anderen beiden Standorten ebenfalls zwischen 20 und 30 vol\%, wobei in der Lüneburger Heide $(5 \mathrm{~cm})$ aufgrund der geringeren Steigung bei der Austrockung auf 18 vol\% nur ein pF-Wert von 2.4 erreicht wurden. Im Solling stieg der pF-Wert in $20 \mathrm{~cm}$ Tiefe bereits bei der Austrocknung von 30 bis auf 24 vol\% auf 2.8. Die tieferen Schichten im Mineralboden des Sollings - hier wurden Tensiometerwerte aus $40 \mathrm{~cm}$ tdr-Werten aus $60 \mathrm{~cm}$ gegenübergestellt - binden das Wasser deutlich stärker: Hier verlief der Ausschnitt aus der pF-Kurve im Meßbereich der Tensiometer bei Wassergehalten zwischen 33 und 41 vol\%. In der Lüneburger Heide hingegen stellten sich in 30 und $60 \mathrm{~cm}$ Tiefe pF-Werte zwischen 2 und 2.5 bei sehr geringen Wassergehalten von etwa 10 vol\% ein.

Tabelle 4.1: Biometrische Daten der 1998 mit der Stammsaftflußmethode untersuchten Bäume an den Standorten Solling (SL), Lüneburger Heide (LH) und Ziegelrodaer Forst (ZF). Die in Zeilen dargestellten Parameter sind $\mathbf{h}$ : Gesamthöhe des Baumes $[\mathrm{m}], \mathbf{h}_{c}$ : Kronenansatzhöhe [m], $\mathbf{A}_{c}$ : Kronenprojektionsfläche [ $\left.{ }^{2}\right]$, BHD: Brusthöhendurchmesser [cm], Age: geschätztes Alter [Jahre], $\mathbf{C}_{w}$ : Holzumfang am Meßpunkt in ca. $2 \mathrm{~m}$ Höhe $[\mathrm{cm}], \mathbf{A}_{w}$ : Holzfläche $\left[\mathrm{cm}^{2}\right]$, $\mathbf{T}_{s w}$ : Splintholzdicke [cm], $\mathbf{A}_{s w}$ : Splintholzfläche $\left[\mathrm{cm}^{2}\right]$. Die Splintholzdicke bzw. -fläche wurden aus Tabellen (Fa. EMS, Brünn) anhand des Baumalters und des BHD abgeschätzt.

\begin{tabular}{l|rrr|rrr|rrr} 
& SL1 & SL2 & SL3 & LH1 & LH2 & LH3 & ZF1 & ZF2 & ZF3 \\
\hline $\mathrm{h}$ & 34 & 33 & 35 & 25 & 27 & 27 & 36 & 34 & 29 \\
$\mathrm{~h}_{c}$ & 18 & 17 & 17 & 17 & 15 & 16 & 18 & 12 & 17 \\
$\mathrm{~A}_{c}$ & 91.71 & 90.74 & 86.54 & 49.57 & 57.34 & 71.36 & 79.23 & 67.65 & 67.25 \\
$\mathrm{BHD}$ & 50.49 & 57.61 & 52.52 & 32.15 & 29.13 & 35.49 & 50.29 & 47.27 & 48.27 \\
$\mathrm{Age}$ & 150 & 150 & 150 & 100 & 100 & 100 & 120 & 120 & 120 \\
\hline $\mathrm{C}_{w}$ & 150 & 171 & 155 & 97.5 & 86.5 & 108.5 & 144 & 137.5 & 141 \\
$\mathrm{~A}_{w}$ & 1790.49 & 2326.92 & 1911.85 & 756.48 & 595.41 & 936.81 & 1651.12 & 1504.51 & 1582.08 \\
$\mathrm{~T}_{s w}$ & 4.5 & 5.0 & 4.6 & 4.0 & 3.7 & 4.2 & 4.8 & 4.7 & 4.8 \\
$\mathrm{~A}_{s w}$ & 611.38 & 776.46 & 646.52 & 339.73 & 277.04 & 400.28 & 618.81 & 576.85 & 609.95
\end{tabular}




\subsubsection{Stammsaftflußrate}

Bedingt durch die unterschiedliche demographische Struktur der drei Bestände ergeben sich bei den jeweils repräsentativ ausgewählten herrschenden Altbäumen geringfügige Unterschiede im Alter zwischen den Untersuchungsflächen (Tab. 4.1): Die drei Meßbäume im Solling waren mit 150 Jahren deutlich älter als diejenigenim Ziegelrodaer Forst (120 Jahre) und in der Lüneburger Heide (100). Dies äußert sich auch in den biometrischen Daten. So betrug der Brusthöhendurchmesser der Bäume im Solling und in Ziegelrodaer Forst etwas über bzw. unter $50 \mathrm{~cm}$, während in der Lüneburger Heide nur etwa $30 \mathrm{~cm}$ erreicht wurden. Auch die Höhe der Bäume und die Kronenprojektionsfläche folgten dieser Reihung.

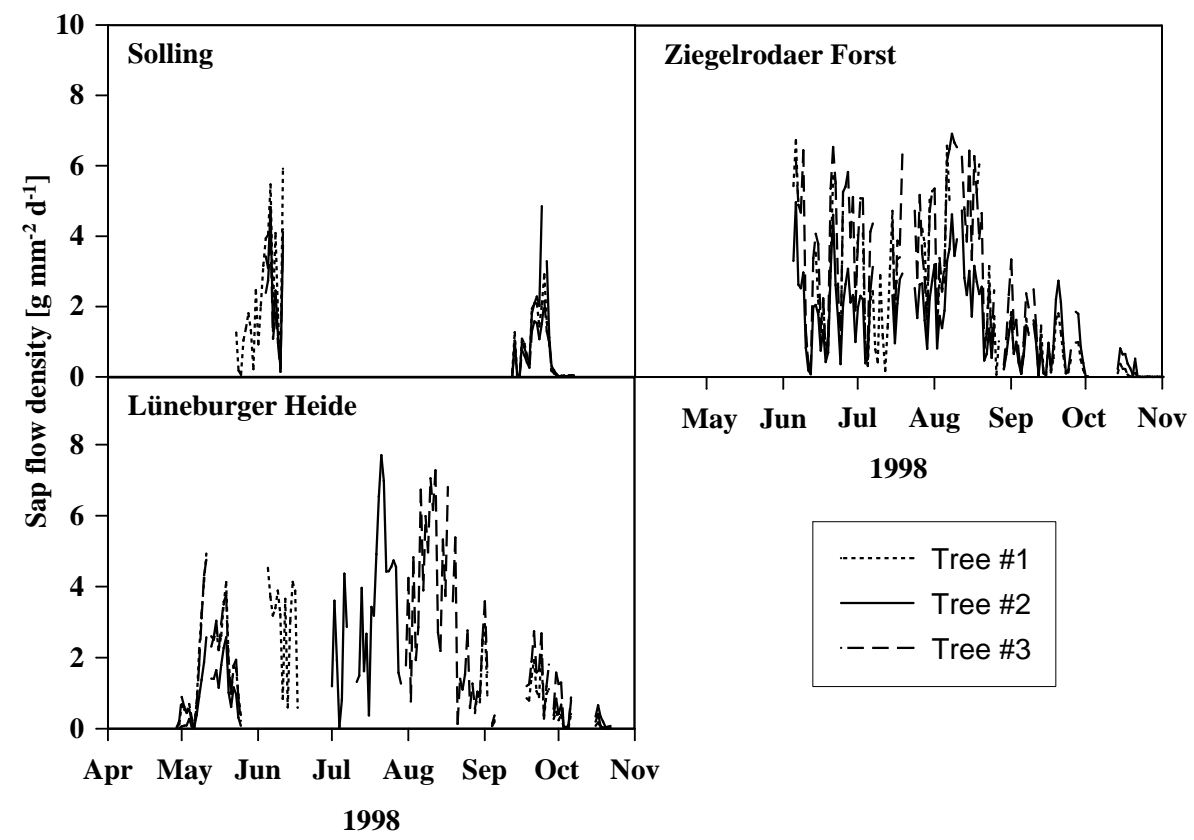

Abb. 4.13: Tageswerte der Saftflußdichte im Stamm der Meßbäume auf den drei Untersuchungsflächen in der Vegetationsperiode 1998, gemessen mit der heat-balance Methode nach Cermak et al. (1973).

Im unteren Teil der Tab. 4.1 sind die wesentlichen biometrischen Daten wiedergegeben, die für die Installation der Saftflußmeßanlagen am Stamm und für die Auswertung der Daten von Belang sind. Diese stellen abgeleitete Größen aus dem Stammumfang am Meßpunkt in 2 m Höhe dar. Die Werte des Stammumfangs, der Holzfläche sowie der Splintholzdicke und -fläche waren erwartungsgemäß im Solling am höchsten und in der Lüneburger Heide am geringsten. Die Splintholzfläche, die als hydroaktiver Teil des Holzes eine wichtige Bezugsgröße für den Vergleich der Stammsaftflußraten verschiedener Bäume darstellt, war bei den etwas jüngeren Buchen in der Lüneburger Heide mit Werte zwischen 277 und $400 \mathrm{~cm}^{2}$ deutlich kleiner als auf den anderen beiden Untersuchungsflächen $\left(>600 \mathrm{~cm}^{2}\right)$. 
Die Tageswerte der Saftflußdichte im Stamm der untersuchten Buchen wiesen witterungsbedingt große Variation zwischenverschiedenen Meßtagen auf (Abb 4.13). Diese Schwankung verlief in allen 3 untersuchten Bäumen einer Fläche gleichsinnig, wobei die auf die Splintholzfläche bezogenen Werte in der Größenordnung ähnliche Werte annahmen. Dabei stehen aufgrund technischer Probleme nicht auf allen Flächen für jeden Tag des Jahres Daten zur Verfügung.

In der Lüneburger Heide war Ende April der Laubaustrieb durch einen Anstieg der Saftflußraten zu erkennen. Bereits nach 2 Wochen erreichte die tägliche Saftflußrate im Stamm Spitzenwerte von $4 \mathrm{~g} \mathrm{~mm}^{-2} \mathrm{~d}^{-1}$, ein Wert der nur in der darauffolgenden Schönwetterperiode Mitte Juli bis etwa Ende August (max. $7 \mathrm{~g} \mathrm{~mm}^{-2} \mathrm{~d}^{-1}$ ) überschritten wurde. Im Herbst war ein kontinuierliches Absinken der maximalen Tageswerte bis zum Laubfall Mitte Oktober zu beobachten.

Auf der Untersuchungsfläche Ziegelrodaer Forst waren von Beginn der Messung Anfang Juni bis etwa Ende August mit $6 \mathrm{~g} \mathrm{~mm}^{-2} \mathrm{~d}^{-1}$ etwas höhere maximale Saftflußdichten zu beobachten. Auch hier endete die Vegetationsperiode für die untersuchten Buchen etwa Mitte Oktober.

Im Solling setzte die Transpiration der Bäume im Frühjahr deutlich verspätet Mitte Mai ein. Auch hier stieg innerhalb von 2 Wochen die Stammsaftflußdichte auf bis zu $6 \mathrm{~g} \mathrm{~mm}^{-2} \mathrm{~d}^{-1}$ an. An diesem Standort ging im Herbst bereits in den letzten Septembertagen die Saftflußrate gegen Null. Durch einen langen Ausfall der Meßanlage stehen stehen für die Sommermonate der Vegetationsperiode 1998 im Solling keine Stammsaftflußraten zur Verfügung.

\subsubsection{Wasserpotential in Feinwurzeln}

Über den gesamten Verlauf der Meßperiode waren am Standort Ziegelrodaer Forst die niedrigsten Wurzelwasserpotentiale zu verzeichnen (Abb. 4.14). Im Juni und Juli sowie Ende September lagen die Werte um -0.6 MPa und sanken in den Perioden mit trockenerem Boden auf -0.9 MPa ab.

Ein ähnlicher Verlauf wurde in der Lüneburger Heide gefunden, wobei hier das Wasserpotential der Auflagewurzeln an allen Terminen weniger stark abgesenkt wurde: Im Juni und Juli wurden -0.2 bis -0.5 MPa gemessen, das Minimum Ende August lag bei -0.7 , und am letzten Termin Ende September waren nur noch -0.13 MPa festzustellen.

Für den Solling liegen nur für die erste Hälfte des Untersuchungszeitraums Potentialwerte vor. Hier waren die ersten beiden Termine (26.6. und 16.7.) mit den Werten der Lüneburger Heide vergleichbar (-0.40 bzw. -0.23 MPa). Am 7.8. hingegen lag das Wurzelwasserpotential an diesem Standort bei nur -0.37 MPa, während in den anderen beiden Beständen die fortschreitende Bodenaustrocknung zu dieser Zeit bereits eine wesentlich ausgeprägtere Absenkung der Potentiale in den Wurzeln bewirkt hatte. 


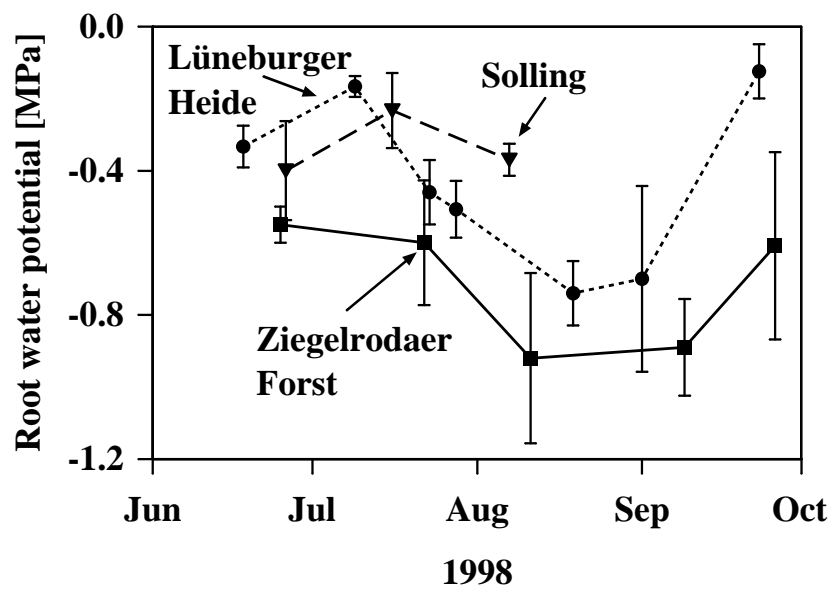

Abb. 4.14: Wurzelwasserpotentiale an den drei Standorten Solling, Ziegelrodaer Forst und Lüneburger Heide, gemessen mit der Scholander-Methode jeweils zur Mittagszeit (12-14 Uhr) von Strahlungstagen an frisch freigelegten Feinwurzelenden der Buche in der organischen Auflage $(\mathrm{n}=5)$.

\subsubsection{Wasseraufnahme durch die Wurzeln}

\subsubsection{Wasseraufnahme im Verlauf der Vegetationsperiode 1998}

Querschnittsflächenbezogene Saftflußraten (Saftflußdichten) Wie die Stammsaftflußrate unterlagen die Tageswerte der Saftflußdichte in den Wurzeln witterungsbedingten Schwankungen (Abb. 4.15). Hierbei folgten stets alle zeitgleich untersuchten Wurzeln eines Bestandes einem parallelen Verlauf. Selbst in den bis zu zweimonatigen Untersuchungszeiträumen kam es so gut wie nie zu Überschneidungen der Kurvenverläufe zweier Wurzeln. Vergleicht man an einzelnen Tagen die Saftflußdichte verschiedener benachbarter Wurzeln, so ergibt sich eine große Spannweite der Werte, die oft einem Variationskoeffizienten von über $100 \%$ entsprechen.

An allen Standorten wurden periodisch Maximalwerte um $10 \mathrm{~g} \mathrm{~mm}^{-2} \mathrm{~d}^{-1}$ in einzelnen Wurzeln erreicht. Die Flußdichte in den Schwach- und Feinwurzeln lag also zumindest in derselben Größenordnung wie im Stamm der untersuchten Bäume (s. Abb. 4.13). Tendenziell scheinen allerdings in den Wurzeln höhere Flußdichten (auf allen Flächen kurzfristig bis zu $15 \mathrm{~g} \mathrm{~mm}^{-2} \mathrm{~d}^{-1}$ ) als im Stamm aufzutreten (Maxima bei $8 \mathrm{~g} \mathrm{~mm}^{-2} \mathrm{~d}^{-1}$ ). Herausragend ist die Wurzel 6 der organischen Auflage in der Lüneburger Heide, in der während der Schönwetterperiode Anfang August Saftflußdichten bis zu $35 \mathrm{~g} \mathrm{~mm}^{-2} \mathrm{~d}^{-1}$ gemessen wurden.

Sieht man von diesem Spitzenwert ab, sind für die Lüneburger Heide kaum horizontspezifische Unterschiede in der Saftflußdichte der Wurzeln zu erkennen. Dies gilt auch für den Solling. Im Ziegelrodaer Forst dagegen wurde im Mineralboden eine größere Zahl von Wurzeln mit höherer Saftflußdichte als in der organischen Auflage gefunden. 

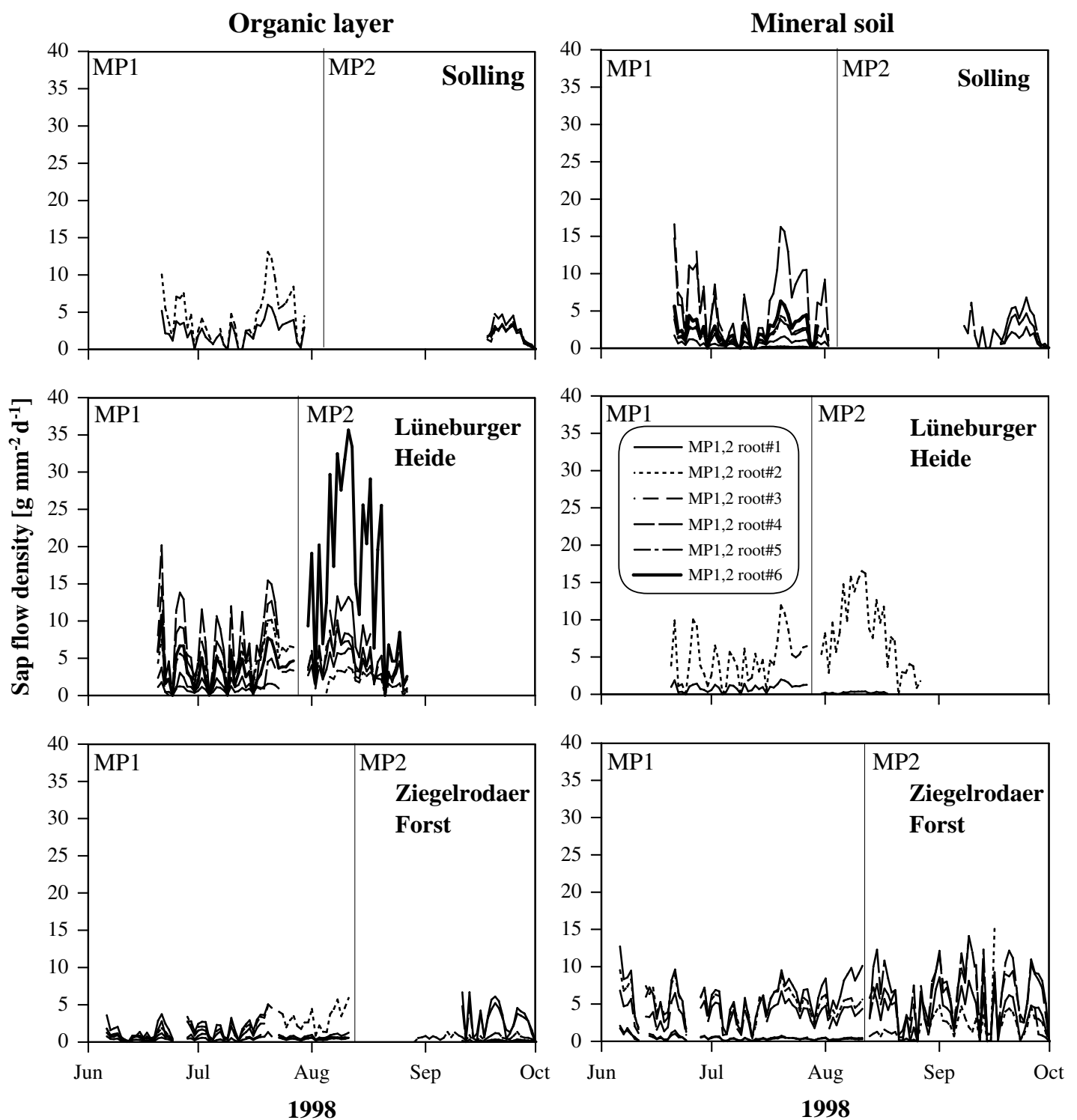

Abb. 4.15: Tageswerte der Saftflußdichte in 3-4 mm starken Buchenwurzeln der Standorte Solling, Lüneburger Heide und Ziegelrodaer Forst, gemessen in der Vegetationsperiode 1998. Als Bezugsgöße dient jeweils die gesamte Xylemquerschnittsfläche am Meßpunkt. Die jeweiligen Meßperioden (Mp1, MP2) sind durch vertikale Linien angedeutet. 
Eine deutliche witterungsbedingte Variabilität der Saftflußdichte wurde nur bei den Wurzeln der Lüneburger Heide gefunden: Wie bereits erwähnt, fällt hier besonders Wurzel 6 in der organischen Auflage auf, aber auch Wurzel 2 im Mineralboden wies in der Schönwetterperiode im August deutlich erhöhte Saftflußdichten auf. Während für den Standort Solling für diese Periode keine Daten vorliegen, war im Ziegelrodaer Forst, also an dem Standort mit der ausgeprägtesten Variation der Bodenfeuchteverhältnisse (s. Abb.4.12), keine so deutlich ausgeprägte Saisonalität zu erkennnen.

Oberflächenspezifische Wasseraufnahmeraten Die Berechnung oberflächenspezifischer Wasseraufnahmeraten aus den gemessenen Saftflußraten und den Wurzeloberflächen ergibt ein deutlich anderes Bild beim Vergleich der Standorte und der Horizonte als bei Betrachtung der Saftflußdichten (Abb. 4.16). Hier fallen mit Werten bis zu $7000 \mathrm{~g} \mathrm{~m}^{-2} \mathrm{~d}^{-1}$ besonders die hohen Aufnahmeraten der Mineralbodenwurzel 1 aus der zweiten Meßperiode im Ziegelrodaer Forst auf. Dies ist bei einer gegebenen Saftflußdichte von 3-5 $\mathrm{g} \mathrm{mm}^{-2} \mathrm{~d}^{-1}$ auf die extrem kleine Oberfläche von $54 \mathrm{~cm}^{2}$ des betreffenden Wurzelstrangs zurückzuführen. Ähnlich hohe Werte wurden in der ersten Meßperiode von Wurzel 4 im Mineralboden erreicht. Diese verfügte mit $37 \mathrm{~cm}^{2}$ sogar über eine noch geringere Gesamtoberfläche. Am Standort Ziegelrodaer Forst fand sich auch eine der wenigen Ausnahmen bezüglich des Verhältnisses zwischen den Flußraten zeitgleich untersuchter Wurzeln: Nahm diese Wurzel im Juni noch deutlich mehr Wasser auf als die anderen, so lag sie zum Ende der Meßperiode Mitte August mit etwa $1000 \mathrm{~g} \mathrm{~m}^{-2} \mathrm{~d}^{-1}$ zwischen den Werten der anderen Wurzeln. Hier kommt es also im zeitlichen Verlauf zu einer Überschneidung mit dem Kurvenverlauf benachbarter, synchron untersuchter Wurzeln.

Im Verhältnis zu den Wurzeln des Mineralbodens nahmen im Ziegelrodaer Forst die Auflagewurzeln deutlich weniger Wasser pro Oberfläche auf. Über den gesamten Untersuchungszeitraum im Sommer 1998 wurden Aufnahmeraten von $1000 \mathrm{~g} \mathrm{~m}^{-2} \mathrm{~d}^{-1}$ kaum überschritten. In dieser Größenordnung lagen auch die in der Lüneburger Heide untersuchten Wurzeln. An diesem Standort waren auch keine nennenswerten Unterschiede zwischen den Wurzeln der organischen Auflage und des Mineralbodens zu beobachten.

Der Standort Solling nimmt bezüglich der oberflächenspezifischen Wasseraufnahmeraten eine Mittelstellung ein. Einzelne Wurzeln im Mineralboden erreichten in der zweiten Junihälfte Tageswerte von bis zu $3500 \mathrm{~g} \mathrm{~m}^{-2} \mathrm{~d}^{-1}$, also etwa doppelt so viel wie diejenigen in der Lüneburger Heide. Auch waren auf dieser Untersuchungsfläche höhere Aufnahmeraten aus dem Mineralboden als aus der organischen Auflage zu verzeichnen. Allerdings wiesen bei den Freilegearbeiten drei der fünf installierten Oberflächenwurzeln große Anteile in tieferen Horizonten auf, so daß nur zwei Wurzelstränge ausschließlich der organischen Auflage zugeordnet werden konnten.

Vergleich der Standorte in 2 Perioden mit unterschiedlicher Witterung Der direkte Vergleich der oberflächenspezifischen Wasseraufnahmerate anhand von 

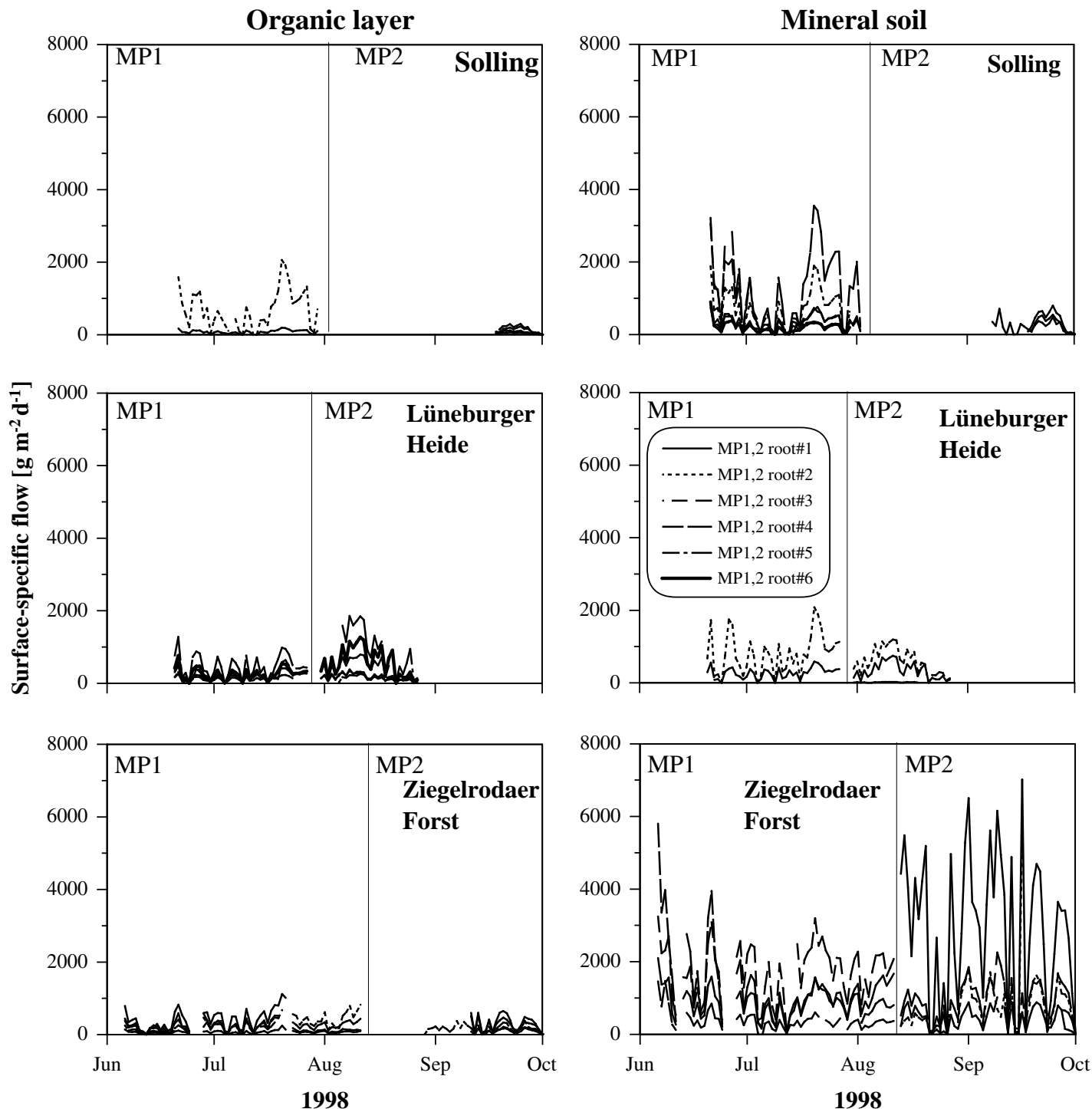

Abb. 4.16: Oberflächenspezifische Wasseraufnahmeraten (Tageswerte) von 3-4 mm starken Buchenwurzeln der Standorte Solling, Lüneburger Heide und Ziegelrodaer Forst, gemessen in der Vegetationsperiode 1998. Die Aufnahmeraten wurden jeweils für den gesamten hinter der Meßstelle befindlichen Wurzelstrang, also für alle Durchmesserklassen zwischen 0 und ca. $4 \mathrm{~mm}$ berechnet. Die jeweiligen Meßperioden (Mp1, MP2) sind durch vertikale Linien angedeutet. 
Mittelwerten über 11 bzw. 4 Tage im Juli 1998 ergibt keine signifikanten Unterschiede zwischen den 3 untersuchten Standorten (Tab. 4.2). In der ersten Periode vom 3. bis zum 13. Juli war die atmosphärische Transpirationsbelastung gering und die Wasserverfügbarkeit im Boden hoch. Einzig am Standort Ziegelrodaer Forst wurde in $30 \mathrm{~cm}$ Bodentiefe bereits an diesem Termin ein Matrixpotential von -343 hPa gemessen. Die mittlere oberflächenspezifische Wasseraufnahme entsprach in dieser Periode der Folge Ziegelrodaer Forst $>$ Lüneburger Heide $>$ Solling.

Tabelle 4.2: Bodenfeuchte, Witterung und oberflächenspezifische Wurzelsaftflußrate an 2 Terminen im Sommer 1998 an den Standorten Solling, Lüneburger Heide und Ziegelrodaer Forst. Dargestellt sind für jeden Standort Mittelwerte der gemessenen Parameter über jeweils 11 Tage Anfang Juli bzw. 4 Tage Ende Juli 1998. $\Psi_{5 / 10 \mathrm{~cm}}, \Psi_{30 / 20 \mathrm{~cm}}, \Psi_{60 / 40 \mathrm{~cm}}$ : Bodenmatrixpotential in 5,30 bzw. $60 \mathrm{~cm}$ Tiefe (Solling: 10, 20 bzw. $40 \mathrm{~cm}$ ) [hPa], VPD $\mathrm{Vum}_{\text {cum }}$ G: Tageshellphasensumme des Sättigungsdefizits und der Globalstrahlung [hPa d ${ }^{-1}$ bzw. $\mathrm{MJ} \mathrm{m}^{-2} \mathrm{~d}^{-1}$ ], $\mathrm{J}_{\mathrm{s}}$ : Oberflächenspezifische Wurzelsaftflußrate $\left[\mathrm{g} \mathrm{m}^{-2} \mathrm{~d}^{-1}\right.$ ], VK: Variationskoeffizient [\%]. Unterschiedliche Buchstaben markieren signifikante Unterschiede zwischen den Flächen je Termin; Signifikanztest nach Scheffé ( $p<0.05)$.

\begin{tabular}{lcccccc} 
& & $\Psi_{5 / 10 \mathrm{~cm}}$ & $\Psi_{30 / 20 \mathrm{~cm}}$ & $\Psi_{60 / 40 \mathrm{~cm}}$ & $\mathrm{VPD}_{\text {cum }}$ & $\mathrm{G}$ \\
\hline \multirow{2}{*}{ 3.-13. Juli } & Solling & -12.01 & -16.56 & -34.94 & 15.43 & 9.06 \\
& Lüneburger H. & -51.58 & -64.23 & -71.10 & nd & nd \\
& Ziegelrodaer F. & -9.29 & -367.15 & -113.57 & 67.63 & nd \\
\hline 23.-27. Juli & Solling & -45.85 & -74.52 & -94.04 & 79.30 & 18.90 \\
& Lüneburger H. & -78.08 & -82.33 & -76.31 & 105.46 & 18.82 \\
& Ziegelrodaer F. & -113.04 & -695.46 & -342.66 & 150.06 & nd
\end{tabular}

\begin{tabular}{ccccccccc} 
& & $\mathrm{J}_{\mathrm{s}}$ & Median & Min & Max & Stabw & VK & $\mathrm{n}$ \\
\hline \multirow{2}{*}{ 3.-13.Juli } & Solling & $198.44^{\mathrm{a}}$ & 170.09 & 38.79 & 419.12 & 132.95 & 67.00 & 7 \\
& Lüneburger H. & $242.94^{\mathrm{a}}$ & 186.86 & 95.88 & 558.95 & 153.67 & 63.26 & 8 \\
& Ziegelrodaer F. & $389.56^{\mathrm{a}}$ & 269.76 & 41.44 & 1052.25 & 328.57 & 84.34 & 8 \\
\hline 23.-27.Juli & Solling & $683.39^{\mathrm{a}}$ & 450.27 & 109.14 & 1997.12 & 627.32 & 91.80 & 8 \\
& Lüneburger H. & $455.24^{\mathrm{a}}$ & 336.93 & 247.03 & 986.50 & 303.81 & 66.74 & 5 \\
& Ziegelrodaer F. & $661.88^{\mathrm{a}}$ & 389.19 & 76.34 & 2015.76 & 659.16 & 99.59 & 8
\end{tabular}

In der Periode vom 23. bis 27. Juli - der ersten Schönwetterphase im Sommer 1998 - wurden im Mittel deutlich höhere Tageshellphasensummen des Sättigungsdefizites und der Globalstrahlung gemessen. Das Bodenmatrixpotential war an allen Standorten gegenüber der ersten Monatshälfte des Juli niedriger, wobei in der Lüneburger Heide und im Solling kein Horizont niedriger als -100 hpa lag, während im Ziegelrodaer Forst dieser Wert in allen gemessenen Tiefen unterschritten wurde. Die daraus resultierende oberflächenspezifische Wasseraufnahmerate der Wurzeln war an allen 3 Standorten deutlich höher als in der Zeit vom 3.-13. Juli. Auch die Abfolge der Standorte änderte sich: Im Solling und im Ziegelrodaer Forst wurden mit 683 bzw. $662 \mathrm{~g} \mathrm{~m}^{-2} \mathrm{~d}^{-1}$ nahezu identische Tagessummen der Wasseraufnahme gemessen. In der Lüneburger Heide war der Wert mit $455 \mathrm{~g} \mathrm{~m}^{-2} \mathrm{~d}^{-1}$ deutlich geringer. Auch in dieser Meßperiode waren die Unterschiede nicht signifikant.

Die Tagessummen der oberflächenspezifischen Wasseraufnahmerate weisen an al- 
len 3 Standorten eine sehr große Varianz auf. In den beiden Meßperioden wurden Variationskoeffizienten von 67-100 \% für die jeweils 5-8 untersuchten Wurzeln an einem Standort gefunden. Die Aufnahmeaktivität benachbarter Wurzeln eines Baumes ist also sehr unterschiedlich.

\subsection{Vergleichende Untersuchung der Wasseraufnahme durch die Wurzeln verschiedener Baumarten}

\subsubsection{Morphologische Merkmale der untersuchten Wurzeln}

Vertikalverteilung der Wurzeloberfläche Die in der Vegationsperiode 1999 in der Lüneburger Heide vergleichend untersuchten Buchen-, Eichen- und Fichtenwurzelstränge (3-4 mm Durchmesser) aus der organischen Auflage hatten im Mittel jeweils eine Gesamtoberfläche von etwa $1000 \mathrm{~cm}^{2}$, wobei keine signifikanten Unterschiede zwischen den Arten zu erkennen sind (Abb. 4.17). Die Wurzelstränge im Mineralboden besaßen ebenfalls bei den drei Arten ähnlich große Gesamtoberflächen, die jedoch mit etwa $250 \mathrm{~cm}^{2}$ nur etwa ein Viertel der Werte in der organischen Auflage erreichten. Dieser Unterschied zwischen Wurzeln der organischen Auflage und des Mineralbodens ist bei allen drei Arten statistisch signifikant. In jedem Fall wurden Wurzelstränge, die an der Position der Saftflußmanschette 3-4 mm dick waren, mit allen Feinstwurzelendungen bis zu den Wurzelspitzen untersucht.

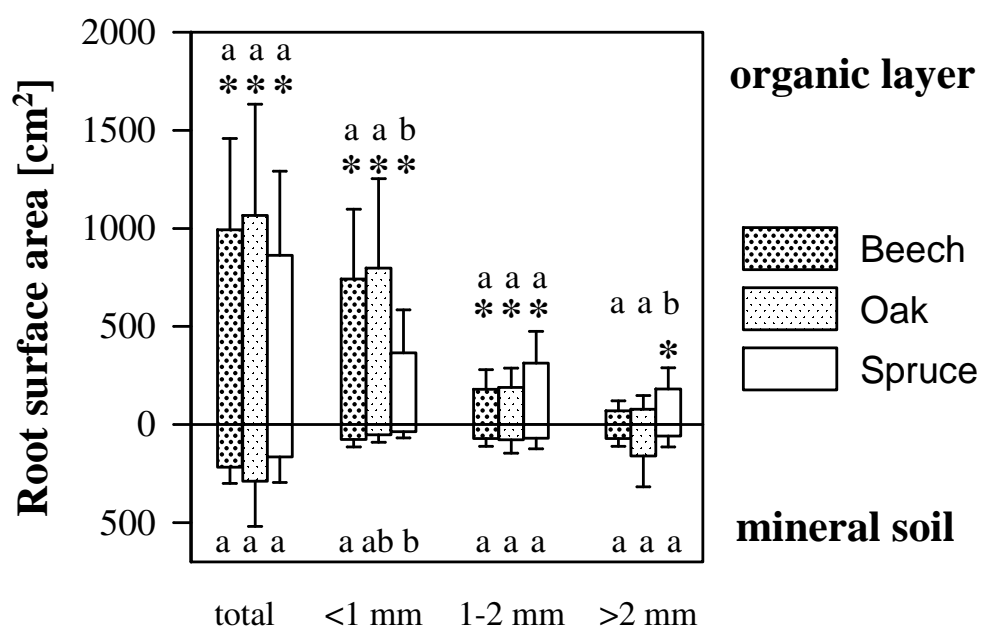

Abb. 4.17: Oberfläche der untersuchten 3-4 $\mathrm{mm}$ starken Wurzelstränge in der organischen Auflage und im Mineralboden. Dargestellt sind Mittelwerte der Buchen-, Eichen- und Fichtenwurzeln aus allen Meßperioden 1999 in der Lüneburger Heide. Unterschiedliche Buchstaben markieren in jeder Durchmesserklasse signifikante Unterschiede zwischen den Arten, Sterne solche zwischen den Wurzeln der organischen Auflage und des Mineralbodens; U-Test nach Mann \& Whitney $(\mathrm{p}<0.05)$.

Bei Betrachtung der Durchmesserklassen fällt in der Feinstwurzelfraktion $(<1 \mathrm{~mm})$ 
eine signifikant kleinere Oberfläche der Fichtenwurzeln in der organischen Oberfläche auf, während die Wurzeln dieser Art signifikant größere Oberflächen in der größten Durchmesserklasse $(>2 \mathrm{~mm}=$ Schwachwurzeln) als Buchen- und Eichenwurzeln hatten. Im Mineralboden sind in den Durchmesserklassen nur bei den Feinstwurzeln signifikante Unterschiede zwischen den Buchen- und Fichtenwurzeln zu erkennen.

Verteilung der Wurzeloberfläche auf die Durchmesserklassen Die Oberfläche der am Meßpunkt 3-4 mm dicken Buchenwurzeln aus der organischen Auflage war mit 75, 18 und 7\% auf die Feinst-, Fein- und Schwachwurzelfraktionen verteilt (Abb.4.18). Bei den Eichenwurzeln waren die Relationen nahezu identisch. Die Oberfläche der Fichtenwurzeln hingegen verteilte sich zu ähnlich großen Teilen (43, 36 und $21 \%$ ) auf die 3 Durchmesserklassen. Der Anteil an Feinstwurzeln war bei den Fichtenwurzelsträngen der organischen Auflage signifikant kleiner, derjenige an Fein- und Schwachwurzeln hingegen signifikant größer als bei den Buchen- und Eichenwurzeln.

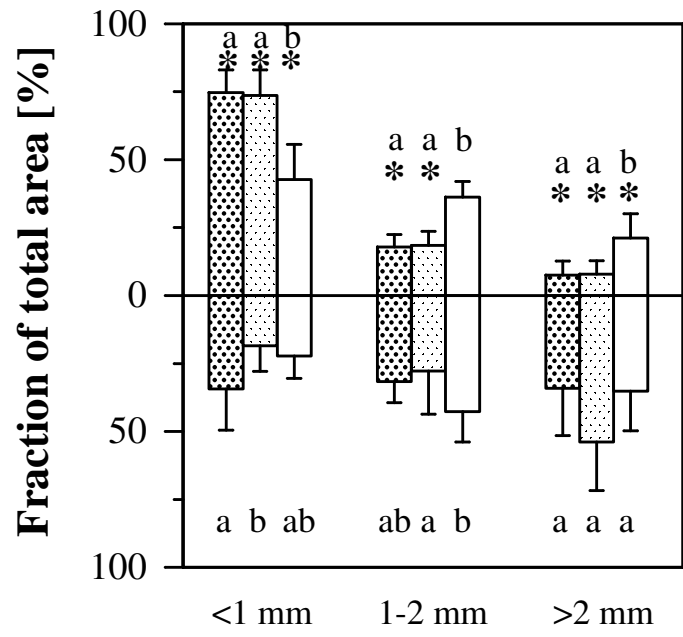

organic layer

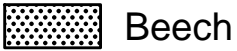

Oak

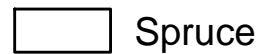

mineral soil

Abb. 4.18: Prozentuale Verteilung der Wurzeloberfläche der geernteten Wurzelstränge auf drei Durchmesserklassen. Dargestellt ist jeweils der Anteil der Durchmesserklasse 0-1 mm, 1-2 mm bzw. $>2 \mathrm{~mm}$ an der Gesamtoberfläche des jeweiligen Wurzelstranges (3-4 $\mathrm{mm}$ an der Schnittstelle). Die Balken repräsentieren Mittelwerte der Buchen-, Eichen- und Fichtenwurzeln aus allen Meßperioden 1999 in der Lüneburger Heide. Unterschiedliche Buchstaben markieren in jeder Durchmesserklasse signifikante Unterschiede zwischen den Arten, Sterne solche zwischen den Wurzeln der organischen Auflage und des Mineralbodens; Signifikanztest nach nach Scheffé $(\mathrm{p}<0.05)$.

Im Mineralboden war bei allen drei Arten ein wesentlich größerer Anteil der gröBeren Durchmesser an der Gesamtoberfläche zu verzeichnen. Hier setzte sich die Oberfläche der Buchenwurzelstränge etwa zu gleichen Teilen aus den Fraktionen Feinst-, Fein- und Schwachwurzeln zusammen, während die Eichenwurzeln zur Hälfte aus der Schwachwurzelfraktion bestand. Die größte Fraktion bei der Fichte wurde mit $43 \%$ 
von den Feinwurzeln gestellt. Signifikante interspezifische Unterschiede lagen hier nur zwischen Buche und Eiche bei den Feinstwurzeln bzw. zwischen Eiche und Fichte bei den Feinwurzeln vor.
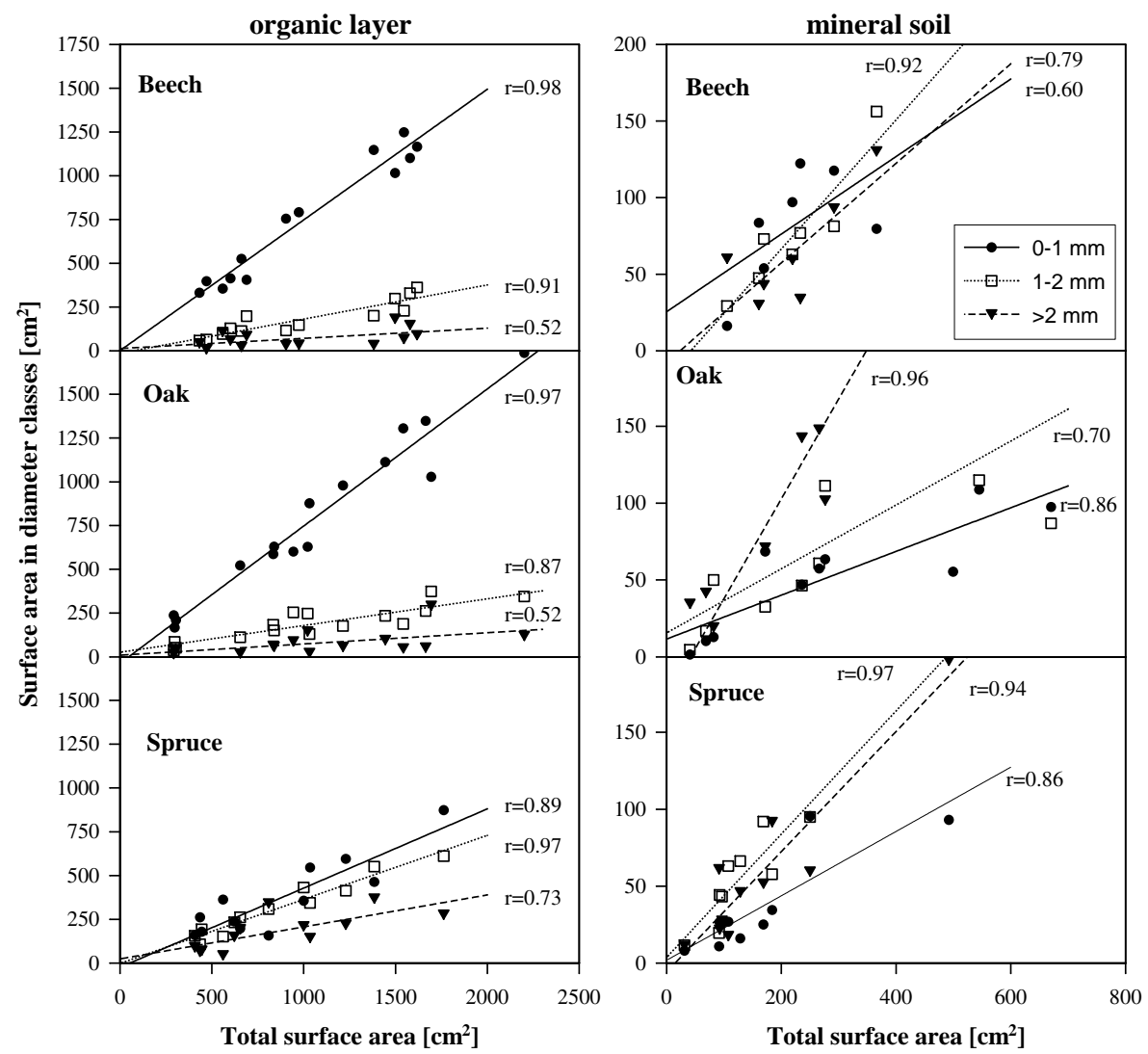

Abb. 4.19: Abhängigkeit der Wurzeloberfläche in den Durchmesserklassen 0-1mm (Feinst-) 1-2 mm (Fein-) und $>2 \mathrm{~mm}$ (Schwachwurzeln) von der Gesamtoberfläche des jeweiligen Wurzelstranges. Dargestellt sind die Werte für alle während der Vegetationsperiode 1999 in der Lüneburger Heide geernteten 3-4 mm starken Buchen-, Eichen- und Fichtenwurzelstränge.

Die Verteilung der Oberflächen der Wurzelstränge auf die Durchmesserfraktionen unterlag bei den drei untersuchten Baumarten einem festen Muster. Abb. 4.19 zeigt die Wurzeloberfläche in den Durchmesserklassen 0-1 mm, 1-2 mm und $>2 \mathrm{~mm}$ in Abhängigkeit von der jeweiligen Gesamtoberfläche des Wurzelstranges. Besonders in der organischen Auflage ergaben sich für die Fein- und Feinstwurzeln sehr enge Korrelationskoeffizienten von 0.87 bis 0.98. Der Anteil der Schwachwurzeln war in der organischen Auflage dagegen nur undeutlich mit der Gesamtoberfläche korreliert ( 0.52 bei Buche und Eiche, 0.73 bei der Fichte). Die Steigung der Regressionsgeraden spiegelt das Bild aus Abb. 4.18 insofern wieder, als bei den Buchen- und Eichenwurzeln der organischen Auflage die Fraktion der Feinstwurzeln die größte Oberfläche besaß, während bei den Fichtenwurzeln die Gesamtoberfläche gleichmäßiger auf die drei Durchmesserklassen verteilt war. 
Bei den Mineralbodenwurzeln ergab sich ein völlig anderes Bild. Hier waren die engsten Korrelationen zur Gesamtoberfläche bei den größeren Durchmessern in der Fraktion der Fein- und Schwachwurzeln zu finden. Bei den Eichen- und Fichtenwurzeln stellten die Feinstwurzeln auch den geringsten Anteil an der Gesamtoberfläche. Die Buchenwurzeln des Mineralbodens waren dagegen gleichmäßig auf die 3 Durchmesserfraktionen verteilt.

Spezifische Wurzeloberfläche Die spezifische Oberfläche der an der Schnittstelle 3-4 mm starken Wurzelstränge war bei den Buchen- und Eichenwurzeln der organischen Auflage mit etwa $160 \mathrm{~cm}^{2} \mathrm{~g} \mathrm{DW}^{-1}$ signifikant größer als bei den Fichtenwurzeln $\left(116 \mathrm{~cm}^{2} \mathrm{~g} \mathrm{DW}^{-1}\right)$. Auch hier sind bei allen drei Arten deutliche Horizontunterschiede zu erkennen: Die spezifische Wurzeloberfläche im Mineralboden lag mit etwa $50 \mathrm{~cm}^{2} \mathrm{~g} \mathrm{DW}^{-1}$ bei der Buche bzw. $70 \mathrm{~cm}^{2} \mathrm{~g} \mathrm{DW}^{-1}$ bei Eiche und Fichte signifikant niedriger als in der organischen Auflage.

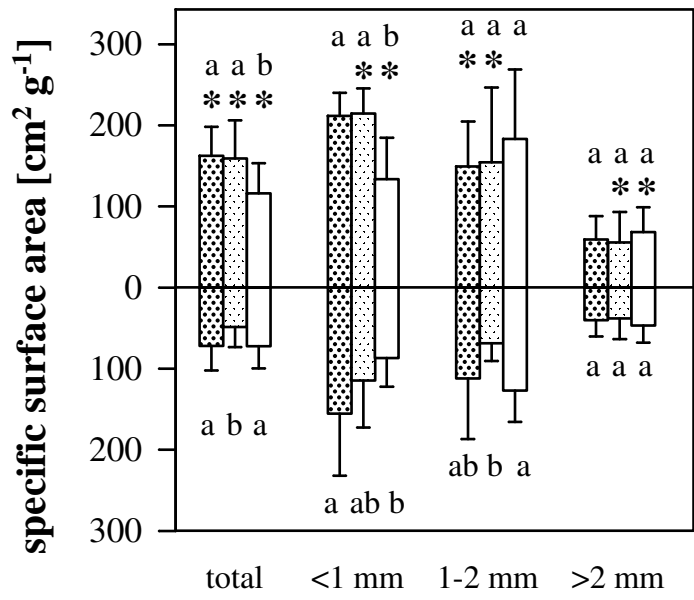

organic layer
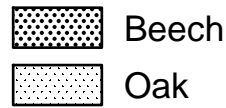

$\square$ Spruce

mineral soil

Abb. 4.20: Spezifische Wurzeloberfläche von Buchen-, Eichen- und Fichtenwurzeln verschiedenen Durchmessers aus der organischen Auflage bzw. dem Mineralboden. Dargestellt sind Mittelwerte aller während der Vegetationsperiode 1999 auf der Untersuchungsfläche OB5 in der Lüneburger Heide untersuchten Wurzeln. Unterschiedliche Buchstaben markieren in jeder Durchmesserklasse signifikante Unterschiede zwischen den Arten, Sterne solche zwischen den Wurzeln der organischen Auflage und des Mineralbodens; U-Test nach Mann \& Whitney $(\mathrm{p}<$ $0.05)$.

Betrachtet man die einzelnen Durchmesserklassen, so ist bei der Buche und Eiche festzustellen, daß sowohl in der organischen Auflage als auch im Mineralboden erwartungsgemäß die spezifische Oberfläche mit steigendem Durchmesser abnahm. So sanken die Werte in der organischen Auflage von etwa $210 \mathrm{~cm}^{2} \mathrm{~g} \mathrm{DW}-1$ bei den Feinstwurzeln über 150 auf unter $60 \mathrm{~cm}^{2} \mathrm{~g} \mathrm{DW}^{-1}$ bei den Schwachwurzeln. Im Mineralboden wurden jeweils etwa 50-70\% dieser Werte erreicht. Die Fichtenwurzeln hingegen besaßen in der Durchmesserfraktion der Feinwurzeln mit 183 (Mineralbo- 
den: 127) $\mathrm{cm}^{2} \mathrm{~g} \mathrm{DW}^{-1}$ die höchste spezifische Oberfläche, während die Feinstwurzeln mit 134 (Mineralboden: 87) $\mathrm{cm}^{2} \mathrm{~g} \mathrm{DW}^{-1}$ deutlich weniger Oberfläche pro Trockengewicht ausbildeten als diejenigen der Buche und Eiche.

\title{
4.3.2 Artspezifische anatomische Eigenschaften der Baumwurzeln
}

\subsubsection{Leitender Querschnitt am Meßpunkt der Saftflußsensoren}

Bei der Untersuchung des leitenden Querschnitts wiesen die Fichtenwurzeln mit 42.6 Xylemelementen pro $\mathrm{mm}^{2}$ in der Durchmesserklasse 20-25 $\mu \mathrm{m}$ die größte Dichte auf (Abb. 4.21). Mit der größten besetzten Durchmesserklasse bei 65-70 $\mu \mathrm{m}$ war der leitende Querschnitt der Fichte also vorwiegend aus einer großen Zahl Tracheiden geringen Durchmessers aufgebaut.

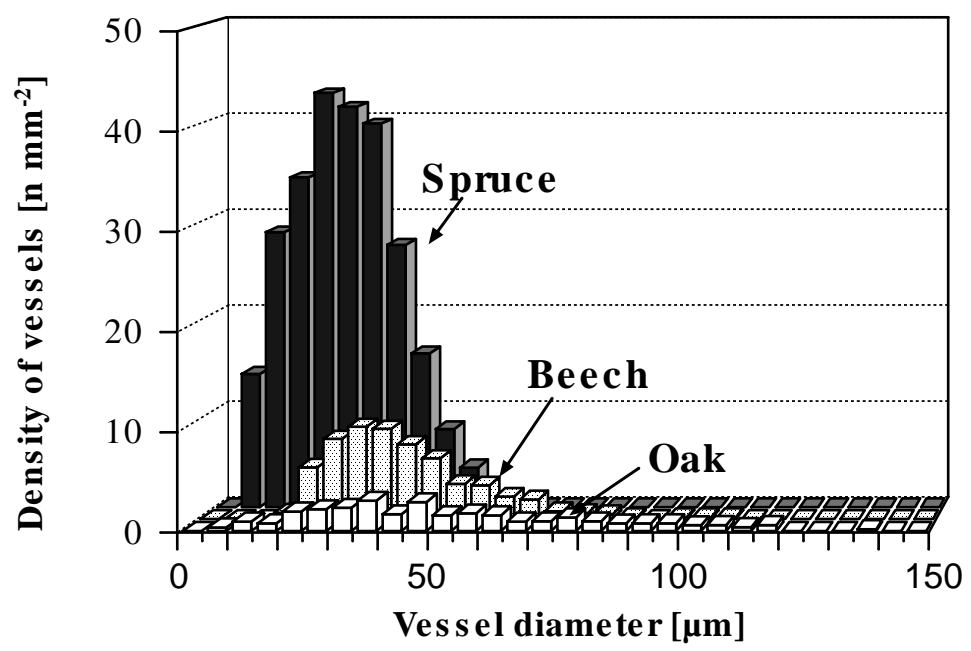

\begin{abstract}
Abb. 4.21: Verteilung der Gefäßdurchmesser in Querschnitten von Buchen-, Eichen- und Fichtenwurzeln. Dargestellt ist für jede Durchmesserklasse die Dichte an Xylemelementen pro Querschnittsfläche. Je Art wurden 5 Querschnitte von 3-4 mm starken Wurzeln der Untersuchungsfläche OB5 in der Lüneburger Heide untersucht, an denen in der Vegetationsperiode 1999 der Saftfluß bestimmt wurde.
\end{abstract}

Bei den Wurzeln der Eiche war eine deutlich flachere Häufigkeitsverteilung zu beobachten, d.h. die Anzahl der Gefäße war geringer als bei der Fichte, während die Gefäße mit bis zu $150 \mu$ m deutlich größere maximale Durchmesser besitzen. Das Häufigkeitsmaximum war mit etwa 3 Xylemelementen pro $\mathrm{mm}^{2}$ bei Durchmessern von $50 \mu \mathrm{m} \mathrm{zu}$ finden. Die Buchenwurzeln verhielten sich mit einem Häufigkeitsmaximum von 9.1 Xylemelementen pro $\mathrm{mm}^{2}$ bei $40-45 \mu \mathrm{m}$ intermediär. Auch die größten Gefäße lagen mit einem Durchmesser von $115 \mu \mathrm{m}$ zwischen denjenigen der Eiche und der Fichte.

Ähnlich deutliche Unterschiede zwischen den drei untersuchten Baumarten waren bei der Betrachtung des Anteils leitender Fläche an der Gesamtquerschnittsfläche 
(Abb. 4.22) zu finden: Die kumulierte Fläche der Tracheiden und Tracheen betrug in den untersuchten 3-4 mm starken Wurzeln der Eiche $0.6 \mathrm{~mm}^{2}$, was einem Anteil von $10 \%$ an der gesamten Querschnittsfläche entspricht.
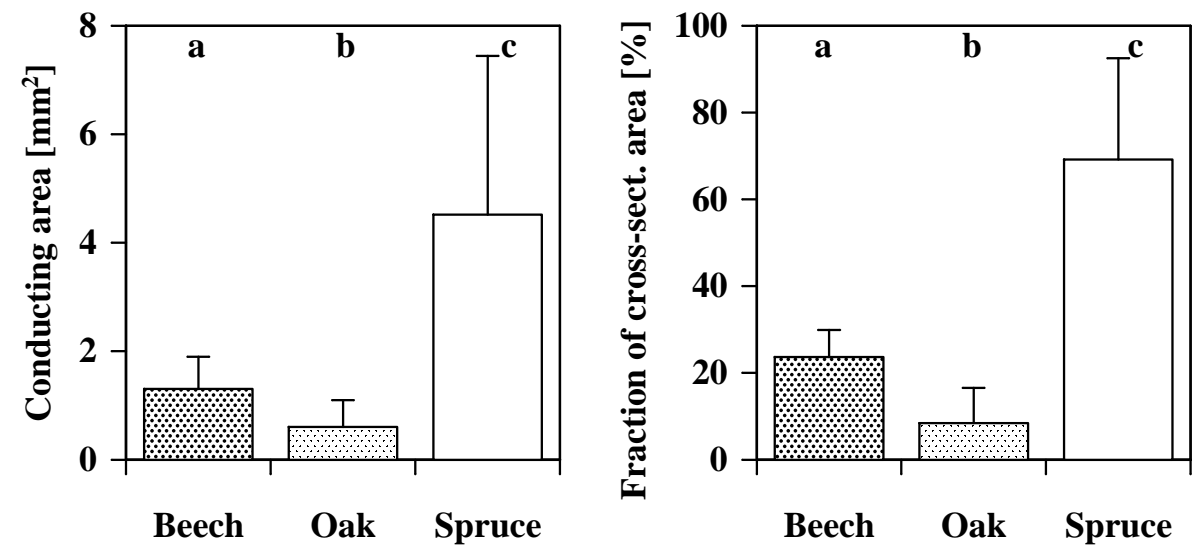

Abb. 4.22: Leitende Xylemfläche (links) und Anteil der leitenden Xylemfläche an der Gesamtquerschnittsfläche (rechts) von Buchen-, Eichen- und Fichtenwurzeln. Je Art wurden 5 Querschnitte von 3-4 mm starken Wurzeln von der Untersuchungsfläche Lüneburger Heide (OB5) untersucht. Unterschiedliche Buchstaben markieren signifikante Unterschiede zwischen den Arten; U-Test nach Mann \& Whitney $(\mathrm{p}<0.05)$.

Bei der Buche war die leitende Fläche in den Wurzeln mit $1.3 \mathrm{~mm}^{2}$ bzw. $20 \%$ Anteil an der Gesamtquerschnittsfläche etwas größer. Die Fichte erreichte mit $4.5 \mathrm{~mm}^{2}$ was einem Querschnittsflächenanteil von $20 \%$ entspricht, eine etwa vierfach größere Leitfläche als die anderen beiden Baumarten. Alle genannten Unterschiede zwischen den Arten waren signifikant.

\subsubsection{Die Differenzierung des Abschlußgewebes entlang der Wurzelachse}

Betrachtet man die Veränderung des Wurzeldurchmessers entlang der Hauptachse von Fein- und Schwachwurzelsträngen, so ist bei allen drei untersuchen Baumarten eine enge lineare Beziehung zum Abstand von der Wurzelspitze zu erkennen (Abb. 4.23).

Alle drei Arten wiesen direkt hinter der Wurzelspitze einen Durchmesser von etwa $0.25 \mathrm{~mm}$ auf. Bei den Fichtenwurzeln nahm der Wurzeldurchmesser entlang der Hauptachse mit einem Faktor von $0.052 \mathrm{~mm} \mathrm{~cm}^{-1}$ am schnellsten zu, so daß der hier untersuchte maximale Durchmesser von $4 \mathrm{~mm}$ bereits in $70 \mathrm{~cm}$ Entfernung von der Wurzelspitze erreicht wurde.

Diese Durchmesserzunahme verlief bei den Wurzelsträngen der Buche und Eiche wesentlich flacher. Die lineare Regression ergab hier Steigungen von 0.029 bzw. $0.034 \mathrm{~mm} \mathrm{~cm}^{-1}$. Der Korrelationskoeffizient für diese Beziehung beträgt bei der $\mathrm{Bu}-$ che und Fichte 0.80 bzw. 0.84, bei der Eiche dagegen 0.92 . 


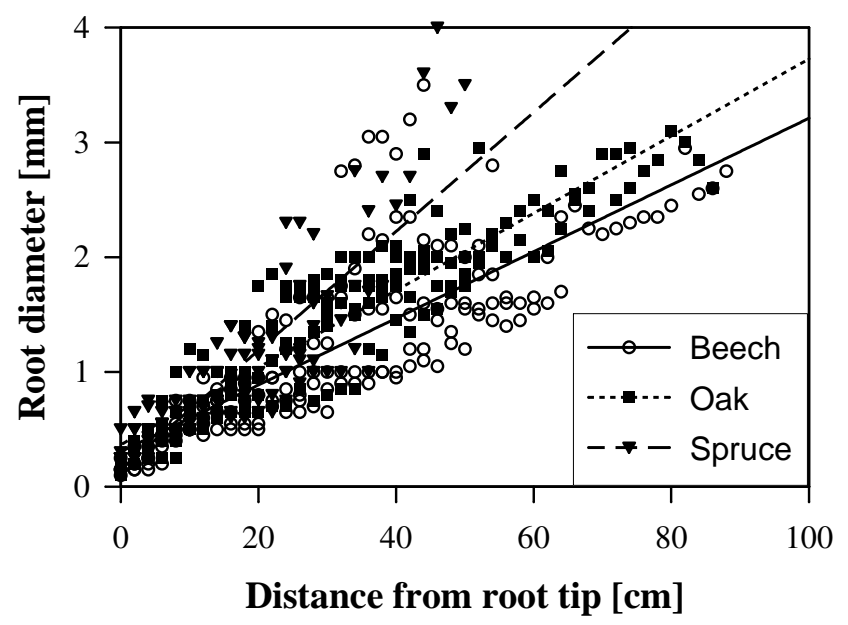

Abb. 4.23: Veränderung des Wurzeldurchmessers in Abhängigkeit von der Entfernung zur Wurzelspitze, gemessen im Sommer 1999 an je 5 mit Druckluft freigelegten Buchen-, Eichenund Fichtenwurzelsträngen der organischen Auflage am Standort OB5 in der Lüneburger Heide.

Bei keiner der untersuchten Wurzelstränge konnte eine intakte Endodermis nachgewiesen werden. Allenfalls bei den Buchenwurzeln waren an einzelnen Querschnitten in den Durchmesserklassen $\leq 1 \mathrm{~mm}$ Reste der Endodermis in Form von kleinen, noch nicht abgestoßenen Zellgruppen außerhalb des Periderms zu erkennen.

Eine Wurzelhaarzone wurde bei den hier untersuchten Wurzelsträngen ebenfalls nicht gefunden. Bei allen drei Baumarten war also direkt hinter der Wurzelspitze ein Periderm als Abschlußgewebe differenziert. Namentlich bei den Fichtenwurzeln wiesen die Querschnitte wenige mm hinter der Wurzelspitze in 2 von 3 Fällen noch ein deutlich zu erkennendes Hartigsches Netz auf.

Mit zunehmendem Durchmesser war bei allen drei untersuchten Baumarten zunächst ein sehr steiler Anstieg der Anzahl von Periderm-Zellschichten zu beobachten, der bei Durchmessern $>1 \mathrm{~mm}$ abflachte (Abb. 4.24 A, oben). Dieser Verlauf läßt sich mit der Michaelis-Menten Beziehung $(y=(a \cdot x) /(x+b))$ gut beschreiben; die nichtlineare Regression besitzt für Buche, Eiche und Fichte Korrelationskoeffizienten von $0.83,0.74$ und 0.89 .

Die Eichenwurzeln besaßen bereits direkt hinter der mykorrhizierten Wurzelspitze bei Durchmessern von $0.25 \mathrm{~mm}$ ein aus 5 Zellagen aufgebautes Periderm, welches bei 0.5 und $2 \mathrm{~mm}$ Durchmesser weiter auf 8 bzw. 12 Schichten anwuchs. In einem untersuchten Querschnitt wurden im Extremfall 22 Zellschichten bei einem Wurzeldurchmesser von $2.2 \mathrm{~mm}$ gezählt. Bei den Wurzeln der Buche war das Periderm in jeder Durchmesserklasse aus etwas weniger Zellschichten aufgebaut als bei der Eiche: Direkt hinter der Wurzelspitze wurden 3, und bei $2 \mathrm{~mm}$ Durchmesser 9 Schichten gezählt. Das Periderm der Fichtenwurzeln hingegen war einheitlich bei allen Durchmessern aus 2-3 Zellagen aufgebaut. 
Bezüglich der Peridermstärke verhielten sich die Wurzeln von Buche und Eiche ähnlich wie bei der Zahl der Periderm-Zellschichten (Abb. 4.24 B, oben). Das Periderm der Eichenwurzeln war bei $0.25 \mathrm{~mm} 30 \mu \mathrm{m}$ stark und erreichte bei Durchmessern von $2 \mathrm{~mm}$ etwa $90 \mu \mathrm{m}$. Die Buchenwurzeln lagen mit $20 \mu \mathrm{m}$ bei dem kleinsten und $60 \mu \mathrm{m}$ bei dem größten Durchmesser etwas darunter. Bei den Fichtenwurzeln, die deutlich geringere Zellzahlen aufwiesen als Buche und Eiche, verhielt sich die Dicke des Periderms in Abhängigkeit vom Durchmesser hingegen wie bei der Buche: Bei beiden Arten stieg die Peridermdicke nur langsam an.
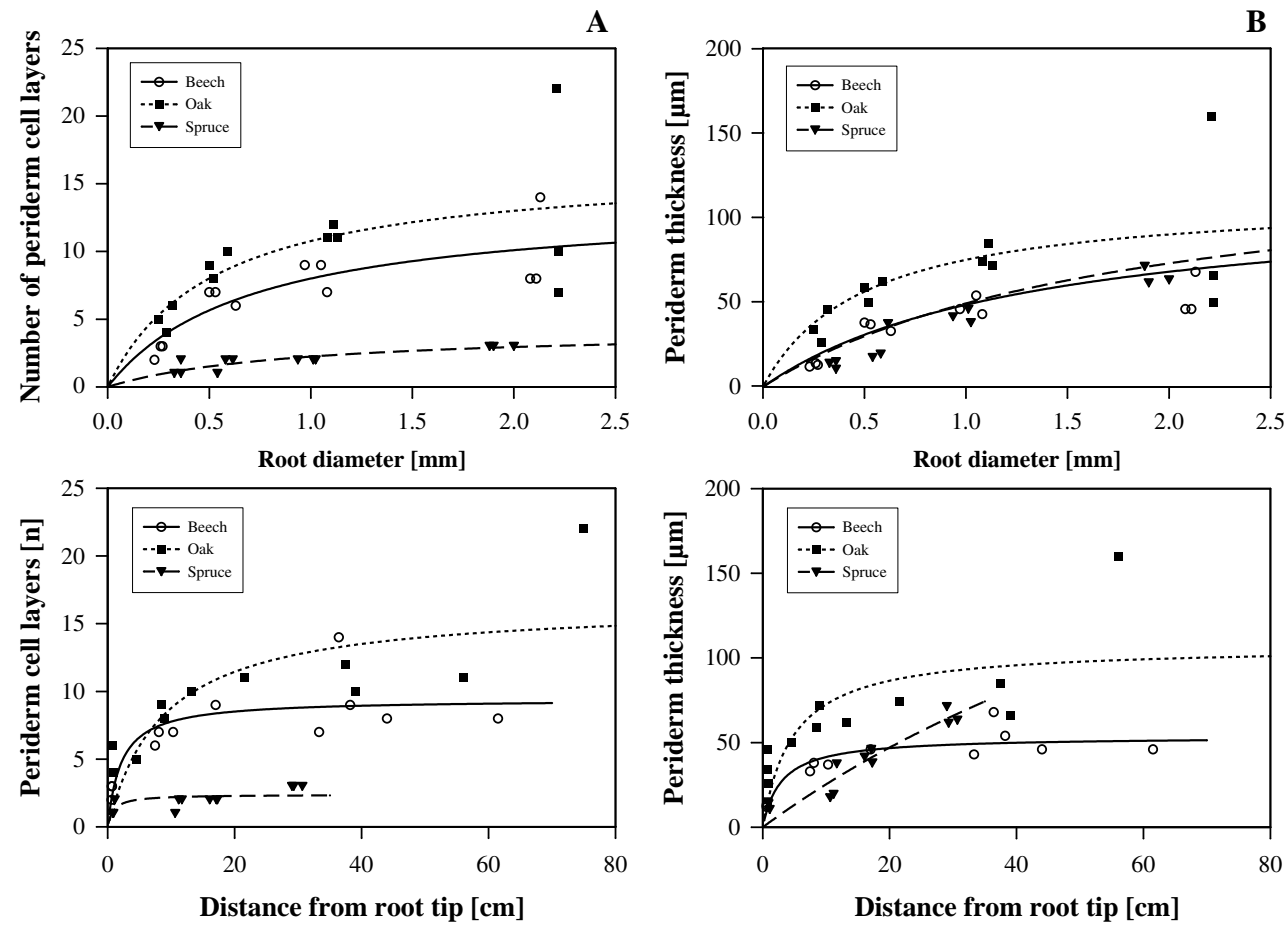

Abb. 4.24: Beziehung zwischen dem Wurzeldurchmesser (oben) bzw. dem Abstand zur Wurzelspitze (unten) und Zahl der Periderm-Zellschichten (A) bzw. der Peridermdicke (B). Je untersuchter Durchmesserklasse (2, 1, $0.5 \mathrm{~mm}$ und direkt hinter der Wurzelspitze) wurden Querschnitte von 3 Buchen-, Eichen- und Fichtenwurzeln der organischen Auflage am Standort OB5 in der Lüneburger Heide mikroskopisch untersucht. Nichtlineare Regression: MichaelisMenten-Beziehung: $y=(a \cdot x) /(x+b)$. Die Werte für Buche und Eiche wurden unter Mithilfe von Regina Icke ermittelt.

Die Veränderung der beiden Parameter Periderm-Zellzahl und Peridermstärke verhielt sich in Abhängigkeit vom Abstand zur Wurzelspitze analog (Abb. 4.24 A und $B$, jeweils unten). Bereits wenige $\mathrm{cm}$ hinter der Wurzelspitze war bei allen drei Arten ein mehrschichtiges Periderm ausgebildet, während in Abständen $\geq 10 \mathrm{~cm}$ zur Spitze kaum noch Veränderungen zu beobachten waren. Da hier Durchmesser bis $2.5 \mathrm{~mm}$ untersucht wurden, liegen aufgrund des hohen Durchmesserzuwachses bei Fichtenwurzeln nur Werte bis etwa $40 \mathrm{~cm}$ Abstand zur Wurzelspitze vor (s. Abb. 4.23), während 
bei der Buche ein Bereich bis $70 \mathrm{~cm}$ und bei der Eiche bis $80 \mathrm{~cm}$ untersucht wurde.

Erwartungsgemäß sind bei der Veränderung der Peridermstärke in Abhängigkeit vom Durchmesser dieselben Verhältnisse zwischen den Arten zu beobachten wie bei derjenigen in Abhängigkeit vom Durchmesser. Die Eichen- und Buchenwurzeln waren also aus deutlich mehr Zellschichten aufgebaut als die Fichtenwurzeln. Die Peridermstärke in den Wurzeln von Buche und Eiche nahm mit zunehmendem Abstand zur Wurzelspitze zunächst rasch zu. Bei Abständen $>10-20 \mathrm{~cm}$ flachte diese Zunahme deutlich ab. Bei den Fichtenwurzeln hingegen war über den gesamten untersuchten Bereich bis $40 \mathrm{~cm}$ eine kontinuierliche Zunahme der Peridermstärke zu verzeichnen.

\title{
4.3.2.3 Chemische Analyse der Periderm-Zellwände
}

Der in Kooperation mit Klaus Hartmann (Arbeitsgruppe PD Dr. Schreiber, Universität Würzburg) ermittelte Suberingehalt in den Zellwänden des Periderms der drei untersuchten Baumarten korreliert mit den Ergebnissen der anatomischen Untersuchungen (Abb. 4.25). Buchen- und Eichenwurzeln zeigten überwiegend einen signifikanten Anstieg des Suberingehalts mit dem Wurzeldurchmesser, während die Fichtenwurzeln mit $130 \mathrm{nmol} \mathrm{cm}{ }^{-2}$ in allen drei untersuchten Durchmesserklassen nahezu identische Mengen an Suberin in den Periderm-Zellwänden enthielten.
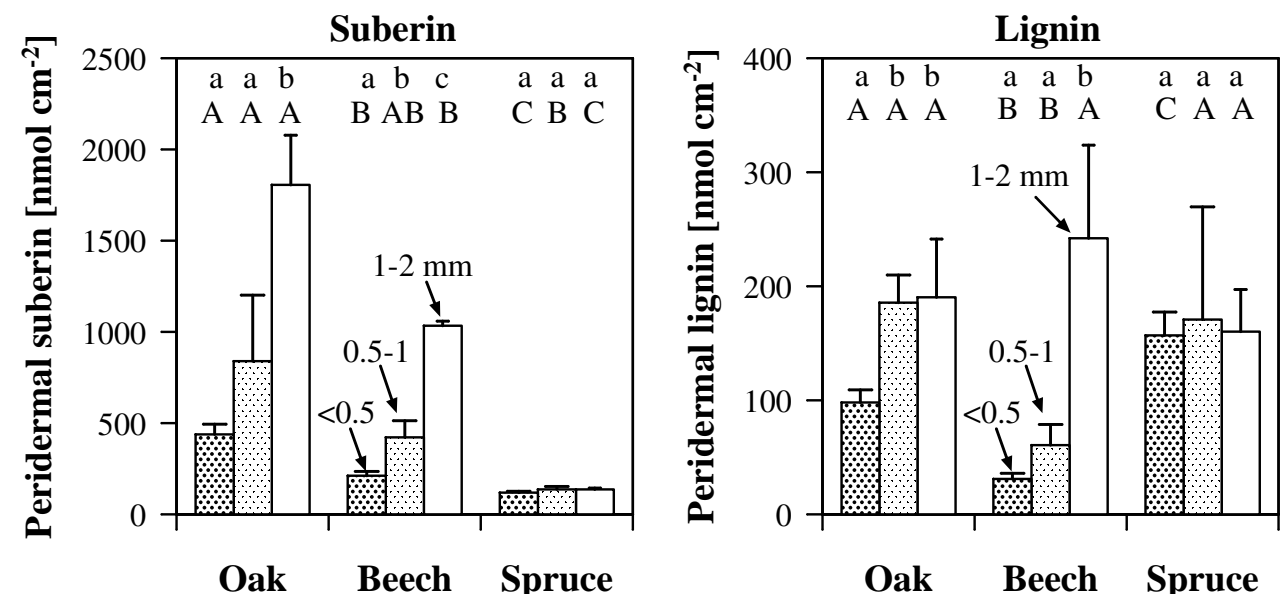

\begin{abstract}
Abb. 4.25: Oberflächenbezogene Gehalte an aliphatischem Suberin (links) und Lignin (rechts) in den Periderm-Zellwänden von Buchen-, Eichen- und Fichtenfeinwurzeln (Durchmesserklassen $<0.5,0.5-1$ und 1-2 mm, $\mathrm{n}=3$ pro Durchmesserklasse). Unterschiedliche Kleinbuchstaben bezeichnen signifikante Unterschiede zwischen den Durchmesserklassen einer Art, Großbuchstaben solche zwischen den Arten innerhalb einer Durchmesserklasse; Signifikanztest nach Scheffé $(\mathrm{p}<0.05)$. Die chemischen Analysen wurden von Dipl. Chem. Klaus Hartmann (Lehrstuhl Botanik II, Universität Würzburg) durchgeführt.
\end{abstract}

Das Periderm der Eichenwurzeln enthielt mit 438, 840 und $1806 \mathrm{nmol} \mathrm{cm}^{-2}$ in den Durchmesserklassen < 0.5, 0.5-1 und 1-2 mm die größten Mengen an aliphatischem Suberin. In den Buchenwurzeln war mit 213, 422 bzw. $1034 \mathrm{nmol} \mathrm{cm}^{-2}$ deut- 
lich weniger Suberin im Abschlußgewebe der Wurzeln enthalten. Mit Ausnahme der Buchenwurzeln mit 0.5-1 mm Durchmesser (Vergleich mit Eiche und Fichte) war der Unterschied zwischen den Arten in allen Durchmesserklassen statistisch signifikant.

Die Ligningehalte in den untersuchten Wurzeln (Abb. 4.25, rechts) wiesen im Vergleich zu den Suberingehalten einen weniger eindeutigen Trend auf. In den meisten Fällen wurde 160 - $180 \mathrm{nmol} \mathrm{cm}{ }^{-2}$ im Periderm der Wurzeln gefunden. Signifikant kleiner war der Ligningehalt mit $98 \mathrm{nmol} \mathrm{cm}^{-2}$ in den Eichenwurzeln $<0.5 \mathrm{~mm}$ und in den Buchenwurzeln der Durchmesserklasse $<0.5$ und 0.5-1 mm (31 bzw. $61 \mathrm{nmol} \mathrm{cm}^{-2}$ ). Die Buchenwurzeln mit 1-2 mm Durchmesser enthielten dagegen 242 $\mathrm{nmol} \mathrm{cm}{ }^{-2}$ Lignin. Dieser Unterschied war jedoch gegenüber den anderen Arten nicht signifikant.

\title{
4.3.3 Klimatische und edaphische Faktoren
}

Globalstrahlung und VPD Die Tagessummen der Globalstrahlung variierten, bei witterungsbedingten Schwankungen, in der Vegetationsperiode 1999 in der Lüneburger Heide zwischen 10 und $30 \mathrm{MJ} \mathrm{m}^{-2} \mathrm{~d}^{-1}$ (Abb. 4.26, vergl. auch Abb.4.11). Längere Perioden mit deutlich eingeschränkten Strahlungsflüssen unter $20 \mathrm{MJ} \mathrm{m}^{-2} \mathrm{~d}^{-1}$ waren nur Mitte August und in der zweiten Septemberhälfte zu beobachten.

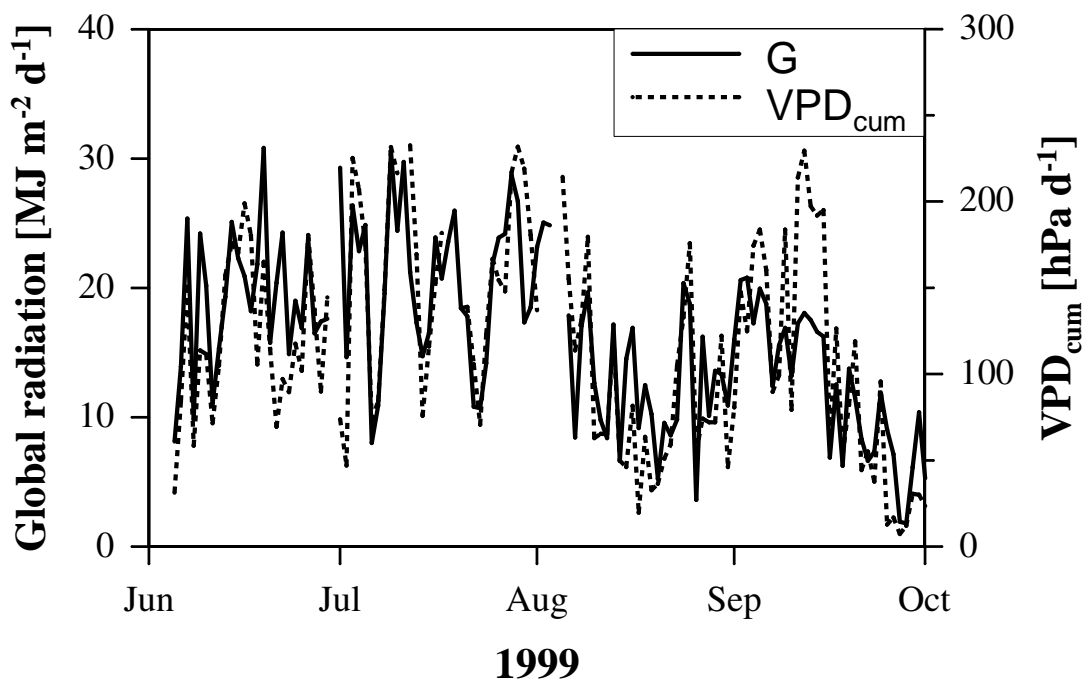

\begin{abstract}
Abb. 4.26: Zeitlicher Verlauf der Globalstrahlung $\left(\mathrm{R}_{g}\right)$ und des Wasserdampfsättigungsdefizits der Luft (VPD) oberhalb der Krone am Standort Lüneburger Heide (OB5) in der Vegetationsperiode 1999. Bei der Globalstrahlung wurden die gemessenen Strahlungsströme [ $\mathrm{W} \mathrm{m}^{-2}$ ] zu Tagessummen $\left[\mathrm{MJ} \mathrm{m}^{-2} \mathrm{~d}^{-1}\right.$ ] aufsummiert. Der Wert für $\mathrm{VPD}_{\text {cum }}$ stellt die Tageshellphasensumme der Stundenwerte des Wassersättigungsdefizits dar.
\end{abstract}

Gleichsinnig zur Strahlung schwankten die Werte des kumulativen Wassersättigungsdefizites zwischen etwa 50 und $230 \mathrm{hPa} \mathrm{d}^{-1}$. Auch hier wurden Mitte August und Ende September über mehrere Tage niedrige Werte aufgezeichnet. Allgemein ist 
gegenüber dem Vorjahr (dort Daten ab dem 16.6.1998) zu beobachten, daß die Werte der Globalstrahlung und des Sättigungsdefizites im trocken-warmen Jahr 1999 deutlich höher lagen.

Bodenwassergehalt Der mittels time-domain reflectometry (TDR) an einer Bodenstation in der Nähe der Meßbäume aufgezeichnete volumetrische Bodenwassergehalt läßt deutliche Unterschiede zwischen den drei untersuchten Bodentiefen erkennen (Abb. 4.27). Die höchsten Werte waren immer im Oberboden $(5 \mathrm{~cm}) \mathrm{zu}$ finden, während in $60 \mathrm{~cm}$ Tiefe der volumetrische Wassergehalt stets am niedrigsten war. Dieses Verhältnis war bereits zu Beginn der Meßperiode Mitte April zu beobachten, obwohl das gesamte Profil vom kühlen und niederschlagsreichen Winter her noch wassergesättigt gewesen sein dürfte, und setzte sich über den gesamten Untersuchungszeitraum bis Ende September fort.
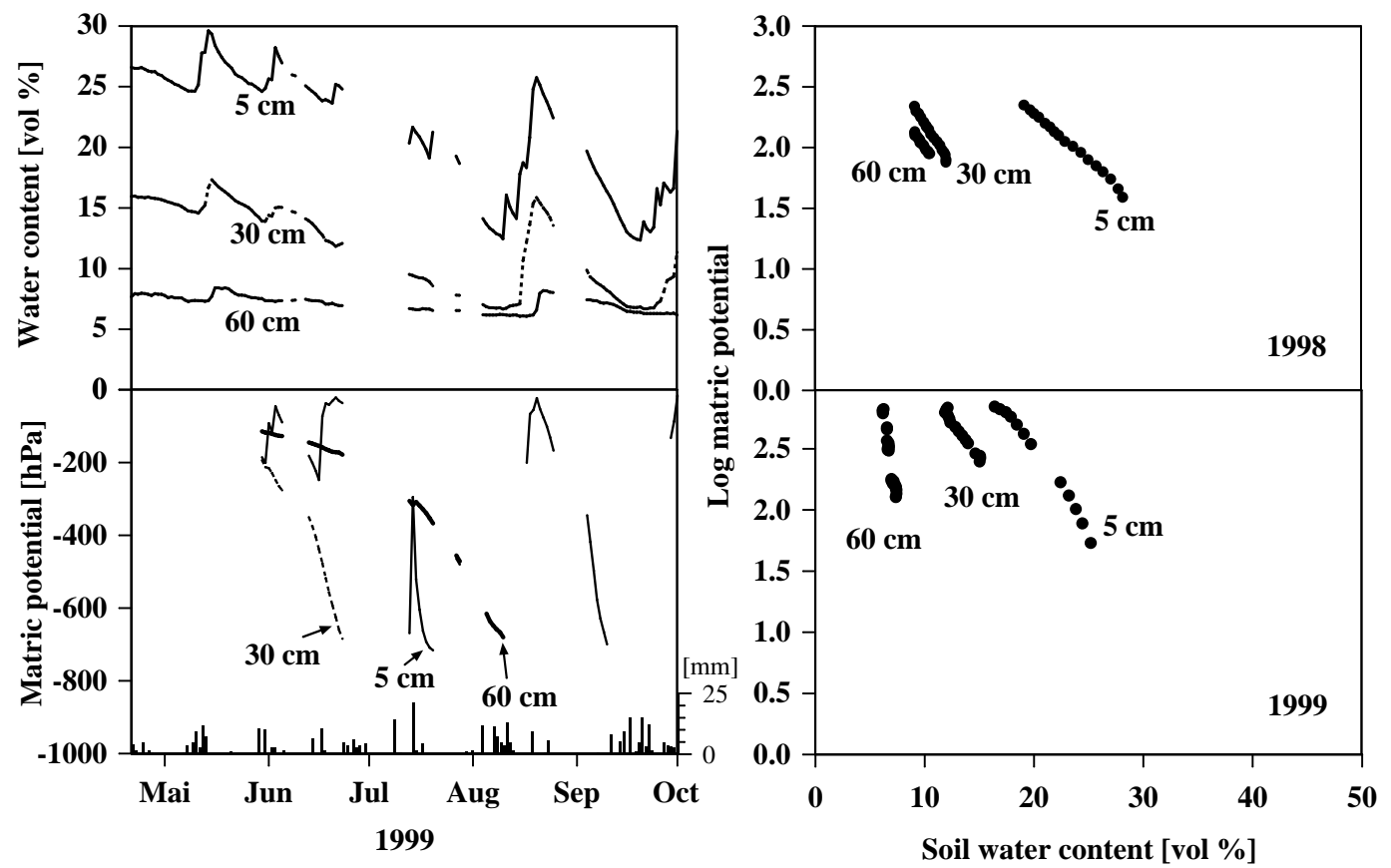

Abb. 4.27: Bodenfeuchteparameter in verschiedenen Tiefen des Mineralbodens am Standort OB5, Lüneburger Heide, in der Vegetationsperiode 1999. Links: Volumetrischer Bodenwassergehalt (2 tdr-Sonden je Tiefe), Bodenmatrixpotential (3-4 Druckaufnehmertensiometern je Tiefe) und tägliche Niederschlagssummen (DWD-Klimastation Unterlüß). Rechts: Feld-pFKurven, basierend auf den Bodenwassergehalten und -matrixpotentialen. Zum Ausschluß von Hystereseffekten bei der Tensiometermessung wurden je Kurve nur Daten aus 1-3 Desorptionsphasen verwendet. Zum Vergleich sind oben die pF-Kurven von 1998 dargestellt.

Die größten absoluten Schwankungen durch Trockenperioden und Niederschlagsereignisse traten in $5 \mathrm{~cm}$ Bodentiefe auf. Hier enthielt der Boden im Frühling 25-30 vol\% Wasser und trocknete, unterbrochen durch einzelne Niederschlagsereignisse, bis $<15$ 
vol\% Anfang August aus. Nachfolgende heftige Niederschläge führten Mitte August zu einer fast vollständigen Wiederaufsättigung, gefolgt von einer zweiten starken Austrocknung, die Mitte September wiederum zu Werten von etwa 15 vol\% führte. Dieser Verlauf war mit jeweils deutlich kleinerer Amplitude auch in $30 \mathrm{~cm}(7-18 \mathrm{vol} \%)$ und in $60 \mathrm{~cm}(6-9 \mathrm{vol} \%)$ Bodentiefe zu beobachten.

Bemerkenswert ist weiterhin, daß sich Änderungen im Bodenwassergehalt mit deutlicher zeitlicher Verzögerung im Profil abwärts fortpflanzen. So stieg am Ende der ersten langen Trockenperiode der Wassergehalt im Oberboden am 11. August wieder leicht an. Dies war in $30 \mathrm{~cm}$ Tiefe verzögert um 5 Tage am 16. August und in $60 \mathrm{~cm}$ erst am 20. August (nach 9 Tagen) zu beobachten.

Bodenmatrixpotential Die Bodenmatrixpotentiale in diesem trocken-warmen Sommer waren geprägt von Datenausfällen durch Überschreiten des Meßbereichs der Tensiometer. So war in $30 \mathrm{~cm}$ Bodentiefe im Verlauf der ersten Junihälfte ein Absinken von -200 hPa auf $-700 \mathrm{hPa}$ zu beobachten. Nach diesem Termin stehen aufgrund der andauernden Trockenheit keine Daten mehr für diesen Horizont zur Verfügung.

In $60 \mathrm{~cm}$ Tiefe sank die Bodensaugspannung ebenfalls auf -700 hPa ab. Dies vollzog sich hier allerdings über den deutlich längeren Zeitraum von Anfang Juni bis zum 10. August. Für den Oberboden $(5 \mathrm{~cm})$ stehen für mehrere kurze Zeitspannen Werte $>-200 \mathrm{hPa}$ zur Verfügung, sowie je eine Desorptionsphase in der Trockenperiode im Juli und im September.

Feld-pF-Kurven Anhand mehrerer Desorptionsphasen wurden für die drei untersuchten Horizonte Feld-pF-Kurven berechnet (Abb. 4.27 unten). Im Oberboden steigt bei einer Austrocknung des Bodens von 25 auf 15 vol\% der pF-Wert von 1.6 auf 2.9 an, was Potentialen von -50 bzw. $-800 \mathrm{hPa}$ entspricht. In $30 \mathrm{~cm}$ Tiefe wird ein Bereich von 12-15 vol\% abgedeckt. In diesem schmalen Bereich ist ein Anstieg von pF 2.4 auf $2.9 \mathrm{zu}$ beobachten. Noch steiler verläuft die Steigung in $60 \mathrm{~cm}$ Tiefe: Hier ist innerhalb von einem vol\% (6-7 vol\%) ein Anstieg von pF 2.5 auf pF 2.8 zu beobachten.

Der Vergleich der Feld-pF-Kurven aus den Jahren 1998 und 1999 ergibt eine erstaunlich gute Übereinstimmung für die Tiefen 5 und $60 \mathrm{~cm}$, obwohl in den beiden zugrundeliegenden Zeiträumen an unterschiedlichen Stellen im Bestand gemessen wurde (Abb.4.27). Die pF-Kurven aus 1999 setzen recht gut die Ergebnisse des kühl-feuchten Jahres 1998 für trockenere Verhältnisse mit höheren $\mathrm{pF}$-Werten fort.

In $30 \mathrm{~cm}$ Tiefe bestand hingegen ein deutlicher Unterschied zwischen den beiden Jahren. Hier wurden 1998 wesentlich kleinere Werte für den Bodenwassergehalt (1998: 9-12 vol\%, 1999: 12-15 vol\%) gemessen. Dadurch ist die pF-Kurve hier stark in Richtung trockenerem Boden verschoben und liegt nahe der Kurve für $60 \mathrm{~cm}$. Die Steigung der beiden Kurven aus 1998 und 1999 für $30 \mathrm{~cm}$ ist jedoch recht ähnlich. 


\subsubsection{Stammsaftflußrate}

Bei allen mit der Stammsaftflußmethode untersuchten Bäumen handelte es sich um Altbäume, deren Kronen bis in das geschlossene Kronendach des Bestandes hineinreichten, wie anhand der einheitlichen Höhe von etwa $30 \mathrm{~m}$ zu erkennen ist (Tab. 4.3). Die Kronenprojektionsfläche der Eichen (Ei3: $118 \mathrm{~m}^{2}$ ) war etwas größer als diejenige der Buchen (59-97 m²), während die beiden untersuchten Fichten mit 28 bzw. 42 m$^{2}$ eine wesentlich kleinere Krone besaßen. Der Brusthöhendurchmesser betrug jeweils etwa $40 \mathrm{~cm}$, nur die beiden Eichen Ei1 und Ei3 hatten mit etwa $60 \mathrm{~cm}$ einen dickeren Stamm.

Tabelle 4.3: Biometrische Daten der mit der Stammsaftflußmethode untersuchten Bäume. Die in Zeilen dargestellten Parameter sind $\mathbf{h}$ : Gesamthöhe des Baumes [m], $\mathbf{h}_{c}$ : Kronenansatzhöhe [m], $\mathbf{A}_{c}$ : Kronenprojektionsfläche [ $\left.\mathrm{m}^{2}\right]$, BHD: Brusthöhendurchmesser [cm], Age: geschätztes Alter [Jahre], $\mathbf{C}_{w}$ : Holzumfang am Meßpunkt in ca. $2 \mathrm{~m}$ Höhe $[\mathrm{cm}], \mathbf{A}_{w}$ : Holzfläche $\left[\mathrm{cm}^{2}\right]$, $\mathbf{T}_{s w}$ : Splintholzdicke [cm], $\mathbf{A}_{s w}$ : Splintholzfläche $\left[\mathrm{cm}^{2}\right]$. Die Splintholzdicke bzw. -fläche wurde aus Tabellen (Fa. EMS, Brünn) anhand des Baumalters und des BHD abgeschätzt.

\begin{tabular}{l|ccc|ccc|cc} 
& Beech1 & Beech2 & Beech3 & Oak1 & Oak2 & Oak3 & Spruce1 & Spruce2 \\
\hline $\mathrm{h}$ & 29 & 30 & 33.5 & 27 & 27 & 29 & 27 & 29 \\
$\mathrm{~h}_{c}$ & 10 & 14 & 15 & 11 & 10 & 14.5 & 10 & 15 \\
$\mathrm{~A}_{c}$ & 96.64 & 76.71 & 58.81 & 107.7 & 72.83 & 118.88 & 28.17 & 41.95 \\
$\mathrm{BHD}$ & 49 & 41.38 & 36.3 & 60.16 & 45.52 & 62.4 & 44.56 & 45.2 \\
Age & 100 & 100 & 100 & 200 & 200 & 200 & 80 & 80 \\
\hline $\mathrm{C}_{w}$ & 139.72 & 120.23 & 108.37 & 174.72 & 136.72 & 183.43 & 109.46 & 122.35 \\
$\mathrm{~A}_{w}$ & 1553.49 & 1150.31 & 934.6 & 2429.26 & 1487.5 & 2677.5 & 953.53 & 1191.2 \\
$\mathrm{~T}_{s w}$ & 4.7 & 4.2 & 4.2 & 1.8 & 1.7 & 1.8 & 4.7 & 4.7 \\
$\mathrm{~A}_{s w}$ & 587.29 & 449.55 & 399.77 & 304.31 & 223.35 & 319.99 & 445.14 & 505.61
\end{tabular}

Der untere Teil von Tab. 4.3 enthält die Parameter, die für die Installation der Saftflußanlagen am Stamm und für die Interpretation der gemessenen Daten relevant sind. Hier fällt vor allem die holzanatomisch bedingte geringe Splintholzdicke der Eichen auf $(<2 \mathrm{~cm}$ gegenüber $>4 \mathrm{~cm}$ bei Buche und Fichte). Trotz des größeren Stammumfangs ergibt sich daher für die Eichen Ei1 und Ei3 eine Splintholzfläche von etwa $300 \mathrm{~cm}^{2}$ (Ei2 nur $223 \mathrm{~cm}^{2}$ ) gegenüber 400 bis über $500 \mathrm{~cm}^{2}$ bei Buche und Fichte. Allerdings handelt es sich bei diesen Angaben um Schätzungen, die anhand von mit dem Saftflußsystem mitgelieferten Tabellen aus dem BHD und dem Alter berechnet wurden.

Die witterungsbedingte Variation der Saftflußrate im Stamm verhielt sich in den jeweils 2 bzw. 3 untersuchten Bäume einer Art zeitlich synchron (Abb.4.28). Die auf den hydroaktiven Teil des Xylems bezogene Stammsaftflußrate lag bei den Bäumen einer Art in derselben Größenordnung. Aus technischen Gründen (z.B. mangelhafte Solarstromversorgung in Regenperioden) konnten nicht immer alle Anlagen an den Meß- 


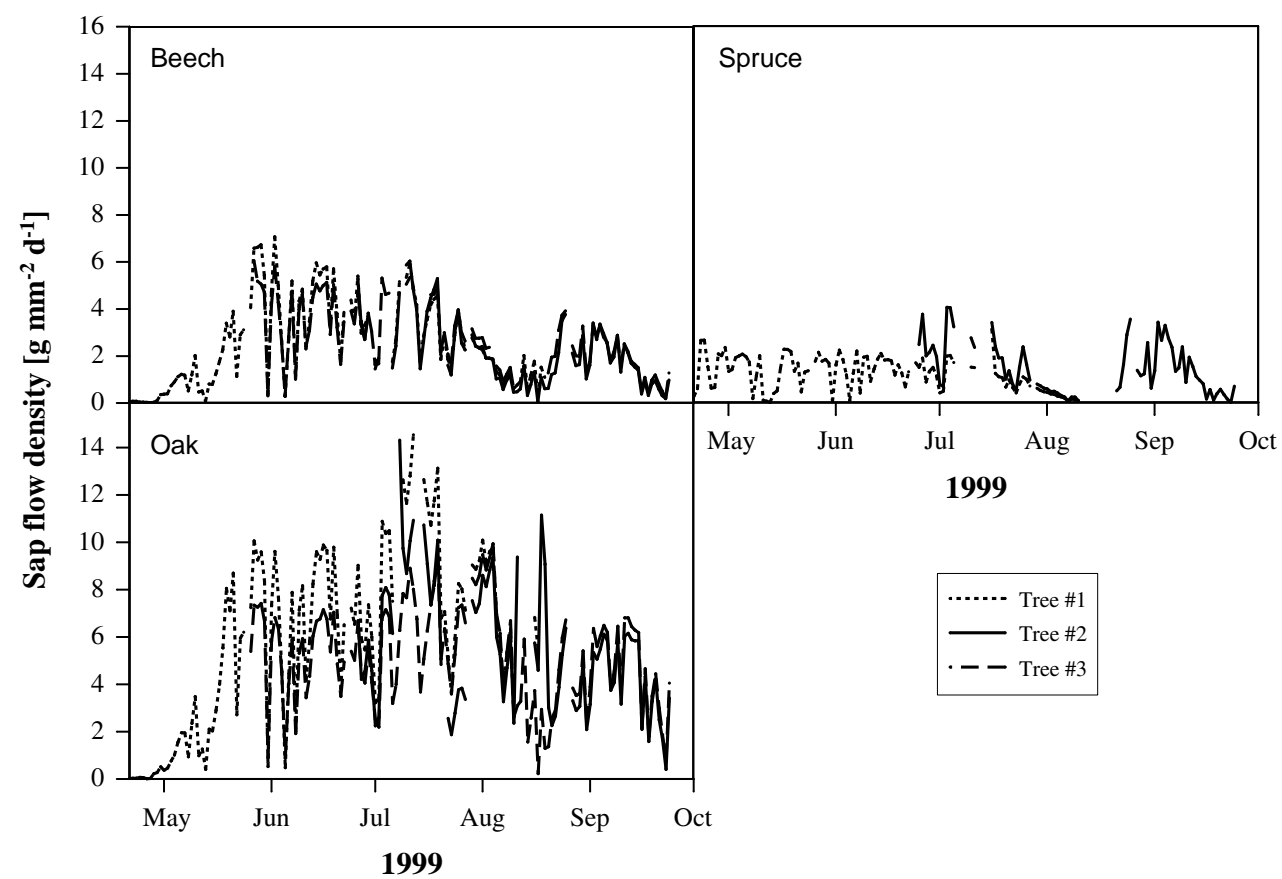

Abb. 4.28: Tageswerte der Saftflußdichte im Stamm der Meßbäume in der Vegetationsperiode 1999 gemessen mit der heat-balance Methode nach Cermak et al. (1973) auf der Untersuchungsfläche OB5 in der Lüneburger Heide.

bäumen parallel betrieben werden, jedoch ergibt sich aus den überlappenden Zeitreihen für jede Baumart ein charakteristisches Bild der Transpiration im Jahresgang: Bei Buche und Eiche setzte Ende April mit beginnendem Laubaustrieb die Transpiration ein. Anfang Juni wurde, abgesehen von witterungsbedingten Schwankungen, ein Plateau erreichet, das etwa bis Ende Juli gehalten wurde. Bei der Eiche lag die Flußdichte in dieser Periode mit ca. $8 \mathrm{~g} \mathrm{~mm}^{-2} \mathrm{~d}^{-1}$ deutlich höher als bei der Buche mit $4 \mathrm{~g} \mathrm{~mm}^{-2} \mathrm{~d}^{-1}$. Die Fichte als immergrüne Baumart hatte bereits Mitte April einen relativ konstanten Wert der Transpiration erreicht, der mit $2 \mathrm{~g} \mathrm{~mm}^{-2} \mathrm{~d}^{-1}$ wiederum deutlich niedriger lag als bei der Buche.

Während der Trockenperiode Juli/August (s. Abb 4.27) kam es bei Buche und Fichte zu einer deutlichen Einschränkung der Transpiration. Bei der Eiche hingegen stieg die Stammsaftflußrate bei allen drei untersuchten Bäumen bis zum 4. August an; erst danach kam es auch hier zu einer Transpirationseinschränkung. Nach Wiederbefeuchtung des Bodens in der zweiten Augusthälfte erholte sich bei den drei untersuchten Baumarten die Transpiration wieder auf die vorher gemessenen Werte und sank dann im Laufe des Septembers wieder ab. Dieses herbstliche Absinken kann bei Buche und Eiche mit der einsetzenden Seneszenz der Blätter erklärt werden, was bei der Fichte jedoch nicht der Fall ist. Allerdings kam es auch während dieser Zeit zu einer ähnlich starken Bodenaustrocknung wie im August.

Für den Zeitraum vom 22.7. bis 10.8.1999 liegen bei den 3 Baumarten parallel ge- 
messene Werte für jeweils alle untersuchten Meßbäume vor (Abb.4.29). Die über diese 20 Tage gemittelten Werte der Saftflußdichte spiegeln die Transpirationseinschränkung bei der Buche (etwa $2 \mathrm{~g} \mathrm{~mm}^{-2} \mathrm{~d}^{-1}$ bei allen 3 Meßbäumen) und bei der Fichte $\left(0.6 \mathrm{~g} \mathrm{~mm}^{-2} \mathrm{~d}^{-1}\right)$ wider. Die mittlere Saftflußdichte war in diesem Zeitraum in den Eichen wesentlich höher, wobei die Werte der Meßbäume Nr. 1 und 3 mit 6.9 und $6.6 \mathrm{~g} \mathrm{~mm}^{-2} \mathrm{~d}^{-1}$ etwas höher lagen als in Eiche Nr. $2\left(5.2 \mathrm{~g} \mathrm{~mm}^{-2} \mathrm{~d}^{-1}\right)$.
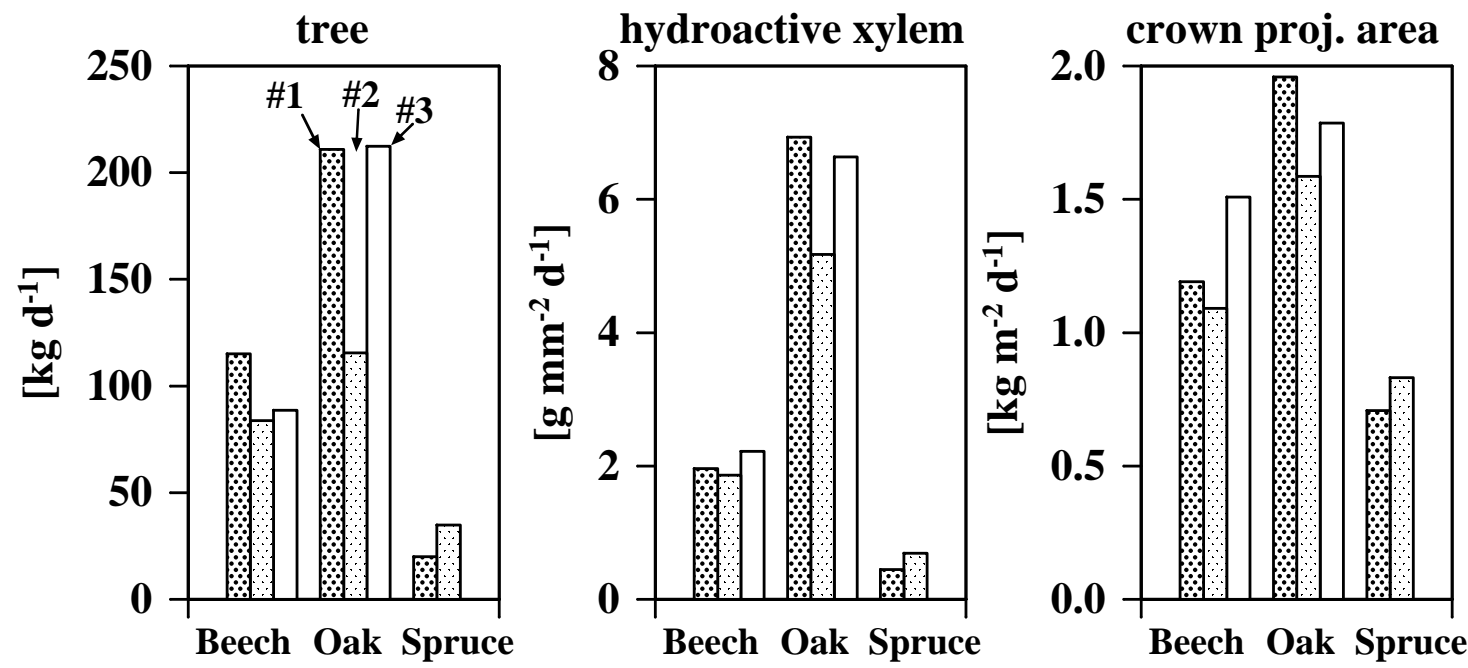

Abb. 4.29: Tageswerte des Stammsaftflusses von Buche, Eiche und Fichte, gemittelt über den Zeitraum 22.7 bis 10.8.1999, gemessen mit der heat-balance Methode nach Cermak et al. (1973) auf der Untersuchungsfläche OB5 in der Lüneburger Heide. Dargestellt ist die Saftflußrate der Meßbäume als Flußrate pro Baum (links), bezogen auf den Splintholzanteil (Saftflußdichte, Mitte) und bezogen auf die Kronenprojektionsfläche (rechts).

Diese Relationen zwischen den Meßbäumen sind auch bei der Saftflußrate pro Baum und bei Bezug auf die Kronenprojektionsfläche zu erkennen (Abb. 4.29 links bzw. rechts). Im Stamm von Eiche Nr. 1 und 3 wurden $220 \mathrm{~kg} \mathrm{~d}^{-1}$ gemessen. Dagegen lag die zweite untersuchte Eiche mit $110 \mathrm{~kg} \mathrm{~d}^{-1}$ auf dem Niveau der Buchen. Die Fichten erreichten nur etwa $20 \mathrm{~kg} \mathrm{~d}^{-1}$, also nur $10 \%$ der in den Eichen $\mathrm{Nr} .1$ und 2 gemessenen Saftflußrate.

Durch den Bezug der Stammsaftflußrate auf die Kronenprojektionsfläche werden die Unterschiede zwischen den Arten etwa geringer. Hier entspricht die Differenz zwischen Eiche und Fichte nur noch dem Verhältnis 2.5:1 (Eiche $1.8 \mathrm{~kg} \mathrm{~m}^{-2} \mathrm{~d}^{-1}$ gegenüber $0.7 \mathrm{~kg} \mathrm{~m}^{-2} \mathrm{~d}^{-1}$ bei der Fichte). Auch unterscheiden sich die drei Meßbäume der Eiche bei dieser Bezugsgröße nicht so stark voneinander. Die Buchen Nr. 1 und 2 verhalten sich mit $1.2 \mathrm{~kg} \mathrm{~m}^{-2} \mathrm{~d}^{-1}$ intermediär. Buche Nr. 3 hingegen weist ähnlich hohe Werte auf wie die Eichen $\left(1.5 \mathrm{~kg} \mathrm{~m}^{-2} \mathrm{~d}^{-1}\right)$. 


\subsubsection{Wasseraufnahme durch die Wurzeln}

\subsubsection{Saftfluß und Witterung im Tagesverlauf}

Der Verlauf der Saftflußrate in Wurzel und Stamm ist im Tagesgang bei den drei untersuchten Baumarten jeweils sehr ähnlich (Abb. 4.30). Dabei ist während der Hellphase eine weitgehende Korrelation mit den Änderungen der Globalstrahlung zu erkennen. So war am 7. August 1999 ein Anstieg der Strahlung bis auf $500 \mathrm{~W} \mathrm{~m}^{-2}$ zu verzeichnen, dem für den Rest des Tages ein stetiger Abfall des Strahlungsflusses bis zur Abenddämmerung folgte. Dieser Tagesgang ist in ähnlicher Form sowohl im Stamm als auch in den Wurzeln von Buche, Eiche und Fichte zu beobachten. Dagegen wirkte sich das kurzeitige Absinken der Strahlung zur Mittagszeit des 9. August nicht sichtbar auf die Saftflußrate aus.

Der Einfluß des Sättigungsdefizits der Atmosphäre auf den Saftfluß ist anhand unterschiedlicher Nachtwerte zu erkennen: In der Nacht vom 6. auf den 7. August war die Luft recht trocken; erst gegen Sonnenaufgang wurde das Minimum von etwa $3 \mathrm{hPa}$ erreicht. Dies bewirkte im Stamm aller 3 Baumarten ein deutliches Nachklingen des Saftflusses ebenfalls bis hin zum Morgengrauen. Auch in den Wurzeln von Buche und Fichte zeichneten sich deutliche Nachtsaftflußraten ab. In der folgenden Nacht (7.8.8.) war dagegen die Luft etwa 10 Stunden lang nahezu wasserdampfgesättigt (VPD $<1 \mathrm{hPa}$ ). In dieser Zeit wurde auch im Stamm und in den Wurzeln kein nennenswerter Saftfluß gemessen.

Bei den Wurzeln fällt vor allem das besondere Verhalten der Eichenwurzeln auf. Besonders in der organischen Auflage, aber auch im Mineralboden sank die Saftflußrate in der jeweiligen Wurzel gegen Abend deutlich früher ab als in den Buchen- und Fichtenwurzeln. Der morgendliche Anstieg verlief bei allen 3 Baumarten fast synchron.

Zeitliche Unterschiede zwischen charakteristischen Änderungen in Strahlung und Stamm- bzw. Wurzelsaftfluß sind aufgrund der langen Aufzeichnungsintervalle (Klima: 30 min, Saftfluß: 15 min) in Abb. 4.30 kaum zu erkennen. Am 6. Juli 2000 dagegen wurde an einer Buche in Abständen von 1 min die Flußrate im Stamm sowie in einer Wurzel und einem Zweig über einen Zeitraum von 7 Stunden aufgezeichnet (Abb. 4.31). Die querschnittsbezogene Saftflußdichte war während des Nachmittags mit bis zu $0.15 \mathrm{~g} \mathrm{~mm}^{-2} \mathrm{~h}^{-1}$ im Zweig am höchsten. Hier war auch die größte Fluktuation der Werte im zeitlichen Verlauf zu beobachten. Im Stamm wurden maximal $0.05 \mathrm{~g} \mathrm{~mm}^{-2} \mathrm{~h}^{-1}$ und in der Wurzel nur bis zu $0.025 \mathrm{~g} \mathrm{~mm}^{-2} \mathrm{~h}^{-1}$ gemessen, wobei die Schwankungen in diesen kronenfernen Baumkompartimenten eine deutlich abgeschwächte Amplitude zeigten.

Bei dieser hohen zeitlichen Auflösung war deutlich zu erkennen, daß herausragende Extremwerte der Strahlung (in diesem Experiment wurde die PAR- statt der Globalstrahlung gemessen) mit einer Verzögerung von 5 min im Sättigungsdefizit der Atmosphäre sowie im Saftfluß des Zweiges sichtbar wurden. Wiederum mit jeweils 5 min Versatz pflanzte sich ein solches Signal bis in den Stammsaftfluß und in den 


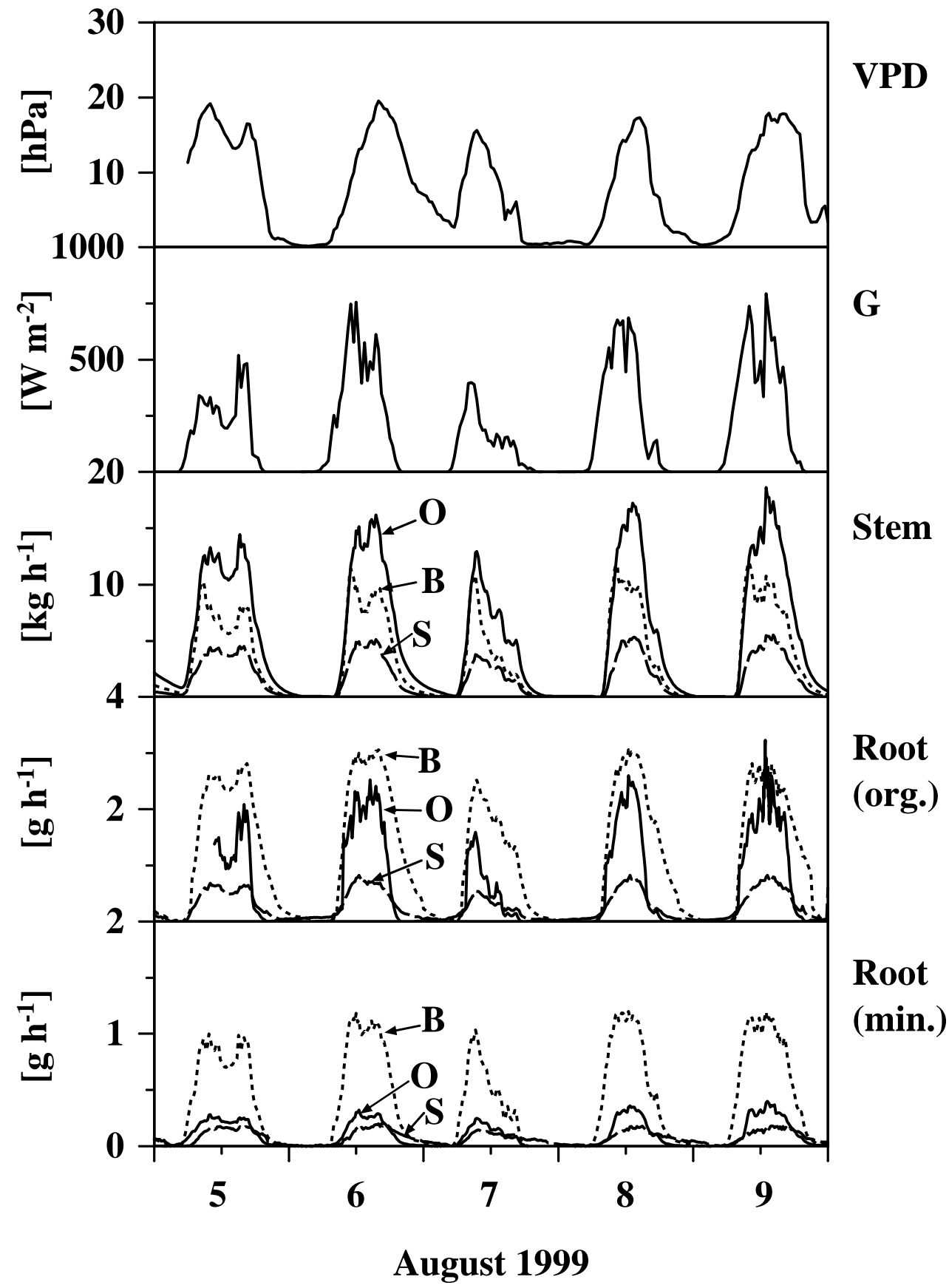

Abb. 4.30: Tagesgänge des Sättigungsdefizites (VPD), der Globalstrahlung (G) und der Saftflußrate in Stamm, und jeweils einer Wurzel aus der organischen Auflage bzw. dem Mineralboden. Dargestellt sind jeweils Messungen an Buche $(\mathbf{B})$, Eiche $(\mathbf{O})$ und Fichte $(\mathbf{S})$ für den Zeitraum 5.8.-9.8.1999 am Standort OB5 in der Lüneburger Heide. VPD und G: 30-min Mittelwerte, gemessen oberhalb des Kronenraums; Stammsaftfluß: 15-min Mittelwerte, gemessen mit der Heat-balance Methode nach Cermak et al. (1973); Wurzelsaftfluß: 15-min Mitelwerte, gemessen mit Miniatursaftflußsystemen. 
Wurzelsaftfluß fort. Peaks im Saftfluß eines Sonnenkronenzweiges und einer peripheren Schwachwurzel lagen also rund 10 min auseinander. In der ersten Hälfte des Nachmittags wies die PAR-Strahlung aufgrund durchziehender Wolkenfelder nur geringe kurzfristige Schwankungen auf, so daß innerhalb von 3 Stunden nur 4 Spitzenwerte auftraten, die sich mit abnehmender Deutlichkeit ebenfalls in der Saftflußdichte in Zweig, Stamm und Wurzel abzeichneten. Ab 15 Uhr dagegen war der Himmel wolkenfrei, was zu kurzfristigen Schwankungen der Strahlung (5-10 min) mit weitaus geringerer Amplitude führte. Diese Änderungen erschienen im Saftfluß des Zweiges nur noch mit einer Frequenz von 20-30 min und waren in der Wurzel nur noch undeutlich, im Stamm dagegen nicht mehr zu erkennen.

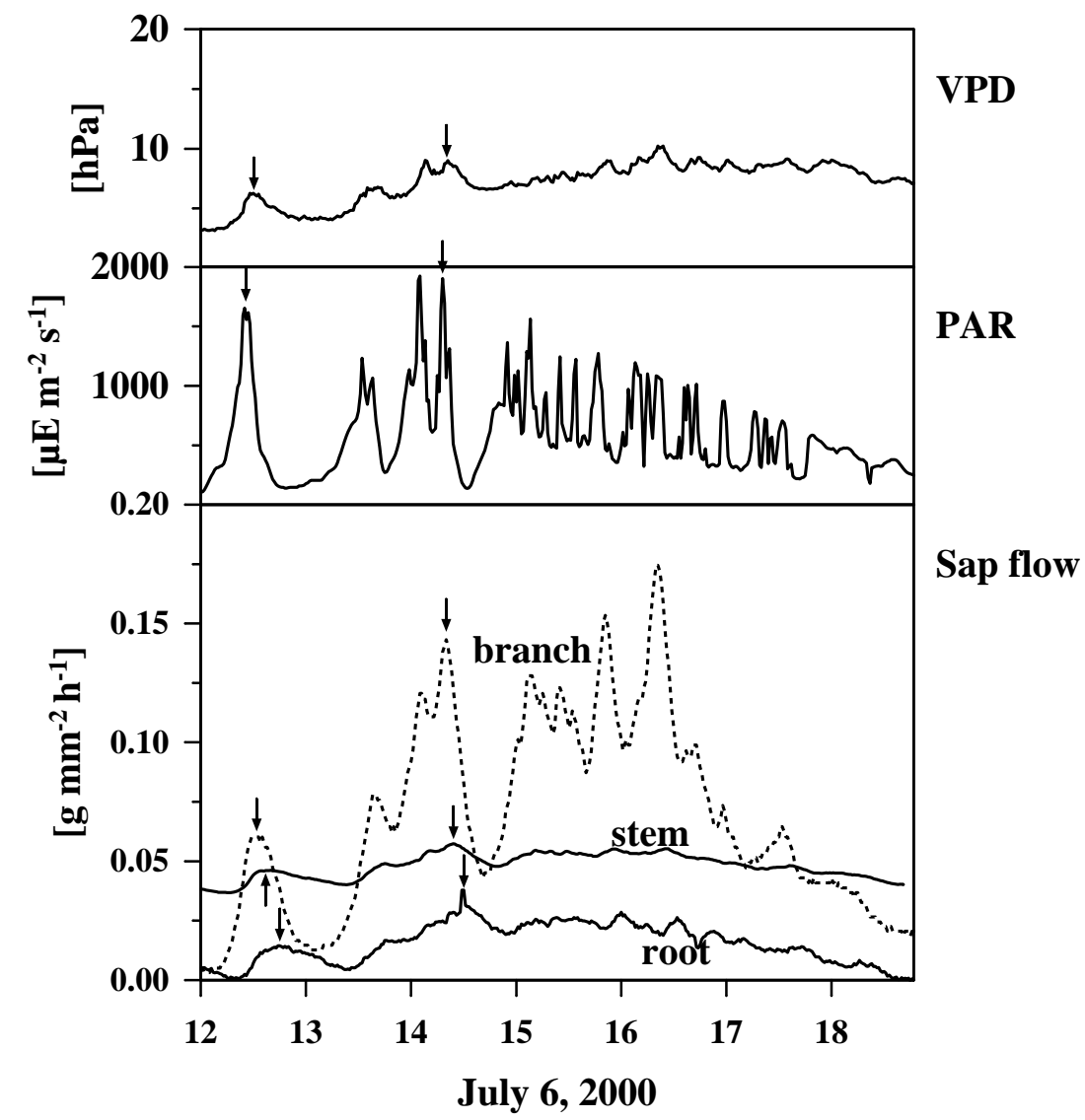

Abb. 4.31: Zeitlicher Verlauf des Sättigungsdefizites (VPD), der PAR-Strahlung und der Saftflußdichte in einem Zweig $(\mathrm{d}=4 \mathrm{~mm})$, im Stamm, und einer Wurzel $(\mathrm{d}=4 \mathrm{~mm})$ einer Buche am Standort OB5 in der Lüneburger Heide. Alle Daten wurden am 6.7.2000 mit einem gemeinsamen Datenlogger in Intervallen von 1 min aufgezeichnet. VPD und PAR: gemessen oberhalb des Kronenraums; Stammsaftfluß: Heat-balance Methode mit radialen Sensoren nach Cermak \& Nadezhdina (1998); Zweig- und Wurzelsaftfluß: Miniatursaftflußsysteme. 


\subsubsection{Wasseraufnahme im Verlauf der Vegetationsperiode 1999}

Querschnittsbezogene Saftflußraten (Saftflußdichten) Die Wurzel-Saftflußdichten wiesen generell ein große Variation zwischen den einzelnen Wurzelsträngen einer Art auf (Abb. 4.32). Recht einheitlich verhielten sich dagegen die Wurzeln aller Arten bezüglich der relativen Änderung der Saftflußdichte an verschiedenen Tagen. Dies deutet darauf hin, daß alle Wurzeln auf tägliche Änderungen des Bestandesklimas und damit der Transpiration aus der Baumkrone gleichsinnig reagieren.

Die Buchenwurzeln Nr. 2-4 der organischen Auflage (Abb. 4.33 linke Seite) zeigten im Verlauf der ersten Meßperiode einen kontinuierlichen Anstieg der Saftflußdichten von etwa $5 \mathrm{~g} \mathrm{~mm}^{-2} \mathrm{~d}^{-1}$ Anfang Juni auf $10-15 \mathrm{~g} \mathrm{~mm}^{-2} \mathrm{~d}^{-1}$ Mitte Juli, während Wurzel Nr. 1 in diesem Zeitraum immer wieder Werte von $10-20 \mathrm{~g} \mathrm{~mm}^{-2} \mathrm{~d}^{-1}$ erreichte. Ein ähnlicher Anstieg in derselben Größenordnung war in diesem Zeitraum bei der Eiche zu beobachten. Bei der Fichte erreichten einzelne Wurzeln (Nr. 3 und 4) an einigen Tagen Saftflußdichten über $40 \mathrm{~g} \mathrm{~mm}^{-2} \mathrm{~d}^{-1}$. Ein saisonaler Anstieg war hier nicht zu erkennen.

Im weiteren Verlauf der Vegetationsperiode war bei den Buchenwurzeln der organischen Auflage eine deutliche Abnahme der Saftflußdichten während der Trockenperiode Ende Juli bis Anfang August zu beobachten (vergl. Abb. 4.27). Dabei sanken die Werte Anfang August unter $5 \mathrm{~g} \mathrm{~mm}^{-2} \mathrm{~d}^{-1}$ ab. Nach einigen starken Regenfällen Mitte August stiegen die Flußraten wieder auf etwa $10 \mathrm{~g} \mathrm{~mm}^{-2} \mathrm{~d}^{-1}$ an.

Dieses zeitliche Muster war ebenfalls bei Eiche und Fichte zu beobachten, wobei die Flußrate in den Eichenwurzeln während der Trockenperiode deutlich stärker absank und sich anschließend auch nur auf Werte um $5 \mathrm{~g} \mathrm{~mm}^{-2} \mathrm{~d}^{-1}$ erholte. Bei den Fichtenwurzeln liegen aus technischen Gründen nur Daten für das Ende der Trockenperiode vor, die allerdings auch hier unter $5 \mathrm{~g} \mathrm{~mm}^{-2} \mathrm{~d}^{-1}$ lagen, während Anfang September wieder bis zu $20 \mathrm{~g} \mathrm{~mm}^{-2} \mathrm{~d}^{-1}$ erreicht wurden. Für die Fichte konnte ein weiteres Absinken der Wasseraufnahmeraten im Lauf des Septembers, wiederum als Folge einer niederschlagsarmen Periode, beobachtet werden. Hier liegen für Buche und Eiche keine Daten vor.

Im Mineralboden lagen die gemessenen Flußdichten aller 3 Baumarten deutlich niedriger (Abb. 4.32, rechts), so daß der Wertebereich der Ordinate um den Faktor 5 kleiner ist als bei den Wurzeln der organischen Auflage auf der linken Seite.

Allgemein sind bei den Tiefenwurzeln dieselben Tendenzen im zeitlichen Verlauf zu erkennen: Die höchsten Flußdichten wurden im Juni und Anfang September erreicht, während Anfang August die Wasseraufnahme bei allen drei Arten durch die fortschreitende Bodenaustrocknung deutlich gehemmt war. Nur bei den Eichenwurzeln waren auch in der ersten Meßperiode im Juni und Juli ähnlich geringe Flußdichten zu verzeichnen wie Anfang August. Bei allen drei Arten sank die Flußdichte im September ab.

Das Verhältnis der drei Arten untereinander war bei den Wurzeln der organischen Auflage und des Mineralbodens gleich: Die höchsten Flußdichten wurden bei der Fichte, die niedrigsten bei der Eiche aufgezeichnet. 

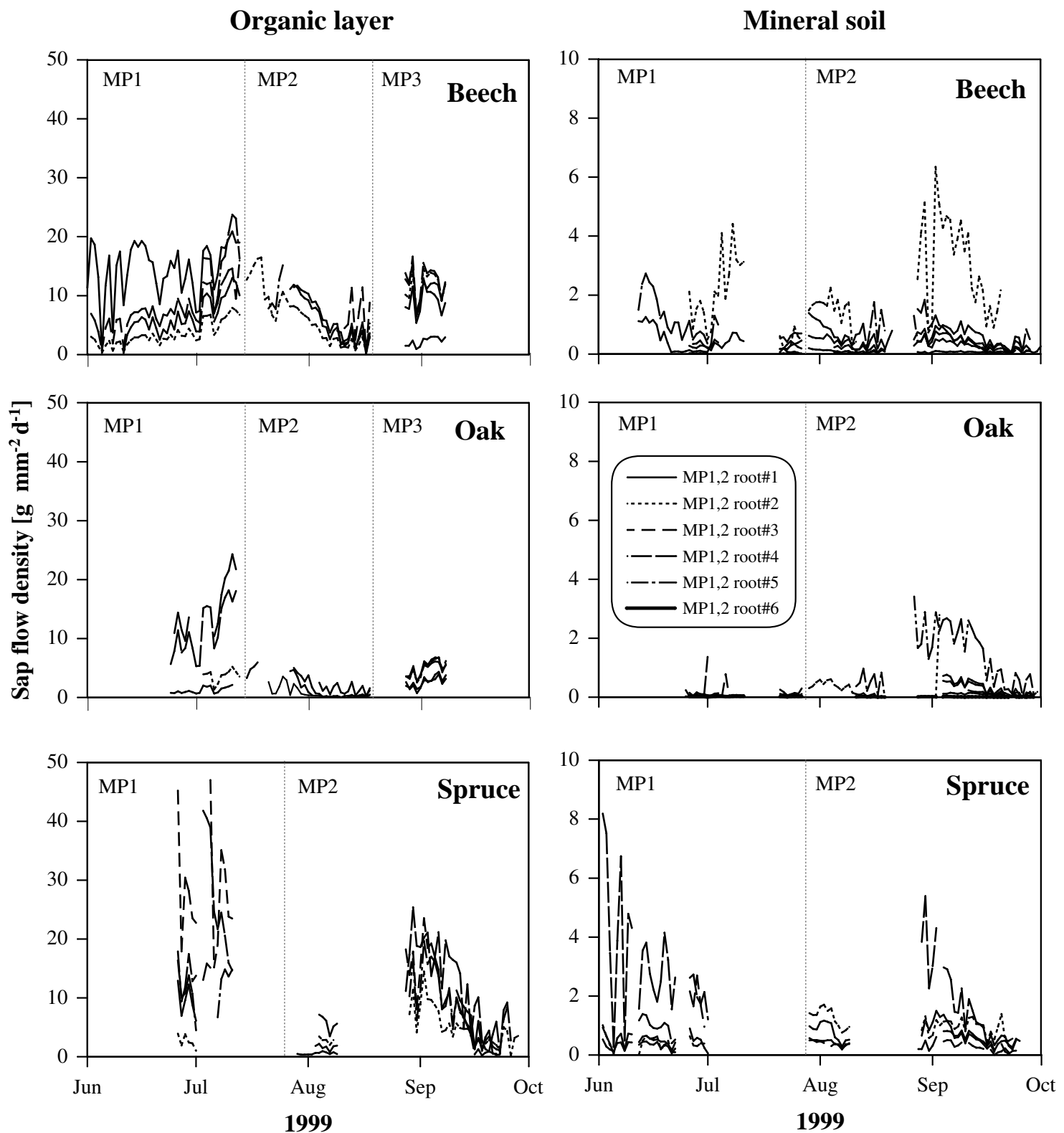

Abb. 4.32: Tageswerte der Saftflußdichte in Buchen-, Eichen- und Fichtenwurzeln gemessen in der Vegetationsperiode 1999 auf der Untersuchungsfläche OB5 in der Lüneburger Heide. Als Bezugsgöße dient jeweils die gesamte Xylemquerschnittsfläche am Meßpunkt. Die jeweiligen Meßperioden (MP1, MP2, MP3) sind durch gepunktete vertikale Linien getrennt. Abstand der Meßbäume: max. 20 m. Die Werte für Buche und Eiche in der organischen Auflage wurden unter Mithilfe von Regina Icke ermittelt. 

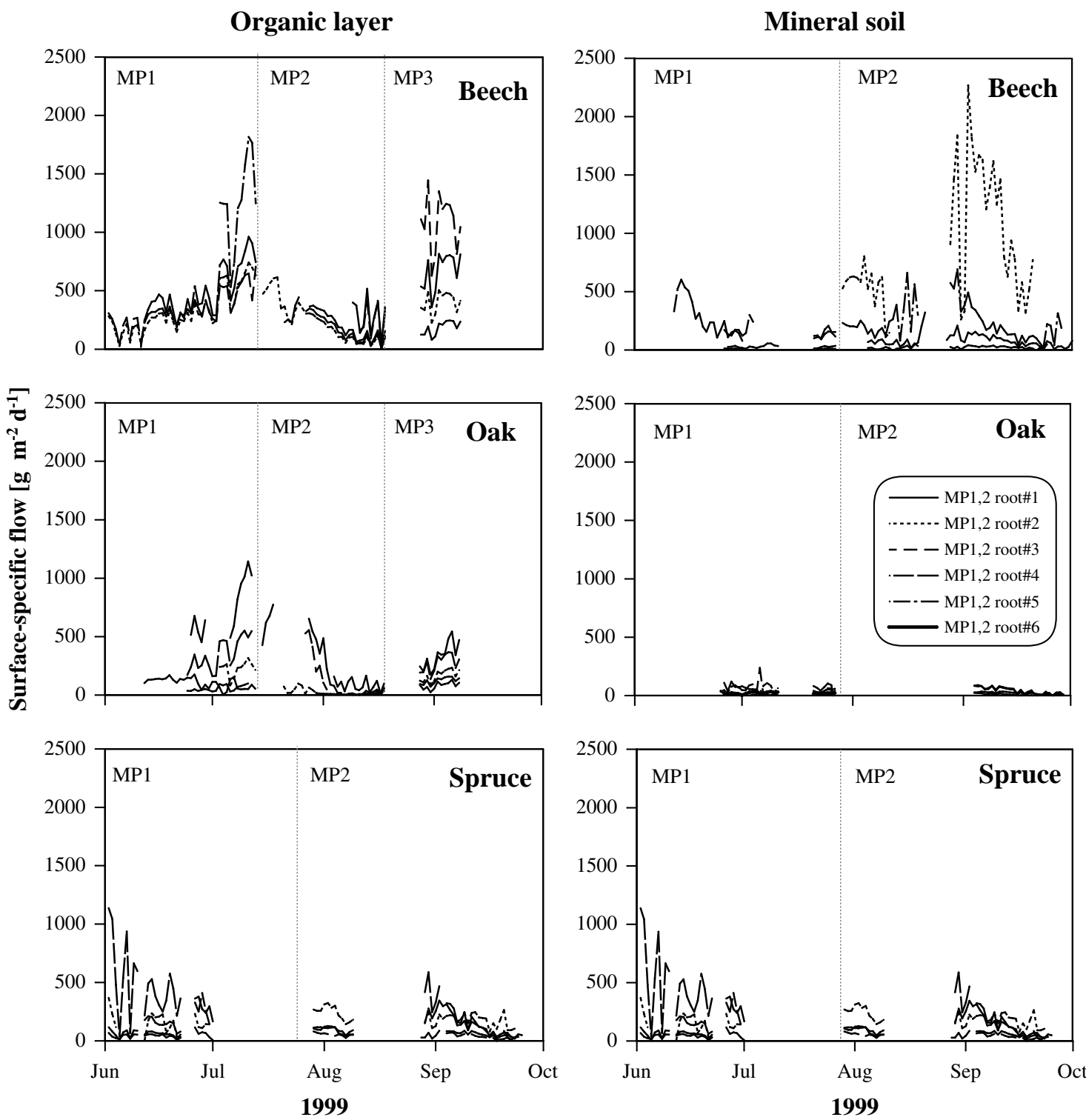

Abb. 4.33: Oberflächenspezifische Wasseraufnahmeraten (Tageswerte) von Buchen-, Eichenund Fichtenwurzeln gemessen in der Vegetationsperiode 1999 auf der Untersuchungsfläche OB5 in der Lüneburger Heide. Die Aufnahmeraten wurden jeweils auf den gesamten Wurzelstrang distal zum Saftflußsensor bezogen und betreffen damit Wurzeldurchmesser zwischen 0 und max. $4 \mathrm{~mm}$. Die jeweiligen Meßperioden (MP1, MP2, MP3) sind durch gepunktete vertikale Linien angedeutet. Die Werte für Buche und Eiche in der organischen Auflage wurden unter Mithilfe von Regina Icke ermittelt. 
Oberflächenspezifische Wasseraufnahmeraten In der organischen Auflage war bei den oberflächenspezischen Saftflußraten derselbe zeitliche Verlauf wie bei den querschnittsbezogenen Werten zu beobachten (Abb.4.33). Die Unterschiede zwischen den Arten waren bei dieser Bezugsgröße weniger deutlich ausgeprägt. So wurden bei allen 3 Arten in den Wurzeln der organischen Auflage oberflächenspezifische Aufnahmeraten bis zu $500 \mathrm{~g} \mathrm{~m}^{-2} \mathrm{~d}^{-1}$, bei einzelnen Wurzeln bis zu $2000 \mathrm{~g} \mathrm{~m}^{-2} \mathrm{~d}^{-1}$, gemessen.

Bei den Tiefenwurzeln von Buche und Fichte im Mineralboden ergab sich dagegen durch den Bezug auf die Oberfläche ein gänzlich anderes Bild als bei den Saftflußdichten. Durch die deutlich geringere wasseraufnehmende Oberfläche lagen die Werte in derselben Größenordnung wie in der organischen Auflage. Bei der Eiche hingegen wurden nur Aufnahmeraten von maximal $100 \mathrm{~g} \mathrm{~m}^{-2} \mathrm{~d}^{-1}$ erreicht.

Vergleich verschiedener Wurzelsaftflußgrößen Der direkte Vergleich der Wurzelsaftflußrate bezogen auf die Wurzel, den Wurzelquerschnitt bzw. auf die aufnehmenden Oberfläche ergibt in den meisten Fällen eindeutige Unterschiede zwischen der organischen Auflage und dem Mineralboden, während die Unterschiede zwischen den Arten nur gering sind (Tab.4.4). Die jeweils für jeden untersuchten Wurzelstrang über 4 bzw. 5 Tage gemittelten Werte repräsentieren in der ersten dargestellten Periode im Juni die Verhältnisse bei guter Wasserversorgung:vom 4. bis 8. September war der Boden in den oberen Horizonten dagegen deutlich trockener. Für die trockensten Phasen Mitte August und Mitte September liegt nicht für alle Arten und Horizonte eine ausreichende Parallelenzahl vor, was nicht zuletzt darauf zurückzuführen ist, daß in dieser Zeit der Saftfluß stark eingeschränkt war und mit den Miniatursaftflußanlagen nicht mehr mit ausreichender Genauigkeit gemessen werden konnte.

Bei Buche und Eiche waren in beiden dargestellten Perioden die Saftflußraten in der organischen Auflage deutlich höher als im Mineralboden. Auch durch den Bezug auf die Querschnittsfläche oder die aufnehmende Oberfläche änderten sich diese Relationen nicht. Die Fichtenwurzeln verhielten sich anders: Die Flußrate der Wurzeln aus der organischen Auflage war auch hier deutlich höher als im Mineralboden. Der Bezug auf die Oberfläche, die im Mineralboden wesentlich kleiner war als in der organischen Auflage, führte dazu, daß bei dieser Art die Wurzeln im Mineralboden annähernd so viel Wasser pro Wurzeloberfläche aufnahmen wie in der organischen Auflage.

Bis auf wenige Ausnahmen ergibt sich bei der Mehrheit der in Tab. 4.4 dargestellten Parameter eine Abfolge Buche $>$ Fichte $>$ Eiche. Die Unterschiede zwischen den Arten in dieser Abfolge waren in der organischen Auflage meist gering; hier ergaben sich auch in den wenigsten Fällen signifikante Unterschiede zwischen den Arten. Im Mineralboden dagegen hob sich vor allem die Eiche von den beiden anderen Arten mit wesentlich kleineren Flußraten ab.

Bei allen drei untersuchten Arten ist eine hohe Varianz zwischen den Wurzeln einer Art innerhalb eines Horizonts zu beobachten. Fast in allen Fällen wurden Variationskoeffizienten von etwa 50-100 \% gefunden. Tendenziell waren die Variationskoeffizienten im Mineralboden etwas höher als in der organischen Auflage. 
Tabelle 4.4: Vergleich verschiedener Wurzelsaftflußgrößen aus 2 mehrtägigen Meßperioden im Sommer 1999 in der Lüneburger Heide. Dargestellt sind jeweils Mittel der Tageswerte über die angegebene Zeitspanne. J: Saftflußrate pro Wurzel, $\mathbf{J}_{\mathrm{d}}$ : Saftflußdichte, $\mathbf{J}_{\mathrm{s}}$ : oberflächenspezifische Saftflußrate, VK: Variationskoeffizient. Unterschiedliche Großbuchstaben bezeichnen signifikante Unterschiede zwischen den Horizonten, Kleinbuchstaben solche zwischen den Arten; Signifikanztest nach Scheffé $(\mathrm{p}<0.05)$.

\begin{tabular}{|c|c|c|c|c|c|c|c|c|c|c|}
\hline & & & $\bar{x}$ & Scheffé & Median & Min & Max & Stabw & VK & $\mathrm{n}$ \\
\hline & 26. Jun & bis 29 & Juni 19 & & $\Theta 5,30$ & $60 \mathrm{~cm}: 2$ & $.8,11.5,6$ & 9 vol\% & & \\
\hline $\mathbf{J}$ & org & $\mathrm{Bu}$ & 46.07 & $\mathrm{~A}, \mathrm{a}$ & 44.40 & 27.78 & 67.72 & 19.63 & 42.61 & 4 \\
\hline$\left(\mathrm{g} \mathrm{d}^{-1}\right)$ & & $\mathrm{Ei}$ & 45.93 & $\mathrm{~A}, \mathrm{a}$ & 46.22 & 9.65 & 81.62 & 29.43 & 64.08 & 4 \\
\hline & & $\mathrm{Fi}$ & 22.97 & $\mathrm{~A}, \mathrm{a}$ & 16.39 & 4.99 & 64.24 & 23.58 & 102.67 & 5 \\
\hline & $\min$ & $\mathrm{Bu}$ & 4.04 & $\mathrm{~B}, \mathrm{a}$ & 3.29 & 0.40 & 11.57 & 4.46 & 110.33 & 5 \\
\hline & & $\mathrm{Ei}$ & 0.32 & $\mathrm{~B}, \mathrm{a}$ & 0.20 & 0.09 & 0.69 & 0.23 & 72.58 & 7 \\
\hline & & $\mathrm{Fi}$ & 1.94 & $\mathrm{~A}, \mathrm{a}$ & 1.96 & 0.47 & 3.38 & 1.41 & 72.77 & 4 \\
\hline & org & $\mathrm{Bu}$ & 8.11 & $\mathrm{~A}, \mathrm{a}$ & 7.25 & 3.69 & 14.25 & 4.50 & 55.45 & 4 \\
\hline & & $\mathrm{Ei}$ & 11.48 & $\mathrm{~A}, \mathrm{a}$ & 10.92 & 0.95 & 23.12 & 9.14 & 79.61 & 4 \\
\hline & & $\mathrm{Fi}$ & 14.14 & A, a & 12.73 & 3.02 & 30.41 & 10.05 & 71.08 & 5 \\
\hline & $\min$ & $\mathrm{Bu}$ & 0.54 & $\mathrm{~B}, \mathrm{ab}$ & 0.24 & 0.02 & 1.57 & 0.65 & 119.85 & 5 \\
\hline & & $\mathrm{Ei}$ & 0.04 & $\mathrm{~B}, \mathrm{a}$ & 0.02 & 0.01 & 0.11 & 0.04 & 89.25 & 7 \\
\hline & & $\mathrm{Fi}$ & 1.34 & $\mathrm{~B}, \mathrm{~b}$ & 1.33 & 0.41 & 2.26 & 0.95 & 71.35 & 4 \\
\hline $\mathrm{J}_{\mathrm{s}}$ & org & $\mathrm{Bu}$ & 391.19 & $\mathrm{~A}, \mathrm{a}$ & 365.42 & 345.93 & 462.23 & 62.29 & 15.92 & 3 \\
\hline (g m & & $\mathrm{Ei}$ & 252.80 & $\mathrm{~A}, \mathrm{a}$ & 195.77 & 43.99 & 575.67 & 239.79 & 94.85 & 4 \\
\hline & & $\mathrm{Fi}$ & 274.29 & $\mathrm{~A}, \mathrm{a}$ & 276.61 & 114.45 & 402.09 & 115.86 & 42.24 & 5 \\
\hline & $\min$ & $\mathrm{Bu}$ & 89.41 & $\mathrm{~B}, \mathrm{ab}$ & 89.50 & 10.82 & 167.83 & 80.90 & 90.48 & 4 \\
\hline & & $\mathrm{Ei}$ & 33.65 & $\mathrm{~A}, \mathrm{a}$ & 24.42 & 7.51 & 84.15 & 28.67 & 85.19 & 6 \\
\hline & & $\mathrm{Fi}$ & 213.87 & $\mathrm{~A}, \mathrm{~b}$ & 231.22 & 79.48 & 313.55 & 117.62 & 55.00 & 4 \\
\hline & 4. Sep & bis 8 & Sept. 19 & & $\Theta 5,30$ & $60 \mathrm{~cm}: 1$ & $.5,9.1,7$. & vol\% & & \\
\hline $\mathrm{J}$ & org & $\mathrm{Bu}$ & 51.42 & $\mathrm{~A}, \mathrm{a}$ & 61.22 & 14.99 & 64.98 & 20.95 & 40.73 & 5 \\
\hline & & $\mathrm{Ei}$ & 18.07 & $\mathrm{~A}, \mathrm{~b}$ & 21.05 & 12.26 & 22.42 & 4.87 & 26.94 & 5 \\
\hline & & $\mathrm{Fi}$ & 24.70 & $\mathrm{~A}, \mathrm{~b}$ & 22.47 & 18.17 & 35.70 & 7.85 & 31.78 & 4 \\
\hline & $\min$ & $\mathrm{Bu}$ & 9.07 & $\mathrm{~B}, \mathrm{a}$ & 4.81 & 0.56 & 25.20 & 9.39 & 103.61 & 6 \\
\hline & & $\mathrm{Ei}$ & 4.67 & $\mathrm{~B}, \mathrm{a}$ & 2.28 & 0.19 & 18.16 & 6.90 & 147.81 & 6 \\
\hline & & $\mathrm{Fi}$ & 2.58 & $\mathrm{~B}, \mathrm{a}$ & 1.96 & 1.07 & 4.16 & 1.32 & 51.23 & 5 \\
\hline $\mathrm{J}_{\mathrm{d}}$ & org & $\mathrm{Bu}$ & 9.74 & $\mathrm{~A}, \mathrm{ab}$ & 11.57 & 2.91 & 12.67 & 4.05 & 41.60 & 5 \\
\hline$\left(\mathrm{g} \mathrm{mm}^{-2} \mathrm{~d}^{-1}\right)$ & & $\mathrm{Ei}$ & 4.83 & $\mathrm{~A}, \mathrm{a}$ & 5.59 & 3.06 & 6.04 & 1.44 & 29.72 & 5 \\
\hline & & $\mathrm{Fi}$ & 12.50 & $\mathrm{~A}, \mathrm{~b}$ & 13.20 & 6.99 & 16.62 & 4.04 & 32.30 & 4 \\
\hline & $\min$ & $\mathrm{Bu}$ & 1.12 & $\mathrm{~B}, \mathrm{a}$ & 0.62 & 0.07 & 4.15 & 1.51 & 134.71 & 6 \\
\hline & & $\mathrm{Ei}$ & 0.61 & $\mathrm{~B}, \mathrm{a}$ & 0.30 & 0.01 & 2.38 & 0.90 & 148.55 & 6 \\
\hline & & $\mathrm{Fi}$ & 1.08 & $\mathrm{~B}, \mathrm{a}$ & 0.93 & 0.41 & 2.27 & 0.71 & 65.26 & 5 \\
\hline $\mathrm{J}_{\mathrm{s}}$ & org & $\mathrm{Bu}$ & 626.49 & $\mathrm{~A}, \mathrm{a}$ & 592.16 & 226.70 & 1094.95 & 382.10 & 60.99 & 4 \\
\hline$\left(g \mathrm{~m}^{-2} \mathrm{~d}^{-1}\right)$ & & $\mathrm{Ei}$ & 242.45 & A, a & 206.77 & 101.03 & 437.42 & 136.91 & 56.47 & 5 \\
\hline & & $\mathrm{Fi}$ & 317.77 & $\mathrm{~A}, \mathrm{a}$ & 318.90 & 181.71 & 451.57 & 120.92 & 38.05 & 4 \\
\hline & $\min$ & $\mathrm{Bu}$ & 470.70 & $\mathrm{~A}, \mathrm{a}$ & 184.70 & 29.51 & 1483.89 & 681.33 & 144.75 & 4 \\
\hline & & $\mathrm{Ei}$ & 47.10 & $\mathrm{~B}, \mathrm{a}$ & 49.90 & 17.00 & 71.58 & 28.61 & 60.74 & 4 \\
\hline & & $\mathrm{Fi}$ & 159.06 & $\mathrm{~A}, \mathrm{a}$ & 200.01 & 58.15 & 246.53 & 85.67 & 53.86 & 5 \\
\hline
\end{tabular}




\subsubsection{Die Wasseraufnahme in Abhängigkeit von verschiedenen Einflußfaktoren}
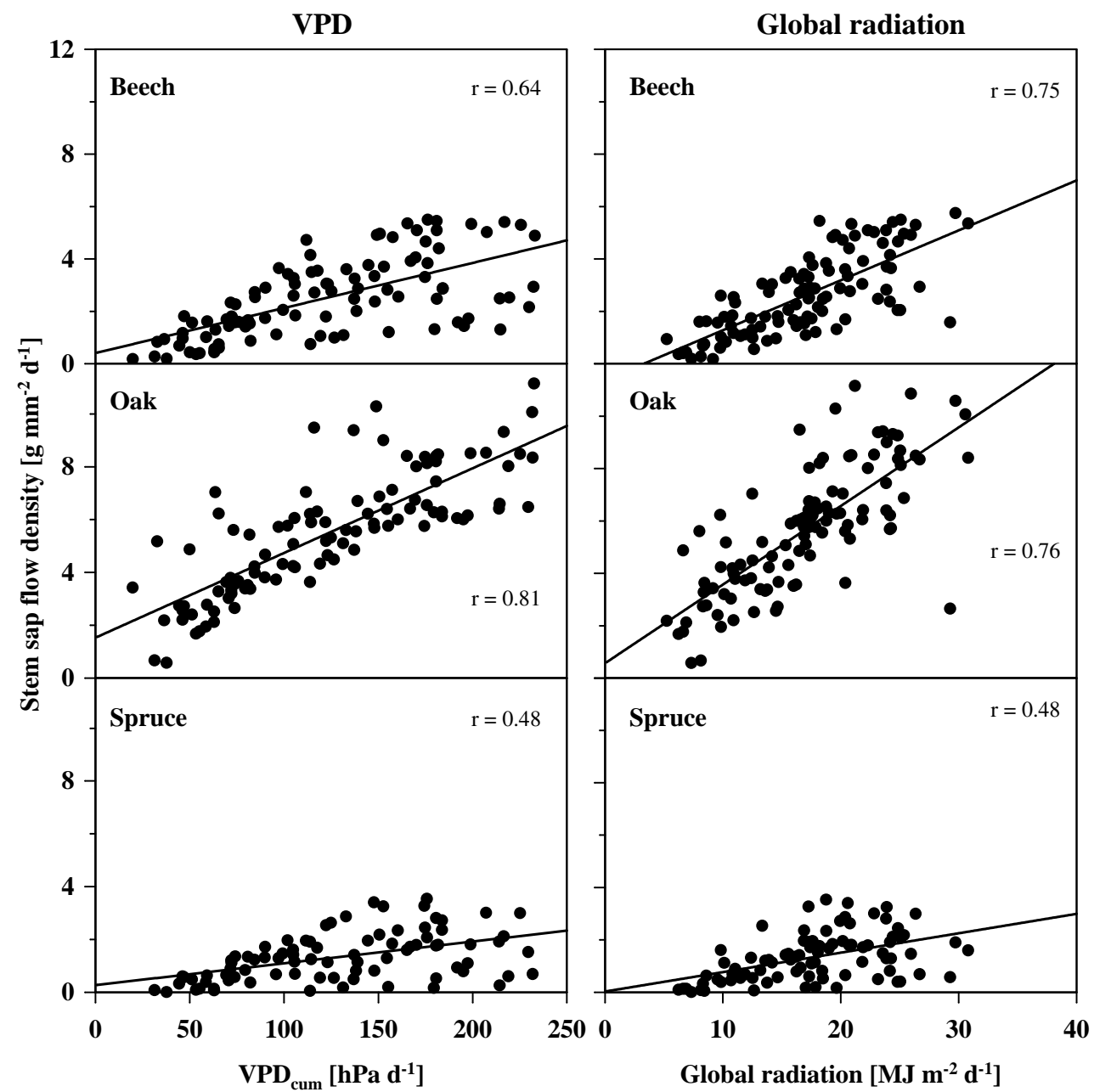

Abb. 4.34: Tageswerte der Stammsaftflußdichte in den untersuchten Buchen, Eichen und Fichten in Abhängigkeit vom Sättigungsdefizit (VPD cum $)$ der Luft und der Globalstrahlung (Tagessumme) in der Vegetationsperiode 1999 auf der Untersuchungsfläche OB5 in der Lüneburger Heide. Stammsaftfluß: heat balance Methode an je 3 Buchen bzw. Eichen und 2 Fichten. VPD und G: Messungen oberhalb des Bestandes.

Transpirationsrate Eine mögliche Einflußgröße des Wurzelsaftflusses ist die Transpirationsrate der Krone, die durch Stammsaftflußrate näherungsweise wiedergegeben wird. Diese wird wiederum von den klimatischen Parametern VPD und Globalstrahlung maßgeblich beeinflußt (Abb. 4.34). Die Abhängigkeit tritt in Form eines linearen Zusammenhanges am deutlichsten bei der Eiche zutage. Hier beträgt der Korrelationskoeffizient der Regressionsgeraden 0.81 beim VPD bzw. 0.76 bei der Globalstrahlung. Weiterhin wurden bei dieser Baumart die höchsten Flußdichten erzielt: An 
sehr trockenen Strahlungstagen mit einem VPD $_{\text {cum }}$ von 200-250 hPa d ${ }^{-1}$ bzw. einer Globalstrahlung von etwa $30 \mathrm{MJ} \mathrm{m}^{-2} \mathrm{~d}^{-1}$ betrug die Flußrate im Splintholz des Eichenstamms maximal etwa $9 \mathrm{~g} \mathrm{~mm}^{-2} \mathrm{~d}^{-1}$. Die Buche erreichte maximal 5, die Fichte $3 \mathrm{~g} \mathrm{~mm}^{-2} \mathrm{~d}^{-1}$.

In dieser Reihenfolge nimmt auch der Korrelationskoeffizient der linearen Regression zwischen Stammsaftflußrate und Mikroklimagrößen ab. So beträgt R bei der Buche für die Beziehung zum VPD cum $_{0.64}$ und zur Globalstrahlung 0.75. Der Zusammenhang ist bei der Fichte mit R-Werten von jeweils 0.48 dagegen wesentlich schwächer.
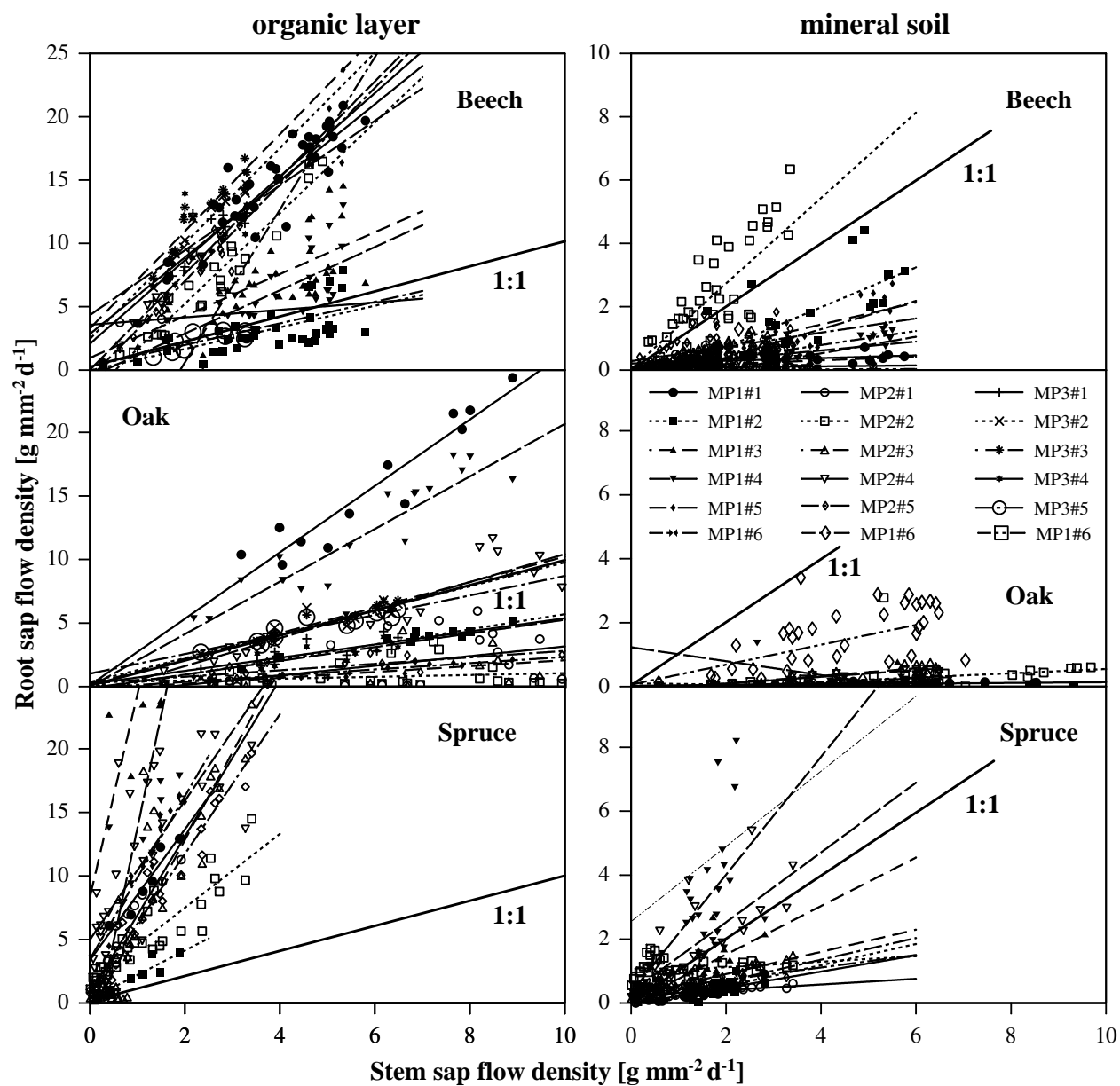

Abb. 4.35: Saftflußdichten in Buchen-, Eichen- und Fichtenwurzeln (3-4 mm) in Abhängigkeit von der synchron gemessenen Stammsaftflußdichte. Flußraten gemessen mit der heat balance Methode am Standort OB5 in der Lüneburger Heide. MP1, 2, 3: Meßperiode in der Vegetationsperiode 1999 (s. Abb. 4.33). Die Ordinaten für die organische Auflage und den Mineralboden sind unterschiedlich skaliert.

Zwischen der Transpirationsrate des Baumes und der Saftflußrate in den Wurzeln besteht ebenfalls ein enger linearer Zusammenhang (Abb. 4.35, Korrelationskoeffizi- 
enten der Regressionsgeraden: Tab. 4.5) Für einzelne Wurzeln besitzt dieser Zusammenhang der beiden Flußdichten meist einen Korrelationskoeffizienten $\geq 0.6$. Zwischen den Wurzeln einer Baumart unterliegt die Steigung der jeweiligen Art jedoch einer großen Streuung. Dies ist in der organischen Auflage besonders bei der Eiche zu beobachten. Bei der Buche ist eine Häufung von Kurven mit einer Steigung von $5 \mathrm{zu}$ verzeichnen. Eine ähnliche Kurvenschar weist bei der Fichte Steigungen um 6 auf.

Tabelle 4.5: Korrelationskoeffizienten zur linearen Beziehung zwischen der Saftflußdichte in Wurzeln und Stamm bei Buche, Eiche und Fichte auf der Untersuchungsfläche OB5 Lüneburger Heide für die Vegetationsperiode 1999 (vergl. Abb. 4.35). Die Ziffern 1-6 bezeichnen verschiedene Wurzeln in den Meßperioden (MP) 1-3.

*(Negative Beziehungen wurden bei der Mittelwertbildung nicht berücksichtigt.)

\begin{tabular}{cc|ccc|ccc}
\hline & & \multicolumn{3}{|c|}{ organische Auflage } & \multicolumn{3}{c}{ Mineralboden } \\
& & Buche & Eiche & Fichte & Buche & Eiche & Fichte \\
\hline \multirow{4}{*}{ MP1 } & 1 & 0.93 & 0.95 & 0.96 & 0.44 & 0.33 & 0.85 \\
& 2 & 0.64 & 0.96 & 0.87 & 0.71 & $-0.48^{*}$ & 0.66 \\
& 3 & 0.72 & - & 0.70 & 0.82 & 0.43 & 0.62 \\
& 4 & 0.72 & 0.90 & 0.69 & 0.73 & $-0.54^{*}$ & 0.58 \\
& 5 & 0.61 & 0.87 & 0.91 & 0.80 & 0.74 & 0.93 \\
& 6 & - & - & - & 0.83 & 0.75 & - \\
\hline \multirow{4}{*}{ MP2 } & 1 & - & 0.50 & 0.95 & 0.10 & 0.87 & 0.56 \\
& 2 & 0.95 & 0.21 & 0.91 & 0.74 & 0.35 & 0.24 \\
& 3 & - & 0.52 & 0.91 & 0.89 & 0.82 & 0.90 \\
& 4 & 0.99 & 0.93 & 0.77 & 0.90 & 0.89 & 0.83 \\
& 5 & 0.95 & 0.78 & 0.98 & 0.47 & 0.64 & 0.92 \\
& 6 & - & - & - & 0.72 & 0.44 & - \\
\hline \multirow{4}{*}{ MP3 } & 1 & 0.85 & 0.76 & - & - & - & - \\
& 2 & 0.97 & 0.89 & - & - & - & - \\
& 3 & 0.94 & 0.97 & - & - & - & - \\
& 4 & 0.62 & 0.81 & - & - & - & - \\
& 5 & 0.76 & 0.93 & - & - & - & - \\
\hline
\end{tabular}

Die Steigungen für die Wurzeln der Buche und noch mehr für diejenigen der Fichte sind deutlich größer als im Falle der Eiche. Bei der Buche und der Fichte ist also die Saftflußdichte in den Wurzeln jeweils höher als diejenige im Stamm, während bei der Eiche der Großteil der Wurzeln kleinere Saftflußdichten aufweist als der Stamm (Wurzel-Flußdichte $<10 \mathrm{~g} \mathrm{~mm}^{-2} \mathrm{~d}^{-1}$, Steigung $<1$ ).

Im Mineralboden besitzt die Abhängigkeit zwischen Wurzel- und Stammsaftfluß aufgrund der deutlich geringeren Wurzel-Saftflußdichten generell eine deutlich kleinere Steigung. Wie in der organischen Auflage verlaufen die Geraden bei der Fichte deutlich steiler als bei der Buche. Dadurch ergeben sich bei der Fichte in Wurzel und Stamm ähnlich hohe Saftflußdichten, während bei Buche und Eiche die Flußdichte in den Wurzeln deutlich geringer ist als im Stamm. Die lineare Beziehung zwischen den beiden Flußdichten ist im Fall der Eiche z.T. undeutlich oder auch negativ, weil die 
Saftflußdichte in den Wurzeln nur sehr geringe Werte annimmt. Einzig Wurzel 6 aus der zweiten Meßperiode tritt mit einer Steigung von 0.3 deutlich hervor.

Eine Häufung von Geraden mit gleicher oder ähnlicher Steigung ist im Mineralboden bestenfalls bei der Fichte zu beobachten. Hier folgt eine größere Zahl Wurzeln einer Beziehung mit einer Steigung von etwa 0.3. Bei den Wurzeln der Buche und der Eiche ist kein solcher Trend zu verzeichnen.

Die Beziehung der Saftflußdichte in Wurzel und Stamm ist im Mineralboden weniger einheitlich als in der organischen Auflage. Wie aus Tab. 4.5 hervorgeht, ist der mittlere Korrelationskoeffizient für die Auflagewurzeln von Buche, Eiche und Fichte $(0.82,0.78$ bzw. 0.87$)$ deutlich größer als derjenige für die Mineralbodenwurzeln $(0.68,0.63$ bzw 0.71$)$.
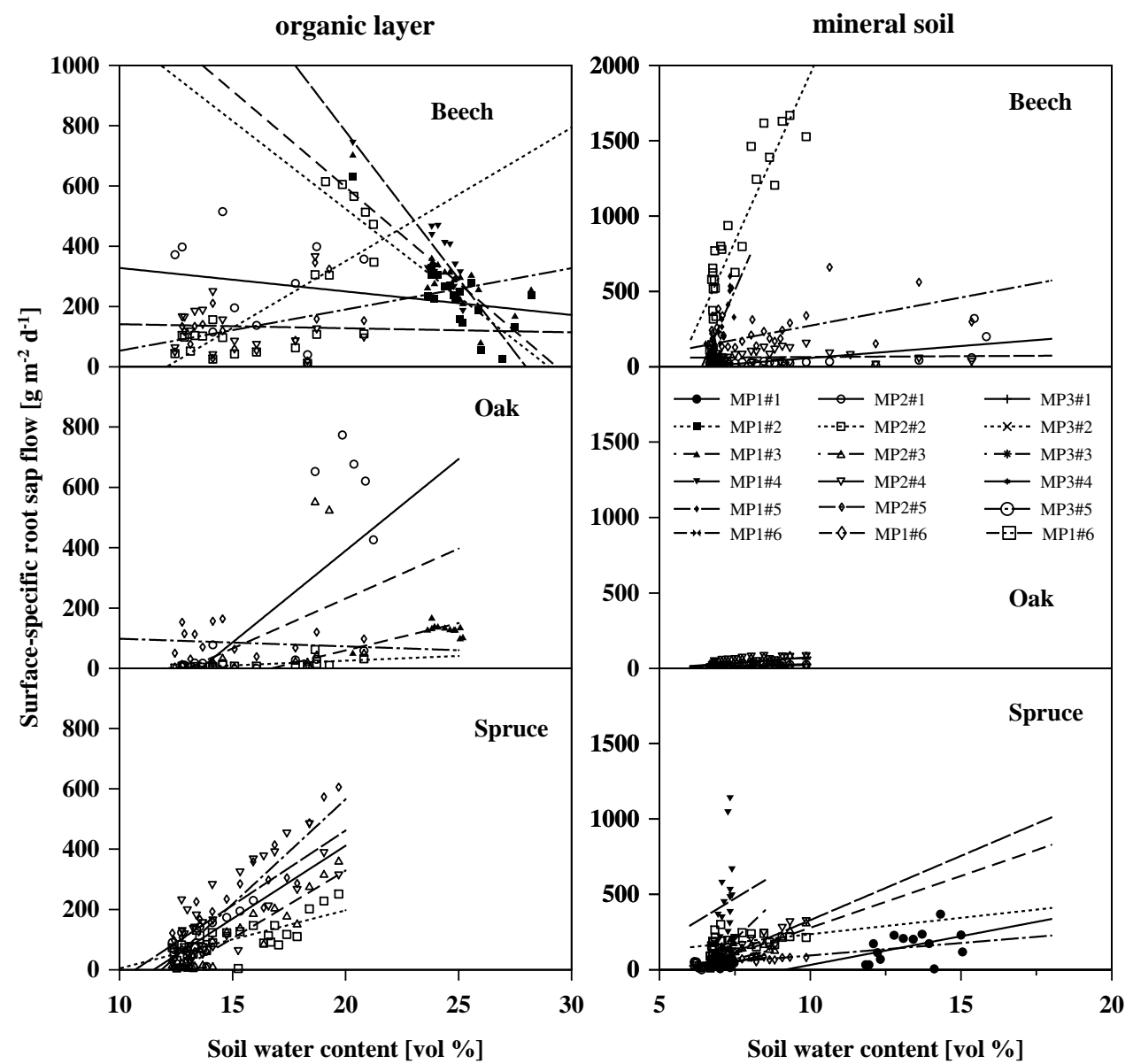

\begin{abstract}
Abb. 4.36: Oberflächenspezifische Wasseraufnahme von Buchen-, Eichen- und Fichtenwurzeln der organischen Auflage in Abhängigkeit vom Bodenwassergehalt. Flußraten gemessen mit der heat balance Methode, Bodenwassergehalt mittels tdr-Sonden am Standort OB5 in der Lüneburger Heide. MP1, 2, 3: Meßperiode in der Vegetationsperiode 1999 (s. Abb.4.33). Die Ordinaten und Abszissen für die organische Auflage und den Mineralboden sind unterschiedlich skaliert.
\end{abstract}


Bodenwassergehalt Die Abhängigkeit der Wurzelwasseraufnahme vom Bodenwassergehalt ist bei den drei untersuchten Baumarten in der organischen Auflage bzw. im Mineralboden unterschiedlich ausgeprägt (Abb. 4.36, Tab. 4.6). Allein in Wurzeln der Fichte stieg während der zweiten Meßperiode die oberflächenspezifische Wasserflußrate mit steigendem Bodenwassergehalt eindeutig an. Hier wurden in den meisten Fällen Korrelationskoeffizienten zwischen 0.7 und 0.9 ermittelt. Für die erste Meßperiode liegen für diese Baumart nur Werte für den Mineralboden vor. Hier war kaum eine Abhängigkeit zwischen der Bodenfeuchte und dem Wurzelsaftfluß zu erkennen $(\mathrm{R}<0.5)$.

Tabelle 4.6: Korrelationskoeffizienten zur Abhängigkeit der oberflächenspezifischen Wasseraufnahme vom Bodenwassergehalt (Abb. 4.36) bei Buche, Eiche und Fichte auf der Untersuchungsfläche OB5 in der Lüneburger Heide für die Vegetationsperiode 1999.

*(Negative Beziehungen wurden bei der Mittelwertbildung nicht berücksichtigt.)

\begin{tabular}{cc|ccc|ccc}
\hline & & \multicolumn{3}{|c|}{ organische Auflage } & \multicolumn{3}{c}{ Mineralboden } \\
& & Buche & Eiche & Fichte & Buche & Eiche & Fichte \\
\hline \multirow{4}{*}{ MP1 } & 1 & - & - & - & - & - & 0.44 \\
& 2 & $-0.78^{*}$ & - & - & - & - & 0.42 \\
& 3 & $-0.81^{*}$ & 0.56 & - & - & - & 0.74 \\
& 4 & $-0.88^{*}$ & - & - & - & - & 0.06 \\
& 5 & $-0.14^{*}$ & - & - & 0.76 & - & 0.28 \\
\hline \multirow{4}{*}{ MP2 } & 1 & - & 0.67 & 0.74 & 0.72 & 0.33 & 0.53 \\
& 2 & 0.69 & 0.58 & 0.74 & 0.90 & - & 0.37 \\
& 3 & - & 0.45 & 0.94 & - & 0.58 & 0.90 \\
& 4 & $-0.04^{*}$ & - & 0.79 & 0.06 & 0.50 & 0.92 \\
& 5 & 0.40 & $-0.13^{*}$ & 0.92 & 0.56 & 0.78 & 0.82 \\
\hline & $\bar{x}$ & 0.54 & 0.57 & 0.83 & 0.60 & 0.63 & 0.55 \\
\hline
\end{tabular}

Bei den Wurzeln von Buche und Eiche hingegen war die Abhängigkeit vom Bodenwassergehalt deutlich schwächer. Zwar wurden für einige Wurzeln Korrelationskoeffizienten $>0.5$ gefunden, jedoch ließ bei den beiden Laubbaumarten eine erstaunlich große Zahl von Wurzeln kaum eine Abhängigkeit der oberflächenspezifischen Saftflußrate vom Bodenwassergehalt erkennen.

Sättigungsdefizit Ähnlich wie bei der Korrelation zwischen Wurzel- und Stammsaftflußdichte war beim Großteil der Wurzeln von Buche und Eiche eine enge lineare Beziehung der oberflächenspezifischen Wurzelsaftflußrate einzelner Wurzeln zum Sättigungsdefizit der Atmosphäre zu beobachten (Abb. 4.37, Tab. 4.7). Besonders in der organischen Auflage waren die Korrelationskoeffizienten der linearen Regression mit einem Mittelwert von 0.78 recht hoch. Im Mineralboden hatten dagegen mehrere Buchen- und Eichenwurzeln sehr kleine Korrelationskoeffizienten, der Mittelwert lag hier bei 0.56 für die Buche bzw. 0.63 für die Eiche.

Bei der Fichte wurden sowohl für die Wurzeln der organischen Auflage als auch für diejenigen des Mineralbodens deutlich geringere mittlere Korrelationskoeffizien- 
ten (0.47 bzw. 0.50) für die Abhängigkeit vom Sättigungsdefizit gefunden. Einzelne Wurzeln reagierten jedoch sehr unterschiedlich auf eine Änderung der Transpirationsbeanspruchung. So wurden für einige Wurzeln der Fichte sehr enge lineare Beziehungen mit Korrelationskoeffizienten bis zu 0.97 gefunden, während beim größeren Teil der untersuchten Wurzeln die Wurzelsaftflußrate nahezu unabhängig vom Sättigungsdefizit war $(\mathrm{R}<0.3)$.
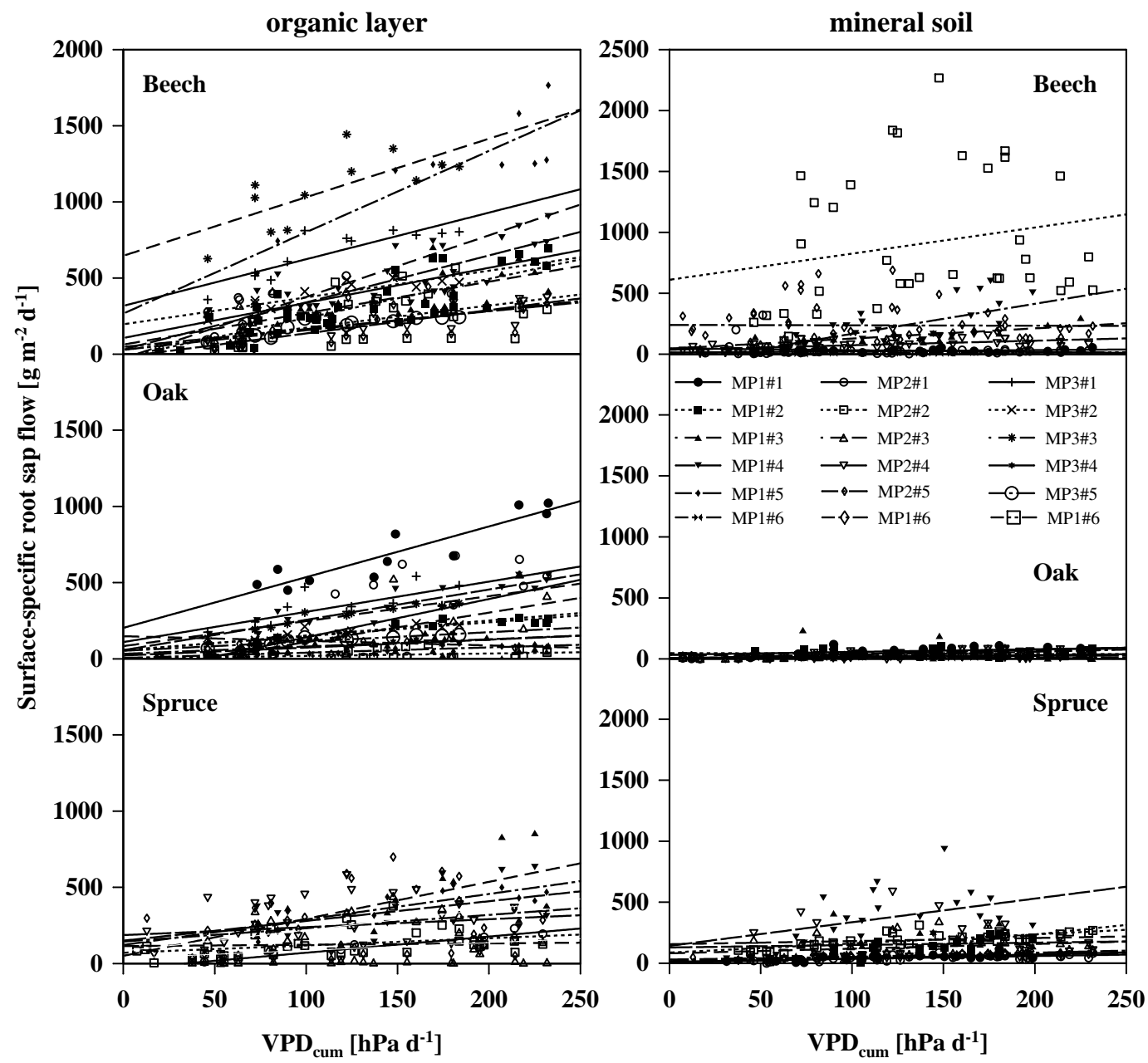

Abb. 4.37: Oberflächenspezifische Wasseraufnahmeraten von Buchen-, Eichen- und Fichtenwurzeln in Abhängigkeit vom Sättigungsdefizit. Flußraten gemessen mit der heat balance Methode, VPD mit Psychrometern oberhalb der Kronen am Standort OB5 in der Lüneburger Heide. MP1, 2, 3: Meßperiode in der Vegetationsperiode 1999 (s. Abb. 4.33). Die Ordinaten für die organische Auflage und den Mineralboden sind unterschiedlich skaliert. 
Tabelle 4.7: Korrelationskoeffizienten zur Abhängigkeit der oberflächenspezifischen Wasseraufnahme vom Sättigungsdefizit (Abb. 4.37) bei Buche, Eiche und Fichte auf der Untersuchungsfläche OB5 in der Lüneburger Heide für die Vegetationsperiode 1999.

*(Negative Beziehungen wurden bei der Mittelwertbildung nicht berücksichtigt.)

\begin{tabular}{cc|ccc|ccc}
\hline & & \multicolumn{3}{|c|}{ organische Auflage } & \multicolumn{3}{c}{ Mineralboden } \\
& & Buche & Eiche & Fichte & Buche & Eiche & Fichte \\
\hline \multirow{4}{*}{ MP1 } & 1 & & 0.92 & - & 0.45 & 0.23 & 0.62 \\
& 2 & 0.78 & 0.89 & - & - & $-0.04^{*}$ & 0.83 \\
& 3 & 0.77 & $-0.36^{*}$ & 0.65 & 0.75 & $-0.10^{*}$ & 0.11 \\
& 4 & 0.80 & 0.89 & 0.46 & - & 0.76 & 0.43 \\
& 5 & 0.88 & 0.86 & 0.80 & 0.61 & 0.59 & 0.65 \\
& 6 & - & - & - & 0.75 & & - \\
\hline \multirow{4}{*}{ MP2 } & 1 & 0.68 & 0.60 & 0.97 & $-0.16^{*}$ & - & 0.63 \\
& 2 & 0.53 & 0.36 & 0.37 & 0.22 & 0.87 & 0.76 \\
& 3 & 0.81 & 0.71 & 0.04 & - & 0.86 & 0.23 \\
& 4 & 0.88 & - & 0.20 & 0.55 & 0.88 & 0.09 \\
& 5 & 0.65 & 0.56 & 0.26 & $-0.01^{*}$ & 0.23 & 0.69 \\
& 6 & - & - & - & - & - & - \\
\hline \multirow{4}{*}{ MP3 } & 1 & 0.86 & 0.76 & - & - & - & - \\
& 2 & 0.87 & 0.89 & - & - & - & - \\
& 3 & 0.72 & 0.96 & - & - & - & - \\
& 4 & - & 0.77 & - & - & - & - \\
& 5 & 0.89 & 0.92 & - & - & - & - \\
\hline
\end{tabular}

Bedeutung der verschiedenen Einflußgrößen Bei der Analyse der oberflächenspezifischen Wurzelsaftflußraten mittels multipler Regression für die Umweltfaktoren Bodenwassergehalt, Sättigungsdefizit und Globalstrahlung, konnte keine der 3 Variablen eindeutig ausgeschlossen werden (Tab.4.8). Als wichtigste Einflußgröße für die Saftflußrate in Buchen- und Eichenwurzeln wurde bei der Variablenselektion bei etwa $80 \%$ der untersuchten Wurzeln das Sättigungsdefizit der Atmosphäre mit einer Irrtumswahrscheinlichkeit von $5 \%$ in die multiple Regression aufgenommen. Bei der Fichte spielt das Sättigungsdefizit eine nicht so dominante Rolle. Hier wurde das VPD nur bei etwa $50 \%$ der Wurzeln als signifikante Einflußgröße identifiziert.

Die Umweltfaktoren Bodenwassergehalt und Globalstrahlung sind bei den Fichtenwurzeln des Mineralbodens von ebenbürtiger Bedeutung (Selektion bei $67 \mathrm{bzw}$. $56 \%$ der Wurzeln). Für die Fichtenwurzeln der organischen Auflage und bei Buche und Eiche traten diese beiden Variablen etwas hinter das VPD zurück, trugen aber auch bei mindestens $40 \%$ der untersuchten Wurzeln signifikant zur Verbesserung der berechneten multiplen Regression bei. Nur bei den Eichenwurzeln der organischen Auflage und den Buchenwurzeln des Mineralbodens wurde die Globalstrahlung bei etwa $85 \%$ der untersuchten Wurzeln nicht in das endgültige bestangepaßte Rechenmodell aufgenommen. 
Tabelle 4.8: Ergebnisse der multiplen Regressionsanalyse mit Variablenselektion für die oberflächenspezifische Saftflußrate einzelner Buchen-, Eichen- und Fichtenwurzeln in Abhängigkeit von den Einflußgrößen Bodenwassergehalt $(\Theta)$, Sättigungsdefizit der Luft (VPD) und Globalstrahlung $(\mathrm{G})$. Angegeben ist die absolute (n) und die relative Häufigkeit (\%), mit der die jeweilige Einflußgröße bei der Variablenselektion mit $\mathrm{p}<5 \%$ in die multiple Regression aufgenommen wurde. Da jeweils mehr als eine Einflußgröße aufgenommen werden kann, ist die Summe $>100 \%$. Alle Parameter (Tagessummen) wurden in der Vegetationsperiode 1999 am Standort OB5 in der Lüneburger Heide gemessen. $\mathrm{n}_{\mathrm{r}}$ : Anzahl der untersuchten Wurzeln, $\mathrm{n}_{\mathrm{d}}$ : Anzahl der betrachteten Tage je Wurzel (Mittelwert).

\begin{tabular}{|c|c|c|c|c|c|c|c|c|c|}
\hline \multirow[t]{2}{*}{ Art } & \multirow{2}{*}{ Horizont } & \multicolumn{3}{|c|}{ Selektion (n) } & \multicolumn{3}{|c|}{ Selektion (\%) } & \multirow[b]{2}{*}{$\mathrm{n}_{\mathrm{r}}$} & \multirow[b]{2}{*}{$\mathrm{n}_{\mathrm{d}}$} \\
\hline & & $\Theta$ & VPD & G & $\Theta$ & VPD & G & & \\
\hline Buche & & 6 & 10 & 5 & 46.15 & 76.92 & 38.46 & 13 & 20.62 \\
\hline Eiche & org. Auflage & 10 & 11 & 2 & 71.43 & 78.57 & 14.29 & 14 & 16.36 \\
\hline Fichte & & 4 & 4 & 2 & 50.00 & 50.00 & 25.00 & 8 & 17.08 \\
\hline Buche & & 4 & 5 & 1 & 66.67 & 83.33 & 16.67 & 6 & 37.33 \\
\hline Eiche & Mineralboden & 3 & 6 & 3 & 42.86 & 85.71 & 42.86 & 7 & 22.71 \\
\hline Fichte & & 6 & 4 & 5 & 66.67 & 44.44 & 55.56 & 9 & 2590 \\
\hline
\end{tabular}

Modellhafte Beschreibung der Wasseraufnahme Für die Berechnung der oberflächenspezifischen Saftflußrate in den Wurzeln aus den Umweltfaktoren Bodenwassergehalt, Sättigungsdefizit und Globalstrahlung ließen sich für alle drei Arten mittels multipler Regression hochsignifikante Modelle finden; die Irrtumswahrscheinlichkeit lag in jedem Fall unter $1 \%$ (Abb. 4.38, Tab. 4.9). Mit einem Korrelationskoeffizienten von 0.70 war die Vorhersagegenauigkeit bei den Fichtenwurzeln der organischen Auflage am höchsten, während für die Mineralbodenwurzeln mit $\mathrm{R}=0.36$ eine größere Abweichung des Modells von den tatsächlichen Wasseraufnahmeraten zu erwarten ist. Dieser Unterschied zwischen organischer Auflage und Mineralboden besteht in gleicher Form bei Buche und Eiche. Das Modell für die organische Auflage liegt mit $\mathrm{R}=0.48$ bei der Buche bzw. 0.44 bei der Eiche recht nahe an den tatsächlichen Werten; im Mineralboden dagegen ist bei Korrelationskoeffizienten von 0.22 bzw. 0.28 nur noch eine grobe Vorhersage der Saftflußraten aus den Klimaparametern zu erwarten.

Alternativ kann der Wurzelsaftfluß mit ähnlicher Präzision anhand der Stammsaftflußrate der jeweiligen Art modelliert werden. Auch hier lag die Irrtumswahrscheinlichkeit der linearen Regression in der Regel unter $1 \%$, nur für die Mineralbodenwurzeln der Buchen betrug p $2.2 \%$. Auch die Korrelationskoeffizienten der linearen Regression standen bei den 3 untersuchten Arten in organischer Auflage und Mineralboden in ähnlichen Relationen zueinander. Die besten Vorhersagen der Wurzelsaftflußrate anhand der Transpiration sind für die Fichte zu erwarten $(R=0.80$ bzw. 0.41 für die organische Auflage bzw. den Mineralboden). Wiederum sind bei diesem Zusammenhang die Korrelationskoeffizienten allgemein für die organische Auflage höher als für den Mineralboden.

Im zeitlichen Verlauf über den gesamten Untersuchungszeitraum ist in den meisten Fällen eine recht gute Übereinstimmung zwischen längerfristigen Veränderungen 
Tabelle 4.9: Parameter der Regressionsgleichungen zur modellhaften Beschreibung der oberflächenspezifischen Saftflußrate aus den klimatischen Einflußgrößen VPD, G und $\Theta$ bzw. der Stammsaftflußrate (Abb. 4.38). Zugrundeliegende Gleichungen: $y=a+b \cdot V P D+c \cdot G+d \cdot \Theta$ $\left(\mathrm{VPD}_{\text {cum }}=\right.$ kumulatives Wassersättigungsdefizit der Atmosphäre $\left[\mathrm{hPa} \mathrm{d}^{-1}\right], \mathrm{G}=$ Globalstrahlung [MJ m $\left.{ }^{-2} \mathrm{~d}^{-1}\right], \Theta=$ Bodenwassergehalt $[$ vol \%] $), y=a+b \cdot J \quad\left(\mathrm{~J}_{\text {stem }}=\right.$ Stammsaftflußdichte $\left[\mathrm{g} \mathrm{mm}^{-2} \mathrm{~d}^{-1}\right]$ ) R - adj.: adjustierter Korrelationskoeffizient (korrigiert um Variablenzahl).

\begin{tabular}{lc|cccc|cc} 
Art & Horizont & $\mathrm{a}$ & $\mathrm{b}(\mathrm{VPD})$ & $\mathrm{c}(\mathrm{G})$ & $\mathrm{d}(\Theta)$ & $\mathrm{R}-\mathrm{adj}$. & $\mathrm{p}$ \\
\hline Buche & & -97.45 & 2.64 & -0.64 & 8.45 & 0.48 & $<.0001$ \\
Eiche & org. Auflage & -204.73 & 1.26 & 0.55 & 11.02 & 0.44 & $<.0001$ \\
Fichte & & -356.84 & 0.95 & -2.08 & 27.96 & 0.70 & $<.0001$ \\
\hline Buche & & -261.31 & 1.23 & -1.46 & 47.58 & 0.22 & 0.0016 \\
Eiche & Mineralboden & -32.20 & 0.19 & -0.84 & 6.56 & 0.28 & 0.0002 \\
Fichte & & -116.94 & 0.24 & 4.12 & 18.52 & 0.36 & $<.0001$ \\
\hline \multicolumn{1}{r|c}{} & $\mathrm{a}$ & $\mathrm{b}\left(\mathrm{J}_{\text {stem }}\right)$ & & & \\
\hline Buche & & 101.12 & 105.37 & & 0.50 & $<.0001$ \\
Eiche & \multirow{2}{*}{ org. Auflage } & -19.95 & 33.80 & & 0.37 & $<.0001$ \\
Fichte & & 30.38 & 144.74 & & 0.80 & $<.0001$ \\
\hline Buche & & 150.63 & 41.80 & & 0.14 & 0.0228 \\
Eiche & Mineralboden & 12.64 & 3.32 & & 0.20 & 0.0038 \\
Fichte & & 63.42 & 62.23 & & 0.41 & $<.0001$
\end{tabular}

der oberflächenspezifischen Wurzelsaftflußrate und den Vorhersagen der beiden Modelle aus den Umweltfaktoren bzw. der Transpirationsrate zu erkennen (Abb. 4.38). Vor allem bei den Buchenwurzeln der organischen Auflage beschreiben die Modelle sehr eng den Anstieg der Wurzelsaftflußrate bis Anfang Juli, das darauf folgende trockenheitsbedingte Absinken bis Mitte August und das herbstliche Absinken nach einem vorübergehenden Maximum nach ausgiebigen Regenfällen Ende August des Jahres 1999. Aber auch bei Eiche und Fichte werden die Wasserflußraten in der organischen Auflage mit diesen jahreszeitlichen Trends durch die modellierten Werte wiedergegeben. Bei allen Arten ist jedoch eine breite Streuung der gemessenen Werte zu beobachten, wobei einige Wurzeln sich besonders weit abheben (z.B. Buchenwurzel Nr. 5, Meßperiode1, Buchenwurzel Nr. 3, MP3 sowie jeweils die Eichenwurzel Nr. 1 aus MP 1 und 2).

Die beiden Modelle (Umweltfaktoren bzw. Stammsaftflußrate) stimmen für die Auflagewurzeln aller 3 Baumarten und für die Mineralbodenwurzeln der Fichte in ihren Vorhersagen recht gut überein. Dies gilt sowohl für die berechnete Saftflußrate als auch für die zeitlichen Veränderungen in der Vegetationsperiode. Bei den Buchenund vor allem bei den Eichenwurzeln des Mineralbodens hingegen gibt es deutliche Abweichungen zwischen den Modellen. Hier sagt das Modell aus den Umweltfaktoren für den Zeitraum der Wiederaufsättigung des Bodens in der zweiten Augusthälfte wesentlich höhere Wurzelsaftflußraten vorher als dasjenige aus dem Stammsaftfluß. Diese Abweichung kann nicht anhand gemessener Daten geprüft werden, weil für diesen Zeitraum keine Meßdaten für die Eichenwurzeln aus dem Mineralboden vorliegen. 
Die Überprüfung anhand der gemessenen Daten belegt die große Variabilität der oberflächenspezifischen Wasseraufnahmeraten, die anhand der empirischen Modelle nur bis zu einem gewissen Grad abzubilden ist. Beide Modelle liefern recht gute Vorhersagen für die Aufnahmeraten von Buchen- und Fichtenwurzeln der organischen Auflage (Abb. 4.39). Große Abweichungen zwischen den berechneten und den gemessenen Werten sind hingegen bei den anhand der Stammsaftflußdichte modellierten Aufnahmeraten von Buchen- und Eichenwurzeln im Mineralboden zu beobachten
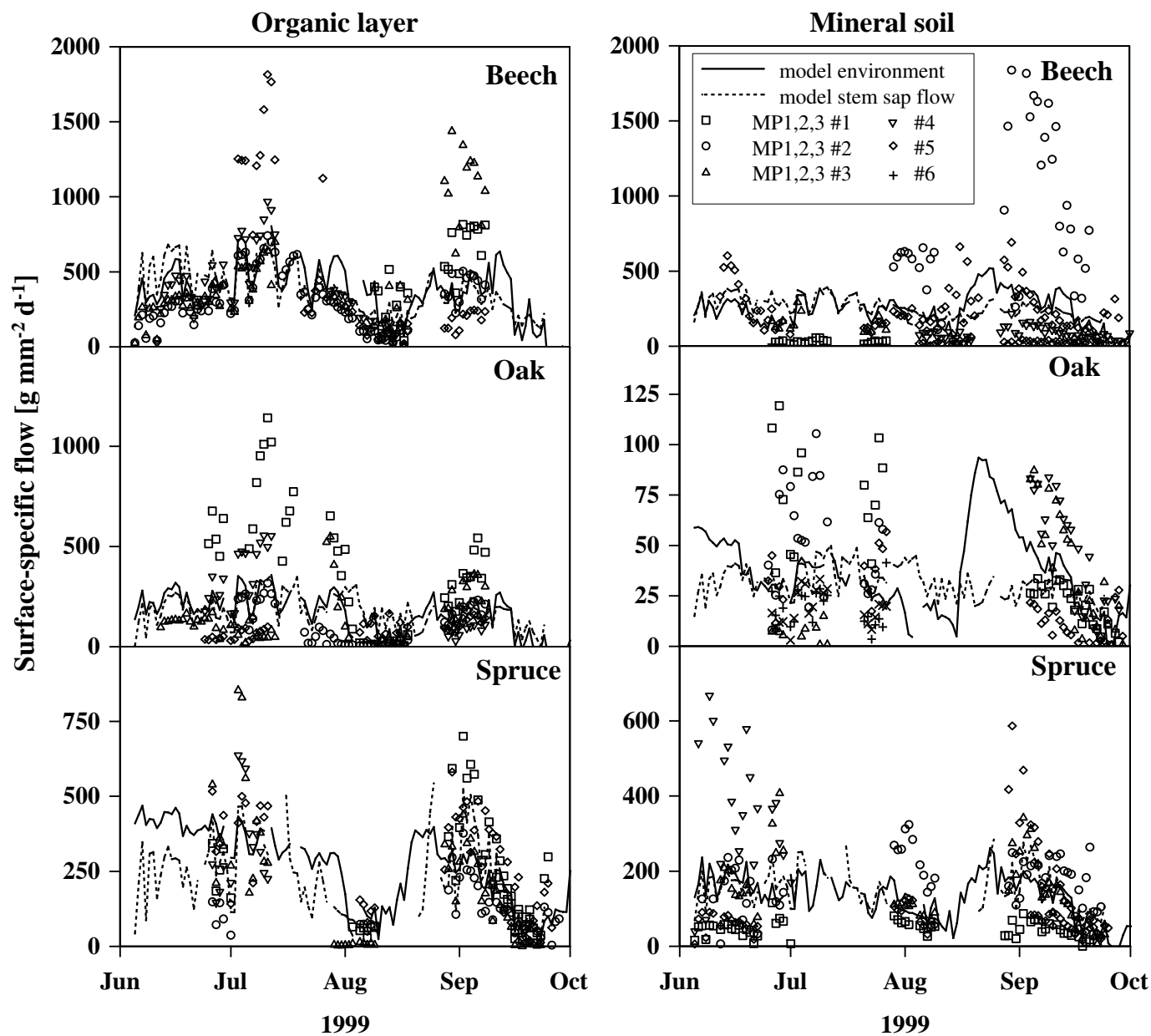

Abb. 4.38: Modellierte oberflächenspezifische Wasseraufnahmerate durch die Wurzeln von Buche, Eiche und Fichte im Vergleich zu den am Standort gemessenen Werten. Dargestellt sind die oberflächenspezifischen Wasseraufnahmeraten (Tageswerte) von Buchen-, Eichenund Fichtenwurzeln gemessen in der Vegetationsperiode 1999 auf der Untersuchungsfläche OB5 in der Lüneburger Heide. Die dargestellten modellierten Werte wurden auf der Basis einer multiplen linearen Regression aus den Umweltfaktoren VPD, Globalstrahlung, Bodenwassergehalt und Bodentemperatur (durchgezogene Linie) bzw. aus der Beziehung zur Saftflußrate im Stamm des jeweiligen Baumes (gepunktete Linie) berechnet. 

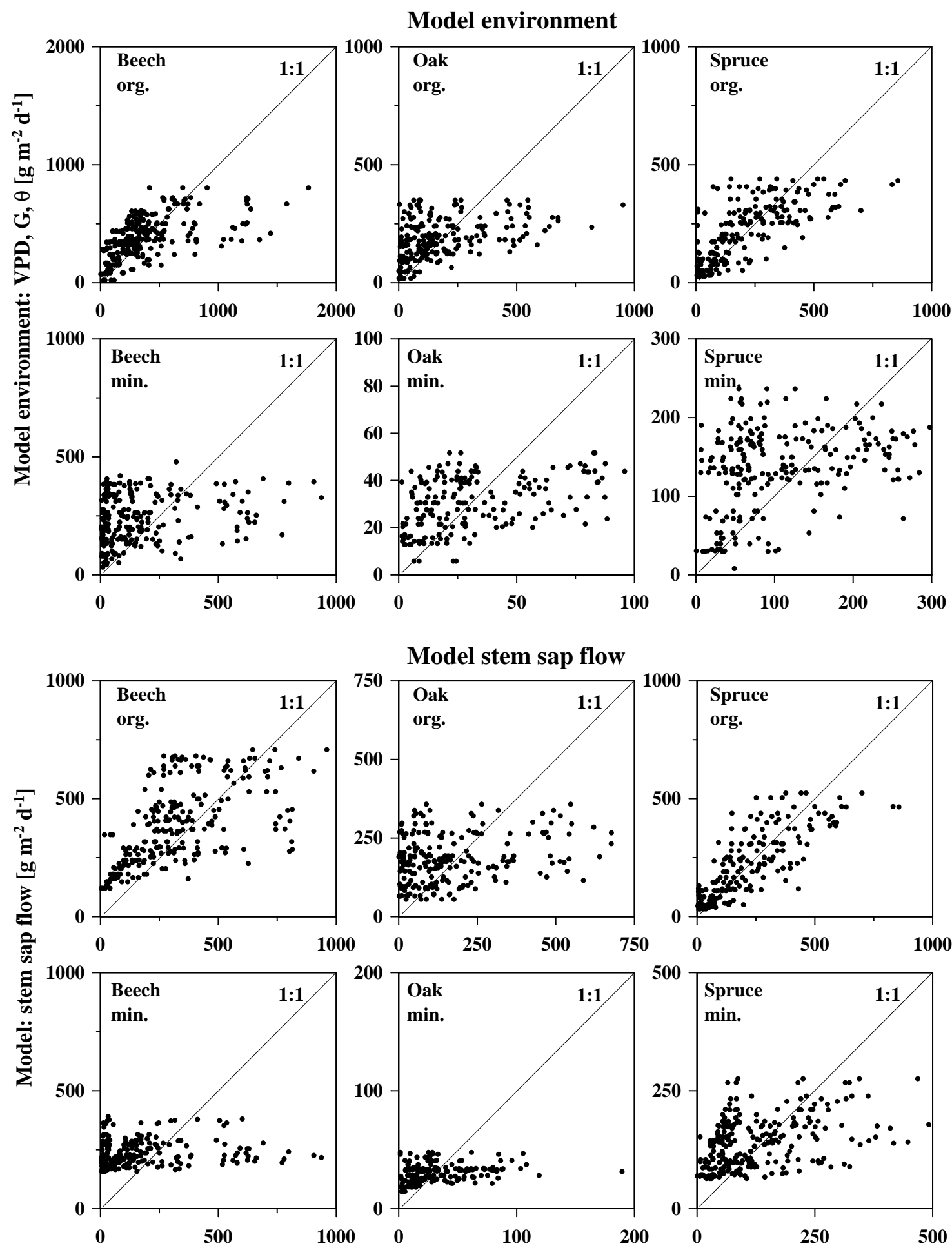

Surface-specific root water uptake (measured values) $\left[\mathrm{g} \mathrm{m}^{-2} \mathbf{d}^{-1}\right]$

Abb. 4.39: Vergleich der modellierten mit den gemessenen oberflächenspezifischen Wasseraufnahmeraten. Oben: Modellierung auf der Basis von VPD, G und $\Theta$, unten: auf Basis der Stammsaftflußdichte. Die berechneten Werte beruhen auf den mittels multipler linearer Regression ermittelten empirischen Gleichungen (s. Tab. 4.9) auf der Basis von Tageswerten der jeweiligen Parameter aus der Vegetationsperiode 1999 am Standort OB5 in der Lüneburger Heide. 


\subsubsection{Wurzelwasserpotentiale}

\subsubsection{Potentialabsenkung und Wasseraufnahme}

Das Wasserpotential der Feinwurzeln in der organischen Auflage zeigte bei Buche, Eiche und Fichte im Verlauf des Sommers 1999 einen ähnlichen saisonalen Verlauf. In Abb. 4.40 sind die mit der Scholander-Methode bestimmten Tagesminima von 7 Strahlungstagen (10.6., 24.6., 27.7., 25.8., 2.9. und 9.9.1999) dargestellt. Die höchsten Werte zwischen -0.4 und -0.8 MPa waren zu Anfang des untersuchten Zeitraums im Juni sowie Ende August zu beobachten. Im Verlauf der niederschlagsarmen Zeit im Juli und August senkte die Buche das Wasserpotential in ihren Wurzeln auf -1.52 MPa am 12.7. bzw -1.78 MPa am 27.7. ab. Die Wurzeln von Eiche und Fichte folgten diesem Trend, wiesen jedoch mit etwa -0.8 bzw. $-1.1 \mathrm{MPa}$ an beiden Terminen signifikant höhere Potentiale auf.

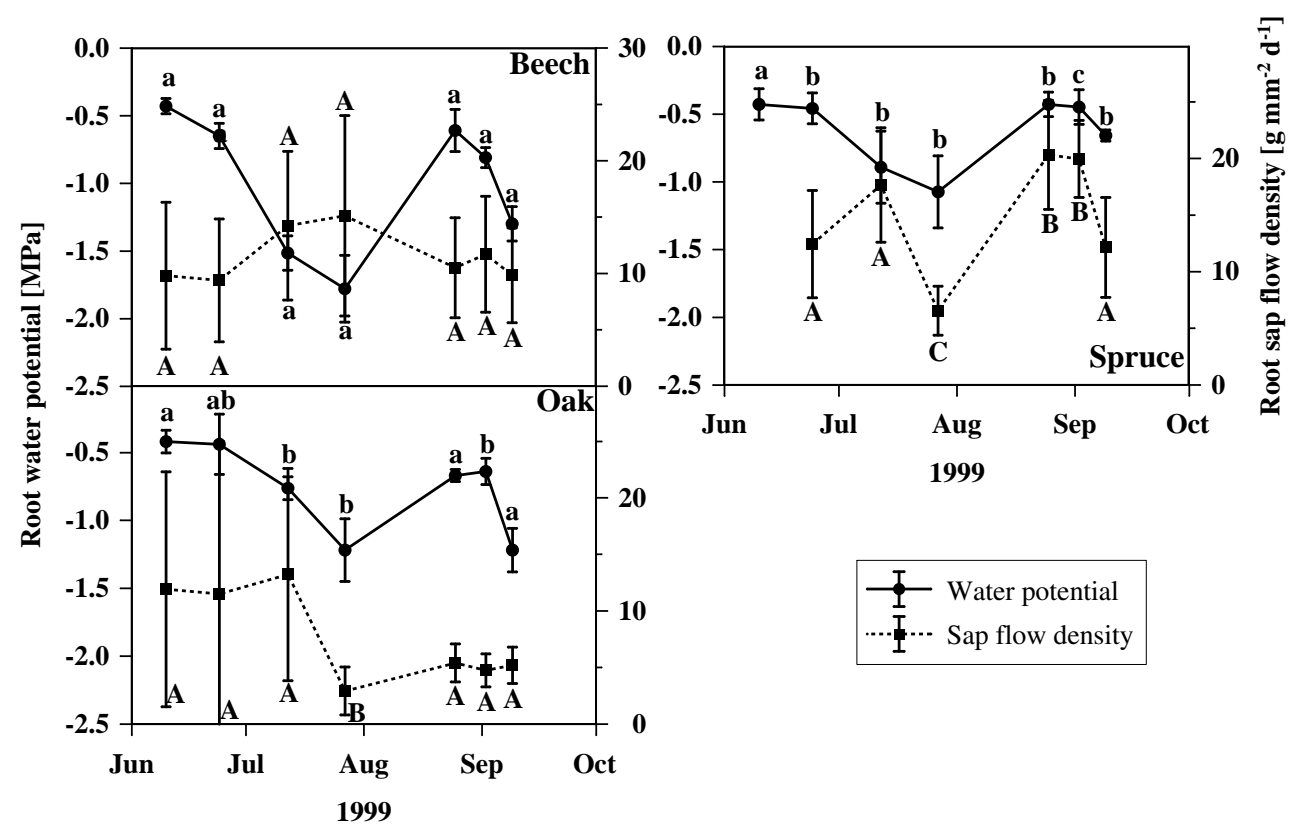

Abb. 4.40: Mittagsminima des Wasserpotentials und Tageswerte der Saftflußdichte in BuchenEichen- und Fichtenfeinwurzeln der organischen Auflage der Lüneburger Heide an 7 Strahlungstagen in der Vegetationsperiode 1999. Potentiale wurden gemessen mit der ScholanderMethode $(\mathrm{n}=5)$ an frisch freigelegten Feinwurzelenden, die Saftflußdichte mit MiniaturSaftflußmeßsystemen an 3-4 mm starken Wurzeln $(n=4-5)$. Kleine Buchstaben markieren signifikante Unterschiede zwischen den Potentialwerten der Arten an einem Termin, große Buchstaben solche zwischen den Saftflußdichten; U-Test nach Mann \& Whitney $(\mathrm{p}<0.05)$.

In der zweiten Phase ausgeprägter Bodentrockenheit (Meßtermin 9.9.) sank in den Wurzeln der Buche und der Eiche das Wasserpotential nochmals auf jeweils -1.2 MPa ab. An diesem Tag lag die Fichte signifikant höher (-0.66 MPa). 
Die Wurzelsaftflußdichten in der organischen Auflage zeigten im Zeitraum JuniOktober 1999 bei den drei untersuchten Arten sehr unterschiedliche Verläufe: An den ersten drei Terminen waren keine signifikanten Unterschiede zwischen den Arten zu erkennen, wobei alle drei Arten Werte von 10-15 $\mathrm{g} \mathrm{mm}^{-2} \mathrm{~d}^{-1}$ aufwiesen. Am 27.7. sank die Saftflußdichte in den Wurzeln der Eiche und Fichte deutlich ab, während bei der Buche ein deutlicher Anstieg zu verzeichnen war. An diesem Termin waren die Flußdichten bei allen drei Arten signifikant voneinander verschieden: Die Wurzeln der Buche erreichten $15.1 \mathrm{~g} \mathrm{~mm}^{-2} \mathrm{~d}^{-1}$, diejenigen der Fichte und Eiche nur $6.5 \mathrm{bzw}$. $2.9 \mathrm{~g} \mathrm{~mm}^{-2} \mathrm{~d}^{-1}$.

An den folgenden drei Terminen waren zwischen Buche und Eiche keine signifikanten Unterschiede mehr zu beobachten. Die Buche sank auf Werte um $10 \mathrm{~g} \mathrm{~mm}^{-2} \mathrm{~d}^{-1}$ $\mathrm{ab}$, die Eiche blieb bei täglichen Saftflußdichten von etwa $5 \mathrm{~g} \mathrm{~mm}^{-2} \mathrm{~d}^{-1}$. Die Wurzeln der Fichte hingegen zeigten in diesem Zeitraum eine deutliche Veränderung: während der Phase mit höherem Bodenwassergehalt Ende August bis Anfang September waren bei dieser Art die Saftflußdichten um $20 \mathrm{~g} \mathrm{~mm}^{-2} \mathrm{~d}^{-1}$ signifikant höher als die der anderen beiden Arten. Erst am letzten Termin sank die Saftflußdichte in den Fichtenwurzeln mit $12.1 \mathrm{~g} \mathrm{~mm}^{-2} \mathrm{~d}^{-1}$ wieder auf das Niveau von Buche und Eiche ab.
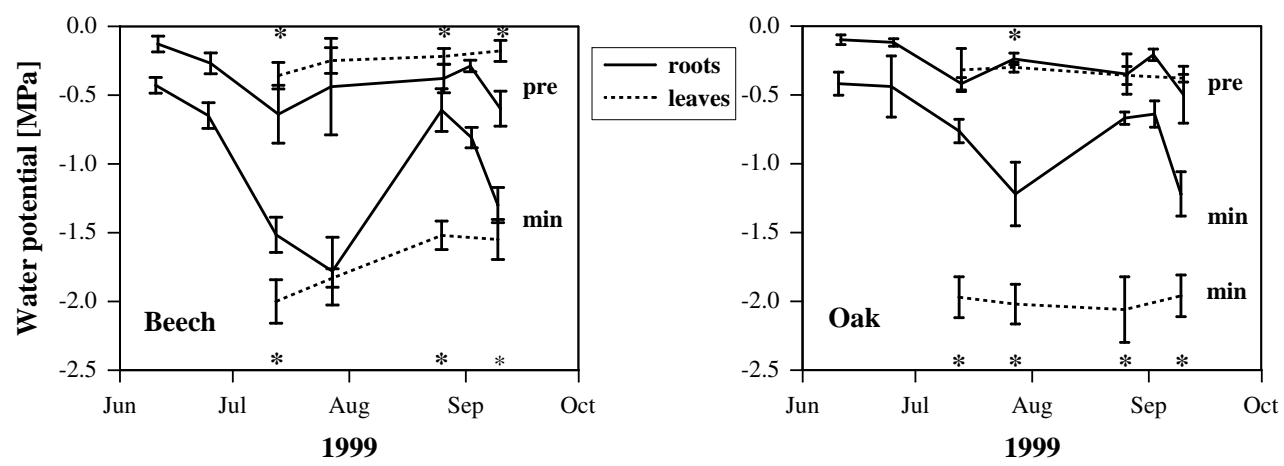

\begin{abstract}
Abb. 4.41: Wasserpotentiale in Wurzeln und Blättern von Buche und Eiche in der Vegetationsperiode 1999, gemessen mit der Scholander-Methode an frisch freigelegten Wurzeln bzw. an Blättern von einem Meßturm im Bestand OB5 in der Lüneburger Heide $(n=5)$. pre $=$ predawn-Wert, $\min =$ Mittagsminimum. Sterne oberhalb der Linien markieren signifikante Unterschiede zwischen den predawn-Potentialwerten, Sterne unterhalb der Linien solche zwischen den Minima in Wurzeln und Blättern an einem Termin; U-Test nach Mann \& Whitney $(\mathrm{p}<0.05)$.
\end{abstract}

\title{
4.3.6.2 Wasserpotentialgradienten zwischen Wurzel und Blatt
}

An 4 Terminen der Vegetationsperiode 1999 wurde zusätzlich zum Wasserpotential in den Feinwurzeln von einem Meßturm im Bestand das Wasserpotential von Sonnenblättern der Buche und Eiche bestimmt (Abb. 4.41). Generell lagen die predawnWasserpotentiale bei beiden Arten in Wurzeln und Blättern bei Werten zwischen -0.05 und - $0.5 \mathrm{MPa}$, während bei den Mittagsminima eine wesentlich größere Amplitude zu 
verzeichnen war. In den Wurzeln wurden Potentiale zwischen -0.4 und -1.5 MPa und in den Blättern zwischen -1.5 und -2 MPa gemessen.

Das predawn-Wasserpotential in den Buchenwurzeln lag an allen 4 Terminen um etwa 0.25 MPa niedriger als in den Buchenblättern. Nachts kehrte sich demnach der Wasserpotentialgradient im Stamm der Buche um. Bis auf den 27.7. waren diese Unterschiede statistisch signifikant. Bei der Eiche hingegen waren nur geringe Unterschiede zwischen dem predawn-Wasserpotential in Wurzeln und Blättern zu erkennen. Nur am 13.7. war das Wasserpotential in den Blättern signifikant niedriger als in den Feinwurzeln.

Der Verlauf der Mittagsminima war in den Wurzeln beider Arten ähnlich. Hier war am 27.7. und am 9.9. jeweils ein Tiefstwert zu beobachten (s. auch Abb. 4.40). Das Potential in den Blättern lag mit einer einzigen Ausnahme an jedem Termin signifikant tiefer als dasjenige der Wurzeln, wobei die Eichenblätter an allen Terminen etwa $-2.0 \mathrm{MPa}$ aufwiesen, während bei der Buche ein deutlicher Anstieg von -2.0 MPa am 12.7. auf etwa -1.5 MPa am 2. und 9.9. zu erkennen war.

Am 27.7. näherte sich bei der Buche das Wasserpotential in den Wurzeln dem der Blätter so weit an, daß hier kein signifikanter Unterschied mehr festzustellen war. Auch am 9.9. wurde der Potentialgradient zwischen den Wurzeln und Blättern der Buche sehr klein, allerdings war das Wasserpotential der Blätter an diesem Termin signifikant negativer als in den Wurzeln. Auch bei der Eiche war ein ähnlicher Verlauf der Potentiale zu beobachten, bei dem das Mittagsminimum in den Blättern recht konstant blieb und das Potential in den Wurzeln sich bodenfeuchtebedingt änderte. Allerdings war an allen Terminen mit einer Differenz von 1.0 bis $1.5 \mathrm{MPa}$ das Wasserpotential in den Blättern signifikant niedriger als in den Blättern.

Zwischen den Auflagewurzeln und den Blättern in etwa $26 \mathrm{~m}$ Höhe bestand also im Xylem der Eiche ein vertikaler Potentialgradient von 0.04-0.06 $\mathrm{MPa} \mathrm{m}^{-1}$. Auch bei der Buche wurde in Zeiten ausreichender Wasserversorgung ein solcher Wert beobachtet. Bei zunehmender Bodentrocknis hingegen wurde das Wasserpotential in den den Wurzeln der organischen Auflage so weit abgesenkt, daß die Differenz zwischen Blättern und Wurzeln nahezu Null wurde.

\subsubsection{Axiale hydraulische Leitfähigkeit}

Die im Labor an jeweils sechs Wurzelsegmenten nach der Methode Sperry et al.(1988) bestimmte maximale axiale hydraulische Leitfähigkeit war bei den Buchenwurzeln mit

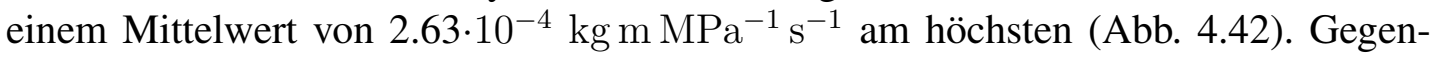
über den Eichenwurzeln $\left(1.66 \cdot 10^{-4} \mathrm{~kg} \mathrm{~m} \mathrm{MPa}^{-1} \mathrm{~s}^{-1}\right)$ war kein signifikanter Unterschied zu erkennen. Die axiale Leitfähigkeit der Fichtenwurzeln war mit nur $1.74 \cdot 10^{-5}$ $\mathrm{kg} \mathrm{m} \mathrm{MPa}{ }^{-1} \mathrm{~s}^{-1}$ hingegen signifikant kleiner als die der Buchen- und Eichenwurzeln.

Die hydraulische Leitfähigkeit in den einzelnen Wurzelsegmenten lag bei den Fichtenwurzeln einheitlich bei $1.7 \cdot 10^{-5} \mathrm{~kg} \mathrm{~m} \mathrm{MPa}^{-1} \mathrm{~s}^{-1}$, variierte jedoch im Gegensatz dazu bei den Buchenwurzeln sehr stark. Zwei der Segmente wiesen hier nur Werte von etwa $1 \cdot 10^{-4} \mathrm{~kg} \mathrm{~m} \mathrm{MPa}^{-1} \mathrm{~s}^{-1}$ auf, während die übrigen 4 untersuchten Wurzeln 
den fünffachen Wert zeigten. Bei der Eiche wich nur ein untersuchtes Wurzelsegment extrem von den anderen ab.
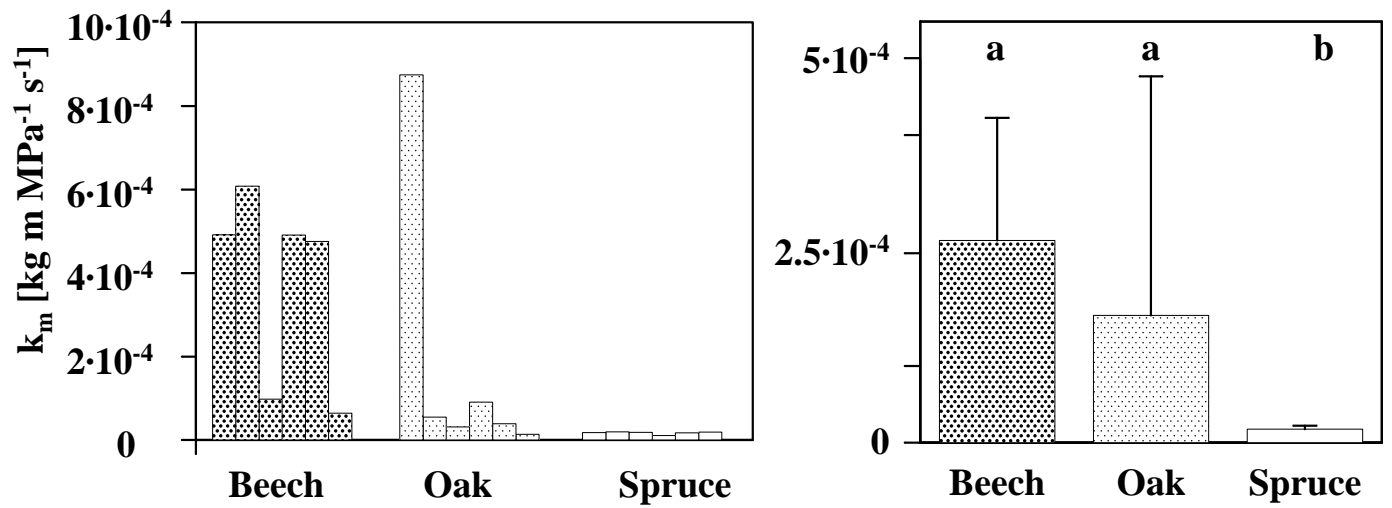

Abb. 4.42: Maximale axiale hydraulische Leitfähigkeit $\mathrm{k}_{m}$ von 3-4 mm dicken Buchen-, Eichen- und Fichtenwurzeln, gemessen mit der Methode nach Sperry et al. (1988). Untersucht wurden jeweils 6 Segmente mit $5 \mathrm{~cm}$ Länge (links: Einzelwerte, rechts: Mittelwerte). Unterschiedliche Buchstaben markieren signifikante Unterschiede zwischen den Arten; U-Test nach Mann \& Whitney $(\mathrm{p}<0.05)$.

\subsubsection{Radiale Leittähigkeit $\left(L p_{r}\right)$ unter in situ-Bedingungen}

Für 4 Termine in der Vegetationsperiode 1999 wurden für die Buchen-, Eichen- und Fichtenwurzeln der organischen Auflage in situ-Lp $\mathrm{p}_{\mathrm{r}}$-Werte berechnet (Tab. 4.10). Das Bodenmatrixpotential als Eingangsgröße für die berechnete Potentialdifferenz lag an diesen Terminen zwischen -0.008 und -0.06 MPa. Das Wurzelwasserpotential war bei jeder Art an den 4 untersuchten Terminen mit Werten zwischen -0.6 und -1.5 MPa deutlich negativer, es bestand also jeweils eine Potentialdifferenz von mindestens 0.5 MPa. Die größte Potentialdifferenz zwischen Wurzel und Rhizosphäre wiesen mit bis zu 1.5 MPa die Buchenwurzeln auf.

Die aus der Potentialdifferenz und der maximalen oberflächenspezifischen Saftflußrate der Auflagewurzeln berechnete radiale Leitfähigkeit lag bei allen 3 untersuchten Baumarten mit Werten zwischen 0.82 und 3.94 $10^{-8} \mathrm{~m} \mathrm{MPa}^{-1} \mathrm{~s}^{-1}$ in einer Größenordnung. Die kleinste Leitfähigkeit wurde an 3 von 4 Terminen für die Wurzeln der Eiche berechnet, allerdings war dieser Unterschied zu den anderen Arten nur am 2. September signifikant. Am 12. Juli wiesen die Fichtenwurzeln die niedrigste radiale Leitfähigkeit der drei Arten auf $\left(1.06 \cdot 10^{-8} \mathrm{~m} \mathrm{MPa}^{-1} \mathrm{~s}^{-1}\right)$. Bei den 2 Terminen Anfang September wurden für diese Art hingegen jeweils höhere Werte als für Buche und Eiche ermittelt. 
Tabelle 4.10: Radiale hydraulische Leitfähigeit $\left(L p_{r}\right)$ von Buchen-, Eichen- und Fichtenwurzeln der organischen Auflage unter in situ-Bedingungen an 4 Terminen in der Vegetationsperiode 1999 am Standort OB5 in der Lüneburger Heide. $\Psi_{\text {soil }}$ : Bodenmatrixpotential, $\Psi_{\text {root }}$ : Wurzelwasserpotential (Scholander-Methode), $\mathrm{A}_{\mathrm{r}}$ : Wurzeloberfläche, J: maximale Flußrate zur Mittagszeit, $\mathrm{Lp}_{\mathrm{r}}$ : radiale hydraulische Leitfähigkeit. Unterschiedliche Buchstaben markieren signifikante Unterschiede zwischen den Arten an einem Termin $(n=4-5)$; U-Test nach Mann \& Whitney $(\mathrm{p}<0.05)$.

\begin{tabular}{lcccccc} 
& $\begin{array}{c}\Psi_{\text {soil }} \\
{[\mathrm{MPa}]}\end{array}$ & $\begin{array}{c}\Psi_{\text {root }} \\
{[\mathrm{MPa}]}\end{array}$ & $\begin{array}{c}\mathrm{A}_{\mathrm{r}} \\
{\left[\mathrm{m}^{2}\right]}\end{array}$ & $\begin{array}{c}\mathrm{J} \times 10^{9} \\
{\left[\mathrm{~m}^{3} \mathrm{~s}^{-1}\right]}\end{array}$ & $\begin{array}{c}\mathrm{Lp}_{\mathrm{r}} \times 10^{8} \\
{\left[\mathrm{~m} \mathrm{MPa}^{-1} \mathrm{~s}^{-1}\right]}\end{array}$ \\
\hline Beech & -0.008 & -0.65 & $0.09 \pm 0.05$ & $1.31 \pm 0.4$ & $2.66 \pm 1.18$ & $\mathrm{a}$ \\
Oak & -0.008 & -0.44 & $0.28 \pm 0.3$ & $1.5 \pm 1.23$ & $1.7 \pm 1.53$ & $\mathrm{a}$ \\
Spruce & -0.008 & -0.46 & $0.08 \pm 0.06$ & nd & $\mathrm{nd}$ & \\
\multicolumn{7}{c}{$\mathrm{Jul} .12$} \\
Beech & -0.052 & -1.52 & $0.09 \pm 0.05$ & $3.77 \pm 3.15$ & $3.22 \pm 2.36$ & $\mathrm{a}$ \\
Oak & -0.052 & -0.76 & $0.28 \pm 0.3$ & $1.82 \pm 1.19$ & $1.57 \pm 1.5$ & $\mathrm{ab}$ \\
Spruce & -0.052 & -0.89 & $0.08 \pm 0.06$ & $0.84 \pm 0.78$ & $1.06 \pm 0.25$ & $\mathrm{~b}$ \\
Beech & -0.030 & -0.81 & $0.09 \pm 0.04$ & $1.72 \pm 0.78$ & $2.87 \pm 1.66$ & $\mathrm{a}$ \\
Oak & -0.030 & -0.64 & $0.09 \pm 0.05$ & $0.58 \pm 0.15$ & $1.27 \pm 0.67$ & $\mathrm{~b}$ \\
Spruce & -0.030 & -0.45 & $0.09 \pm 0.04$ & $1.34 \pm 0.48$ & $3.94 \pm 1.08$ & $\mathrm{a}$ \\
Beech & -0.061 & -1.3 & $0.09 \pm 0.04$ & $1.68 \pm 0.64$ & $1.78 \pm 0.96$ & $\mathrm{a}$ \\
Oak & -0.061 & -1.22 & $0.09 \pm 0.05$ & $0.68 \pm 0.13$ & $0.82 \pm 0.54$ & $\mathrm{a}$ \\
Spruce & -0.061 & -0.66 & $0.09 \pm 0.04$ & $0.86 \pm 0.37$ & $1.87 \pm 0.92$ & $\mathrm{a}$
\end{tabular}

\subsubsection{Flußrate in Wurzeln bei optimaler Wasserversorgung}

$\mathrm{Abb} 4.43$ zeigt beispielhaft den Verlauf eines Dekapitationsexperiments an einer Fichtenwurzel am 2.7.1999. Kurz vor Versuchsbeginn war in der Fichtenwurzel eine Saftflußrate von $2.8 \mathrm{~g} \mathrm{~h}^{-1} \mathrm{zu}$ verzeichnen. Nachdem die Wurzel um 12.40 Uhr unter Wasser dekapitiert wurde und so über die Schnittfläche unbegrenzt mit Wasser versorgt war, stieg die Flußrate auf $59.4 \mathrm{~g} \mathrm{~h}^{-1}$ am nächsten gespeicherten Meßpunkt um 12.45 Uhr, also auf das 20-fache des Ausgangswertes an. In den nachfolgenden etwa $30 \mathrm{~min}$ sank die Flußrate rasch wieder auf ein Niveau von etwa $4 \mathrm{~g} \mathrm{~h}^{-1} \mathrm{ab}$, welches auch nach weiteren 2 Stunden kaum unterschritten wurde.

Bei jedem der Dekapitationsexperimente war ein deutlicher Anstieg der Flußrate in der untersuchten Wurzel festzustellen (Tab.4.11). Die größte Differenz zwischen dem Fluß vor und nach dem Dekapitieren war bei einer Fichtenwurzel am 5.7.1999 zu beobachten. Hier stieg die Flußrate bei optimaler Wasserversorgung auf $107.2 \mathrm{~g} \mathrm{~h}^{-1}$ also fast auf das 150-fache des Ausgangswertes von $0.72 \mathrm{~g} \mathrm{~h}^{-1}$ an. Den geringsten Anstieg zeigte die dritte untersuchte Eichenwurzel am 9.9.1999, bei der nach dem Schneiden das 3.75-fache des Ausgangwertes erreicht wurde. Der größte Teil der untersuchten Wurzeln wies einen Anstieg um etwa das 10-fache auf. 


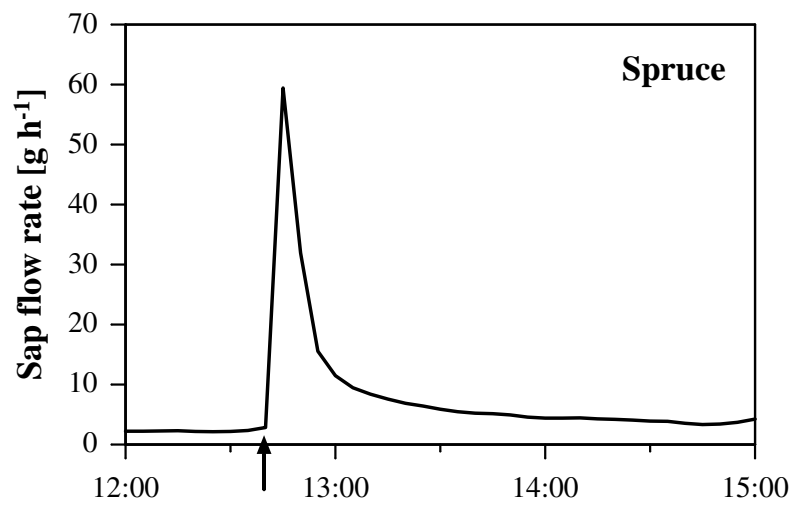

July 2, 1999

\begin{abstract}
Abb. 4.43: Zeitlicher Verlauf eines Dekapitationsexperiments an einer $3 \mathrm{~mm}$ starken Fichtenwurzel auf der Untersuchungsfläche Lüneburger Heide am 2.7.1999. Der Pfeil markiert den Zeitpunkt des Schnittes. Die Flußrate wurde mit einem Miniatur-Saftflußsensor in 5-Minuten Intervallen aufgezeichnet.
\end{abstract}

Die aus den oberflächenspezifischen Flußraten und der Potentialdifferenz zwischen Wurzel und Boden berechnete Leitfähigkeit $\mathrm{Lp}$ r lag mit $0.42-3.36 \cdot 10^{-8} \mathrm{~m} \mathrm{MPa}^{-1} \mathrm{~s}^{-1}$ in derselben Größenordnung, wie die in Tab. 4.10 dargestellten Werte; tatsächlich basieren die Mittelwerte vom 9. September in Tab. 4.10 zum Teil auf den hier dargestellten in situ-Ergebnissen der Dekapitationsexperimente.

Die Berechnung der radialen und axialen Widerstände aus dem Gesamtwiderstand (Kehrwert von $\mathrm{Lp}_{\mathrm{r}}$ ) ergab für alle untersuchten Wurzeln einen deutlich höheren radialen $R_{\text {rad }}$ als axialen Widerstand $R_{a x}$. Das Verhältnis $R_{\text {rad }}: R_{a x}$ lag bei maximal 147.89 bei der Fichte am 2. Juli und betrug minimal 2.75 bei Eichenwurzel Nr. 3 am 9. September (Tab. 4.11). Als Richtwert ergab sich für die Buche ein Verhältnis von 8.4:1, bei der Eiche von 8.2:1 und bei der Fichte von 61.6:1.

\title{
4.3.10 Bewässerungsversuche
}

Bei Experimenten, in denen der Wurzelraum Anfang Juli 1999 in der Lüneburger Heide mit 50-100 mm bewässert wurde, konnte bei allen 3 untersuchten Baumarten ein deutlicher Anstieg der Saftflußrate in den besser wasserversorgten Wurzelsträngen gegenüber der Kontrolle beobachtet werden (Abb. 4.44). Alle 6 dargestellten Wurzeln wiesen vor Beginn der Bewässerung sehr geringe Saftflußraten von 0.2 bis $0.5 \mathrm{~g} \mathrm{~h}^{-1}$ auf. Erfolgte die 3-5 h dauernde Bewässerung am Vormittag des betreffenden Meßtages, so konnte noch am selben Tag ein eindeutiger Anstieg der Flußrate beobachtet werden; bei Bewässerung am Nachmittag hingegen erfolgte die sichtbare Reaktion erst am darauffolgenden Tag. Während der Bewässerung waren Störungen an den Miniatursaftflußsystemen durch Befeuchtung der Sensoren nicht immer zu vermeiden. Aufgrund der dadurch bedingten vorübergehenden technischen Ausfälle sind genauere Angaben über die zeitliche Reaktion der Wurzeln nicht möglich. 
Tabelle 4.11: Ergebnisse von Dekapitationsexperimenten an Buchen-, Eichen- und Fichtenschwachwurzeln an verschiedenen Terminen in der Vegetationsperiode 1999. $\mathrm{J}_{\mathrm{in}-\mathrm{situ}}$ : Flußrate vor dem Dekapitieren, $J_{\text {decap. }}$ : maximale Flußrate bei optimaler Wasserversorgung 2 min nach dem Dekapitieren, $A_{\text {root}}$ : Wurzeloberfläche, $\Psi_{\text {soil }}$ : Bodenmatrixpotential, $\Psi_{\text {root }}$ : Wurzelwasserpotential (Scholander-Methode), $\mathrm{L}_{\mathrm{r}}$ : radiale hydraulische Leitfähigkeit, $\mathrm{R}_{\mathrm{tot}}, \mathrm{R}_{\mathrm{rad}}, \mathrm{R}_{\mathrm{ax}}$ : gesamter, radialer und axialer Wurzelwiderstand.

\begin{tabular}{|c|c|c|c|c|c|c|c|c|}
\hline & \multicolumn{2}{|c|}{ Beech } & \multicolumn{3}{|c|}{ Oak } & \multicolumn{3}{|c|}{ Spruce } \\
\hline & Sep. 9 & Sep. 9 & Sep. 9 & Sep. 9 & Sep. 9 & Jul. 2 & Jul. 5 & Jul 27 \\
\hline $\begin{array}{l}J_{\text {in }-s i t u} \\
{\left[\mathrm{~g} \mathrm{~h}^{-1}\right]}\end{array}$ & 8.30 & 2.60 & 2.20 & 2.10 & 3.20 & 2.81 & 0.72 & 2.40 \\
\hline $\begin{array}{l}J_{\text {decap. }} \\
{\left[\mathrm{g} \mathrm{h}^{-1}\right]}\end{array}$ & 60 & 30 & 15 & 36 & 12 & 90 & 107 & 17 \\
\hline $\begin{array}{l}\mathrm{A}_{\text {root }} \\
{\left[\mathrm{m}^{2}\right]}\end{array}$ & 0.06 & 0.07 & 0.03 & 0.12 & 0.07 & 0.06 & 0.04 & 0.12 \\
\hline $\begin{array}{l}\Psi_{\text {soil }} \\
{[\mathrm{MPa}]}\end{array}$ & -0.07 & -0.07 & -0.07 & -0.07 & -0.07 & -0.01 & -0.02 & -0.04 \\
\hline $\begin{array}{l}\Psi_{\text {root }} \\
{[\mathrm{MPa}]}\end{array}$ & -1.30 & -1.30 & -1.22 & -1.22 & -1.22 & -0.89 & -0.89 & -1.08 \\
\hline $\begin{array}{l}\mathrm{Lp} \mathrm{p}_{\mathrm{r}} \cdot 10^{8} \\
{\left[\mathrm{~m} \mathrm{MPa} \mathrm{MP}^{-1} \mathrm{~s}^{-1}\right]}\end{array}$ & 3.36 & 0.89 & 1.75 & 0.42 & 1.18 & 1.42 & 0.52 & 1.47 \\
\hline $\begin{array}{l}\mathrm{R}_{\text {tot }} \times 10^{-7} \\
{\left[\mathrm{MPa} \mathrm{s} \mathrm{m} \mathrm{m}^{-1}\right]}\end{array}$ & 2.98 & 11.24 & 5.71 & 23.87 & 8.45 & 7.03 & 19.12 & 6.79 \\
\hline 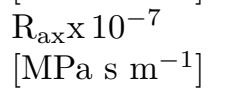 & 0.41 & 0.97 & 0.84 & 1.39 & 2.25 & 0.22 & 0.13 & 0.99 \\
\hline $\begin{array}{l}\mathrm{R}_{\mathrm{rad}} \times 10^{-7} \\
{\left[\mathrm{MPa} \mathrm{s} \mathrm{m}^{-1}\right]}\end{array}$ & 2.56 & 10.26 & 4.87 & 22.48 & 6.19 & 6.81 & 18.99 & 5.81 \\
\hline $\mathrm{R}_{\mathrm{rad}}: \mathrm{R}_{\mathrm{ax}}$ & 6.23 & 10.54 & 5.82 & 16.14 & 2.75 & 31.03 & 147.89 & 5.87 \\
\hline
\end{tabular}

Die deutlichste Reaktion zeigten die Fichtenwurzeln, die vor der Bewässerung etwa auf dem Niveau der Kontrollwurzel lagen (maximal $0.2 \mathrm{~g} \mathrm{~h}^{-1}$ ) und am folgenden Tag die 6-10-fache Saftflußrate aufwiesen. Eine ähnlich deutliche Reaktion zeigte die in Abb. 4.44 links dargestellte Eichenwurzel, während die andere Wurzel dieser Art weniger stark reagierte. Jedoch stieg auch in dieser Wurzel die Flußrate von 0.2 auf $0.4 \mathrm{~g} \mathrm{~h}^{-1}$, also auf das Doppelte, an.

In beiden untersuchten Buchenwurzeln stieg die Flußrate ebenfalls auf das 5-6fache des Ausgangswertes an. Bei der rechts dargestellten Wurzel war bereits am 2 . Juli ein leichter Anstieg gegenüber der Kontrollwurzel zu verzeichnen, obwohl die gezielte Bewässerung in dieser Meßgrube erst 3 Tage später, am 5. Juli, durchgeführt wurde. Bei der späteren Freilegung dieser Wurzel wurde festgestellt, daß sich ein kleiner Seitenast in der Nähe der anderen Meßgrube befand, die bereits am 1. Juli befeuchtet wurde. Die Bewässerung des gesamten Wurzelstrangs am 5. Juli führte nochmals etwa zu einer Verdreifachung der Flußrate. 

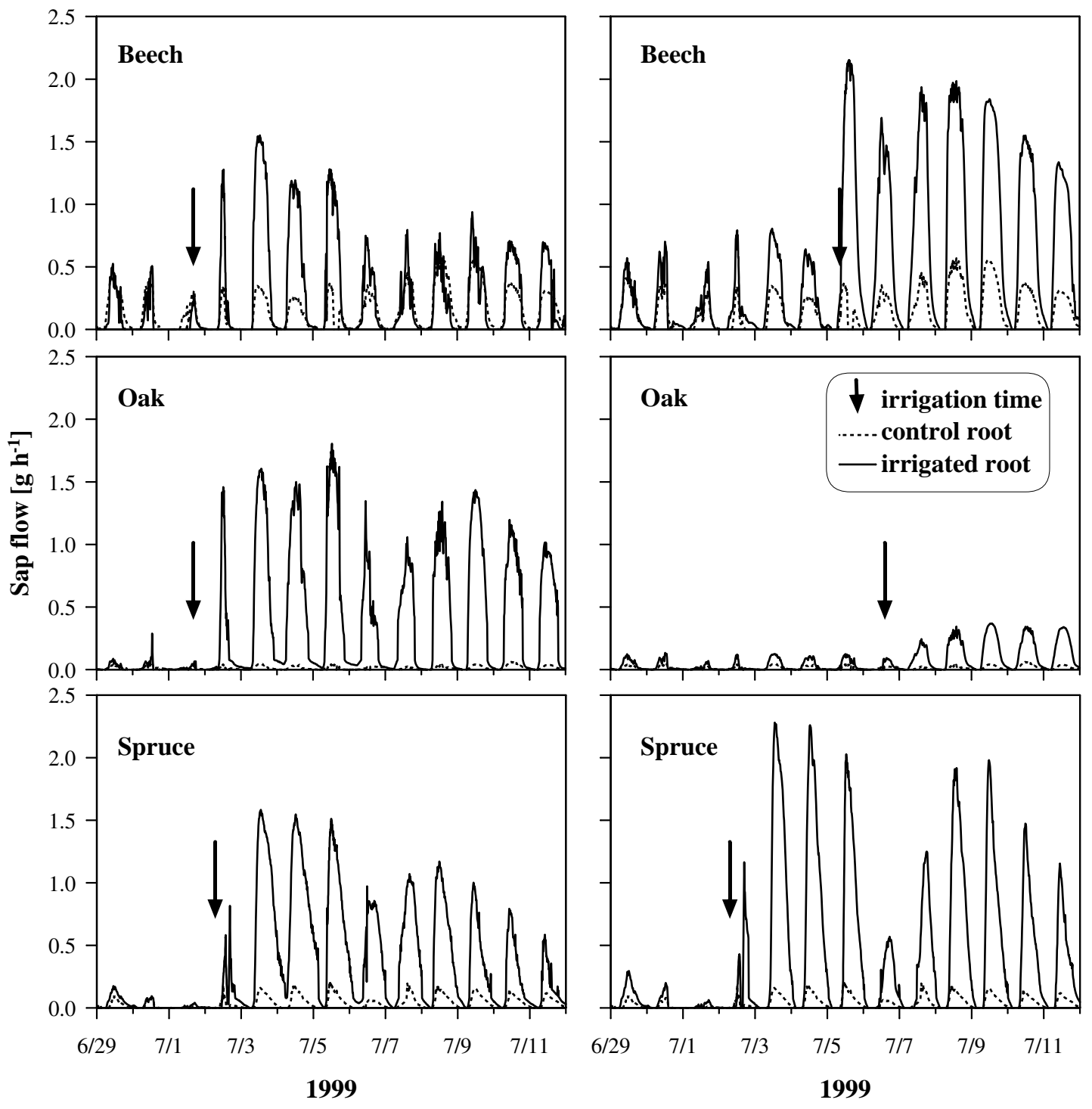

Abb. 4.44: Bewässerungsversuche an Buchen-, Eichen- und Fichtenwurzeln des Mineralbodens an verschiedenen Terminen Anfang Juli 1999 am Standort OB5 in der Lüneburger Heide. Bewässerung: 251 pro Bodengrube (entspricht ca. 50-100 mm) als Tropfberegnung über 3-5 Stunden. Saftflußrate gemessen mit Miniatursaftflußsystemen. 


\section{Diskussion}

\subsection{Die Eignung von Miniatur-Saftflußmeßsystemen zur Messung der Wasseraufnahme von Baumwurzeln}

In der vorliegenden Arbeit wurden erstmals Miniatur-Saftflußmeßsysteme an Baumwurzeln der Durchmesserklasse $<5 \mathrm{~mm}$ eingesetzt. Nur in dieser Durchmesserklasse ist es möglich, nach der Messung die wasseraufnehmenden Wurzelstränge vollständig freizulegen und so die Saftflußraten auf die jeweilige Oberfläche bzw. das Trockengewicht zu beziehen. Die Einführung dieser Methode ist eine wichtige Neuerung für die Untersuchung des Wasserflusses im Wurzelsystem von Altbäumen. Die größte Innovation liegt dabei in der Tatsache, daß die Rhizosphäre während der Messung nicht gestört wird. Auf diese Weise kann die Wasseraufnahme intakter Baumwurzeln über längere Zeiträume unter natürlichen Bedingungen des Bodenwassergehalts, des Bodengefüges und des Mykorrhizierungsgrades gemessen werden.

Der Methode der Saftflußbestimmung mit Miniatur-Meßsystemen wurde gegenüber anderen störungsfreien Methoden der Vorzug gegeben, weil sie im Freiland einsetzbar ist und nicht, wie z.B. die NMR-Technik (MacFall et al., 1991), nur an getopften Pflanzen im Labor. Außerdem erlauben die geringen Kosten der Sensoren (3040 DM im Eigenbau) die parallele Untersuchung einer größeren Anzahl an Wurzeln.

Der größte Nachteil dieser Methode liegt in der Möglichkeit großer Meßungenauigkeiten bei sehr kleinen nächtlichen Flußraten. Die Genauigkeit von heat balanceSensoren ähnlicher Bauart wurde in vielen Untersuchungen analysiert. Weibel \& de Vos (1994) geben, basierend auf den Angaben 16 weiterer Autoren, eine übliche Meßgenauigkeit von $\pm 10 \%$ für die Saftflußmessung an Stämmen oder Grobwurzeln von mehreren cm Durchmesser an. Auch bei diesen größeren Durchmessern spielen Abweichungen bei kleinen nächtlichen Flüssen eine bedeutende Rolle. Allerdings werden dort viel höhere Flußraten gemessen: Fichtner \& Schulze (1990), Dugas et al. (1994), Allen \& Grime (1995), Herzog et al. (1997) und Kjelgaard et al. (1997) geben Tagesmaxima von $100 \mathrm{~g} \mathrm{~h}^{-1}$ und mehr an, was dem 10-fachen der in der vorliegenden Arbeit gemessenen Werte entspricht. Grime et al. (1995b) benutzen einen ,low-flow filter“, weil die berechneten Nachtwerte $100 \mathrm{~g} \mathrm{~h}^{-1}$ überschritten, während das Tagesmaximum bei $200-250 \mathrm{~g} \mathrm{~h}^{-1}$ lag.

Meßfehler bei größeren Saftflußsystemen haben üblicherweise andere Ursachen als die in der vorliegenden Arbeit festgestellte Überschätztung der Nachtwerte. So spielen z.B. Temperaturgradienten durch externe Einflüsse bei der Messung an oft sonnenexponierten Stämmen oder Zweigen eine bedeutende Rolle. In den vergangenen 10 Jahren wurden viele technische Verbesserungen vorgeschlagen, darunter eine Kontrol- 
le der Heizleistung (Ishida et al., 1991, Weibel \& Boersma, 1995), ein verbesserter Kontakt zwischen Stamm und Heizung (Weibel \& de Vos, 1994) oder eine Minimierung der Wärmeverluste entlang der Anschlußkabel (Groot \& King, 1992) für die heat balance-Sensoren. Außerdem muß bei größeren Durchmessern die Wärmespeicherung im Pflanzengewebe berücksichtigt werden (Grime et al., 1995a).

Die meisten dieser Fehlerquellen sind bei der Saftflußmessung an Wurzeln von Altbäumen in geschlossenen Beständen von untergeordneter Bedeutung, weil der umgebende Boden und das geschlossene Kronendach eine effektive Isolation gegen Temperaturschwankungen bieten, die flexible Korkmanschette einen guten Kontakt zur Wurzel ermöglicht und die Wärmespeicherung im Gewebe bei diesen dünnen Durchmessern vernachlässigbar klein ist. Allerdings müssen die Sensoren für niedrige Flüsse $<2$ oder $5 \mathrm{~g} \mathrm{~h}^{-1}$ präzise kalibriert werden, weil sich die Beziehung zwischen $\mathrm{T}_{\mathrm{so}}-\mathrm{T}_{\mathrm{si}}$ und der Flußrate in diesem Bereich umkehrt.

Die Einführung eines empirischen Faktors zur Bestimmung sehr kleiner Flußraten ist sicherlich ein Rückschritt gegenüber der auf rein physikalischen Zusammenhängen basierenden Berechnung der Saftflußrate. Andererseits stellt die gravimetrische Kalibrierung für niedrige Flußraten ein einfaches und präzises Werkzeug dar, die Anwendbarkeit der Methode in Bereiche zu erweitern, die üblicherweise unterhalb der Meßgenauigkeitsgrenze liegen. Außerdem repräsentieren die fehlerbehafteten kleinen Flüsse nur einen geringen Teil $(<10 \%)$ der Tagessaftflußrate in den untersuchten dünnen Wurzeln, wodurch der durch den empirischen Faktor bedingte maximale Fehler deutlich reduziert wird.

Zusammenfassend läßt sich also folgern, daß die Kombination der Saftflußmessung an dünnen Baumwurzeln und die anschließende Bestimmung der aufnehmenden Oberfläche bzw. Biomasse ein großes Potential für die weitere experimentelle Untersuchung des Wasserflusses in Baumwurzelsystemen bietet. Neuere Publikationen über Wurzelsaftflußmessungen (Green \& Clothier, 1988, 1995, Lott et al., 1996, Burgess et al., 1998, Senock \& Leuschner, 1999, Smith et al., 1999) gaben wichtige Einblicke in die Mechanismen des Wassertransports in Wurzeln, ermöglichten jedoch keinen Bezug der Aufnahmeraten auf die Wurzeloberfläche oder Biomasse, weil die untersuchten Wurzeln in der Regel zu groß waren, um quantitativ geerntet zu werden.

\subsection{Standörtliche Variabilität der Wasseraufnahme von Buchenwurzeln in Abhängigkeit von der Wasserversorgung}

\subsubsection{Die Wasserversorgung der Buchen an den drei Standorten}

Regionalklima Trotz der geringen geographischen Distanz von etwa $200 \mathrm{~km}$ sind deutliche Unterschiede in der Wasserversorgung der Buchen an den 3 untersuchten Standorten zu erkennen. Dies äußert sich zunächst in den langjährigen Mitteln der Niederschläge, die in den Hochlagen des Sollings über $1000 \mathrm{~mm} \mathrm{a}^{-1}$ liegen, während 
der Standort Ziegelrodaer Forst im Regenschatten des Harzes nur etwa die Hälfte an Niederschlag erhält. Das Untersuchungsjahr 1998, in dem dieser Standortsvergleich durchgeführt wurde, erwies sich als äußerst kühles regenreiches Jahr, in dem während der Vegetationsperiode 20-30 \% mehr Regen fielen als im langjährigen Mittel.

Weiterhin ist die Buche an den 3 untersuchten Standorten einer unterschiedlichen Transpirationsbeanspruchung durch die Atmosphäre ausgesetzt. Das VPD als treibende Kraft der Transpiration wurde an den Standorten in der Folge Ziegelrodaer Forst $>$ Lüneburger Heide $>$ Solling kleiner, wobei die Tageshellphasensumme VPD cum $_{\text {im }}$ Ziegelrodaer Forst dasjenige in der kühlen Höhenlage des Sollings etwa um $30 \%$ überstieg. Hierbei muß allerdings beachtet werden, daß die Werte für den Ziegelrodaer Forst nicht oberhalb des Buchen-Eichen-Mischwaldes am Standort auf dem Höhenzug gemessen wurden, sondern von der $14 \mathrm{~km}$ entfernten und etwas tiefer gelegenen DWD-Meßstation in Artern stammen. Oberhalb des Bestandes dürfte das Sättigungsdefizit etwas kleiner sein.

Auffällig war die enge Übereinstimmung der witterungsbedingten Schwankungen im Jahresverlauf an den 3 weit voneinander entfernt liegenden Standorten. Nur an wenigen Tagen konnte eine Abweichung der relativen zeitlichen Änderung von Strahlung und Sättigungsdefizit zwischen den Untersuchungsflächen nachgewiesen werden. Langanhaltende Schönwetter- bzw. Regenperioden waren an allen Standorten in gleicher Form ausgeprägt.

Edaphische Unterschiede Neben dem Regionalklima spielen edaphische Unterschiede zwischen den Standorten eine bedeutende Rolle für die Wasserversorgung der Bäume. So bewirkten niederschlagsarme Perioden im Juli und August 1998 am Standort Solling aufgrund des hohen Feinporenanteils im schluffigen Lehmboden eine sehr rasche Potentialabsenkung trotz hoher Wassergehalte über 25 vol\%. Sandböden hingegen besitzen eine weitaus geringere Wasserhaltekapazität. Bei Austrocknung des Bodens bleibt das Matrixpotential aufgrund des großen Porenvolumens zunächst über eine gewisse Spanne von Bodenwassergehalten bei hohen Werten, sinkt dann aber durch die rasche Entleerung der Grobporen sehr steil ab (Larcher, 1994). Der Sandboden in der Lüneburger Heide entspricht dieser Charakteristik. So bewirkte an diesem Standort die etwa 14-tägige Trockenphase im August des niederschlagsreichen Jahres 1998 nur eine geringe Abnahme des Bodenwassergehaltes, die mit einer geringen Potentialabsenkung auf etwa $-250 \mathrm{hPa}$ verbunden war. Der Boden in der Lüneburger Heide kann also während der gesamten beobachteten Vegetationsperiode als nahezu wassergesättigt angesehen werden.

Der lehmige Sand am Standort Ziegelrodaer Forst ist bezüglich der Korngrößenverteilung und des Wasserhaltevermögens zwischen dem Sandboden der Lüneburger Heide und dem deutlich feinkörnigeren schluffigen Lehm im Solling anzusiedeln. Dies belegt auch der Verlauf der Feld-pF-Kurven. Allerdings war im Ziegelrodaer Forst während des Untersuchungsjahres eine Dynamik der Bodenfeuchteparameter zu erkennen, die sich deutlich von den andern beiden Standorten unterschied. Bereits in der ersten 
niederschlagsärmeren Periode Mitte Juli 1998 sank der Bodenwassergehalt deutlich ab und erreichte erst im September wieder das Niveau vom Sommeranfang. Das Matrixpotential war fast über diesen gesamten Zeitraum zu negativ für die Erfassung mittels Tensiometertechnik, jedoch erlaubt die Beziehung aus den Feld-pF-Kurven eine zumindest sehr grobe Abschätzung der Potentiale. Anhand dieser Extrapolation ergeben sich für $30 \mathrm{~cm}$ Bodentiefe Matrixpotentiale von etwa -10000 hPa während der zweiten Augusthälfte. In dieser mittleren Tiefe ist also selbst in diesem niederschlagsreichen Jahr eine starke Austrocknung des Bodens zu erkennen. Im Oberboden und in größerer Tiefe wurde ergibt diese grobe Abschätzung ein Bodenmatrixpotential von etwa -2000 hPa. Diese Bodenhorizonte trockneten also im Untersuchungsjahr 1998 weit weniger stark aus als in $30 \mathrm{~cm}$ Tiefe.

Transpiration der Buche bei unterschiedlicher Wasserversorgung Die anhaltende Bodentrocknis trotz wiederholter Niederschlagsereignisse am Standort Ziegelrodaer Forst deutet darauf hin, daß dem Boden durch die Baumwurzeln mehr Wasser entzogen wurde als durch Niederschläge nachgeliefert werden konnte. Im Solling und in der Lüneburger Heide hingegen war in diesem feuchten Jahr kaum eine Absenkung des Bodenwassergehalts aufgrund der Wasserschöpfung durch den Baumbestand zu erkennen. Daraus ergibt sich die Frage, wie hoch die Transpirationsrate der Buche unter verschiedenen Umweltbedingungen ist und inwieweit sie ihren Wasserverbrauch an das jeweilige Wasserangebot an unterschiedlichen Standorten anpaßt. Am Standort Ziegelrodaer Forst wurde im Jahr 1996, das bezüglich der Niederschläge und Bodenfeuchtedynamik dem Jahr 1998 vergleichbar war, eine Bestandestranspiration von $224 \mathrm{~mm} \mathrm{a}^{-1}$ gefunden (Strobel, 1997). Der Einfluß der Bodenwasserverfügbarkeit erwies sich dabei als erstaunlich gering. Schipka (in Vorber.) beobachtete am Standort Ziegelrodaer Forst mit $207 \mathrm{~mm} \mathrm{a}^{-1}$ in der Vegetationsperiode 1999 eine ähnlich hohe Transpirationsrate. Zeitgleiche Messungen ergaben für den Solling einen ähnlich hohen Wert (229 $\left.\mathrm{mm} \mathrm{a}^{-1}\right)$, während die Buche in der Lüneburger Heide mit $274 \mathrm{~mm} \mathrm{a}^{-1}$ eine deutlich größere Wasserumsatzrate aufwies. Im Ziegelrodaer Forst ist jedoch das Sättigungsdefizit deutlich größer als im Solling. Die Buche scheint also aufgrund mangelhafter Wasserversorgung im Ziegelrodaer Forst ihre Transpirationsrate gegenüber der atmosphärischen Beanspruchung einzuschränken. Dies deckt sich mit den von Schipka (in Vorb.) gemessenen Werten des Blattwasserpotentials, welches im Ziegelrodaer Forst am tiefsten abgesenkt wurde. Im Jahresverlauf änderte sich das Blattwasserpotential an den 3 Standorten in gleicher Weise wie die in der vorliegenden Arbeit gemessenen Wurzelwasserpotentiale. Ferner konnte Landwehr (1997) eine trockenheitsbedingte Einschränkung des Photosynthesevermögens am Standort Ziegelrodaer Forst gegenüber der Lüneburger Heide feststellen und sie deutet die hohen LAI sowie die kurze Lebensdauer der Sonnenblätter als Kompensationsmechanismen der Buche für das verminderte Assimilationsvermögen an diesem Standort. 


\subsubsection{Das Wurzelsystem der Buche an den drei Standorten}

Eine mögliche Erklärung für die relativ gleichmäßige Transpirationsrate der Buche an den unterschiedlich wasserversorgten Standorten wäre eine Anpassung auf der Ebene des Wurzelsystems. Für eine ausreichende Wasserversorgung an den trockeneren Standorten wäre also eine erhöhte Wurzeldichte für die bessere Erschließung der Reserven zu erwarten. In einer detaillierten Studie über die Feinwurzelverteilung und -produktion an denselben Standorten wie in der vorliegenden Studie konnte Hertel (1999) zeigen, daß dies nicht der Fall ist: Sowohl die Bestandesbiomasse an Feinwurzeln $(\mathrm{d}<2 \mathrm{~mm})$ als auch der root area index (RAI) nahmen in der Reihenfolge Lüneburger Heide $>$ Solling $>$ Ziegelrodaer Forst ab (Wurzelmasse: 550, 300 bzw. 250 g TM m${ }^{-2}$, RAI: 9.0, 6.0 bzw. $3.5 \mathrm{~m}^{2} \mathrm{~m}^{-2}$ ). Dies deckt sich weitgehend mit den Ergebnissen der vorliegenden Untersuchung, bei denen die nach der Saftflußmessung geernteten Wurzelstränge im Ziegelrodaer Forst signifikant kleinerere Oberflächen aufwiesen als an den anderen Standorten.

Die untersuchten Wurzelstränge der organischen Auflage wiesen im Ziegelrodaer Forst tendenziell eine gröbere Verzweigungstruktur mit einem geringeren Feinstwurzelanteil auf als die Wurzeln der anderen beiden Buchenwälder. Auch dies steht in Einklang mit den Ergebnissen von Hertel (1999), der für die Feinwurzelbestandesbiomasse im Ziegelrodaer Forst einen Feinstwurzelanteil von etwa $50 \%$ gegenüber 60-70 \% in der Lüneburger Heide und im Solling berechnete.

Auch in der Vertikalverteilung der Buchenwurzeln unterschieden sich die 3 Standorte. In jedem untersuchten Bestand war eine oberflächenahe Durchwurzelung zu beobachten. Im Solling und in der Lüneburger Heide enthielten die oberen $40 \mathrm{~cm}$ des Bodens etwa 85-90 \% der Bestandeswurzelbiomasse. Im Ziegelrodaer Forst hingegen betrug dieser Anteil nur etwa $65 \%$ (Hertel, 1999). Die absolute Menge an Fein- und Grobwurzeln ist jedoch in der Lüneburger Heide am größten (Coners, 1996, Muhs, 1997). Auch wird am Standort Lüneburger Heide der Boden tiefgründiger durch die Buchenwurzeln erschlossen $(<1 \mathrm{~m})$ als im Solling und im Ziegelrodaer Forst, wo das anstehende Gestein die tieferreichende Bodenerschließung limitiert.

Bezüglich der Morphologie und der Vertikalstruktur des Wurzelsystems ist also keine eindeutige Anpassung der Buche an die jeweilige Wasserversorgung des Standorts zu erkennen. Entgegen der Erwartung wurden am trockensten Standort sogar die niedrigsten Feinwurzeldichten gefunden.

\subsubsection{Die Wasseraufnahme durch die Buchenwurzeln}

Ergebnisse der Untersuchung mit der heat balance Methode Die Xylemsaftflußrate in Baumwurzeln ist im zeitlichen Verlauf eng mit der Stammsaftflußrate und damit der Transpirationsrate der Baumkrone korreliert. Als treibende Kraft für die Wasseraufnahme kann daher die Potentialdifferenz zwischen dem Boden und der Atmosphäre angesehen werden. Ein direkter Vergleich der Wasseraufnahmeraten von Buchenwurzeln an räumlich weit getrennt liegenden Standorten ist daher aufgrund un- 
terschiedlicher Witterungsänderungen im Tagesverlauf nicht möglich. Dagegen war die zeitliche Dynamik der Tageswerte von Sättigungsdefizit und Globalstrahlung trotz der großen Distanz weitgehend synchron. Daher erscheint es sinnvoll, die Tagesraten der Wasseraufnahme für Vergleiche zwischen den 3 Standorten heranzuziehen. Der Einfluß geringer regionalklimatisch bedingter Abweichungen wird weiterhin durch die Betrachtung von Mittelwerten über den Zeitraum von mehreren Tagen minimiert.

Angesichts der geringen Transpirationseinschränkung der Buche entlang des Feuchtegradienten der 3 untersuchten Standorte und der deutlich kleineren Wurzelbiomasse am trockensten Standort im Ziegelrodaer Forst waren deutliche Unterschiede in der Wasseraufnahmeeffizienz zu erwarten. Tatsächlich entsprach beim direkten Vergleich der Standorte in einer Periode mit hohen Bodenwassergehalten und geringer atmosphärischer Transpirationsbeanspruchung (Anfang Juli 1998) die oberflächenspezifische Wasseraufnahmerate der Reihenfolge Ziegelrodaer Forst $>$ Lüneburger Heide > Solling (390, 240 bzw. $200 \mathrm{~g} \mathrm{~m}^{-2} \mathrm{~d}^{-1}$ ).

Ein verändertes Bild bot sich hingegen in der ersten längerfristigen Schönwetterperiode des Sommers 1998. In der zweiten Julihälfte reagierten die Buchenwurzeln auf das erhöhte Sättigunsgsdefizit der Luft mit einem deutlichen Anstieg der oberflächenspezifischen Wasseraufnahmerate. Dieser Anstieg war im Solling wesentlich steiler als an den anderen beiden Standorten, so daß die oberflächenbezogene Wasseraufnahmerate hier der Reihe Solling $>$ Ziegelrodaer Forst $>$ Lüneburger Heide entsprach. Der Boden war zu dieser Zeit in der Lüneburger Heide und im Solling noch nahezu wassergesättigt ( $\Psi>100 \mathrm{hPa}$ ), während im Ziegelrodaer Forst bereits deutlich abgesenkte Wasserpotentiale gemessen wurden. Es liegt also der Schluß nahe, daß die Buchen im Solling auf das erhöhte VPD mit nahezu uneingeschränkter Transpiration reagieren, während im Ziegelrodaer Forst bereits ein milder Trockenstreß zu einer Limitierung der Transpirationsrate führt.

Bedeutung verschiedener Bodenhorizonte für die Wasseraufnahme An den Standorten Lüneburger Heide und Solling waren im Verlauf der Vegetationsperiode 1998 zwischen der organischen Auflage und dem Mineralboden kaum Unterschiede in der oberflächenspezifischen Wasseraufnahmerate zu erkennen. Dies ist vornehmlich auf das hohe Wasserangebot im Jahr 1998 zurückzuführen, wie der Vergleich mit dem sehr trocken-warmen Jahr 1999 am Standort Lüneburger Heide zeigt. Dort wurden in der Vegetationsperiode 1999 beim Vergleich der Wasseraufnahme von Buche, Eiche und Fichte bei jeder untersuchten Baumart deutliche höhere Wasseraufnahmeraten in der organischen Auflage als im Mineralboden gefunden (s. Kap. 5.3.2). In jenem sehr trockenen Jahr war offenbar das Wasserpotential in der organischen Auflage weniger stark abgesunken als im Mineralboden, so daß die Buche den Großteil des transpirierten Wassers aus der Auflage schöpfte. Im kühl-feuchten Jahr 1998 hingegen war die Saugspannung des Mineralbodens so gering, daß hier ähnlich hohe Wasseraufnahmeraten möglich waren wie bei den Wurzeln der organischen Auflage. Ein ähnliches Verhältnis zwischen den beiden Jahren mit deutlich verschiedener Witterung war bei 
der Eiche zu beobachten. Unter Trockenstreß (1999) nahmen die Auflagewurzeln der Eiche wesentlich mehr Wasser pro Wurzeloberfläche auf als diejenigen im Mineralboden (bis $1 \mathrm{~m}$ Tiefe); bei guter Wasserversorgung und geringer Transpirationsbeanspruchung im Jahr 1998 traten hingegen kaum Unterschiede zwischen den Horizonten auf (Korn, 1999).

Im Ziegelrodaer Forst hingegen war die Aufnahmerate der Wurzeln im Mineralboden deutlich höher als in der organischen Auflage. Dies unterstreicht die große Bedeutung der organischen Auflage für den Wasserumsatz von Wäldern (Schaap, 1996). Dieses Substrat zeichnet sich durch eine hohe Wasserspeicherkapazität und ein gleichmäßiges Absinken des Wasserpotentials bei sinkendem Wassergehalt aus (Leuschner. 1998). Weiterhin ist dieser Horizont direkt an den Austauschprozessen mit der Atmosphäre in Form von Niederschlägen und der Evaporation beteiligt. Modellrechnungen für den Bestand in der Lüneburger Heide ergaben, daß etwa ein Drittel des gesamten Wasserumsatzes aus der organischen Auflage bestritten werden (Leuschner, 1998).

Dem Buchenwald im Ziegelrodaer Forst steht eine deutlich geringere organische Auflage (ca. $3 \mathrm{~cm}$ gegenüber 10 bzw. $12 \mathrm{~cm}$ in der Lüneburger Heide bzw. im Solling) als Wasserspeicher zur Verfügung. Die schnelle Entleerung dieses Reservoirs zeigt der Jahresgang des Wassergehalts in der organischen Auflage 1996 (Strobel, 1997). Gegenüber 50 vol\% im Frühling lag hier der Wassergehalt während der ganzen Vegetationsperiode bei 4-13 vol\% und stieg erst im Oktober wieder an. In der Lüneburger Heide hingegen sank der Wassergehalt der organischen Auflage selbst im trockenen Jahr 1992 kaum unter 20 vol\% (Leuschner, 1998). Mögliche Ursachen für die deutlich geringeren Wassergehalte in der organischen Auflage am Standort Ziegelrodaer Forst sind (i) die geringere Mächtigkeit, (ii) eine höhere Evaporation durch höhere Temperaturen und Sättigungsdefizite und (iii) eine frühzeitige Entleerung dieses Wasserspeichers durch die Wurzeln.

Aufgrund dieser geringen Wasserverfügbarkeit in der organischen Auflage sind die Buchen im Ziegelrodaer Forst also auf eine vermehrte Wasseraufnahme aus tieferen Bodenhorizonten angewiesen. Hier ist eine Anpassung des Wurzelsystems der Buche an die bodenhydrologischen Eigenschaften dieses Standorts zu erkennnen. Wie die Ergebnisse der Saftflußmessungen belegen, waren die oberflächenspezifischen Wasseraufnahmeraten der Mineralbodenwurzeln höher als diejenigen der Auflagewurzeln. Die oberen Mineralbodenhorizonte sind an diesem Standort ebenfalls intensiver durchwurzelt. Diese Eigenschaften der Buchenwurzeln im Ziegelrodaer Forst stehen im Einklang mit der Beobachtung, daß der Boden in einer Tiefe von $30 \mathrm{~cm}$ über ausgedehnte Zeiträume am stärksten austrocknete.

„High capacity roots“ In der zweiten Meßperiode des Jahres 1998 wurde im Ziegelrodaer Forst bei 2 Wurzeln eine auffallend hohe oberflächenspezifische Wasseraufnahmerate festgestellt. Die querschnittsbezogenen Saftflußraten waren denen benachbarter Wurzeln etwa vergleichbar. Bei der Freilegung nach Abschluß der Saftflußmessung stellten sich diese Wurzeln jedoch als extrem kurz verzweigt heraus und besa- 
Ben eine deutlich geringere Gesamtoberfläche als die simultan untersuchten Wurzeln. Das große oberflächenspezifische Wasseraufnahmevermögen ist also nicht auf hohe Flußraten, sondern auf eine sehr kleine aufnehmende Oberfläche zurückzuführen. Beide Wurzeln wiesen recht steil abwärts und endeten in der Nähe des Stamms (ca. $50 \mathrm{~cm}$ ) in etwa $50 \mathrm{~cm}$ Bodentiefe mit einem kurzen, strauchartigen Verzweigungsmuster. Solche abwärtsgerichteten „krähenfußartigen“ Verzweigungen (Steinmeyer, 1988) wurden auch bei der Untersuchung des Grobwurzelsystems von Buchen und Eichen in der Lüneburger Heide unterhalb des Stammes gefunden (Coners, 1996). Basierend auf diesen Befunden wurde im folgenden Jahr beim Vergleich der Wasseraufnahme von Buchen, Eichen und Fichten versucht, solche kurz verzweigten Wurzeln ebenfalls für diesen Standort nachzuweisen. Jedoch erwies sich in allen Fällen der Boden in Stammnähe, vor allem bei Buche und Eiche, als zu dicht durchwurzelt, um solche Wurzeln störungsfrei herauspräparieren zu können. Ob die beiden Funde im Ziegelrodaer Forst eine zufällige Häufung darstellen und welche Bedeutung solche „high capacity roots“

für die Wasserversorgung der Bäume haben, kann anhand dieser Untersuchung nicht abschließend geklärt werden. Auch bleibt offen, wie diese Wurzeln, die nur ein kleines Bodenvolumen erschließen, mit Wasser versorgt werden. In Stammnähe wäre eine verbesserte Wasserzufuhr durch den Stammablauf möglich.

\subsection{Baumarten-Unterschiede in der Wurzelwasseraufnahme}

\subsection{1 Ökologische Ansprüche der Buche, Eiche und Fichte bezüglich der Wasserversorgung}

Von den drei untersuchten Baumarten ist die Traubeneiche besser an trockene Standorte angepaßt als die Buche, während die Fichte wesentlich trockenheitsempfindlicher ist und eher in kühl-feuchten Höhenlagen optimalen Wuchs zeigt (Ellenberg, 1996). Die Tatsache, daß den Buchen-Eichen-Mischwald am armen und zeitweise trockenheitsgefährdeten Standort in der Lüneburger Heide weitläufige Fichtenforste umgeben, ist auf die jahrelange forstliche Praxis zurückzuführen, schnellwüchsige Fichten (und in der Lüneburger Heide vor allem auch Kiefern) der Buche und anderen Laubbaumarten vorzuziehen.

Die unterschiedliche Trockenstreßreaktion von Buche und Eiche wurde in diesem Bestand verschiedentlich nachgewiesen. So fand Backes (1996) bei der Buche eine frühere Einschränkung der stomatären Leitfähigkeit im Tagesverlauf als bei der Eiche (s. auch Leuschner et al. (2001a)). Auch wies die Buche im Gegensatz zur Eiche in Trockenperioden einen reduzierten Stammzuwachs auf. Terborg (1998) konnte an Buchenblättern weiterhin eine Einschränkung der Nettophotosyntheserate bei eingeschränkter Blattleitfähigkeit nachweisen. Für die Fichte am untersuchten Standort liegen keine Daten zur oberirdischen Trockenstreßantwort vor, doch wurde bei dieser Art eine frühzeitige Einschränkung der Transpirations- und Photosyntheserate festgestellt 
(Maier-Mercker, 1998)

Dieses artspezifische Verhalten bei mangelhafter Wasserversorgung konnte mit der Stammsaftflußmessung in der vorliegenden Untersuchung ebenfalls nachgewiesen werden. In der ausgeprägten Trockenperiode im Sommer 1999 schränkte die Fichte ihre Transpiration wesentlich früher ein als die Buche. Die Eiche hingegen konnte ihre Transpirationrate zunächst sogar noch ein wenig erhöhen und zeigte erst in den letzten Tagen der Trockenperiode Anfang August 1999 eine leichte Einschränkung der Stammsaftflußrate. Zwar konnten pro Art nur jeweils 2-3 Stämme untersucht werden, jedoch verhielten sich diese im zeitlichen Verlauf auffallend gleichsinnig, so daß hier über die Reaktion einzelner Individuen hinaus auf artspezifisches Verhalten geschlossen werden darf.

\subsubsection{Artspezifische Unterschiede in der Wasseraufnahme durch die Wurzeln}

Die deutlichen Unterschiede im Wasserhaushalt und Wasserumsatz der Krone zwischen den Arten konnten im Wurzelbereich nicht bestätigt werden. Alle drei Arten wiesen ähnliche oberflächenspezifische Wasseraufnahmeraten auf. Aufgrund der hohen Variabilität der Wasseraufnahme zwischen benachbarten Wurzeln eines Baumes (Variationskoeffizient: 50-100 \%) konnten nur in den seltensten Fällen signifikante Unterschiede zwischen den Arten festgestellt werden.

Tendenziell wurde in den meisten Fällen sowohl in der organischen Auflage als auch im Mineralboden die höchste Wasseraufnahmerate bei der Buche und die niedrigste bei der Eiche gefunden. Dies steht in scheinbarem Gegensatz zum ökologischen Verhalten der Baumarten. Speziell in der Trockenperiode bis Anfang August 1999 schränkte die Eiche als letzte der 3 Baumarten die Transpiration ein, obwohl weder die Wurzeln der organischen Auflage noch des Mineralbodens höhere Wasseraufnahmeraten aufwiesen als diejenigen der Buche und der Fichte.

Wesentlich größere Unterschiede wurden dagegen bei allen 3 Baumarten zwischen der organischen Auflage und dem Mineralboden gefunden. Bei Buche und Fichte war die Aufnahmerate der Auflagewurzeln jeweils etwa doppelt so hoch wie im Mineralboden; bei der Eiche sogar 3-4-fach. Werden zusätzlich die unterschiedlichen Durchwurzelungsverhältnisse in den Horizonten berücksichtigt, so nimmt die relative Bedeutung noch zu. Nach Hertel (1999) und Leuschner et al. (2001b) beträgt im untersuchten Buchen-Eichen Mischwald in der Lüneburger Heide der root area index der Buchenwurzeln 5.1 in der organischen Auflage bzw. 4.4 im Mineralboden bis $60 \mathrm{~cm}$. Dagegen wurden für die Eiche nur Werte von 1.5 bzw. 1.9 gefunden. Anhand dieser RAI-Werte und der modellierten oberflächenspezifischen Wasseraufnahmerate von Buchen- und Eichenwurzeln kann die Wasseraufnahme in einer grob abschätzenden Bilanz der Transpiration (aus den gemessenen Stammsaftflußraten bezogen auf die Kronenprojektionsfläche) gegenübergestellt werden (Abb. 5.1).

Eine mögliche Fehlerquelle stellt in dieser Bilanz der RAI dar, der nur als Mittelwert für den gesamten Mischbestand vorliegt. Da die Stammzahl der Eichen deutlich 
geringer ist als diejenige der Buchen, sind am jeweiligen Stamm einer Eiche deutlich größere Wurzeloberflächen pro Bodenfläche zu erwarten. Die hier berechnete Wurzelwasseraufnahme wird also vor allem bei der Eiche deutlich unterschätzt. Weiterhin ist die große Variabilität zwischen einzelnen Wurzeln zu beachten, die eine genaue Vorhersage der Wasseraufnahme erschwert. Die in der Bilanz zugrundegelegten Mittelwerte der Wasseraufnahmerate sind also in einem gewissen Ausmaß fehlerbehaftet.

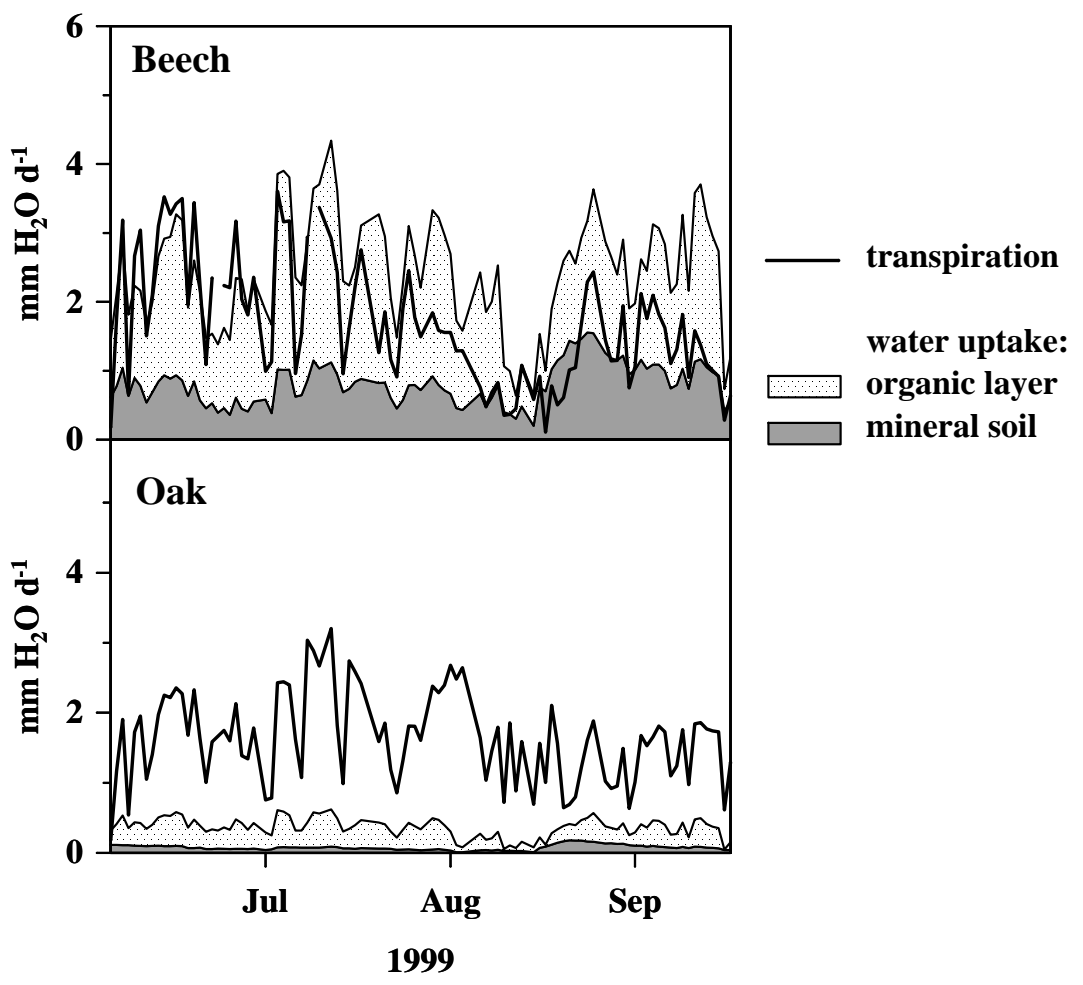

Abb. 5.1: Vergleich der Wasseraufnahme aus der organischen Auflage bzw. dem Mineralboden mit der Transpiration der Krone von Buche und Eiche am Standort OB5 in der Lüneburger Heide. Transpiration: Stammsaftflußraten bezogen auf die Kronenprojektionsfläche der Meßbäume. Wasseraufnahme: Ergebnisse der Modellrechnung für die oberflächenspezifische Wasseraufnahmerate der Wurzeln anhand des Bodenwassers, VPD und G; hochgerechnet auf den Bestand anhand des root area index. RAI-Werte nach Hertel (1999) und Leuschner et al. (2001b): Organische Auflage: Buche: 5.1, Eiche: 1.5; Mineralboden bis $60 \mathrm{~cm}$ Tiefe: Buche: 4.4, Eiche: 1.9 .

Auch bei Berücksichtigung der unsicheren Bilanzierung des Wasserhaushalts ist in Abb. 5.1 die große Bedeutung der organischen Auflage für den Wasserhaushalt der Buche an diesem Standort zu erkennen. Obwohl der hier betrachtete Mineralboden gegenüber der organischen Auflage ein etwa 6-fach größeres Bodenvolumen repräsentiert, trägt dieser Horizont nur etwa zu 30-50 \% zur Wasserversorgung der Buche bei. Dies bestätigt die Ergebnisse aus Modellrechnungen, die für die organische Auflage einen Anteil von etwa einem Drittel an der Wasserversorung des gesamten Bestandes 
ergaben (Leuschner, 1998). Bei der Eiche ist die Wasseraufnahme aus der organischen Auflage gegenüber den ersten $60 \mathrm{~cm}$ des Mineralbodens sogar noch größer (Verhältnis ca. 2:1). Allerdings scheint die Wasserbilanz der Eiche höchstens zur Hälfte aus dem Oberboden gedeckt zu werden. Es ist also zu vermuten, daß ein bedeutender Teil des transpirierten Wassers bei der Eiche aus tieferen Bodenhorizonten aufgenommen wird. Wiederholt wurden in diesem Bestand höhere Bodenwassergehalte und damit verbunden eine geringere Bodensaugspannung in Tiefen unterhalb von $100 \mathrm{~cm}$ gefunden (Coners, 1996, Leuschner, 1993, 1994). Diese Bodentiefen werden jedoch von der Eiche wesentlich intensiver durchwurzelt als von der Buche, wie eine Untersuchung des Schwach- und Grobwurzelsystems zeigte (Coners et al., 1998). Die Schlußfolgerung, daß die Eiche im Gegensatz zur Buche bei anhaltender Trockenheit einen bedeutenden Anteil ihrer Wasserbilanz aus feuchten Horizonten in 1-2 m Bodentiefe decken kann, steht in Einklang mit Tensiometermessungen an beiden Baumarten, die in einer Tiefe von $170 \mathrm{~cm}$ während der zweiten Hälfte der Vegetationsperiode 1990 signifikant negativere Wasserpotentiale unter Eiche ergaben (Leuschner, 1993).

Abschließend ist also festzuhalten, daß die grobe Abschätzung der Wasserbilanz von Buche und Eiche an diesem Standort in der Lüneburger Heide für beide Baumarten die große Bedeutung der organischen Auflage für die Wasserversorgung der Bäume unterstreicht. Während die Buche nahezu ausschließlich auf die Wasservorräte im Oberboden angewiesen ist, und eine deutliche Einschränkung der Transpiration und des Zuwachses bei anhaltender Trockenheit zeigt, kann die Eiche auch in Trockenperioden Bodenfeuchtereserven in größerer Tiefe nutzen.

Für die Fichte liegen für diesen Standort keine Daten zur Vertikalverteilung der Wurzeln vor. Gegenüber dem Herzwurzelsystem von Buche und Eiche ist das Senkerwurzelsystem der Fichte deutlich auf den Oberboden konzentriert (Köstler et al., 1968). Dies bestätigte sich in der vorliegenden Arbeit auch bei den Freilegungsarbeiten zur Bestimmung der aufnehmenden Oberfläche der untersuchten Wurzelstränge. Für die deutlich kürzer verzweigten Wurzelstränge im Mineralboden wurde gegenüber den Wurzeln von Buche und Eiche nur ein Bruchteil der Arbeitszeit für die Ernte eines Wurzelstranges benötigt.

Daß die Fichte kaum Wasserreserven in größerer Tiefe nutzen kann, zeigt die Transpirationseinschränkung während der Trockenperiode im August 1999. Da diese Einschränkung im Verlauf der Bodenaustrocknung deutlich früher eintrat als bei der $\mathrm{Bu}-$ che, kann darauf geschlossen werden, daß die Fichte das oberflächennahe Bodenwasser nicht so effektiv nutzen konnte wie die Buche. Hier ist ein Zusammenhang mit den gemessenen Wurzelwasserpotentialen in der organischen Auflage zu erkennen, die bei der Buche signifikant tiefer abgesenkt wurden als bei der Fichte. Für den Sommer 1999 liegen keine Werte zum Wassergehalt und -potential der organischen Auflage vor, doch ist zu vermuten, daß die Auflagewurzeln der Fichte im Gegensatz zur Buche in der Trockenperiode im August keine ausreichend große Potentialdifferenz zur Rhizosphäre aufbauen konnten und daher die verbliebenen, stark gebundenen Wasservorräte der organischen Auflage für die Fichte kaum noch nutzbar waren. 


\subsubsection{Anatomie und Chemie der Wurzel-Abschlußgewebe}

In der vorliegenden Arbeit konnte erstmals die Wasseraufnahme unter in situ-Bedingungen mit chemischen Parametern des Wurzel-Abschlußgewebes direkt verglichen werden, weil Wasserfluß und chemische Daten auf die Wurzeloberfläche bezogen wurden. Die Oberfläche als physiologisch relevante Einheit für Transportprozesse stellt besonders beim Vergleich verschiedener Baumarten eine wesentlich bessere Bezugsgröße dar als die Trockenmasse des Periderms oder der Endodermis, da diese Gewebe artspezifisch unterschiedlich dick sein können und so möglicherweise massenbezogene chemische Daten zu falschen Schlüssen führen könnten.

In keiner der untersuchten Buchen-, Eichen- und Fichtenfeinwurzeln konnte das Primärstadium der Wurzelentwicklung mit Stele, Endodermis, Cortex und Exodermis sowie einer apikalen Wurzelhaarzone festgestellt werden. Nur an einzelnen Buchenwurzeln wurden in der dünnsten Durchmesserklasse Reste einer noch nicht vollständig abgestoßenen Endodermis gefunden, die jedoch nur in Form loser Zellgruppen vorlag und keine physiologische Bedeutung als Transportbarriere mehr haben kann.

Es ist bemerkenswert, daß alle Feinwurzeln sogar direkt hinter der Wurzelspitze bereits ein vollständig differenziertes Periderm aufwiesen. Dies steht in Widerspruch zu den Ergebnissen von McKenzie \& Peterson (1995), die mehrere $\mathrm{cm}$ lange peridermfreie Wurzelabschnitte bei Sämlingen von Pinus banksiana $(10-11 \mathrm{~cm})$ und Eucalyptus pilularis $(6-7 \mathrm{~cm})$ fanden. In der vorliegenden Arbeit waren jedoch alle anatomisch untersuchten Wurzeln mykorrhiziert. Dies kann zu einer ausgeprägten Hemmung des Längenwachstums und zum völligen Fehlen einer Endodermis führen, wie bereits von Guttenberg (1968) an Fichtenwurzeln beobachten konnte.

In den Zellwänden des Periderms wurden bei den untersuchten Baumwurzeln aliphatische Suberinmengen gefunden, die mit denen in der Endo- und Hypodermis von Maiswurzeln vergleichbar sind (4-10 bzw ca. $21 \mu \mathrm{g} \mathrm{g}^{-1}$, Zimmermann et al. (2000)). Hingegen wies das Baumwurzelperiderm nur geringe Spuren aromatischer Suberinbestandteile auf (Hartmann, mündl. Mitt.). Lignin wurde in wesentlich kleineren Mengen gefunden als Suberin und zeigte keine deutlichen Unterschiede zwischen den Arten bzw. den Durchmesserklassen einer Art. Da keine weißen unsuberinisierten Wurzelabschnitte gefunden wurden, muß das aufgenommene Wasser also PeridermZellschichten mit mindestens 200 (Fichte), 250 (Buche) bzw. 450 (Eiche) nmol Suberin $\mathrm{cm}^{-2}$ passieren.

Die Wurzelstränge der organischen Auflage, an denen die anatomischen und chemischen Analysen durchgeführt wurden, hatten Gesamtoberflächen von etwa 800$1000 \mathrm{~cm}^{2}$, wobei auf die Feinstwurzeln $<1 \mathrm{~mm}$ bei Buche und Eiche jeweils $75 \%$, bei der Fichte dagegen nur $43 \%$ der Gesamtoberfläche entfielen. Innerhalb dieser doch recht großen Wurzeloberfläche kann die Aufnahmeaktivität mit der zur Verfügung stehenden Methodik nicht genauer lokalisiert werden. Die spezifische Rolle der Feinbzw. Grobwurzeln bei der Wasseraufnahme wird zur Zeit diskutiert (z.B. (Peterson \& Cholewa, 1998, Escamilla \& Comerford, 2000)). Neuere Untersuchungen an Zwiebelwurzeln haben gezeigt, daß apikale Wurzelabschnitte bemerkenswerterweise einen 
höheren radialen Einstromwiderstand aufweisen als weiter differenzierte und stärker suberinisierte Wurzelzonen (Barrowclough et al., 2000). Dies bestätigt eine Reihe von Untersuchungen zur Wasser- und Ionenaufnahme durch suberinisierte Wurzeln (Addoms, 1946, Chung \& Kramer, 1975, van Rees \& Comerford, 1990, MacFall et al., 1991). Hierbei ist allerdings die Frage noch nicht geklärt, ob tote peridermale Korkzellen eine ausreichend hohe Permeabilität für den Durchfluß von Wasser aufweisen, oder ob die Wasseraufnahme größtenteils durch Lücken im Periderm stattfindet (McKenzie \& Peterson, 1995). Wenn der Wasserfluß durch die Anzahl an Passage-Zellen oder Peridermlücken bestimmt wird, ist keine enge Beziehung zwischen der chemischen Zusammensetzung des Periderms und der Wasseraufnahme zu erwarten.

Möglicherweise sind erhöhte Suberin- und Ligningehalte in Feinwurzeln von Bäumen von größerer Bedeutung für die Trockenheitsresistenz der Wurzeln als für die Wasseraufnahme. In mehreren Untersuchungen wurde ein Anstieg des Suberingehalts in der Endo- und Exodermis krautiger Pflanzen nach Einwirkung von Trockenheit oder osmotischem Streß festgestellt (Cruz et al., 1992, North \& Nobel, 1996). Die Feinwurzeln der Eiche können am untersuchten Standort als trockenheitsresistent eingestuft werden, weil sie in der organischen Auflage in größerer Dichte im austrocknungsgefährdeten obersten Horizont zu finden sind als darunter. In einem sehr trockenen Sommer zeigten diese zudem in geringerem Maße eine trockenheitsinduzierte Mortalität als die Buchenfeinwurzeln unter den selben Bedingungen (Hertel, 1999, Leuschner, 2001). Dies steht mit dem hohen Gehalt an aliphatischem Suberin in den hier untersuchten Eichenwurzeln in Einklang. Auch die sehr niedrigen Suberingehalte in den Feinwurzeln der Fichte könnten mit der hohen Trockenheitsempfindlichkeit der Fichte in Zusammenhang stehen (Ellenberg, 1996).

\subsubsection{Die Bedeutung verschiedener wurzelspezifischer Widerstände im SPAC}

Radiale Leitfähigkeit, $\mathbf{L p}_{\mathrm{r}} \quad$ Als wichtige Größe zur Charakterisierung der Wasseraufnahme verschiedener Pflanzenarten wird von vielen Autoren die radiale Leitfähigkeit der Wurzeln (,,root hydraulic conductivity“, L $\mathrm{p}_{\mathrm{r}}$ ) herangezogen. Die verbreitetste Methode zur Ermittlung von $\mathrm{Lp}_{\mathrm{r}}$ ist die Wurzeldrucksonde (Steudle \& Jeschke, 1983, Steudle et al., 1987, Steudle, 1993), mit der in den vergangenen Jahren die Wasseraufnahme verschiedener krautiger, aber auch einiger verholzter Pflanzenarten an dekapitierten Wurzelsträngen untersucht wurde (Frensch \& Steudle, 1993, Steudle, 2000b).

Aus den durch Saftflußmessungen ermittelten oberflächenspezifischen Wasseraufnahmeraten und der Wasserpotentialdifferenz zwischen der Wurzel und dem Boden konnten in der vorliegenden Untersuchung für die Wurzeln von Buche, Eiche und Fichte die in situ-Leitfähigkeitswerte errechnet werden. Mit Werten zwischen 0.82 und 3.84 $10^{-8} \mathrm{~m} \mathrm{MPa}^{-1} \mathrm{~S}^{-1}$ liegen diese in derselben Größenordnung wie die Ergebnisse aus Messungen mit der Wurzeldrucksonde (0.35-6.4 $10^{-8} \mathrm{~m} \mathrm{MPa}^{-1} \mathrm{~s}^{-1}$, Rüdinger et al. (1994), Steudle \& Meshcheryatov (1996), Steudle \& Heydt (1997)). Diese gute Übereinstimmung ist bemerkenswert, weil die beiden Werte auf völlig unter- 
schiedlichen Methoden basieren: Bei der Messung mit der Wurzeldrucksonde werden unter Laborbedingungen unterschiedliche Wurzeldrücke und Flußraten in Wurzelsystemen von dekapitierten Sämlingen durch Volumenänderungen in der Meßapparatur oder durch Variation des osmotischen Wertes im Medium induziert. Die in situ-LprWerte hingegen spiegeln die Wurzelleitfähigkeit von Altbäumen unter natürlichen Bedingungen im Bestand wider. Die treibende Kraft ist in diesem Fall die Transpiration der Bäume, also negative Wurzelwasserpotentiale anstatt positiver Wurzeldrücke wie im Laborexperiment. Allerdings beinhaltet der aus in situ-Messungen berechnete Widerstand nicht nur die radiale Leitfähigkeit der Wurzel, sondern schließt auch den Nachleitwiderstand des Wassers im Boden mit ein. Schließlich ist zu berücksichtigen, daß bei extremer Trockenheit Kontaktprobleme zwischen Wurzel und Boden durch Schrumpfungsprozesse auftreten können, die den in situ-Lp $\mathrm{p}_{\mathrm{r}}$-Wert beeinflussen.

Osmotische Gradienten zwischen Rhizosphäre und Wurzelxylem dürften an dem untersuchten Standort mit seinem äußerst armen Sandboden dagegen kaum eine Rolle bei der Wasseraufnahme spielen. Auch unter Laborbedingungen standen die durch osmotische Gradienten bzw. hydrostatischen Druck getriebenen Wasserflüsse in dekapitierten Wurzelsystemen im Verhältnis 1:100, die Wurzeln reagierten also auf osmotische Gradienten wesentlich geringfügiger als auf hydrostatischen Druck (Rüdinger et al., 1994, Steudle \& Meshcheryatov, 1996, Steudle \& Heydt, 1997).

Stimmen die beiden völlig unterschiedlichen Methoden zur Messung von $L p_{r}$ auch erstaunlich gut in der Größenordnung der Werte überein, so liefern sie doch leicht abweichende Ergebnisse bezüglich der Relationen zwischen den drei Baumarten. Laboruntersuchungen mit der Wurzeldrucksonde an Buchen-, Traubeneichen- und Fichtensämlingen ergaben Lpr-Werte von 0.35-1.6, 0.5-1.1 bzw. $6.4 \cdot 10^{-8} \mathrm{~m} \mathrm{~s}^{-1} \mathrm{MPa}^{-1}$; auch die Stieleiche (Quercus robur) wies mit $0.5-4.8 \cdot 10^{-8} \mathrm{~m} \mathrm{~s}^{-1} \mathrm{MPa}^{-1}$ eine vergleichbare radiale Leitfähigkeit auf (Rüdinger et al., 1994, Steudle \& Meshcheryatov, 1996, Steudle \& Heydt, 1997). Während Buche und Traubeneiche sich also kaum unterschieden, war die radiale Leitfähigkeit der Fichtenwurzeln deutlich höher als die der anderen beiden Arten. Die in der Lüneburger Heide ermittelten in situ-Leitfähigkeiten ergeben an 2 von 4 Terminen die Abfolge Fichte $>$ Buche $>$ Traubeneiche. Nur an einem von 4 Terminen hatte die Fichte die kleinste radiale Leitfähigkeit, an einem weiteren lagen keine Ergebnisse für diese Art vor. An jedem Termin war jedoch unter in situ-Bedingungen die radiale Leitfähigkeit der Eichenwurzeln deutlich geringer als diejenige der Buchen. Dies entspricht den chemischen und anatomischen Eigenschaften der Wurzeln, die aufgrund der signifikanten Unterschiede der Peridermstärke und der Suberingehalte den höchsten radialen Widerstand bei der Eiche bzw. den geringsten bei der Fichte vermuten lassen. Jedoch waren auch die in situ-Leitfähigkeiten der drei Arten nur in Einzelfällen signifikant voneinander verschieden.

Die Untersuchung der Anatomie und Chemie des Wurzelperiderms ergab sehr deutliche, meist signifikante Unterschiede zwischen den drei Baumarten. Im Vergleich zu Differenzen im Suberingehalt sind die Unterschiede in der radialen Leitfähigkeit gering, so daß hier nur von Trends die Rede sein kann. Bei krautigen Pflanzen wurden wesentlich höhere radiale Leitfähigkeiten in Wurzelsystemen festgestellt (Mais bzw. 
Bohne: 21 bzw. 30 $10^{-8} \mathrm{~m} \mathrm{MPa}^{-1} \mathrm{~s}^{-1}$, (Steudle, 2000a) $)$. Der Unterschied in der radialen Leitfähigkeit dürfte demnach zwischen Bäumen und krautigen Arten wesentlich größer als zwischen den verschiedenen Baumarten sein. Es bleibt festzuhalten, daß sich trotz der z.T. erheblichen Unterschiede in der Struktur des Wurzelsystems und der Anatomie und chemischen Zusammensetzung der Feinwurzeln alle drei hier untersuchten Baumarten in ihren hydraulischen Eigenschaften erstaunlich ähnlich sind.

Axiale Leitfähigkeit Eine ähnlich schwache Abhängigkeit, wie sie zwischen der radialen Leitfähigkeit und der Wurzelanatomie gefunden wurde, ergibt sich auch bei der Betrachtung der axialen Leitfähigkeit der Wurzel. Hier wies die Fichte signifikant geringere Werte auf als Buche und Eiche, obwohl der Anteil leitender Xylemfläche bei dieser Art deutlich höher war. Dies steht in Zusammenhang mit dem Durchmesser der Xylemelemente, die bei den beiden Laubbaumarten deutlich weitlumiger sind. Allerdings wäre dann für den Ringporer Eiche mit ihren großen Tracheen eine größere Leitfähigkeit zu erwarten als bei der Buche, was die Messungen nicht bestätigen konnten. Der große Unterschied in der axialen Leitfähigkeit zwischen den beiden Laubbaumarten und der Fichte ist wahrscheinlich auf die Gefäßlänge zurückzuführen. So konnten Zimmermann \& Jeje (1981) im Stamm der zerstreutporigen Baumart Acer saccharum Gefäßlängen bis zu $32 \mathrm{~cm}$ Länge nachweisen, bei der ringporigen Art Quercus rubra sogar bis zu $10 \mathrm{~m}$. Bei einer Segmentlänge von $5 \mathrm{~cm}$ ist mit einer gewissen Wahrscheinlichkeit zu erwarten, daß einzelne Tracheen die beiden Schnittflächen direkt miteinander verbinden, während die Tracheiden der Fichte nur wenige mm lang werden. Dies deckt sich mit der Beobachtung, daß die erhöhten Leitfähigkeitswerte der Buchen- und Eichenwurzeln jeweils auf einzelne Segmente mit extrem erhöhter Leitfähigkeit zurückzuführen war. Zusätzlich kann austretendes Harz die Schnittflächen der Fichtenwurzelsegmente partiell verstopft und so die gemessene Gesamtleitfähigkeit in den Wurzeln dieser Art gegenüber den anderen künstlich herabgesetzt haben. Das hier festgestellte Ausmaß der Leitfähigkeitsunterschiede zwischen Buche, Eiche und Fichte dürfte also zum Teil rein methodisch bedingt sein.

Axiale und radiale Leitfähigkeit im Vergleich Im „,composite model“ der Wasseraufnahme werden unabhängige apoplastische und symplastische Wege des Wassers in das Wurzelxylem als wesentliche Steuergrößen für die Gesamtwasseraufnahme diskutiert (Steudle, 2000a, 2001). Hierbei wird der axiale Widerstand des Xylems auf dem Weg der Fernleitung des Wassers zum Stamm üblicherweise als vernachlässigbar klein gegenüber dem radialen hydraulischen Widerstand in der Wurzel angesehen. Ein direkter Vergleich der gemessenen axialen und radialen Leitfähigkeit bzw. des Widerstands ist nicht möglich, weil $\mathrm{Lp}_{\mathrm{r}}$ auf die Wurzeloberfläche, $\mathrm{k}_{m}$ hingegen auf die Wurzellänge bezogen wird (Whitehead \& Jarvis, 1981). Zur Abschätzung des Verhältnisses zwischen axialem und radialem hydraulischen Widerstand führten Steudle \& Meshcheryatov (1996) Abschneideexperimente an Wurzelsystemen von Eichensämlingen durch. Die Halbwertszeit der Druckrelaxation war hier nach dem Abschneiden 
des kompletten Wurzelsystems um den Faktor 11 kleiner als im intakten Wurzelsystem. Die Autoren folgern daraus, daß der radiale Widerstand der Wurzeln wesentlich größer war als der axiale, weil Druckänderungen im Medium nach Wegfall des radialen Widerstandes fast ohne Verzögerung zu einer Änderung der Flußrate führten.

Die Dekapitationsexperimente an Buchen-, Eichen- und Fichtenwurzeln in der Lüneburger Heide deuten ebenfalls darauf hin, daß der radiale Widerstand etwa das 10fache des axialen beträgt. In einzelnen Experimenten wurden aber auch deutlich größere Verhältnisse bis zum fast 150 -fachen festgestellt. Auch diese Freilandexperimente erlauben jedoch keinen direkten Vergleich des axialen und radialen Widerstands, weil keine einheitliche Bezugsgröße zur Verfügung steht. In Gleichung (3.9) wurde für die Berechnung von $J_{\text {decap }}$ die Oberfläche des Wurzelstrangs eingesetzt; hier wurde also die hypothetische axiale Leitfähigkeit berechnet, die ein Wurzelstrang mit einer gegebenen Oberfläche aufweist.

Schneideexperimente zur Untersuchung der hydraulischen Eigenschaften verschiedener Kompartimente eines Baumes wurden bereits von Roberts (1977) an Pinus sylvestris und von Running (1980) an Pinus contorta durchgeführt. In diesen Untersuchungen wurde der Stamm kleiner Bäume unter Wasser abgesägt und in den folgenden Stunden bzw. Tagen die Transpiration und das Blattwasserpotential gemessen. Die aus diesen Werte berechneten Widerstände ergaben, daß der Widerstand von Boden und Wurzelsystem etwa $50 \%$ des gesamten hydraulischen Widerstandes im SPAC ausmachte. Für den Vergleich zwischen radialer und axialer Leitfähigkeit der Wurzeln liefern diese Untersuchungen jedoch keine eindeutige Aussage, weil hier der gesamte (radiale und axiale) Widerstand des Wurzelsystems mit dem Widerstands des gesamten Baumes verglichen wird. Hier spielt also auch die stomatäre Leitfähigkeit und der Phasenübergang bei der Transpiration eine bedeutende Rolle.

Leitfähigkeitsverluste durch Kavitationen Nach dem oben gesagten kann der axiale hydraulische Widerstand des Xylems für die Beschreibung der Wasseraufnahme in die Wurzeln zunächst als vernachlässigbar klein angesehen werden. Die axiale Leitfähigkeit des Wurzelsystems hat jedoch eine große Bedeutung im Hinblick auf die Propagation des in den Blättern durch die Transpiration aufgebauten negativen Wasserpotentials in die Wurzeln. Gemäß SPAC-Modell und Kohäsionstheorie des Wassertransports steht der Wasserfaden im Xylem unter einer sehr großen Spannung. Wird durch eine zu hohe Transpirationsbelastung bei nicht ausreichender Wassernachlieferung vom Wurzelsystem diese Saugspannung zu groß, kann dieser Faden reißen (Sperry et al., 2001). Die dadurch entstehenden Embolien in einzelnen Xylemelementen blockieren nachfolgend die Fernleitung des Wassers. Durch Leitfähigkeitsmessungen an Wurzel- und Zweigsegmenten nach Applikation unterschiedlich hoher Drücke konnte eine Druckabhängigkeit der Embolierate ( „vulnerability curve“) für einzelne Baumkompartimente verschiedener Arten ermittelt werden, wobei sich die Wurzeln als deutlich empfindlicher erwiesen als der Kronenbereich (Sperry \& Saliendra, 1994. Alder et al., 1996, Hacke \& Sauter, 1996, Mecuccini \& Comstock, 1997). Aufgrund 
der Tatsache, daß die größte Kavitationsempfindlichkeit bei den dünnsten Wurzeln gefunden wurden, werden diese von Sperry et al. (2001) als „Sicherung“ im hydraulischen System des Baumes angesehen: Gerät der Baum unter Trockenstreß, werden die am leichtesten ersetzbaren Teile zuerst geschädigt. Bei anhaltender Trockenheit sterben die Feinwurzeln ab und können bei Wiederbefeuchtung nachwachsen. Bei kurzem, weniger intensivem Streß können die embolierten Gefäße in lebenden Wurzeln nach Yang \& Tyree (1992) widerbefüllt werden, wenn sich das Wasserpotential in den Wurzeln wieder über Werte von $-2 T / r$ entspannt ( $T=$ Oberflächenspannung des Wassers, $r=$ Radius des gasgefüllten Xylemelements). Weiterhin können durch diesen Sicherungsmechanismus der frühzeitigen Kavitation in Feinwurzeln Teile des Wurzelsystems in trockenen, oberen Bodenhorizonten vom hydraulischen System des Baumes abgekoppelt werden, ohne das gesamte Fernleitungsystem zu stören (Sperry et al., 2001). Dadurch wird die Verlagerung der Wasseraufnahme auf tiefergelegene Wurzelstränge in feuchteren Bodenhorizonten ermöglicht. Vulnerability curves liegen für die Wurzeln der hier untersuchten Baumarten nicht vor. Bei 30-jährigen Traubeneichen fanden Cochard et al. (1996) für das Wasserpotential im Xylem der Zweige einen kritischen Wert von -2.5 MPa, dessen Unterschreitung zu einem raschen Verlust der Leitfähigkeit führt. Tatsächlich wurde durch die Regulation der Stomata das Blattwasserpotential stets oberhalb dieser kritischen Grenze gehalten. Eine vergleichbare Feinregulation der Eiche konnte auch 1999 in der Lüneburger Heide beobachtet werden. Hier fiel das Blattwasserpotential auch in der ausgeprägten Trockenperiode im August nicht unter -2.0 MPa. Das Potential in den Wurzeln der organischen Auflage wurde bei der Eiche bis -1.22 MPa, dasjenige der Buchenwurzeln sogar auf -1.78 MPa abgesenkt, während Fichtenwurzeln nur -1.08 MPa erreichten. Ob diese Werte bereits zu einer Absenkung der hydraulischen Leitfähigkeit durch Kavitation führten, bleibt noch zu untersuchen.

Eine bleibende Schädigung der Wurzeln in der sommerlichen Trockenperiode 1999 ist jedoch nicht wahrscheinlich. Durch Bewässerungsexperimente konnte bei Mineralbodenwurzeln aller 3 Baumarten ein sofortiger Anstieg der Saftflußrate nachgewiesen werden, obwohl diese zuvor bei Trockenheit eine nur geringe Aufnahmerate zeigten. In allen auf diese Weise bewässerten Wurzelsträngen war in den Tagen zuvor die Saftflußrate unter $0.5 \mathrm{~g} \mathrm{~h}^{-1}$ gefallen, so daß diese mit den Miniatursaftflußsystemen trotz deutlicher Verbesserung der Genauigkeit bei niedrigen Flußraten kaum noch mit ausreichender Präzision bestimmbar war. Spätestens am Tag nach der Bewässerung wurden in allen bewässerten Wurzeln der Buche, Eiche und Fichte maximale Flußraten bis zu $2.5 \mathrm{~g} \mathrm{~h}^{-1}$ gemessen, was einem Anstieg um das 2-10-fache entsprach. Diese schnelle Reaktion auf ein verbessertes Wasserangebot im Boden wäre nicht möglich gewesen, wenn die Wurzeln bereits abgestorben wären, oder embolierte Gefäße nicht in kurzer Zeit wiederbefüllt worden wären. Langandauernde Bodenaustrocknung wie im Juli 1995 kann allerdings zum Absterben von Feinwurzeln führen, wie bei der Buche an diesem Standort von Hertel (1999) beobachtet wurde. Ob dem Absterben Kavitationsereignisse vorausgingen, ist nicht bekannt. 
Leitfähigkeit der Rhizosphäre Außer dem hydraulischen Widerstand der Wurzel spielt die Wassernachleitfähigkeit des Bodens und der Widerstand an der Grenzfläche zur Wurzel eine große Rolle bei der Wasseraufnahme (Kramer, 1983). Die Feinerde auf der Untersuchungsfläche Lüneburger Heide besteht zu über $80 \%$ aus Grob-, Mittel- und Feinsand; der Ton- bzw. Schluffgehalt beträgt dagegen maximal 5 bzw. $10 \%$ (Leuschner, 1994). Grobporen im Sand können bei zunehmender Trockenheit das Wasser weit schlechter binden als Feinporen, was schnell zu einem großen Anteil luftgefüllter Bodenporen führt und die Wasserleitfähigkeit reduziert (Scheffer \& Schachtschabel, 1992). Wasser kann dann nur noch in Form von Wasserdampf bzw. entlang matrikal gebundener Wasserfilme an den Partikeloberflächen bewegt werden, was einen erhöhten Nachleitwiderstand impliziert (Lösch, 2001). Neben einer geringen hydraulischen Leitfähigkeit in austrocknenden Sandböden kann es durch Schrumpfung des Bodens zum Abreißen des Kontaktes zwischen der Wurzel und dem umgebenden Boden kommen. Dieser Effekt dürfte allerdings in der Lüneburger Heide nur eine untergeordnete Rolle spielen, da Quellungs- und Schrumpfungsprozesse in Sandböden weitaus weniger bedeutend sind als in Böden mit höherem Tonanteil. Ein derartiges ,air gap“-Problem spielt laut Kramer (1983) erst bei Erreichen des permanenten Welkepunktes (PWP), also bei etwa -1.5 MPa, eine Rolle. Dieser Kardinalwert wurde jedoch auch in der trockenen Vegetationsperiode 1999 in der Lüneburger Heide nicht erreicht: In $5 \mathrm{~cm}$ Bodentiefe sank der Bodenwassergehalt auf ein Minimum von $13 \mathrm{vol} \%$, in 30 und $60 \mathrm{~cm}$ betrug der Minimalwert etwa 6-7 vol\%. Das Bodenmatrixpotential ist im Bereich > $800 \mathrm{hPa}$ mit der Tensiometertechnik nicht mehr meßbar. Extrapoliert man aber die aufgenommenen Feld-pF Kurven, so ergeben sich für die drei Bodentiefen Jahresminima des Matrixpotentials von etwa -0.2 bis $-0.3 \mathrm{MPa}$. Diese Extrapolation weit über den mit Tensiometern meßbaren Druckbereich hinaus ist allerdings unsicher, weil die pF-Kurve nicht über den ganzen Wertebereich einer linearen Beziehung folgen muß. Leuschner (1994) ermittelte durch Desorption im Laboratorium an Stechzylinderproben aus 15 bzw. $70 \mathrm{~cm}$ Tiefe Bodenwassergehalte von etwa 7 bzw. 3.5 vol \% am PWP. Auch anhand dieser Methode ergeben sich also für das Jahr 1999 Bodenmatrixpotentiale deutlich oberhalb des Welkepunktes, so daß air gap-Phänomene von untergeordneter Bedeutung sein dürften. 


\section{Zusammenfassung}

1. Der Einsatz von Miniatursaftflußanlagen an 3-4 mm starken Wurzeln und die anschließende Bestimmung der Wurzeloberfläche erlaubte in der vorliegenden Untersuchung erstmals die direkte Bestimmung oberflächenspezifischer Wasseraufnahmeraten von Baumwurzeln unter in situ-Bedingungen am natürlichen Standort. Durch präzise Kalibrierung und eine modifizierte Berechnungsmethode konnten auch geringe Saftflußraten in den Wurzeln mitteleuropäischer Waldbäume gemessen werden.

2. Im Tagesgang war ein enger zeitlicher Zusammenhang zwischen der Wurzel- und Stammsaftflußrate zu beobachten. Die Wasseraufnahme ist also im SPAC eng an die Transpirationsrate gekoppelt. Synchrone Messungen an Zweigen, Stamm und Wurzel einer Buche ergaben bei guter Wasserversorgung eine zeitliche Verzögerung der Saftflußrate von jeweils nur etwa 5 min zwischen den Baumkompartimenten.

3. Verschiedene Wurzelstränge eines Baumes unterschieden sich in ihren Wasseraufnahmeraten um ein Vielfaches (Variationskoeffizient: 50-100 \%). Tagesmaxima der Saftflußrate betrugen etwa 2-10 $\mathrm{g} \mathrm{h}^{-1}$, was in der Tagessumme einer oberflächenspezifischen Wasseraufnahmerate von etwa 500-1000 $\mathrm{g} \mathrm{m}^{-2} \mathrm{~d}^{-1}$ entsprach.

4. Ein Vergleich der Wasseraufnahme von Buchenwurzeln an unterschiedlich wasserversorgten Standorten ergab leicht erhöhte oberflächenspezifische Aufnahmeraten am trockensten Standort. Hier wurde auch eine deutliche Tiefenverlagerung der Wasserschöpfung bei Trockenheit beobachtet. In 2 Fällen wurden an diesem Standort extrem kurz verzweigte Wurzelstränge mit Wasseraufnahmeraten bis zu $7000 \mathrm{~g} \mathrm{~m}^{-2} \mathrm{~d}^{-1}$ gefunden. Die Bedeutung solcher ,high capacity roots“ für die Wasserbilanz von Altbäumen konnte aufgrund fehlender weiterer vergleichbarer Befunde nicht abschließend geklärt werden.

5. Die anatomische Analyse von Buchen-, Eichen- und Fichtenschwach- und feinwurzeln vom Standort Lüneburger Heide ergab für alle Arten bereits direkt hinter der meist mykorrhizierten Wurzelspitze ein vollständig ausdifferenziertes Periderm; das Primärstadium der Wurzelentwicklung mit Stele, Endodermis, Cortex und Exodermis sowie einer apikalen Wurzelhaarzone konnte bei keiner Wurzel festgestellt werden. Der Vergleich der Peridermstärke und des Suberingehalts im Abschlußgewebe ergab signifikante Unterschiede zwischen den Arten in der Reihenfolge Eiche > Buche > Fichte.

6. Trotz bedeutender artspezifischer anatomischer Unterschiede wiesen die 3 Baumarten beim direkten Vergleich ähnlich hohe in situ-Wasseraufnahmeraten am Standort Lüneburger Heide auf. Aus den gemessenen oberflächenspezifischen Flußraten und der Potentialdifferenz zwischen Wurzel und Boden wurden radiale Leitfähigkeiten $\left(L p_{r}\right)$ berechnet, die erstaunlich gut mit den Ergebnissen von Laborexperimenten mit der 
Wurzeldrucksonde übereinstimmen, obwohl beiden Werten grundlegend verschiedene Methoden und Rahmenbedingungen zugrunde liegen.

7. Alle 3 Baumarten besaßen deutlich höhere oberflächenspezifische Wasseraufnahmeraten in der organischen Auflage als im Mineralboden. Besonders bei rasch sinkenden Matrixpotentialen im grobporigen Mineralboden spielt die intensiv durchwurzelte organische Auflage am Sandstandort Lüneburger Heide eine bedeutende Rolle im Wasserhaushalt der Bäume.

8. Bei Freilandexperimenten wurde durch Dekapitation einzelner Wurzeln der radiale Wurzelwiderstand ausgeschaltet. Der dadurch stets induzierte rasche Anstieg der Flußrate um etwa das 10-fache läßt darauf schließen, daß der radiale Wurzelwiderstand bedeutend größer ist als der axiale Widerstand im Xylem.

9. Bewässerungsexperimente während einer Trockenperiode am Standort Lüneburger Heide bewirkten einen sofortigen Wiederanstieg der Wurzelsaftflußrate. Eine irreversible Schädigung der Feinwurzeln durch Trockenheit ist also nicht zu vermuten. Mögliche Embolien im Xylem der Feinwurzeln konnten offenbar binnen kurzer Zeit behoben werden.

10. Zusammenfassend läßt sich folgern, daß die Kombination der Saftflußmessung an dünnen Baumwurzeln mit der anschließenden Bestimmung der aufnehmenden Oberfläche bzw. Biomasse ein großes Potential für die weitere experimentelle Untersuchung des Wasserflusses in Baumwurzelsystemen unter in situ-Bedingungen am natürlichen Standort bietet. 


\section{Abbildungsverzeichnis}

3.1 Schematische Darstellung eines Miniatur-Saftflußsensors . . . . . . . 12

3.2 Schematische Darstellung der Freiland-Kalibrierungsmethode. . . . . 13

3.3 Schematische Darstellung der Labor-Kalibrierungsmethode . . . . . . . 14

3.4 Schematische Darstellung der in situ-Installation an Baumwurzeln. . . 16

$4.1 \quad$ Gravimetrische Kontrolle der Saftflußanlage im Freiland . . . . . . . 25

4.2 Gravimetrische Kontrolle der Saftflußanlage im Labor. . . . . . . . . 26

4.3 Flußrate und $\mathrm{T}_{\mathrm{so}}-\mathrm{T}_{\mathrm{si}}$ in einer Buchenwurzel (Laborexperiment) . . 26

$4.4 \quad$ Abhängigkeit des $\mathrm{T}_{\mathrm{so}}-\mathrm{T}_{\mathrm{si}}$-Wertes von der Flußrate $\ldots . . . . .27$

$4.5 \quad$ Abhängigkeit niedriger Flußraten von $\mathrm{T}_{\mathrm{so}}-\mathrm{T}_{\mathrm{si}} \ldots \ldots$. . . . . . . . . 28

4.6 Tagesgänge der Saftflußrate in einer Buchenwurzel (Freiland) . . . . 29

4.7 Gemessene und berechnete Flußraten in einer Buchenwurzel (Labor) . 30

4.8 Oberflächen der 1998 untersuchten Buchenwurzeln . . . . . . . . . 31

4.9 Verteilung der Wurzeloberfläche auf Durchmesserklassen (1998) . . . 32

4.10 Spezifische Oberfläche der 1998 untersuchten Buchenwurzeln . . . . 33

4.11 Globalstrahlung und VPD im Sommer 1998 . . . . . . . . . . . . . 34

4.12 Bodenwassergehalt, -saugspannung und Feld-pF-Kurven 1998 . . . . 36

4.13 Stammsaftflußraten der 1998 untersuchten Buchen . . . . . . . . . 39

4.14 Wurzelwasserpotentiale im Sommer 1998 . . . . . . . . . . . . . . 41

4.15 Saftflußdichten in den 1998 untersuchten Buchenwurzeln . . . . . . . 42

4.16 Oberflächenspezifische Aufnahme der 1998 untersuchten Wurzeln . . 44

4.17 Oberflächen der 1999 untersuchten Wurzeln . . . . . . . . . . . . . . 46

4.18 Verteilung der Wurzeloberfläche auf Durchmesserklassen(1999) . . . 47

4.19 Abhängigkeit der Durchmesserverteilung von der Gesamtoberfläche . 48

4.20 Spezifische Oberfläche der 1999 untersuchten Wurzeln . . . . . . . . . 49

4.21 Durchmesser der Xylemelemente am Saftfluß-Meßpunkt . . . . . . . 50

4.22 Leitender Querschnitt der 1999 untersuchten Wurzeln . . . . . . . . . 51

$\begin{array}{lll}4.23 & \text { Abhängigkeit des Wurzeldurchmessers von der Entfernung zur Spitze } 52\end{array}$

4.24 Peridermstärke und Zellschichten in Buchen-, Eichen-, Fichtenwurzeln 53

4.25 Suberin- und Ligningehalte in Buchen-, Eichen-, Fichtenwurzeln . . . 54

4.26 Globalstrahlung und VPD im Sommer 1999 . . . . . . . . . . . . . . 55

4.27 Bodenfeuchteparameter im Sommer 1999 . . . . . . . . . . . . . 56

4.28 Stammsaftflußrate in den 1999 untersuchten Bäumen . . . . . . . . . 59

4.29 Mittlere Stammsaftflußraten im Zeitraum Jul/Aug1999 . . . . . . . . 60

4.30 VPD, Strahlung und Saftfluß im Tagesgang . . . . . . . . . . . . . . 62

4.31 VPD, PAR und Saftfluß in Zweig, Stamm und Wurzel . . . . . . . . . 63 
4.32 Saftflußdichten in den 1999 untersuchten Wurzeln . . . . . . . . . . . 65

4.33 Oberflächenspezifische Aufnahme der 1999 untersuchten Wurzeln . . 66

4.34 Stammsaftfluß in Abhängigkeit vom VPD 1999 . . . . . . . . . . . . 69

4.35 Wurzel-Saftfluß in Abhängigkeit vom Stammsaftfluß 1999 . . . . . . 70

4.36 Wasseraufnahme in Abhängigkeit vom Bodenwassergehalt 1999 . . . 72

4.37 Wasseraufnahme in Abhängigkeit vom VPD 1999 . . . . . . . . . . . 74

4.38 Modellierte und gemessene Wasseraufnahme 1999 im saisonalen Verlauf 78

4.39 Modellierte Wasseraufnahme verglichen mit den Meßwerten . . . . . 79

4.40 Saftflußdichte und Wasserpotential in Wurzeln (1999) . . . . . . . . . 80

4.41 Wasserpotentiale in Wurzeln und Blättern 1999 . . . . . . . . . . . . 81

4.42 Maximale hydraulische Leitfähigkeit von Baumwurzeln (Labor) . . . 83

4.43 Verlauf eines Dekapitationsexperiments an einer Fichtenwurzel . . . . 85

4.44 Bewässerungsversuche an Buchen-, Eichen- und Fichtenwurzeln . . . 87

5.1 Vergleich von Wasseraufnahme und Transpiration von Buche und Eiche auf Bestandesebene . . . . . . . . . . . . . . . . . . 97 


\section{Tabellenverzeichnis}

2.1 Bestandesstruktur der drei Untersuchungsflächen . . . . . . . . . . . 7

2.2 Niederschlagsummen 1998 und 1999 . . . . . . . . . . . . . . 9

$4.1 \quad$ Biometrische Daten der 1998 untersuchten Buchen . . . . . . . . . . 38

4.2 Wasseraufnahme der 3 Standorte im direkten Vergleich . . . . . . . . 45

4.3 Biometrische Daten der 1999 untersuchten Bäume. . . . . . . . . . . 58

$4.4 \quad$ Vergleich verschiedener Wurzelsaftflußgrößen 1999 . . . . . . . . . . 68

$4.5 \quad$ Korrelationskoeffizienten zur Abhängigkeit zW. Wurzel- und Stamm-

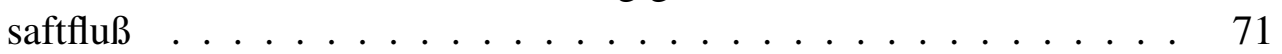

4.6 Korrelationskoeffizienten zur Abhängigkeit zW. oberflächenspez. Wasseraufnahme und Bodenwassergehalt. . . . . . . . . . 73

4.7 Korrelationskoeffizienten zur Abhängigkeit zW. oberflächenspez. Wasseraufnahme und VPD . . . . . . . . . . . . . . 75

$4.8 \quad$ Multiple Regression mit Variablenselektion 1999 . . . . . . . . . . . . . . 76

4.9 Parameter der empirischen Modelle . . . . . . . . . . . . . . . 77

4.10 in situ-Lp L $_{\mathrm{r}}$ Werte 1999 . . . . . . . . . . . . . . . . . . . . . . . 84

4.11 Ergebnisse der Dekapitationsexperimente 1999 . . . . . . . . . . . . 86 


\section{Literaturverzeichnis}

AdDoms R. 1946: Entrance of water into suberized roots of trees. Plant Physiol., 21: 109-111.

Alder N., Sperry J.S. \& PockMan W. 1996: Root and stem xylem embolism, stomatal conductance, and leaf turgor in Acer grandidentatum populations along a soil moisture gradient. Oecologia 105: 293-301.

ALlEN S. \& GRIME V. 1995: Measurements of transpiration from savannah shrubs using sap flow gauges. Agric. For. Met. 75: 23-41.

BACKES K., Der Wasserhaushalt vier verschiedener Baumarten der Heide-WaldSukzession, Cuvillier, Göttingen, 1996, 134 S.

BACKES K. \& LEUSCHNER C. 2000: Leaf water relations of competetive Fagus sylvatica and Quercus petraea trees during 4 years differing in soil drought. Can. J. For. Res. 30: 335-346.

BAKER J. \& VAN BAVEL C. 1987: Measurements of mass flow of water in stems of herbaceous plants. Plant, Cell Environ. 10: 777-782.

Barataud F., Moyne C., Bréda N. \& Granier A. 1995: Soil water dynamics in an oak stand (II A model of the soil-root network compared with experimental data). Plant and Soil 172: 29-43.

Barrowclough D., Peterson C. \& Steudle E. 2000: Radial hydraulic conductivity along developing onion roots. J. Exp. Bot. 51: 547-557.

BÖHM W., Methods of Studying Root Systems, Springer, Berlin, Heidelberg, New York, 1979.

BÜTTNER V. \& LEUSCHNER C. 1994: Spatial and temporal patterns of fine root abundance in a mixed oak-beech forest. For. Ecol. Manage. 70: 11-21.

Burgess S., Adams M., Turner N. \& Ong C. 1998: The redistribution of soil water by tree root systems. Oecologia 115: 306-311.

Cermak J., Deml M. \& Penka M. 1973: A new method of sap flow rate determination in trees. Biologia Plantarum (Praha) 15(3): 171-178. 
Cermak J., Kucera J. \& Penka M. 1976: Improvement of the method of sap flow rate determination in full-grown trees based on heat balance with direct electric heating of xylem. Biologia Plantarum (Praha) 18(2): 105-110.

Cermak J. \& Nadezhdina N. 1998: Sapwood as the scaling parameter - defining according to xylem water content or radial pattern of sap flow? Ann. Sci. For. 55: $509-521$.

Chung H. \& Kramer P. 1975: Absorption of Water and 32P through suberized and unsuberized roots of Loblolly Pine. Can. J. For. Res. 5: 229-235.

COCHARD H., BRÉDA N. \& GRANIER A. 1996: Whole tree hydraulic conductance and water loss regulation in Quercus during drought: evidence for stomatal control of embolism? Ann. Sci. For. 53 : 197-206.

CONERS H. 1996: Untersuchungen zu Struktur und Funktion des Wurzelsystems konkurrierender Buchen und Eichen in einem Mischbestand, Diplomarbeit, Universität Göttingen.

Coners H., Hertel D. \& Leuschner C. 1998: Horizontal- und Vertikalstruktur des Grob- und Feinwurzelsystems von konkurrierenden Buchen und Eichen in einem Mischbestand. Verh. Ges. Ökologie 28: 435-440.

CRUZ R., JORDAN W. \& DREW M. 1992: Structural changes and associated reduction of hydraulic conductance in roots of Sorghum bicolor L. following exposure to water deficit. Plant Physiol. 99: 203-212.

DAUM C. 1967: A method for determining water transport in trees. Ecology 48: 425431.

Dugas W., Heuer M., Hunsaker D., Kimball B., Lewin K., Nagy J. \& JohnSON M. 1994: Sap flow measurements of transpiration from cotton grown under ambient and enriched CO-2 concentrations. Agric. For. Met. 70: 231-245.

Ellenberg H., Vegetation Mitteleuropas mit den Alpen aus ökologischer, dynamischer und historischer Sicht, Ulmer, Stuttgart, 1996, 5. Aufl.

Ellenberg H., Mayer R. \& Schauermann J., Ökosystemforschung - Ergebnisse des Sollingprojekts: 1966-1986, Ulmer, Stuttgart, 1986.

ESCAMILla J. \& COMERFORD N. 2000: Phosphorus and potassium uptake by woody roots of twelve-year-old slash pine trees. For. Ecol. Manage. 129: 153-166.

FichtNeR K. \& SChulze E.D. 1990: Xylem water flow in tropical vines as measured by a steady state heating method. Oecologia 82: 355-361. 
FRENSCH J. \& STEUdLE E. 1993: Axial and radial hydraulic resistance to roots of maize (Zea mays L.). Plant Physiol. 91: 719-726.

Green S. \& Clothier B. 1988: Water use of kiwifruit vines and apple trees by the heat-pulse technique. J. Exp. Bot. 39: 115-123.

Green S. \& Clothier B. 1995: Root water uptake by kivifruit vines following partial wetting of the root zone. Plant and Soil 173: 317-328.

Grime V., MORISON J. \& Simmonds L. 1995a: Including the heat storage term in sap flow measurements with the stem heat balance method. Agric. For. Met. 74: $1-25$.

Grime V., Morison J. \& Simmonds L. 1995b: Sap flow measurements from stem heat balances: a comparison of constant with variable power methods. Agric. For. Met. 74: 27-40.

Groot A. \& King K. 1992: Measurement of sap flow by the heat balance method: numerical analysis and application to coniferous seedlings. Agric. For. Met. 59: 289-308.

von GutTenberg H., Der primäre Bau der Angiospermenwurzel, in: ZimmerMANN W. (Hg.), Handbuch der Pflanzenanatomie, VIII, Gebrüder Bornträger, Berlin, Stuttgart, 1968.

HACKE U. \& SAUTER J. 1996: Drought-induced xylem dysfunction in peitoles, branches and root of Populus balsamifera L. and Alnus glutinosa (L) Gaertn. Plant Physiol. 100: 1020-1028.

HeInKEN T. 1993: Phytosociological and historical investigations in beech forests and birch-oak forests on pleistocene sandy soils without ground water influence in Lower Saxony (NW Germany). Scripta Geobot. 21: 61-66.

Hertel D., Das Feinwurzelsystem von Rein- und Mischbeständen der Rotbuche: Struktur, Dynamik und interspezifische Konkurrenz, Diss. Bot., Stuttgart, 1999.

Hertel D. \& Leuschner C. 1998: Die Rhizosphäre in einem EichenBuchenmischwald: Feinwurzelproduktion und die Bedeutung von Wurzelkonkurrenz. Verh. Ges. Ökologie 28: 441-447.

Herzog K., Thum R., ZweIfel R. \& HÄSLER R. 1997: Heat balance measurements - to quantify sap flow in thin stems only? Agric. For. Met. 83: 75-94.

VAN DEN HONERT T. 1948: Water transport in plants as a catenary process. Discuss. Faraday Soc. 3: 146-153. 
Huber B. 1924: Die Beurteilung des Wasserhaushalts der Pflanze: Ein Beitrag zur vergleichenden. Jahrb. Wiss. Bot. 64: 1-120.

Ishida T., CAMpbell G. \& CAlissendorfF C. 1991: Improved heat balance method for determining sap flow rate. Agric. For. Met. 56: 35-48.

ITTNER E. 1968: Der Tagesgang der Geschwindigkeit des Transpirationsstromes im Stamm einer 75-jährigen Fichte. Oecol. Plant. 3: 177-183.

Kjelgaard J., Stockle C., Black R. \& Campbell G. 1997: Measuring sap flow with the heat balance approach using constant and variable heat inputs. Agric. For. Met. 85: 239-250.

KORN S. 1999: Untersuchungen zu den Mechanismen der Wasseraufnahme von Eichenfeinwurzeln in einem Altbestand, Diplomarbeit, Universität Kassel.

KRAMER P., Water relations of plants, Academic Press, New York, 1983.

Köstler J., BrüCKner E. \& BiebelRiether H., Die Wurzeln der Waldbäume, Parey, Hamburg, Berlin, 1968.

LANDWEHR S. 1997: Photosynthese und Blattleitfähigkeit von Altbuchen (Fagus sylvatica L.) an unterschiedlich wasserversorgten Standorten, Diplomarbeit, Universität Göttingen.

LARCHER W., Ökophysiologie der Pflanzen, Bd. 5., Ulmer, Stuttgart, 1994.

LEUSCHNER C. 1993: Patterns of soil water depletion under coexisting oak and beech trees in a mixed stand. Phytocoenologia 23: 19-33.

LEUSCHNER C., Walddynamik in der Lüneburger Heide: Ursachen, Mechanismen und die Rolle der Ressourcen, unveröffentl. Habilitationsschrift, Universität Göttingen, 1994.

LEUSCHNER C. 1998: Water extraction by tree fine roots in the forest floor of a temperate Fagus-Quercus forest. Ann. Sci. For 55: 141-157.

LEUSCHNER C., Forest succession and water resources: soil hydrology and ecosystem water turnover in early, mid and late stages of a 300-yr-long chronosequence on sandy soil, in: Dohrenbusch A. (Hg.), Processes of Growth and Development in Temperate Mixed Forests, Springer Verlag, 2001.

Leuschner C., Backes K., Hertel D., Schipka F., Schmitt U., Terborg O. \& Runge M. 2001a: Drought responses at leaf, stem and fine root levels of competitive Fagus sylvatica L. and Quercus petraea (Matt.) Liebl. trees in dry and wet years. For. Ecol. and Manage. 149: 33-46. 
Leuschner C., Backes K., Hertel D., Schmitt U., Schipka F. \& Terborg O. 1997: Wasserstreß-Antwort auf Blatt-, Wurzel- und Stammebene von Rotbuchen und Traubeneichen in einem Altholz-Mischbestand in NW-Deutschland. EcoSys Suppl.-Bd 20 : 11-27.

Leuschner C., Hertel D., Coners H. \& Büttner V. 2001b: Root competition between beech and oak: a hypothesis. Oecologia 126: 276-284.

LotT J., Khan A., Ong C. \& Black C. 1996: Sap flow measurements of lateral tree roots in agroforestry systems. Tree Physiology 16: 995-1001.

Lösch R., Wasserhaushalt der Pflanzen, Quelle und Meyer, Wiebelsheim, 2001.

MacFall J., Johnson G. \& Kramer P. 1991: Comparative water uptake by roots of different ages in seedlings of loblolly pine (Pinus taeda L.). New Phytol. 119: 551-560.

MAIER-MERCKER U. 1998: Dynamics of change in stomatal response and water status of Picea abies during a persistant drought period: a contribution to the traditional view of plant water relations. Tree Physiol. 18: 211-222.

McKenzie B. \& Peterson C. 1995: Root browning in Pinus banksiana Lamb. and Eucalyptus pilularis Sm. 2. Anatomy and Permeability of the cork zone. Bot. Acta 108: $138-143$.

MecuCCini M. \& Comstock J. 1997: Vulnerability to cavitation in populations of two desert species, Hymenocle salsola and Ambrosia dumosa, from different climatic regions. J. Exp. Bot. 48: 1323-1334.

Meusel H. 1937: Mitteldeutsche Vegetationsbilder, 1. Die Steinköbe bei Nebra und der Ziegelrodaer Forst. Herzynia 1: 9-99.

Molz F. 1981: Models of water transport in the soil-plant system: A review. Water resources Res. 17: 1245-1260.

MuHS A. 1997: Feinwurzelverteilung und Streuabbau an vier Buchenstandorten mit unterschiedlichem Wasserhaushalt, Diplomarbeit, Universität Göttingen.

NoRTH G. \& Nobel P. 1996: Radial hydraulic conductivity of concentric root tissues of Agave desertii Engelm. under wet and drying conditions. New Phytol. 130: 4757.

Peterson C. \& Cholewa E. 1998: Structural modification of the apoplast and their potential impact on ion uptake. Z. Pflanzenernähr. Bodenk. 161: 521-531.

VAN REES K. \& COMERFORD N. 1990: The role of woody roots of slash pine seedlings in water and potassium absorption. Can. J. For. Res. 20: 1183-1191. 
RICHTER H. 1973: Frictional potential losses and total water potential in plants: A reevaluation. J. Exp. Bot 24: 983-994.

ROBERTS J. 1977: The use of tree-cutting techniques in the study of the water relations of mature Pinus sylvestris L. J. Exp. Bot 28: 751-767.

Rüdinger M., Hallgreen S., Steudle E. \& Schulze E.D. 1994: Hydraulic and osmotic properties of spruce roots. J. Exp. Bot. 45: 1413-1425.

RUNNING S. 1980: Field estimates of root and xylem resistances in Pinus contorta using root excision. J. Exp. Bot. 31: 555-569.

SAKURATANI T. 1981: A heat balance method for measuring water flux in the stem of intact plants. J. Agr. Meteorol. 37: 9-17.

SAKURATANI T. 1984: Improvement of the probe for measung water flux in the stem of intact plants. J. Agr. Meteorol. 40: 273-277.

SCHAAP M. 1996: The role of soil organic matter in the hydrology of forests on dry sandy soils, Dissertation, Univ. of Amsterdam.

Scheffer F. \& Schachtschabel P., Lehrbuch der Bodenkunde, Enke, Stuttgart, 1992.

Scholander P., Hammel H., Bradsteet E. \& Hemmingsen E. 1965: Sap pressure in vascular plants. Science 148: 339-346.

Schreiber L., Hartmann K., Skrabs M. \& Zeier J. 1999: Apoplastical barriers in roots: chemical composition of endodermal and hypodermal cell walls. J. Exp. Bot. 50: $1267-1280$.

SENOCK R. \& HAM J. 1993: Heat balance sap flow gauge for small diameter stems. Plant, Cell Environ. 16: 593-601.

SENOCK R. \& HAM J. 1995: Measurements of water use by prairie grasses with heat balance sap flow gauges. J. Range Manage. 48: 150-158.

SENOCK R. \& LEUSCHNER C. 1999: Axial water flux dynamics in small diameter roots of a fast growing tropical tree. Plant and Soil 208: 57-71.

Smith D., JACKSON N., Roberts J. \& ONG C. 1999: Reverse flow of sap in tree roots and downward siphoning of water by Grevillea robusta. Functional Ecology 13: $256-264$.

Sperry J., Donnelly J. \& Tyree M. 1988: A method for measuring hydraulic conductivity and embolism in xylem. Plant, Cell Environ. 11: 35-40. 
SPERRY J. \& SALIENDRA N. 1994: Intra- and inter-plant variation in xylem cavitation in Betula occidentalis. Plant, Cell Envir. 11: 35-40.

Sperry J., Stiller V. \& Hacke U., Soil water uptake and water transport through root systems, in: WAisel Y., Eshel A. \& KAFKAFI U. (Hg.), Plant Roots: The Hidden Half, Dekker, New York, 2001, 3. Aufl.

STEINMEYER U. 1988: Über die Wurzelentwicklung junger Fichten (Picea abies (L.) Karst) im Hils und auf dem Pokljuka-Plateau, Diplomarbeit, Inst. f. Forstbotanik, Universität Göttingen.

STEUdLE E., Pressure probe techniques: basic principles and application to studies of water and solute relations at the cell, tissue, and organ level., in: SMITH J. \& Griffiths H. (Hg.), Water Deficits: Plant Responses from Cell to Community, BIOS Scientific Publ., 1993, S. 5-35.

STEUDLE E. 2000a: Water uptake by plant roots: an integration of views. Plant and Soil 226: 45-56.

STEUDLE E. 2000b: Water uptake by roots: effect of water deficit. J. Exp. Bot 51: 1531-1542.

STEudLE E. 2001: The cohesion-Tension Mechanism and the acquistion of water by plant roots. Ann. Rev. Plant Physiol. Plant Mol. Biol. 52: 847-875.

Steudle E. \& Heydt H., Water transport across tree roots, in: RenNENBERG H., ESCHRICH W. \& ZIEGLER H. (Hg.), Trees - Contributions to modern tree physiology, Backhuys Publishers, Leiden, NL, 1997, S. 239-255.

Steudle E. \& JeschKe W. 1983: Water transport in barley roots. Planta 158: 237248.

Steudle E. \& MeshCheryatov A. 1996: Hydraulic and osmotic properties of oak roots. J. Exp. Bot. 47: 387-401.

Steudle E., OREn R. \& SChulze E.D. 1987: Water transport in maize roots. Plant Physiol. 84: 1220-1232.

STROBEL J. 1997: Der Wasserhaushalt eines Buchenwaldes im mitteldeutschen Trockengebiet, Diplomarbeit, Universität Göttingen.

TERBorg O. 1998: Die Kohlenstoffassimilation von Rotbuchen und Traubeneichen in einem Mischbestand in der Lüneburger Heide und deren Bedeutung für die interspezifische Konkurrenz, Dissertation, Universität Göttingen. 
Tyree M. \& Jarvis P., Water in tissues and cells, in: Lange O., Nobel P., OsMOND C. \& Ziegler H. (Hg.), Physiological Plant Ecology II New Ser., Bd. 12B von Encyclopedia of Plant Physiology, Springer, Berlin, Heidelberg, New York, 1982, 2. Aufl., S. 36-77.

VIEWEG G. \& ZIEGLER H. 1960: Thermoelektrische Registrierung der Geschwindigkeit des Transpirationsstromes. Deutsche Bot. Ges. 73: 221-226.

Weibel F. \& DE Vos J. 1994: Transpiration measurements on apple trees with an improved stem heat balance method. Plant and Soil 166: 203-219.

Weibel F.P. \& Boersma K. 1995: An improved stem heat balance method using analog heat control. Agric. For. Met. 75: 191-208.

WhiteheAd D. \& JARVis P., Coniferous forests and plantations, in: KozLOWSKI T. (Hg.), Water deficits and plant growth, Bd. VI, Academic Press, New York, 1981.

YANG S. \& TYREE M. 1992: A theoretical model of hydraulic conductivity recovery from embolism with comparison to experimental data on Acer saccharum. Plant Cell Environ. 15: 633-643.

ZEIER J. \& SCHREIBER L. 1997: Chemical composition of hypodermal and endodermal cell walls and xylem vessels isolated from Clivia miniata. Plant Physiol. 113: $1223-1234$.

ZEIER J. \& SCHREIBER L. 1998: Comparative investigation of primary and tertiary endodermal cell walls isolated from the roots of five monocotyledoneous species: chemical composition in relation to fine structure. Planta 206: 349-361.

Zimmermann H., Hartmann K., Schreiber L. \& Steudle E. 2000: Chemical composition of apoplastic transport barriers in relation to radial hydraulic conductivity of corn roots (Zea mays L.). Planta 210: 302-311.

Zimmermann M. \& JeJE A. 1981: Vessel length distribution in stems of some american woody plants. Can. J. Bot 59: 1882-1892. 